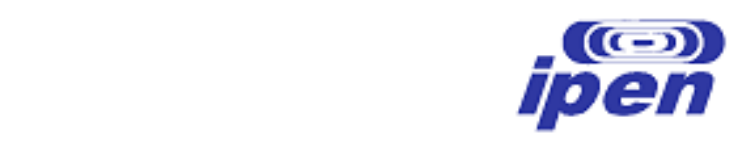

Instituto de Pesquisas Energéticas e Nucleares

Autarquia associada à Universidade de São Paulo

Estudo dos Precursores de Ozônio na Cidade de São Paulo

Através de Simulação Computacional

J oão Paulo Orlando

Dissertação apresentada como parte dos requisitos para obtenção do Grau de Mestre em Ciências na Área de

Tecnologia Nuclear - Materiais

Orientadora: Dra. Luciana Vanni Gatti

SÃO PAULO

2008 


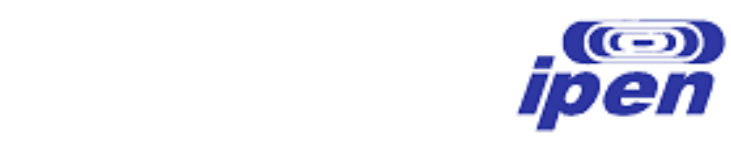

Instituto de Pesquisas Energéticas e Nucleares

Autarquia associada à Universidade de São Paulo

Estudo dos Precursores de Ozônio na Cidade de São Paulo

Através de Simulação Computacional

J oão Paulo Orlando

Dissertação apresentada como parte dos requisitos para obtenção do Grau de Mestre em Ciências na Área de

Tecnologia Nuclear - Materiais

Orientadora: Dra. Luciana Vanni Gatti

SÃO PAULO

2008 


\title{
Estudo dos Precursores de Ozônio na Cidade de São Paulo Através de Simulação Computacional
}

\author{
João Paulo Orlando
}

\begin{abstract}
RESUMO
O ozônio $\left(\mathrm{O}_{3}\right)$ representa o principal poluente atmosférico para a Região Metropolitana de São Paulo (RMSP), sendo freqüentes os dias em que sua concentração excede os padrões nacionais de qualidade do ar. Por se tratar de um poluente secundário, resultante principalmente, da interação entre os óxidos de nitrogênio $\left(\mathrm{NO}_{\mathrm{x}}\right)$ e compostos orgânicos voláteis (COVs) na presença de luz solar, torna-se muito difícil a elaboração de estratégias eficazes para a redução deste poluente.

A utilização de simulação computacional se mostra como uma interessante alternativa para avaliar os muitos fatores que afetam a formação de $\mathrm{O}_{3}$, para o desenvolvimento de escalas de reatividade para COVs e para definição de possíveis estratégias que visem a redução dos níveis de $\mathrm{O}_{3}$.

Neste trabalho foi utilizado o modelo de trajetórias OZIPR (Ozone Isopleth Package for Research) em conjunto com o modelo químico SAPRC (Statewide Air Pollution Research Center) para se determinar a escala de reatividade incremental para COVs para a cidade de São Paulo e para a simulação de diversas situações de redução das emissões de $\mathrm{NO}_{x}$ e COVs.

Para alimentar os modelos foram utilizadas medidas de COVs de duas campanhas: uma realizada pelo Laboratório de Química Atmosférica (LQA-IPEN) em conjunto com a CETESB na estação Cerqueira César, no período de agosto e setembro de 2006 e outra realizada somente pelo LQA durante todo o ano de $2006 \mathrm{com}$ amostragens na Cidade Universitária. Dados de $\mathrm{CO}, \mathrm{NO}_{x}$ e parâmetros meteorológicos foram obtidos através dos monitores automáticos da mesma estação e da estação Pinheiros.

Foram criados cinco casos base: um com os dados de COVs da estação Cerqueira César e quatro com os dados da Cidade Universitária, sendo estes, um para cada estação do ano. Após o ajuste dos casos base, cada COV presente na mistura teve sua concentração aumentada e diminuída em $0,2 \%$ dos COVs totais para se verificar a variação no máximo de ozônio e assim se determinar o potencial de formação de ozônio de cada COV. Estes resultados forneceram uma escala de reatividade para ozônio para cada caso base criado.

Foram também realizadas simulações, onde as emissões horárias de $\mathrm{NO}_{x}$ e COVs foram reduzidas em 5, 10, 20 e 30\% independente e simultaneamente afim de se verificar as variações na formação de $\mathrm{O}_{3}$. Com os dados de saída do simulador foram construídos gráficos de isopletas de ozônio para a cidade de São Paulo.

A análise dos resultados obtidos mostrou que os compostos encontrados com mais freqüência entre os dez principais precursores de ozônio na cidade de São Paulo nas escalas de reatividade criadas a partir dos cinco casos base são: formaldeído, acetaldeído, propeno, isopreno, cis e trans 2-buteno, sendo o formaldeído sempre o principal composto formador de ozônio.

As simulações mostraram também que uma estratégia eficaz para se reduzir os níveis de $\mathrm{O}_{3}$ na cidade de São Paulo é diminuir as emissões totais de COVs. O mesmo não foi observado para os $\mathrm{NO}_{\mathrm{x}}$, já que a redução destes poluentes faria aumentar as concentrações de $\mathrm{O}_{3}$.
\end{abstract}




\title{
A Study About the Ozone Precursors in the São Paulo City Using Computational Simulation
}

\author{
João Paulo Orlando
}

\begin{abstract}
Ozone $\left(\mathrm{O}_{3}\right)$ represents the main atmospheric pollutant for the São Paulo Metropolitan Area (SPMA), being frequent the days when its concentration exceeds the national standards of air quality. Because ozone is a secondary pollutant, which results mainly, of the interaction between nitrogen oxides $\left(\mathrm{NO}_{\mathrm{x}}\right)$ and volatile organic compounds (VOCs) in the presence of solar light, it becomes very hard to elaborate efficient strategies for the reduction of this pollutant.

The use of computational simulation appears as an interesting alternative to evaluate the many factors that affect the $\mathrm{O}_{3}$ formation, for the development of reactivity scales for VOCs and for definition of efficient strategies for the reduction of the concentrations of $\mathrm{O}_{3}$.

In this study was used the trajectory model OZIPR (Ozone Isopleth Package for Research) together with the chemical model SAPRC (Statewide Air Pollution Research Center) to determine the incremental reactivity scale for VOCs in the São Paulo City and to the simulation of diverse situations of reduction of the emissions of $\mathrm{NO}_{x}$ and VOCs.

The input data of VOCs were obtained from two campaigns: one realized by the Atmospheric Chemistry Laboratory (ACL-IPEN) together with the CETESB in the Cerqueira Cesar station, in the period of August and September of 2006 and the other one realized only by the ACL during all the year of 2006 with samplings in the Cidade Universitária. $\mathrm{CO}, \mathrm{NO}_{\mathrm{x}}$ and meteorological parameters data had been gotten through the automatic monitors from the same station and from the Pinheiros station.

Five base cases had been created: one with the VOCs data from the Cerqueira Cesar station and four with the Cidade Universitária data, being these, one for each station of the year. After the adjustment of the base cases, each present VOC in the mixture had its concentration increased and diminished in $0,2 \%$ of the total VOCs to verify the variation in the maximum ozone and thus to determine the ozone formation potential of each VOC. These results had supplied a ozone reactivity scale for each base case created.

Simulations where the hourly emissions of $\mathrm{NO}_{x}$ and VOCs had been reduced in 5 , 10,20 and $30 \%$ independent and simultaneously were realized to verify the variations in the $\mathrm{O}_{3}$ formation. With the simulator output data it was created ozone isopleths charts for the São Paulo City.

The analysis of the obtained results shows that the most frequent found compounds between the ten main ozone precursors in the São Paulo City in the reactivity scales created from the five base cases are: formaldehyde, acetaldehyde, propene, isoprene, cis 2-butene and trans 2-butene, being formaldehyde always the main ozone precursor compound.

The simulations had also shown that an efficient strategy to decrease the concentrations of $\mathrm{O}_{3}$ in the São Paulo City is to reduce the total emissions of VOCs. The same strategy is not posible for the $\mathrm{NO}_{x}$, since the reduction of these pollutants would make to increase the concentrations of $\mathrm{O}_{3}$.
\end{abstract}




\section{Sumário}

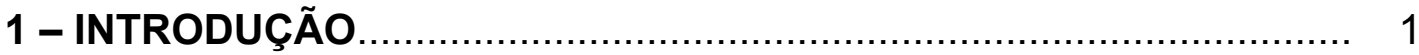

1.1 - Caracterização da atmosfera................................................. 1

1.2 - A formação do ozônio................................................................ 2

1.2 .1 - O destino dos radicais........................................................ 8

1.3 - A influência da meteorologia na poluição do ar............................ 10

1.4 - Simulação computacional..................................................... 12

1.4.1 - Modelo de trajetórias OZIPR ............................................. 12

1.4 .2 - Modelo químico SAPRC ........................................................ 14

1.5 - Escalas de reatividade para COVs............................................. 16

1.6 - Justificativa do trabalho............................................................... 19

1.7 - Caracterização da região de estudo ........................................ 23

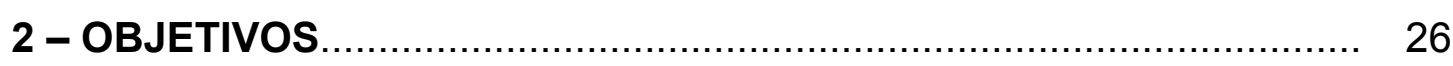

3 - METODOLOGIA ................................................................ 27

3.1 - Obtenção dos dados de emissões de poluentes.......................... 27

3.2 - Metodologia das medidas de poluentes....................................... 28

3.2.1 - Monitor de CO.................................................................. 28

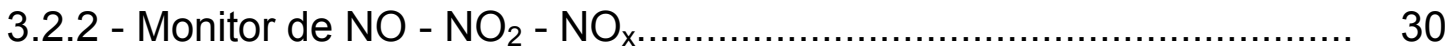

3.2.3 - Monitor de ozônio................................................................ $\quad 30$

3.2.4 - Análise de COVs - Hidrocarbonetos......................................... 32

3.2.5 - Análise de COVs - Aldeídos.................................................. 34

4 - SIMULAÇÃO DA REGIÃO METROPOLITANA DE SÃO PAULO...... 35

4.1 - Caso base da Faculdade de Saúde Pública da USP....................... 35

4.1 .1 - Validação do simulador......................................................... 38

4.1.2 - Determinação da escala de reatividade incremental.................... 42

4.2 - Casos base das amostragens realizadas na Cidade Universitária.... 43

4.2 .1 - Caso base verão..................................................................... 43

4.2.2 - Caso base outono............................................................ 47

4.2 .3 - Caso base inverno............................................................ 51

4.2.4 - Caso base primavera....................................................... 54

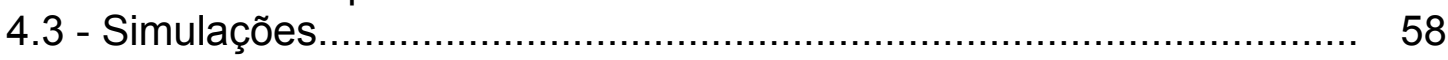

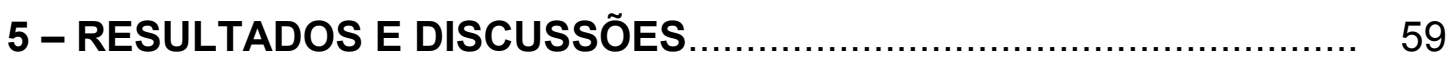

5.1 - Simulações de redução nas emissões....................................... 59

5.2 - Escalas de reatividade incremental.......................................... 65

5.2 .1 - Escala de reatividade incremental Caso base FSP..................... 65

5.2.2 - Escala de reatividade incremental Caso base Cidade Universitária - Verão.

5.2.3 - Escala de reatividade incremental Caso base Cidade Universitária

- Outono..................................................................................... 69

5.2.4 - Escala de reatividade incremental Caso base Cidade Universitária

- Inverno................................................................................... 71

5.2.5 - Escala de reatividade incremental Caso base Cidade Universitária

- Primavera......................................................................... 73

5.2.6 - Comparação entre as escalas de reatividade incremental............ 76 
6 - CONCLUSÕES.

79

7 - REFERÊNCIAS BIBLIOGRÁFICAS................................................ 81

ANEXO A - Dados de entrada do Modelo OZIPR .................................. 84

ANEXO B - Mecanismo Químico SAPRC .......................................... 90

ANEXO C - Escala de Reatividade Incremental Máxima desenvolvida

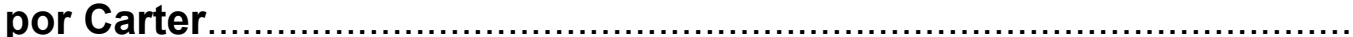




\section{Lista de Acrônimos}

\begin{tabular}{|c|c|}
\hline ALK 1 & 1ㅇg grupo de alcanos \\
\hline ALK 2 & 2o grupo de alcanos \\
\hline ALK 3 & 3o grupo de alcanos \\
\hline ALK 4 & 4 o grupo de alcanos \\
\hline ALK 5 & 5o grupo de alcanos \\
\hline Ar & Argônio \\
\hline ARO 1 & 1 grupo de aromáticos \\
\hline ARO 2 & 2 grupo de aromáticos \\
\hline $\mathrm{CCHO}$ & Acetaldeído \\
\hline CETESB & Companhia de Tecnologia de Saneamento Ambiental \\
\hline CFCs & Clorofluorcarbonos \\
\hline $\mathrm{CH}_{4}$ & Metano \\
\hline CLA & Centro de Lasers e Aplicações - IPEN \\
\hline CLP & Camada Limite Planetária \\
\hline CLN & Camada Limite Noturna \\
\hline CM & Camada de Mistura \\
\hline CONAMA & Conselho Nacional de Meio Ambiente \\
\hline $\mathrm{CO}$ & Monóxido de carbono \\
\hline $\mathrm{CO}_{2}$ & Dióxido de carbono \\
\hline COVs & Compostos Orgânicos Voláteis \\
\hline COVNMs & Compostos Orgânicos Voláteis Não Metano \\
\hline $\mathrm{CR}$ & Camada Residual \\
\hline DEM & Detector de Espectrometria de Massas \\
\hline DIC & Detector de Ionização por Chama \\
\hline EKMA & Empirical Kinetic Modeling Approach \\
\hline ETOH & Etanol \\
\hline EUA & Estados Unidos da América \\
\hline FSP & Faculdade de Saúde Pública \\
\hline GNV & Gás Natural Veicular \\
\hline $\mathrm{HC}$ & Hidrocarbonetos \\
\hline $\mathrm{HCHO}$ & Formaldeído \\
\hline $\mathrm{He}$ & Helio \\
\hline $\mathrm{H} 2$ & Hidrogênio \\
\hline $\mathrm{H}_{2} \mathrm{O}$ & Água \\
\hline $\mathrm{H}_{2} \mathrm{O}_{2}$ & Peróxido de hidrogênio \\
\hline $\mathrm{HO}^{\circ}$ & Hidroxila \\
\hline $\mathrm{HO}_{2}^{\cdot}$ & Hidroperóxido \\
\hline IPEN & Instituto de Pesquisas Energéticas e Nucleares \\
\hline IR & Reatividade incremental \\
\hline LQA & Laboratório de Química Atmosférica- IPEN \\
\hline MIR & Maximum Incremental Reactivity \\
\hline $\mathrm{MEOH}$ & Metanol \\
\hline
\end{tabular}




\begin{tabular}{|c|c|}
\hline MP & Material particulado \\
\hline $\mathrm{N}_{2}$ & Nitrogênio \\
\hline NO & Óxido nítrico \\
\hline $\mathrm{NO}_{2}$ & Dióxido de nitrogênio \\
\hline $\mathrm{NO}_{\mathrm{x}}$ & Óxidos de nitrogênio \\
\hline OLE 1 & 10 grupo de alcenos \\
\hline OLE 2 & 20 grupo de alcenos \\
\hline OZIPR & Ozone Isopleth Package for Research \\
\hline $\mathrm{O}_{3}$ & Ozônio \\
\hline $\mathrm{O}_{2}$ & Oxigênio \\
\hline PIB & Produto Interno Bruto \\
\hline ppb & partes por bilhão \\
\hline $\mathrm{ppbC}$ & partes por bilhão em base de carbono \\
\hline ppbV & partes por bilhão em volume \\
\hline ppm & partes por milhão \\
\hline ppmC & partes por milhão em base de carbono \\
\hline ppmV & partes por milhão em volume \\
\hline PROCONVE & $\begin{array}{l}\text { Programa de Controle Nacional da Poluição do Ar por Veículos } \\
\text { Automotores }\end{array}$ \\
\hline PRODESP & Companhia de Processamento de Dados do Estado de São Paulo \\
\hline RMSP & Região Metropolitana de São Paulo \\
\hline SAPRC & Statewide Air Pollution Research Center \\
\hline $\mathrm{SO}_{2}$ & Dióxido de enxofre \\
\hline $\mathrm{SO}_{\mathrm{x}}$ & Óxidos de enxofre \\
\hline TEI & Thermo Environmental Instruments \\
\hline TERP & Terpenos \\
\hline UR & Umidade Relativa do Ar \\
\hline U.S. EPA & United States Environmental Protection Agency \\
\hline USP & Universidade de São Paulo \\
\hline UV & Ultra violeta \\
\hline VOCs & Volatile Organic Compounds \\
\hline
\end{tabular}




\section{Lista de Figuras}

Figura 1.1 - Camadas da atmosfera e as variação da temperatura $\left({ }^{\circ} \mathrm{C}\right)$ em relação a altura $(\mathrm{km})$ e pressão (mbar) (Adaptado de NASA's Earth Science Enterprise)

Figura 1.2 - Esquema das reações envolvidas na conversão $\mathrm{NO}-\mathrm{NO}_{2}$ e formação de $\mathrm{O}_{3}$ em [a]: sistema NO- $\mathrm{NO}_{2}-\mathrm{O}_{3}$ em ausência de COVs e [b]: sistema NO$\mathrm{NO}_{2}-\mathrm{O}_{3}$ na presença de COVs (Adaptado de Atkinson, 2000).

Figura 1.3 - Isolinhas de formação de ozônio em relação às concentrações de $\mathrm{NO}_{\mathrm{x}}$ e COVs (Fonte: Seinfeld e Pandis, 1998)....

Figura 1.4 - Mecanismo do processo de oxidação do $\mathrm{RHC}=\mathrm{CHR}$ (Fonte: Baird, 1995).

Figura 1.5 - Ciclo diurno da Camada Limite Planetária, de um dia típico sem nuvens (Adaptado de Stull, 1991).

Figura 1.6 - Representação esquemática de um modelo de trajetórias (Corrêa, 2003)

Figura 1.7 - Incerteza das constantes de velocidades no mecanismo químico SAPRC.

Figura 1.8 - Evolução da frota de veículos automotores leves na RMSP

Figura 1.9 - Evolução dos fatores médios de emissão de CO dos veículos movidos a álcool e a gasolina $\mathrm{C}$ da RMSP

Figura $1.10-\mathrm{O}_{3}$ : Distribuição Percentual da Qualidade do Ar Período de 2001 a 2006. Base: Estações Santana, Moóca, Ibirapuera, Diadema, Santo Amaro, Santo André-Capuava e Mauá.

Figura 1.11 - Mapa da Região Metropolitana de São Paulo (Fonte: http://www.igc.sp.gov.br/mapras_spaulo.htm).

Figura 1.12 - Mosaico de composições das imagens TM do satélite LANDSAT-5 mostrando a notável extensão da ocupação urbana na região. (Fonte: IGBP e http://www.cdbrasil.cnpm.embrapa.br)....

Figura 3.1 - Esquema de funcionamento do analisador de CO por correlação de filtro de gás.

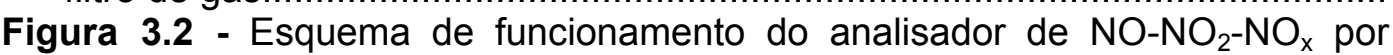
quimiluminescência.

Figura 3.3 - Esquema de funcionamento do analisador de $\mathrm{O}_{3}$.....

Figura 3.4 - [a]: Esquema da amostragem com canister, [b]: Foto de uma amostragem com canister dentro da Estação Cerqueira Cesar da CETESB e [c]: Foto do sistema de limpeza utilizado neste trabalho.

Figura 3.5 - [a]: Injeção da amostra com o canister conectado ao cromatógrafo e

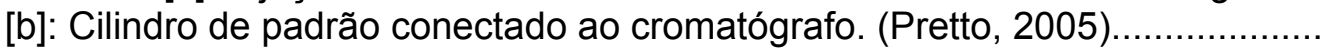

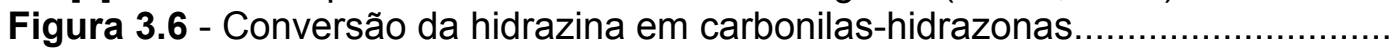

Figura 4.1 - Exemplo de um gráfico da evolução da CLP obtido através do sistema Lidar.

Figura 4.2 - Porcentagem de COVs agrupados por função orgânica para o caso base Faculdade de Saúde Publica...

Figura 4.3 - Comparação dos valores simulados para o caso base com os valores médios obtidos para a concentração de CO para o período em questão na Estação Cerqueira César.

Figura 4.4 - Comparação dos valores simulados para o caso base com os valores médios obtidos para a concentração de $\mathrm{NO}_{x}$ no período estudado na Estação Cerqueira César.

Figura 4.5 - Comparação dos valores simulados para o caso base com os valores médios obtidos para a concentração de $\mathrm{O}_{3}$ no período de setembro de 2006 para 4 estações da RMSP. 
Figura 4.6 - Porcentagem de COVs para o caso base verão agrupados por função orgânica.

Figura 4.7 - Comparação dos valores simulados para o caso base com os valores médios obtidos para a concentração de CO no verão de 2006 na Estação Pinheiros.

Figura 4.8 - Comparação dos valores simulados para o caso base com os valores médios obtidos para a concentração de $\mathrm{NO}_{x}$ no verão de 2006 na Estação Pinheiros.

Figura 4.9 - Comparação dos valores simulados para o caso base com os valores médios obtidos para a concentração de $\mathrm{O}_{3}$ no verão de 2006 para 4 estações da RMSP......

Figura 4.10 - Porcentagem de COVs para o caso base outono agrupados por função orgânica.

Figura 4.11 - Comparação dos valores simulados para o caso base com os valores médios obtidos para a concentração de CO no outono de 2006 na Estação Pinheiros.

Figura 4.12 - Comparação dos valores simulados para o caso base com os valores médios obtidos para a concentração de $\mathrm{NO}_{x}$ no outono de 2006 na Estação Pinheiros. .

Figura 4.13 - Comparação dos valores simulados para o caso base com os valores médios obtidos para a concentração de $\mathrm{O}_{3}$ no outono de 2006 para 4 estações da RMSP.

Figura 4.14 - Porcentagem de COVs para o caso base inverno agrupados por função orgânica.

Figura 4.15 - Comparação dos valores simulados para o caso base com os valores médios obtidos para a concentração de CO no inverno de 2006 na Estação Pinheiros.

Figura 4.16 - Comparação dos valores simulados para o caso base com os valores médios obtidos para a concentração de $\mathrm{NO}_{\mathrm{x}}$ no inverno de 2006 na Estação Pinheiros.

Figura 4.17 - Comparação dos valores simulados para o caso base com os valores médios obtidos para a concentração de $\mathrm{O}_{3}$ no inverno de 2006 para 4 estações da RMSP......

\section{4}

Figura 4.18 - Porcentagem de COVs para o caso base primavera agrupados por função orgânica.

Figura 4.19 - Comparação dos valores simulados para o caso base com os valores médios obtidos para a concentração de CO na primavera de 2006 na Estação Pinheiros.

Figura 4.20 - Comparação dos valores simulados para o caso base com os valores médios obtidos para a concentração de $\mathrm{NO}_{x}$ na primavera de 2006 na Estação Pinheiros.

Figura 4.21 - Comparação dos valores simulados para o caso base com os valores médios obtidos para a concentração de $\mathrm{O}_{3}$ na primavera de 2006 para 4 estações da RMSP.....

Figura 5.1 - Variação percentual de ozônio em função da diminuição das emissões de $\mathrm{NO}_{x}$ e COVs para as quatro estações do ano.

Figura 5.2 - Isopletas de ozônio (em ppb) para diversas concentrações de COVs e $\mathrm{NO}_{x}$, para os cinco casos base construídos. A região com um círculo situa a condição atual da cidade de São Paulo para cada caso base.

Figura 5.3 - Reatividade Incremental (ppb de $\mathrm{O}_{3} / \mathrm{pppC}$ de COV) para os 30 principais precursores de ozônio na atmosfera de São Paulo - caso base Faculdade de Saúde Pública..... 
Figura 5.4 - Reatividade Incremental (ppb de $\mathrm{O}_{3} / \mathrm{pppC}$ de COV) para os 30 principais precursores de ozônio na atmosfera de São Paulo - caso base Cidade Universitária - Verão.

Figura 5.5 - Reatividade Incremental (ppb de $\mathrm{O}_{3} / \mathrm{pppC}$ de COV) para os 30 principais precursores de ozônio na atmosfera de São Paulo - caso base Cidade Universitária - Outono.

Figura 5.6 - Reatividade Incremental (ppb de $\mathrm{O}_{3} / \mathrm{pppC}$ de COV) para os 30 principais precursores de ozônio na atmosfera de São Paulo - caso base Cidade Universitária - Inverno.

Figura 5.7 - Reatividade Incremental (ppb de $\mathrm{O}_{3} / \mathrm{pppC}$ de COV) para os 30 principais precursores de ozônio na atmosfera de São Paulo - caso base Cidade Universitária Primavera. 


\section{Lista de Tabelas}

Tabela 4.1 - Concentrações iniciais de COVs, $\mathrm{NO}_{x}$ e $\mathrm{CO}$, para a Faculdade de Saúde Publica da USP.

Tabela 4.2 - Valores de Temperatura, Umidade Relativa do Ar e Altura da Camada de Mistura para o caso base Faculdade de Saúde Pública.

abela 4.3 - Porcentagem de COVs agrupados por função orgânica - caso base FSP

Tabela 4.4 - Agrupamento dos COVs para 15/09/2007 na Faculdade de Saúde Publica da USP, segundo metodologia SAPRC

Tabela 4.5 - Valores de emissões horárias para $\mathrm{CO}, \mathrm{NO}_{x}$ e $\mathrm{O}_{3}$

Tabela 4.6 - Concentrações iniciais de COVs, $\mathrm{NO}_{x}$ e $\mathrm{CO}$, para a Cidade Universitária e Estação Pinheiros da Cetesb para o verão de 2006.

Tabela 4.7 - Valores de Temperatura, Umidade Relativa do Ar e Altura da Camada de Mistura para o caso base verão.

Tabela 4.8 - Porcentagem de COVs para o caso base verão agrupados por função orgânica.

Tabela 4.9 - Agrupamento dos COVs para o caso base verão 2006, segundo metodologia SAPRC

Tabela 4.10 - Concentrações iniciais de COVs, $\mathrm{NO}_{x}$ e $\mathrm{CO}$, para a Cidade Universitária e Estação Pinheiros da Cetesb para o outono de 2006

Tabela 4.11 - Valores de Temperatura, Umidade Relativa do Ar e Altura da Camada de Mistura para o caso base verão.....

Tabela 4.12 - Porcentagem de COVs para o caso base outono agrupados por função orgânica.

Tabela 4.13 - Agrupamento dos COVs para o caso base outono 2006, segundo metodologia SAPRC.....

Tabela 4.14 - Concentrações iniciais de COVs, $\mathrm{NO}_{x}$ e $\mathrm{CO}$, para a Cidade Universitária e Estação Pinheiros da Cetesb para o inverno de 2006.

Tabela 4.15 - Valores de Temperatura, Umidade Relativa do Ar e Altura da Camada de Mistura para o caso base inverno.

Tabela 4.16 - Porcentagem de COVs para o caso base inverno agrupados por função orgânica.

Tabela 4.17 - Agrupamento dos COVs para o caso base inverno 2006, segundo metodologia SAPRC.

Tabela 4.18 - Concentrações iniciais de COVs, $\mathrm{NO}_{x}$ e $\mathrm{CO}$, para a Cidade Universitária e Estação Pinheiros da Cetesb para a primavera de 2006.

Tabela 4.19 - Valores de Temperatura, Umidade Relativa do Ar e Altura da Camada de Mistura para o caso base primavera.

Tabela 4.20 - Porcentagem de COVs para o caso base primavera agrupados por função orgânica.

Tabela 4.21 - Agrupamento dos COVs para o caso base primavera 2006, segundo metodologia SAPRC.

Tabela 5.1 - Variação do ozônio em função da diminuição das emissões horárias de COVs totais e $\mathrm{NO}_{x}$ para o caso base verão.

Tabela 5.2 - Variação do ozônio em função da diminuição das emissões horárias de COVs totais e $\mathrm{NO}_{x}$ para o caso base outono.

Tabela 5.3 - Variação do ozônio em função da diminuição das emissões horárias de COVs totais e $\mathrm{NO}_{x}$ para o caso base inverno...

Tabela 5.4 - Variação do ozônio em função da diminuição das emissões horárias de COVs totais e $\mathrm{NO}_{x}$ para o caso base primavera...

Tabela 5.5 - Variação do ozônio em função da diminuição das emissões horárias de COVs totais e $\mathrm{NO}_{x}$ para o caso base Faculdade de Saúde Pública. 
Tabela 5.6 - Resultados do cálculo da reatividade incremental (IR) para o caso base Faculdade de Saúde Publica. Valores de IR em ppb de $\mathrm{O}_{3} / \mathrm{ppbC}$ de COV

Tabela 5.7 - Resultados do cálculo da reatividade incremental (IR) para o caso base Verão. Valores de IR em $\mathrm{ppb}$ de $\mathrm{O}_{3} / \mathrm{ppbC}$ de

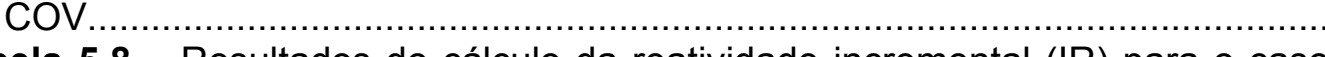

Tabela 5.8 - Resultados do cálculo da reatividade incremental (IR) para o caso base Outono. Valores de IR em ppb de $\mathrm{O}_{3} / p p b C$ de cOV.....

abela 5.9 - Resultados do cálculo da reatividade incremental (IR) para o caso base Inverno. Valores de IR em ppb de $\mathrm{O}_{3} / p p b C$ de COV........

Tabela 5.10 - Resultados do cálculo da reatividade incremental (IR) para o caso base Primavera. Valores de IR em ppb de $\mathrm{O}_{3} / p p b C$ de bOV 5.11 - Especificação dos alcenos e aromáticos mais e menos reativos segundo simulações deste trabalho... 
1 - Introdução

\section{1 - Caracterização da atmosfera}

A atmosfera é definida como uma enorme massa de ar que envolve o planeta Terra e o protege do impacto de meteoros e da penetração de radiação, como dos raios ultravioletas do Sol. É pela atmosfera que a energia solar, que controla o clima, é transmitida e modificada. Sua composição é essencial para a existência da vida no planeta (Hare, 1996).

A atmosfera é dividida em camadas, caracterizadas por gradientes verticais de temperatura, conforme pode-se ver na Figura 1.1.

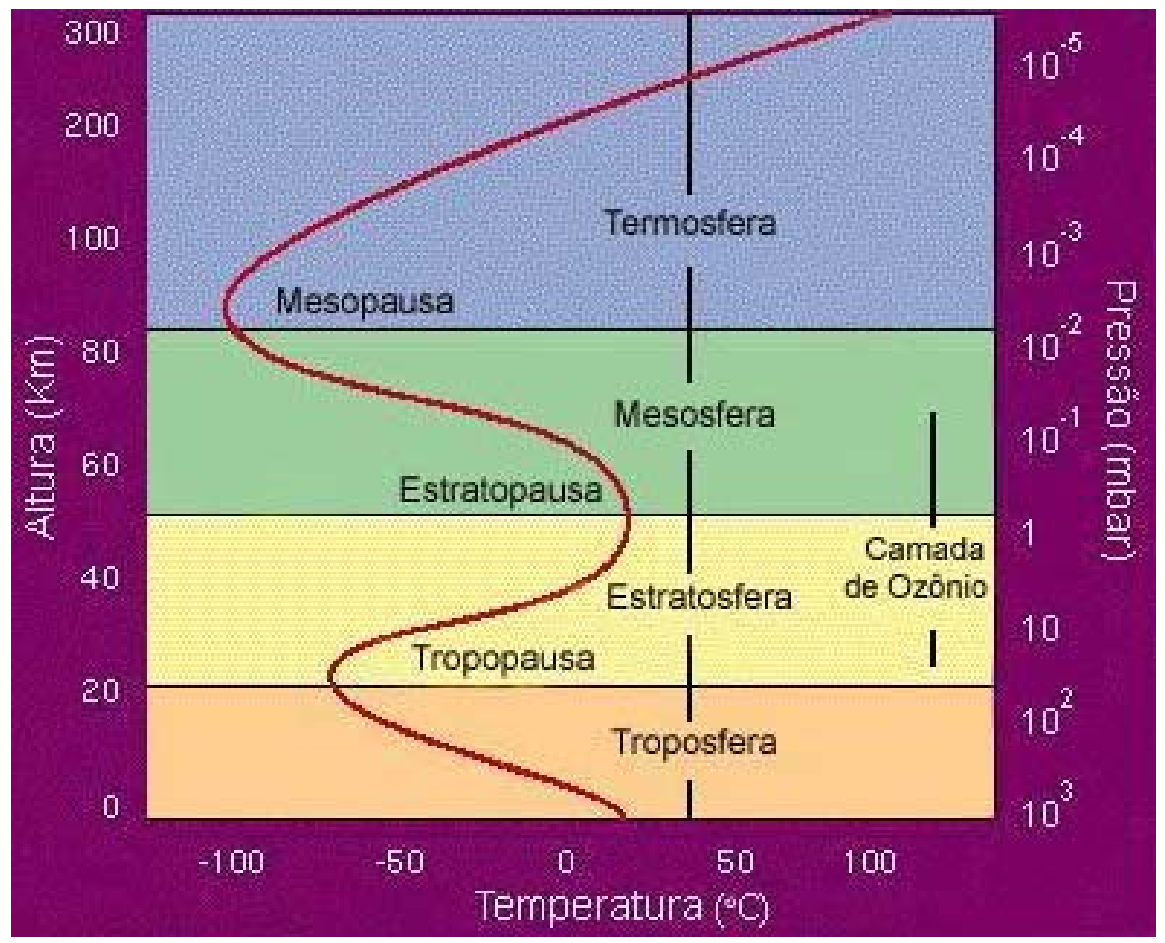

Figura 1.1 - Camadas da atmosfera e as variação da temperatura $\left({ }^{\circ} \mathrm{C}\right)$ em relação a altura $(\mathrm{km}) \mathrm{e}$ pressão (mbar) (Adaptado de NASA's Earth Science Enterprise).

A troposfera é a região que se estende desde o nível da superfície terrestre até cerca de 15 quilômetros de altitude e contém aproximadamente $85 \%$ da massa da atmosfera. A temperatura nesta camada da atmosfera diminui com o aumento da altitude. É freqüentemente instável dinamicamente, com rápidas trocas verticais de energia e massa.

Sobre a troposfera, a atmosfera se torna muito estável e o gradiente vertical de temperatura se inverte. A segunda região da atmosfera é chamada 
estratosfera, essa camada se estende até 50 quilômetros de altura e nela estão contidos cerca de $90 \%$ do ozônio atmosférico.

A camada entre 50 e 90 quilômetros de altitude é a mesosfera. Nessa região, a temperatura volta a diminuir com a altitude.

A termosfera se localiza acima dos 90 quilômetros de altitude e é a camada onde a temperatura aumenta, alcançando os valores mais elevados, que são fortemente dependentes do nível de atividade solar (Brasseur et al., 1999).

A composição química gasosa da troposfera é relativamente homogênea, composta basicamente por nitrogênio $\left(\mathrm{N}_{2} \sim 78,08 \%\right)$, oxigênio $\left(\mathrm{O}_{2} \sim 20,95 \%\right)$, argônio ( $\mathrm{Ar} \sim 0,93 \%$ ), dióxido de carbono $\left(\mathrm{CO}_{2} \sim 0,037 \%\right)$ e outros gases como $\mathrm{CO}, \mathrm{O}_{3}, \mathrm{CH}_{4}, \mathrm{NO}, \mathrm{NO}_{2}, \mathrm{SO}_{2}$, hidrocarbonetos e outros componentes (aproximadamente 0,003\%), também chamados de gases traço. Além dos gases mencionados acima, vapor de água também é encontrado na troposfera variando de acordo com a altitude, temperatura, localidade e época do ano. Esta quantidade de vapor de água contribui significativamente para os processos químicos atmosféricos, pois é fonte dos radicais hidroxila $\left(\mathrm{HO}^{\bullet}\right)$ e hidroperóxido $\left(\mathrm{HO}_{2}{ }^{\bullet}\right)$, representando um papel importante no ciclo hidrológico e no sistema terrestre como um todo (Seinfeld e Pandis, 1998).

\section{2 - A formação do ozônio}

O ozônio é um poluente secundário, que tem como principal fonte na troposfera a interação entre seus gases precursores: óxidos de nitrogênio $\left(\mathrm{NO}_{\mathrm{x}}\right)$, compostos orgânicos voláteis (COVs) e monóxido de carbono (CO) em presença de radiação ultravioleta $(\lambda \leq 335 \mathrm{~nm})$. Além de ser produzido fotoquimicamente na troposfera, é possível ocorrer também o transporte vertical de ozônio oriundo de camadas mais altas da troposfera e da estratosfera (Roelofs e Lelieveld, 1997; Wuebbles et al., 2003).

Óxidos de nitrogênio gasosos são produzidos sempre que um combustível é queimado em presença de ar com uma chama quente. Quando submetido a altas temperaturas, parte do nitrogênio e do oxigênio gasosos do ar combinam-se para formar óxido nítrico (NO), conforme a reação 1.1.

$$
\mathrm{N}_{2}+\mathrm{O}_{2} \stackrel{\text { chama }}{\longrightarrow} 2 \mathrm{NO}
$$


O óxido nítrico no ar é gradualmente oxidado para formar dióxido de nitrogênio $\left(\mathrm{NO}_{2}\right)$ em um período de minutos a horas, dependendo das concentrações de ouros oxidantes. As principais reações que transformam o NO em $\mathrm{NO}_{2}$ ocorrem através dos radicais $\mathrm{HO}_{2}{ }^{\bullet}$ e $\mathrm{RO}_{2}{ }^{\bullet}$, onde $\mathrm{R}$ representa um radical alquil (Atkinson, 2000). As referidas reações podem ser vistas a seguir:

$$
\begin{aligned}
& \mathrm{HO}_{2}+\mathrm{NO} \longrightarrow \mathrm{HO}^{\bullet}+\mathrm{NO}_{2} \\
& \mathrm{RO}_{2}+\mathrm{NO} \longrightarrow \mathrm{RO}^{\bullet}+\mathrm{NO}_{2}
\end{aligned}
$$

O NO é um gás incolor, inodoro e pouco tóxico, enquanto o $\mathrm{NO}_{2}$ é um gás marrom avermelhado, muito irritante e facilmente detectável por seu forte odor. (Baird, 1995). Coletivamente, $\mathrm{NO}$ e $\mathrm{NO}_{2}$ presentes no ar são denominados $\mathrm{NO}_{\mathrm{x}}$.

Já o termo composto orgânico volátil (COV) é utilizado para denominar os compostos orgânicos voláteis na atmosfera. Os COVs são divididos em 2 classes: a primeira, de compostos orgânicos não metano (COVNMs), na qual se incluem os compostos orgânicos oxigenados, os halogenados e os hidrocarbonetos; e a segunda classe na qual o metano faz parte. O metano é estudado separadamente, pois é o hidrocarboneto predominante na atmosfera. Sua alta concentração é influenciada pelo fato de seu tempo de vida ser longo, cerca de 14 $\pm 2,5$ anos (Seinfeld e Pandis, 1998).

A principal fonte de emissão de COVs em atmosferas urbanas são os motores dos veículos. Na Região Metropolitana de São Paulo representa 97\% (CETESB, 2007). Os COVs emitidos a partir de veículos automotores são constituídos principalmente de hidrocarbonetos que resultam da combustão incompleta de combustível e também de sua vaporização. Essas contribuições são geralmente classificadas e relatadas como emissões de cárter e evaporativa. Dentro da classe das emissões de cárter são incluídos o combustível não queimado ou parcialmente queimado e o óleo lubrificante que escapam do motor. A classe das emissões evaporativas inclui o vapor de combustível emitido do motor e do sistema de combustível que pode ser atribuído a várias fontes: vaporização do combustível como resultado do aquecimento do tanque de combustível, vaporização do combustível pelo aquecimento do motor após seu desligamento, vaporização do combustível a partir do sistema de combustível enquanto o veículo está operando e perda de vapor de combustível em função do abastecimento do tanque de combustível do veículo (Seinfeld e Pandis, 1998). 
Os COVs mais reativos no ar urbano são aqueles que contém ligações insaturadas, dado que eles podem adicionar-se aos radicais livres. Esses compostos são encontrados em grandes quantidades na composição da gasolina. Outros hidrocarbonetos também estão presentes e podem reagir, porém, sua velocidade de reação é mais lenta. (Baird, 1995).

O ozônio formado na troposfera é resultado da reação de fotólise do dióxido de nitrogênio, gerando óxido nítrico e um átomo de oxigênio em estado excitado, seguida da combinação deste último com uma molécula de oxigênio, conforme reações 1.4 e 1.5 .

$$
\begin{aligned}
& \mathrm{NO}_{2} \stackrel{\mathrm{UV}-\mathrm{A}}{\longrightarrow} \mathrm{NO}+\mathrm{O}^{*} \\
& \mathrm{O}^{*}+\mathrm{O}_{2} \longrightarrow \mathrm{O}_{3}
\end{aligned}
$$

Em uma via inversa, o óxido nítrico reage com o ozônio gerando novamente dióxido de nitrogênio e oxigênio molecular:

$$
\mathrm{NO}+\mathrm{O}_{3} \longrightarrow \mathrm{NO}_{2}+\mathrm{O}_{2}
$$

Desta forma todo ozônio produzido seria imediatamente consumido na reação de oxidação no NO, resultando numa produção líquida de ozônio igual a zero (Figura 1.2 [a]). Porém, na presença de COVs ocorre a formação de radicais intermediários $\mathrm{HO}_{2}{ }^{\bullet}$ e $\mathrm{RO}_{2}{ }^{\bullet}$, que por sua vez, reagem com $\mathrm{NO}$ produzindo $\mathrm{NO}_{2}$, fornecendo como resultado uma produção liquida de $\mathrm{O}_{3}$ (Figura 1.2 [b]) (Atkinson, 2000).

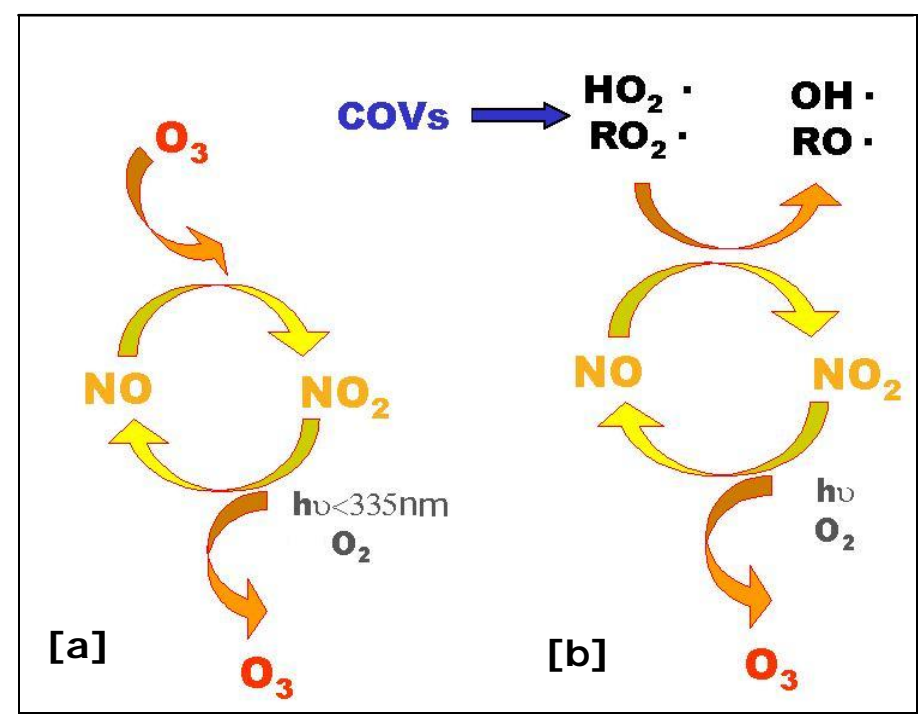

Figura 1.2 - Esquema das reações envolvidas na conversão $\mathrm{NO}^{-\mathrm{NO}_{2}}$ e formação de $\mathrm{O}_{3}$ em [a]: sistema $\mathrm{NO}-\mathrm{NO}_{2}-\mathrm{O}_{3}$ em ausência de COVs e [b]: sistema $\mathrm{NO}-\mathrm{NO}_{2}-\mathrm{O}_{3}$ na presença de COVs (Adaptado de Atkinson, 2000). 
Esta reação de oxidação do $\mathrm{NO}$ para $\mathrm{NO}_{2}$ a partir dos COVs se dá de forma bastante complexa e é iniciada por uma reação entre o COV e um radical hidroxila $\left(\mathrm{OH}^{\bullet}\right)$.

O radical hidroxila não reage com nenhum dos principais constituintes da atmosfera, como $\mathrm{N}_{2}, \mathrm{O}_{2}, \mathrm{CO}_{2}$ e $\mathrm{H}_{2} \mathrm{O}$, mesmo assim é a espécie reativa mais importante da troposfera, pois reage com a maioria dos gases traço presentes na mesma. O radical hidroxila é produzido quando uma fração de átomos de oxigênio no estado excitado, resultantes da decomposição fotoquímica de quantidades traço de ozônio, reage com o vapor de água para abstrair um átomo de hidrogênio de cada molécula de $\mathrm{H}_{2} \mathrm{O}$ (reações 1.7 e 1.8) .

$$
\begin{aligned}
\mathrm{O}_{3} & \stackrel{\text { UV-B }}{\longrightarrow} \mathrm{O}_{2}^{*}+\mathrm{O}^{*} \\
\mathrm{O}^{*}+\mathrm{H}_{2} \mathrm{O} & \longrightarrow 2 \mathrm{OH}^{\bullet}
\end{aligned}
$$

Se o radical hidroxila reagisse com outras espécies e não fosse regenerado de alguma maneira, sua concentração seria muito baixa e mesmo com sua alta reatividade, este radical não seria uma espécie importante para a química da troposfera. O fato é que quando reage com gases traço na atmosfera o $\mathrm{OH}^{\bullet}$ é gerado em ciclos catalíticos fazendo com que sua concentração permaneça na ordem de $10^{6}$ moléculas $\mathrm{x} \mathrm{cm}^{-3}$ enquanto houver luz do Sol (Seinfeld e Pandis, 1998). Durante a noite a concentração dos radicais hidroxila cai rapidamente para zero.

No que diz respeito à formação do ozônio troposférico, os COVs contendo ligações insaturadas reagem com o radical hidroxila e posteriormente com oxigênio molecular gerando radicais peróxido, conforme as seguintes reações esquemáticas:

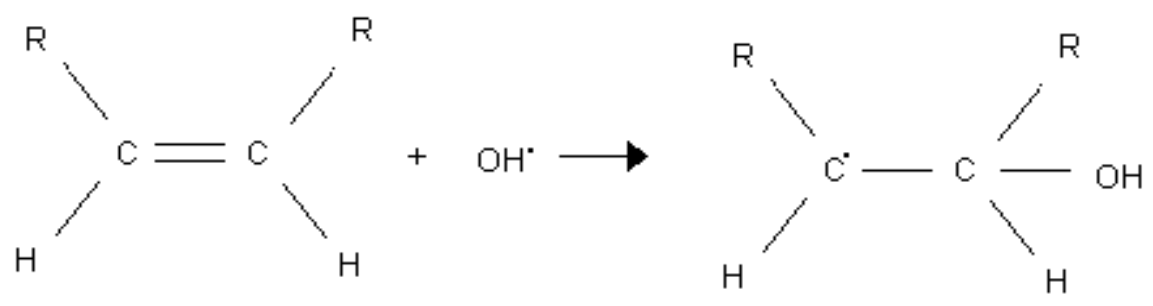




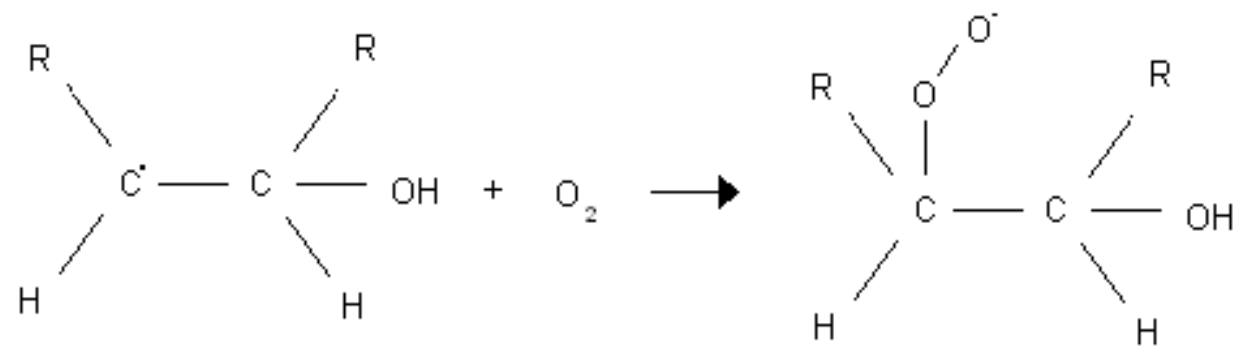

Esses radicais peróxido oxidam o $\mathrm{NO}$, gerando mais $\mathrm{NO}_{2}$ sem destruir as moléculas de $\mathrm{O}_{3}$ formadas, conforme reação 1.11. $\mathrm{E} \circ \mathrm{NO}_{2}$ formado pode sofrer nova fotólise para formar mais ozônio.
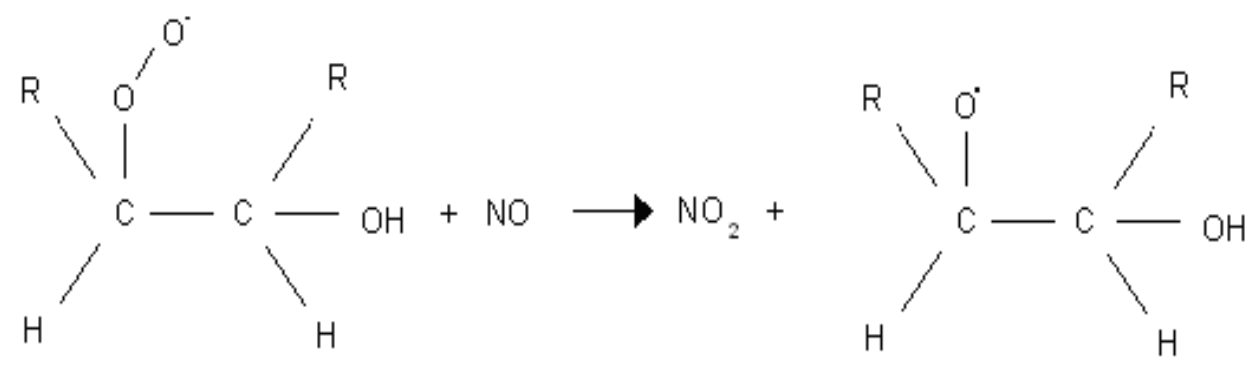

Os COVs que não apresentam ligações insaturadas também formam radicais peróxido que oxidam as espécies $\mathrm{NO}$ a $\mathrm{NO}_{2}$. Em geral esses COVs se comportam de maneira semelhante ao metano. Embora o potencial de formação de ozônio dos alcanos seja baixo, devido às suas baixas velocidades de reação, o metano é um composto que possui grande importância na formação do ozônio troposférico, já que em atmosferas urbanas, atinge concentrações muito elevadas em comparação aos outros COVs. A reação global de oxidação do metano é mostrada a seguir.

$$
\mathrm{CH}_{4}+5 \mathrm{O}_{2}+\mathrm{NO}+2 \mathrm{OH}^{\circ} \stackrel{\mathrm{UV}-\mathrm{A}}{\longrightarrow} \mathrm{CO}_{2}+\mathrm{H}_{2} \mathrm{O}+\mathrm{NO}_{2}+4 \mathrm{HO}_{2}^{\cdot}
$$

A produção ou a perda líquida de $\mathrm{O}_{3}$ são, portanto determinadas não pela quantidade de $\mathrm{NO}_{x}$ na atmosfera, mas sim, pela razão $\mathrm{COVs} / \mathrm{NO}_{x}$. O aumento ou a diminuição destes precursores não significa que irá aumentar ou diminuir a concentração do ozônio formado. A influência das concentrações de $\mathrm{NO}_{x}$ e COVs na formação do ozônio troposférico é apresentada na Figura 1.3. As curvas são as isolinhas de concentração de ozônio em unidades de ppm, construídas por simulação.

$\mathrm{O}$ fato é que a formação do $\mathrm{O}_{3}$ pode ser entendida como uma competição entre os COVs e os $\mathrm{NO}_{x}$ pelos radicais hidroxila. Quando há uma razão entre as concentrações de COV e $\mathrm{NO}_{x}$ de aproximadamente 5,5:1 as taxas de reação 
destes gases com o radical $\mathrm{OH}^{\bullet}$ são iguais. Porém, quando esta razão é menor que 5,5:1, $\mathrm{O} \mathrm{OH}^{\bullet}$ reage preferencialmente com os $\mathrm{NO}_{x}$, para formar ácido nítrico e nitroso, removendo radicais e retardando a formação de $\mathrm{O}_{3}$.

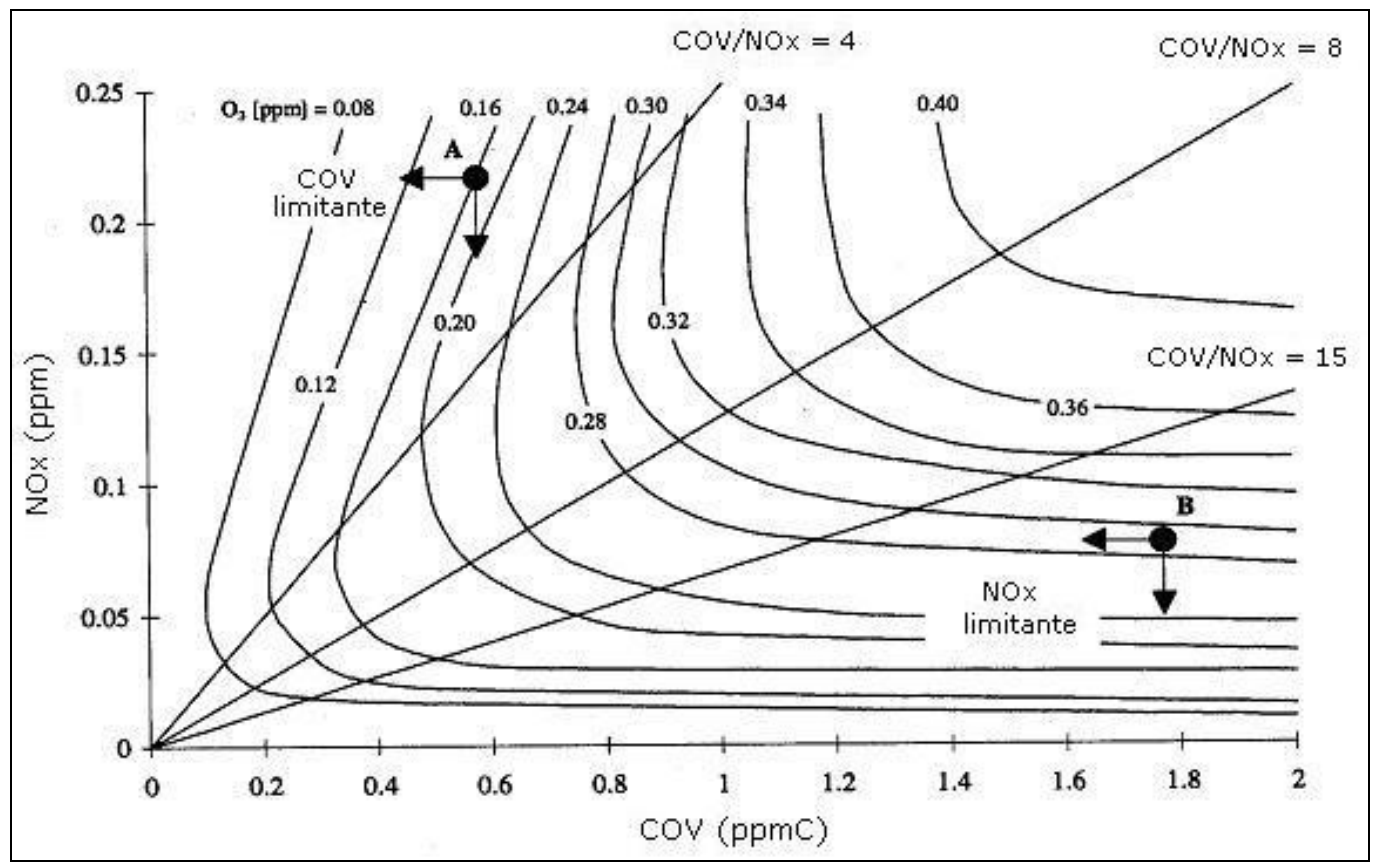

Figura 1.3 - Isolinhas de formação de ozônio em relação às concentrações de $\mathrm{NO}_{\mathrm{x}}$ e COVs (Fonte: Seinfeld e Pandis, 1998).

Sob estas condições um decréscimo na concentração de $\mathrm{NO}_{x}$ favorece a formação de $\mathrm{O}_{3}$. Por outro lado, havendo uma razão maior que 5,5:1 $\circ \mathrm{OH}^{\bullet}$ reage preferencialmente com os COVs. Nestas condições uma diminuição nas concentrações de $\mathrm{NO}_{x}$ retarda a formação de ozônio, pois em um ambiente com uma concentração suficientemente baixa de $\mathrm{NO}_{x}$ ou uma razão entre COV e $\mathrm{NO}_{x}$ suficientemente alta, a diminuição na concentração de $\mathrm{NO}_{x}$ irá favorecer as reações peróxido-peróxido (reações 1.13 e 1.14), que irão retardar a formação de $\mathrm{O}_{3}$ pela remoção dos radicais livres do sistema. Portanto, enquanto em geral, um aumento nas concentrações dos COVs significa um aumento na produção de $\mathrm{O}_{3}$, um aumento nas concentrações dos $\mathrm{NO}_{x}$ pode significar acréscimo ou decréscimo nos níveis de $\mathrm{O}_{3}$, dependendo da razão $\mathrm{COV} / \mathrm{NO}_{x}$ (Seinfeld e Pandis, 1998).

$$
\begin{aligned}
2 \mathrm{OH}^{\bullet} & \longrightarrow \mathrm{H}_{2} \mathrm{O}_{2} \\
2 \mathrm{HO}_{2} & \longrightarrow \mathrm{H}_{2} \mathrm{O}_{2}+\mathrm{O}_{2}
\end{aligned}
$$

Além disso, deve-se lembrar que individualmente cada COV contribui de uma forma diferente para a formação do ozônio. Desta forma pode ser mais eficaz 
diminuir a concentração de um COV específico do que diminuir a concentração total dos COVs na tentativa de diminuir a formação líquida de ozônio.

Outro poluente que contribui para a formação do ozônio troposférico é o monóxido de carbono (CO). O CO de origem antrópica é geralmente emitido na atmosfera como resultado da combustão incompleta de combustíveis fósseis ou de outros materiais que contenham carbono em sua composição (Braga, et al., 2002).

$\mathrm{Na}$ atmosfera, o $\mathrm{CO}$ é oxidado a $\mathrm{CO}_{2}$ pelos radicais hidroxila, gerando radicais hidroperóxidos. Estes radicais hidroperóxidos, de maneira similar aos radicais peróxido formados pelos COVs, oxidam o $\mathrm{NO}$ a $\mathrm{NO}_{2}$ sem destruir as moléculas de $\mathrm{O}_{3}$ e fazendo com que a concentração deste gás aumente na atmosfera (Seinfeld \& Pandis, 1998).

$$
\begin{array}{cl}
\mathrm{CO}+\mathrm{OH}^{\bullet} & \stackrel{\mathrm{O}_{2}}{\longrightarrow} \mathrm{CO}_{2}+\mathrm{HO}_{2} \cdot \\
\mathrm{HO}_{2}+\mathrm{NO} & \longrightarrow \mathrm{NO}_{2}+\mathrm{OH}^{\bullet}
\end{array}
$$

\subsection{1 - O destino dos radicais}

Após oxidar a molécula de $\mathrm{NO}$ a $\mathrm{NO}_{2}$, o radical peróxido originado da reação de um composto insaturado com um radical hidroxila se transforma em um radical $\mathrm{RCHO} C \mathrm{H}(\mathrm{R}) \mathrm{OH}$, conforme descrito na reação 1.11. Este radical formado tende a decompor-se espontaneamente por clivagem da ligação $C-C$, originando um aldeído e um outro radical, $\mathrm{RH} \dot{\mathrm{C} O H}$ :

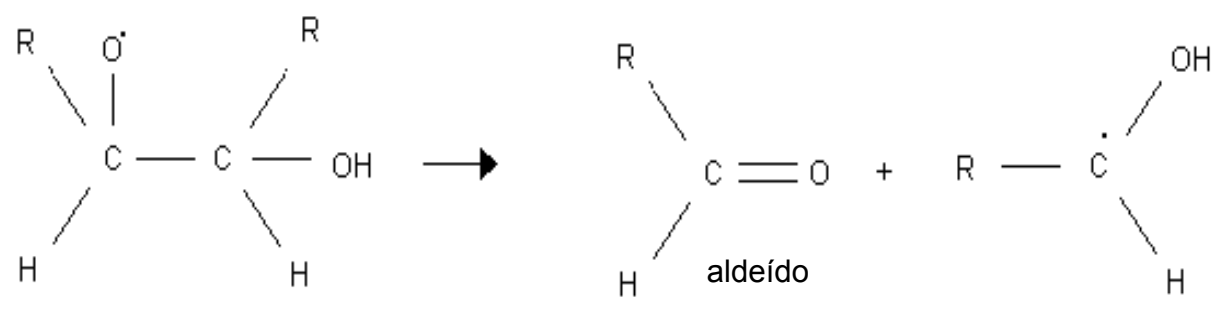

Por sua vez o radical baseado no carbono $\mathrm{RHC} O H$ reage com uma molécula de $\mathrm{O}_{2}$, dando origem a outra molécula de aldeído e um radical hidroperóxido: 


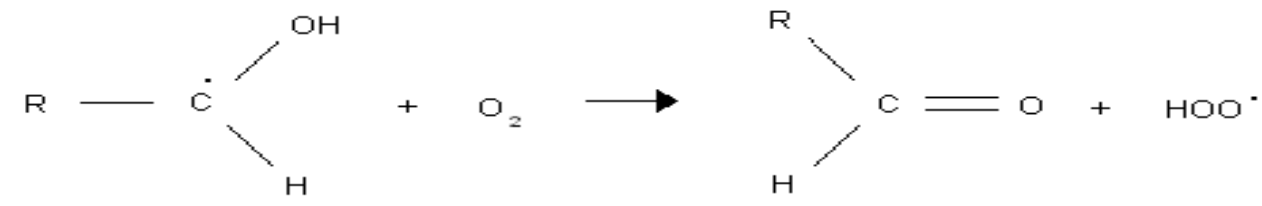

As moléculas de aldeído formadas se decompõe pela ação da luz gerando novos radicais livres:
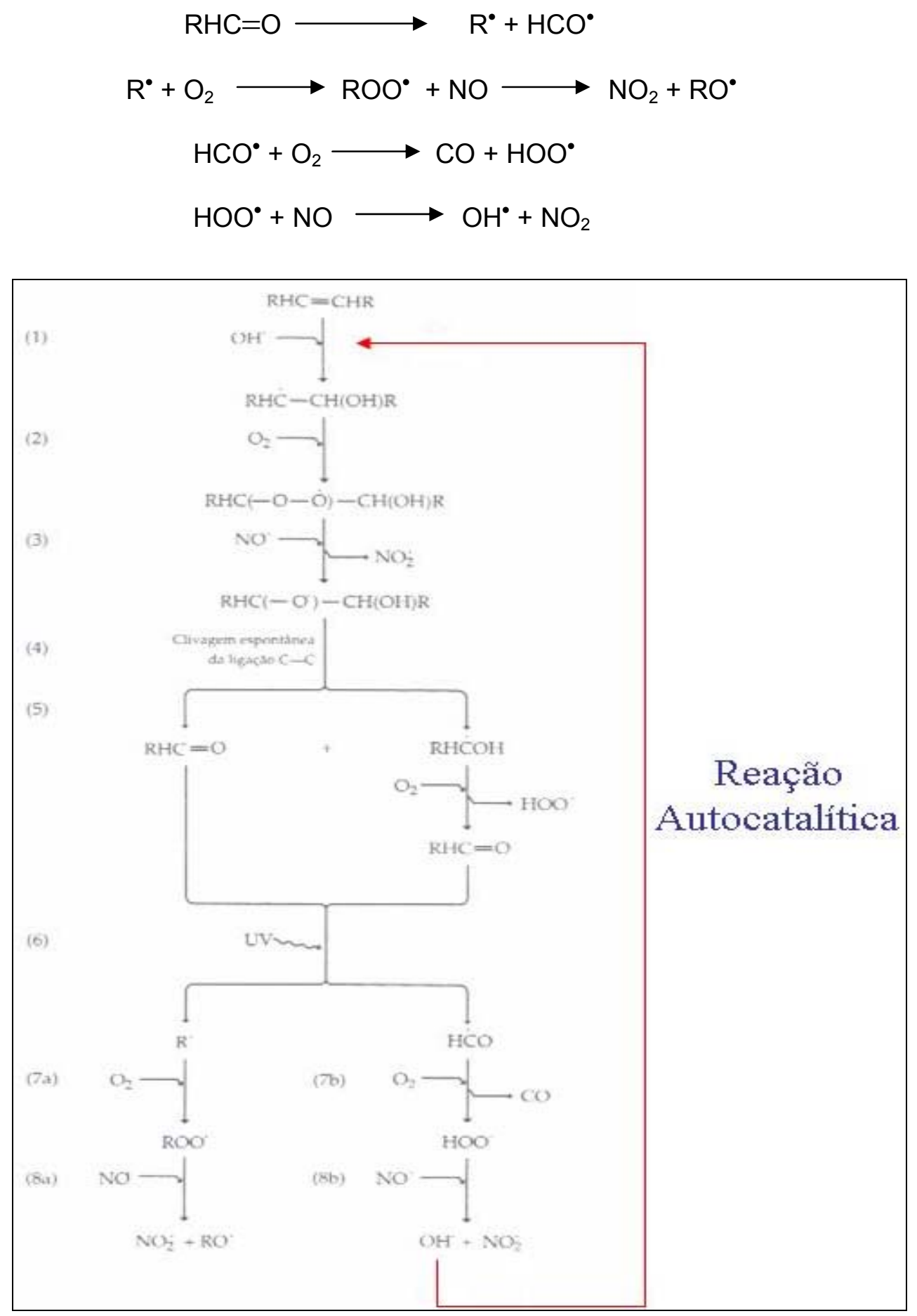

Figura 1.4 - Mecanismo do processo de oxidação do RHC=CHR (Fonte: Baird,1995). 
Como pode ser percebido observando-se as reações, um dos produtos finais da reação é o radical hidroxila, assim, a reação é autocatalítica, sua velocidade aumentará com o tempo, dado que um de seus produtos, neste caso o $\mathrm{OH}^{\circ}$, catalisa a reação para as outras moléculas de reagente (Baird, 1995). As etapas de conversão da molécula original de $\mathrm{RCH}=\mathrm{CHR}$ se encontram resumidas na Figura 1.4.

\section{3 - A Influência da meteororologia na poluição do ar}

A poluição atmosférica está diretamente relacionada com a dispersão e conseqüente diluição dos poluentes. Um fator que afeta significantemente a diluição dos poluentes é a altura da camada de mistura.

A temperatura da atmosfera terrestre em seus primeiros $10 \mathrm{~km}$, em geral, diminui com a altitude: o ar mais quente perto da superfície terrestre sobe e em contrapartida uma parcela de ar mais fria das regiões mais altas da troposfera desce, diminuindo as concentrações na baixa troposfera. A uma certa altura a temperatura começa a aumentar novamente, e aí a tendência da parcela de ar mais quente subir se inverte e ela desce, formando uma camada. Essa altitude é conhecida como camada de mistura ou camada limite planetária: o ar quente fica retido ou confinado embaixo dessa camada de mistura, sendo esta a região na qual o gás pode ser efetivamente misturado.

A altura da camada de mistura é definida como a base da inversão de temperatura em relação à altitude. Sendo assim, o ciclo diurno da camada de mistura é diretamente influenciado pela variação da temperatura da superfície, que oscila principalmente pela intensidade dos raios solares. Sua maior extensão vertical ocorre durante o dia, quando são registrados os maiores valores de temperatura, podendo atingir centenas de metros a quilômetros (1000 a $3000 \mathrm{~m}$ ). Um esquema do ciclo da camada de mistura está apresentado na Figura 1.5. Nos períodos em que há uma menor disponibilidade de energia proveniente do Sol, o crescimento da camada de mistura é limitado, o que contribui para um aumento das concentrações dos poluentes (Stull, 1991). 


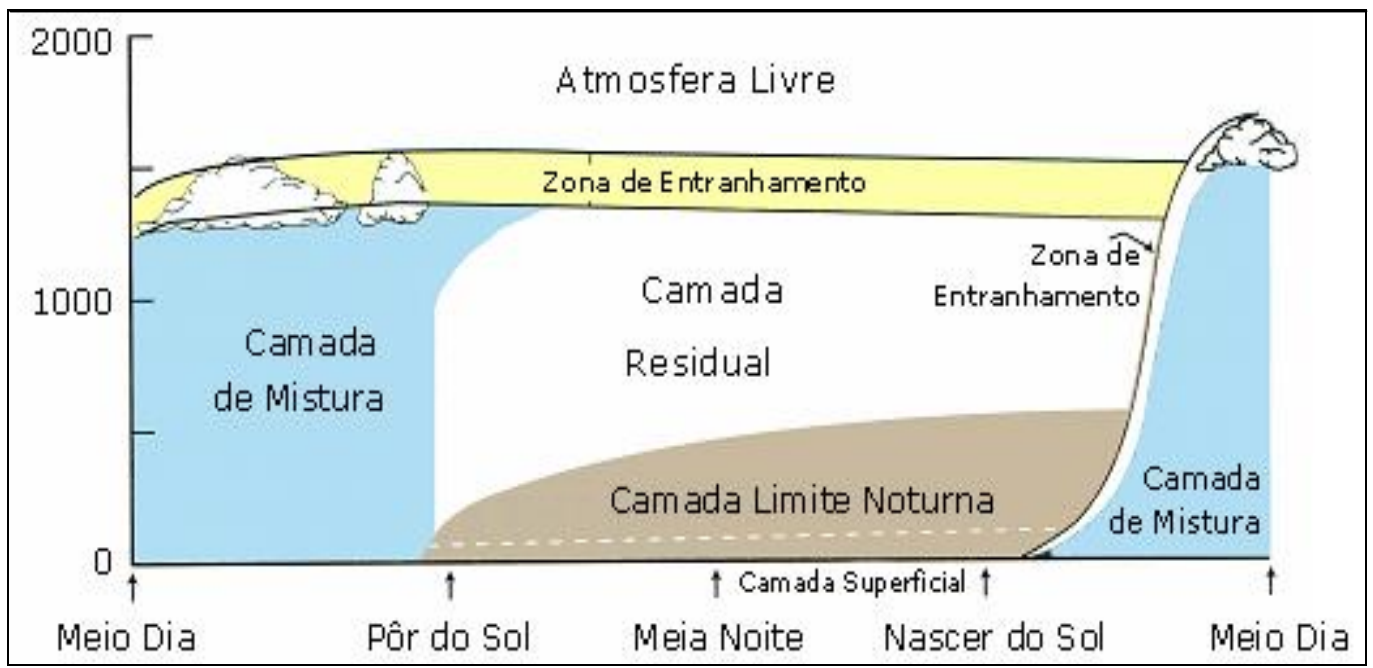

Figura 1.5 - Ciclo diurno da Camada Limite Planetária, de um dia típico sem nuvens (Adaptado de Stull, 1991).

Quando o sol se põe, o resfriamento da atmosfera próxima à superfície ocorre mais rápido que o da atmosfera superior. É iniciada uma situação de inversão de temperatura que faz com que uma camada de ar frio fique sobreposta entre uma camada de ar quente, impedindo o movimento ascendente do ar atmosférico. Esta é uma camada termodinamicamente estável, denominada de Camada Limite Noturna (CLN) e atinge dezenas de metros de altura (cerca de 100 a $300 \mathrm{~m}$ ). Os poluentes ficam estagnados próximos ao solo podendo ocasionar problemas de saúde e no meio ambiente. Este fenômeno agrava-se quando ocorre em locais como nos grandes centros urbanos ou em ambientes industrializados (Stull, 1991).

Sobre a CLN permanece uma camada chamada Camada Residual (CR), que mantém aprisionados os poluentes do dia anterior até o início do dia seguinte quando esta camada é rompida. Este processo propicia o acúmulo de poluentes de um dia para o outro, contribuindo com a elevação da concentração dos mesmos.

Segundo demonstrou Corrêa (2003), a concentração de poluentes como CO e aldeídos aumenta proporcionalmente com a diminuição da altura da camada de mistura. O mesmo já não ocorre com a concentração de ozônio, pois esta depende das concentrações de $\mathrm{NO}_{x}$ e COVs. Ao diminuir a altura da camada de mistura, as concentrações de $\mathrm{NO}_{\mathrm{x}}$ e COVs aumentam, alterando as razões $\mathrm{COV} / \mathrm{NO}_{\mathrm{x}}$, o que pode levar a um decréscimo nas concentrações de ozônio. 


\section{4 - Simulação computacional}

Para a realização deste trabalho foi utilizado o modelo de trajetórias OZIPR (Ozone Isopleth Package for Research) em conjunto com o modelo químico SAPRC (Statewide Air Pollution Research Center), por serem de domínio público e terem grande aceitação no meio acadêmico internacional.

Essa escolha levou em conta também o fato de estes serem modelos relativamente simples de se trabalhar, ideais para um primeiro trabalho com modelamento matemático em áreas urbanas poluídas. Além disso, este modelo prioriza o entendimento das reações fotoquímicas do meio em questão, pois seu mecanismo químico é extremamente detalhado.

\subsection{1 - Modelo de trajetórias OZIPR}

O modelo de trajetórias OZIPR (Gery and Crouse, 1990) foi desenvolvido por encomenda da agência de proteção ambiental dos EUA (U.S. EPA) para ser um suporte para a previsão de cenários de poluição urbana. Suas principais características são:

- ser um modelo relativamente simples, unidimensional, conhecido como modelo "em caixa" ou de trajetórias, que requer dados de concentrações iniciais, emissões e parâmetros meteorológicos, com resolução temporal, sem a necessidade de uma descrição espacial destes parâmetros;

- permitir o uso de diversos modelos químicos, inclusive aqueles com grau de complexidade e detalhamento elevado, como o modelo SAPRC que será utilizado neste trabalho;

- possuir mecanismos internos tipo EKMA (Empirical Kinetic Modeling Approach) que possibilitem calcular o nível de redução dos poluentes, a fim de se atingir os padrões de qualidade do ar;

- possibilitar realizar múltiplas simulações para diversas condições de compostos orgânicos voláteis e óxidos de nitrogênio, fornecendo um gráfico de isopletas para diferentes poluentes secundários em função destes dois precursores, sendo uma ferramenta muito útil na previsão de cenários e elaboração de estratégias de controle ambiental. 
O OZIPR possibilita a simulação dos complexos processos químicos e físicos que acontecem na troposfera urbana, através de um modelo de trajetórias. Pode-se entender o modelo como uma coluna de ar que na base engloba o ponto de estudo em questão e que se projeta para cima, até a camada de mistura da atmosfera, como se fosse uma caixa com uma tampa móvel, que é função da altura da camada de mistura ao longo do dia. Toda a caixa é considerada perfeitamente homogênea e move-se de acordo com a trajetória do vento, mas de modo a não se expandir horizontalmente (Figura 1.6). As emissões provenientes da base da coluna são computadas, assim como as deposições secas e úmidas podem ser implementadas.

Basicamente, os dados de entrada para uma simulação, são os dados da localidade de estudo: concentrações individuais das diferentes espécies na mistura de COVs; concentrações iniciais totais de $\mathrm{NO}, \mathrm{NO}_{2}, \mathrm{COVs}$ totais, $\mathrm{CO}$; dados meteorológicos horários de temperatura, pressão, umidade relativa e altura da camada de mistura; emissões primárias; localização geográfica e data (para se calcular o fluxo solar actínico); coeficientes de deposição seca e úmida e modelo químico.

Os dados de saída são as concentrações médias horárias das espécies químicas que se desejar e as isopletas dos poluentes secundários para valores estabelecidos de COVs e $\mathrm{NO}_{x}$.

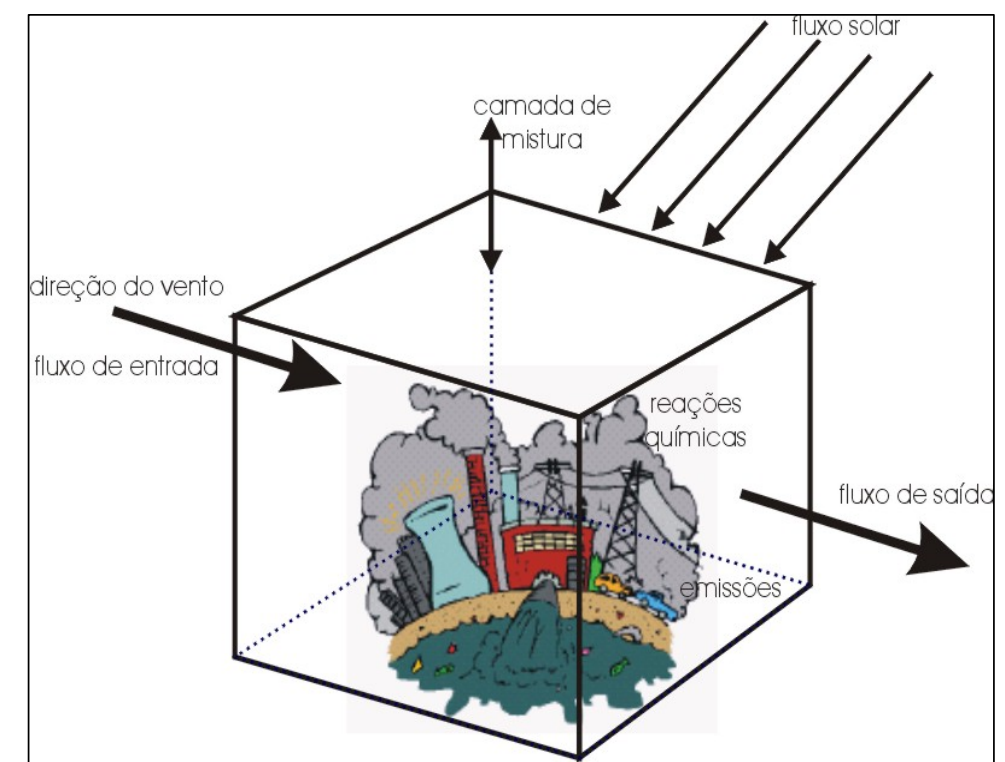

Figura 1.6 - Representação esquemática de um modelo de trajetórias (Corrêa, 2003). 


\subsection{2 - Modelo químico SAPRC}

Modelos químicos são importantes ferramentas utilizadas por planejadores das agências ambientais para prever os impactos das emissões de poluentes na qualidade do ar. Estes modelos estão em constante evolução, como resultado de um melhor entendimento das transformações químicas dos poluentes primários e secundários e de novas medidas dos parâmetros cinéticos. Inúmeros trabalhos estão em andamento para uma melhor compreensão dos fatores cinéticos e estequiométricos que regem estas reações (Corrêa, 2003).

Os modelos químicos são baseados na premissa, amplamente aceita, de que as reações entre os COVs e $\mathrm{NO}_{x}$ regem a formação de ozônio e uma mudança em um simples COV individual pode levar a resultados surpreendentes. Basicamente, os modelos químicos são ajustados para ozônio, pois este composto não é emitido por nenhuma fonte significativa.

O modelo SAPRC (Statewide Air Pollution Research Center) foi desenvolvido por Carter em 1990 na Universidade de Riverside e vem sofrendo inúmeras alterações e atualizações desde então. Devido à sua estrutura e ampla documentação, seu uso e modificações são muito facilitados. Como seus arquivos e opcionais estão em modo texto, é grande a facilidade e flexibilidade com que modificações podem ser feitas sem ter que recorrer a reprogramações em difíceis linguagens. Por esta razão, seu uso foi bastante difundido no mundo, ao contrário dos modelos chamados Eulerianos, onde a mudança em um trecho do mecanismo implica em uma mudança no software.

O SAPRC é um modelo que engloba reações térmicas e fotoquímicas. Em geral, trabalha com cerca de 140 reações e 80 espécies. Nem todas as espécies são tratadas explicitamente dentro de seu mecanismo. Isso se deve a três razões principais: a pouca importância que as referidas espécies impõem ao modelo, pouca informação do valor da constante de velocidade e para se diminuir o tempo computacional. Atualmente, as constantes de velocidade estão classificadas em dez classes (Figura 1.7).

$\mathrm{Na}$ inviabilidade de representar o modelo químico com todas as suas espécies explícitas, uma metodologia de agrupamento em classes foi estabelecida. Entretanto, algumas espécies com constantes de velocidade bem estabelecidas e/ou grande importância para a química da atmosfera, foram 
mantidas explícitas. Os critérios de agrupamento são dois: semelhança de estrutura e reatividade (Carter, 1990). Basicamente, são empregados cinco agrupamentos de alcanos, dois grupos de alcenos e dois de aromáticos. Os compostos com química explícita são colocados em um grupo com este nome. A versão que será utilizada neste trabalho é a versão SAPRC 1999.

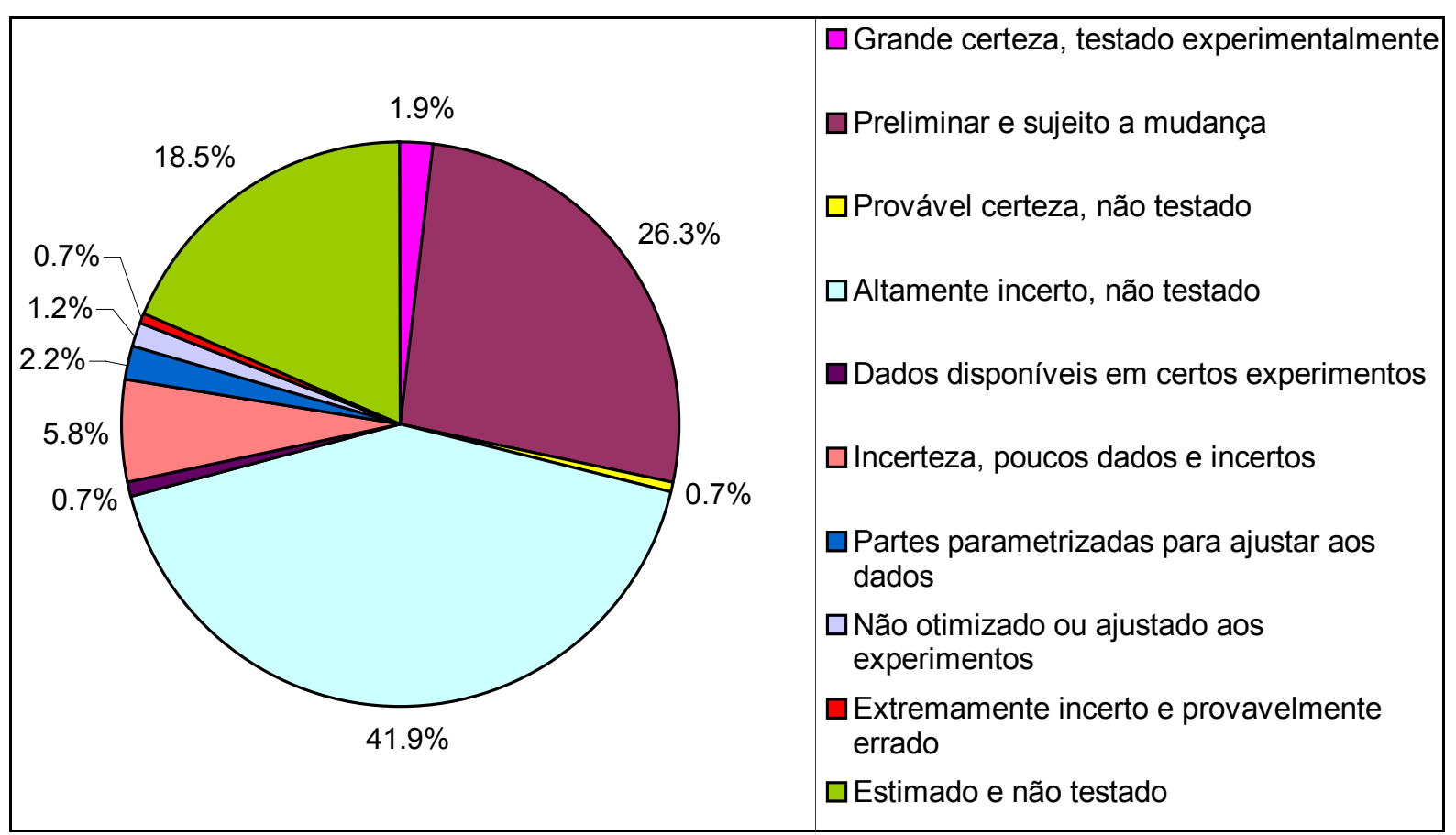

Figura 1.7 - Incerteza das constantes de velocidades no mecanismo químico SAPRC.

Para utilizar o mecanismo SAPRC é preciso conhecer as concentrações de cada COV em termos de ppmC (partes por milhão em base de carbono). Esta informação deve ser obtida, preferencialmente, a partir de medidas das concentrações, em $\mu \mathrm{g} / \mathrm{m}^{3}$, das espécies presentes na atmosfera a ser estudada, no período de 6:00 às 9:00 horas da manhã, que é a hora na qual em geral emitese a maior quantidade de poluentes devido ao engarrafamento matinal. Além disso, até este horário, ocorreram poucas transformações de poluentes primários em secundários, através de reações foto e termoquímicas, em função da baixa intensidade de radiação solar. Este valor de concentração é então usado na Equação 1.1, onde os valores de massa, em $\mu \mathrm{g}$, são transformados em volume, através da equação de Clapeyron.

$$
\operatorname{ppm}_{i}=\frac{\text { Concentração }_{i}\left(\mu \mathrm{g} / \mathrm{m}^{3}\right) x N^{\circ} \text { deCarbonos }}{40,9 x \text { PesoMolecular }}
$$


Em seguida calcula-se a fração de cada espécie do grupo em relação aos demais, segundo a Equação 1.2:

$$
\text { Fração }_{i}=\frac{p p m C_{i} x N^{\circ} \text { deCarbonos }}{\sum_{i} p p m C_{i}}
$$

Os somatórios das $i$ espécies das equações 1 e 2 fornecem então as frações de ppmC e os números médios de átomos de carbono (NC) de cada grupo $\boldsymbol{j}$, como nas equações 1.3 e 1.4:

$$
\begin{aligned}
& \operatorname{ppm}_{j}=\sum_{i} p p m C_{i} \\
& N C_{j}=\sum_{i} \text { Fração }_{i}
\end{aligned}
$$

Finalmente, pode-se então calcular as frações, em termos de ppmC e número médio de carbono, de cada grupo em relação aos demais, como nas Equações 1.5 e 1.6:

$$
\begin{aligned}
& \text { Fração }_{p p m C_{j}}=\frac{p p m C_{j}}{\sum_{j} p p m C_{j}} \\
& \text { Fração }_{N C_{j}}=\frac{N C_{j}}{\sum_{j} N C_{j}}
\end{aligned}
$$

Para facilitar as contas acima foi desenvolvida uma planilha eletrônica que efetua os cálculos acima de modo automático, bastando o usuário entrar com as concentrações $\left(\mathrm{em} \mu \mathrm{g} / \mathrm{m}^{3}\right)$ das espécies conforme descrito.

\section{5 - Escalas de reatividade para COVs.}

Sabe-se que diferentes tipos de COVs possuem diferentes velocidades de reação para a formação de ozônio e outros poluentes secundários em misturas de COV/NO $/ \mathrm{N}_{\mathrm{x}}$ na presença de luz solar (Finlayson-Pitts e Pitts, 2000).

O reconhecimento dessas diferentes reatividades é que possibilitam o desenvolvimento de estratégias de controle de emissões para os COVNMs. O gás metano reage muito devagar, numa escala de horas a poucos dias, que faz com que o mesmo não contribua significantemente para a formação do smog 
fotoquímico. No outro extremo estão a maioria dos alcenos e aldeídos, que são altamente reativos.

Baseado nesse reconhecimento sobre a diferença de reatividade dos COVs, muitas regulamentações têm sido promulgadas ao logo do tempo, como por exemplo, a rule 66, implementada pelo Departamento de Controle de Poluição do Ar de Los Angeles em 1966 para limitar as emissões de solventes baseado em suas reatividades.

Mais recentemente, tem havido um foco maior na aplicação do mesmo princípio para emissão de motores de veículos.

O conceito de escala de reatividade é baseado no ranqueamento dos COVs em função de seus potenciais de produção de ozônio.

Vários parâmetros têm sido usados para ranquear os COVs por suas reatividades, incluindo as taxas de reação observadas, rendimento do produto e efeitos observados em misturas de $\mathrm{COV} / \mathrm{NO}_{x}$ na presença de luz solar. Efeitos como dano às plantações, irritação nos olhos ou redução da visibilidade também têm se mostrado como parâmetros úteis.

Darnall et al., em 1976 desenvolveu uma escala de reatividade baseada na reatividade do radical $\mathrm{OH}^{*}$ com os COVs. Esta escala tem como princípio, que para a maioria dos hidrocarbonetos, o ataque pelo radical $\mathrm{OH}^{\bullet}$ é o responsável pela grande maioria do consumo dos hidrocarbonetos. Esta escala não leva em conta alguns aspectos importantes do mecanismo das reações em misturas $\mathrm{COV} / \mathrm{NO}_{\mathrm{x}}$ na presença de luz solar e nem tampouco a natureza dos produtos formados, no entanto, tem provado ser útil para prover pelo menos uma avaliação inicial das contribuições individuais dos COVs para a formação do smog fotoquímico.

Em geral, independentemente da escala de reatividade escolhida, a reatividade dos hidrocarbonetos tende a seguir a seguinte ordem: [alcenos com ligações duplas internas] > [di e trimetil aromáticos, alcenos terminais] > etileno > [metil aromáticos] > [C5 e alcanos maiores] > [alcanos C2-C5] (Finlayson-Pitts e Pitts, 2000).

É importante lembrar que o efeito de um dado COV para a formação do $\mathrm{O}_{3}$ irá depender não só da velocidade de reação deste COV e da natureza de seu mecanismo de reação, mas também da natureza do ar onde o COV é emitido, incluindo o efeito de outros poluentes que estão presentes. 
Embora o efeito dos COVs na formação do $\mathrm{O}_{3}$ possa ser medido em experimentos com atmosfera controlada, esses efeitos dependem do ambiente onde os COVs reagem e, portanto esses resultados não são totalmente confiáveis. Já o uso de modelagem computacional provê um meio mais realístico e flexível para avaliar os muitos fatores que afetam a formação de $\mathrm{O}_{3}$ pelos COVs e o desenvolvimento de escalas de reatividade para os COVs (Carter, 1994).

Para quantificar os impactos na formação de $\mathrm{O}_{3}$ por um dado COV foi criada a "reatividade incremental". Esta é definida como a mudança no $\mathrm{O}_{3}$ causada pela adição de uma quantidade pequena de um dado COV, dividida pela quantidade de COV adicionada, conforme fórmula abaixo:

$\mathrm{IR}=\frac{\Delta\left[\mathrm{O}_{3}\right]}{\Delta[\text { átomos de } \mathrm{C} \text { do COV adicionado }]}$

Alguns compostos podem causar a formação de 10 ou mais moléculas de $\mathrm{O}_{3}$ por átomo de carbono adicionado, diretamente ou por seus efeitos em reações de outros compostos, enquanto outros, praticamente não causam nenhuma ou até reduzem a formação de $\mathrm{O}_{3}$.

Os estudos de modelagem também predizem que as reatividades incrementais dependem significantemente das condições do ambiente, principalmente da disponibilidade relativa de $\mathrm{NO}_{\mathrm{x}}$. Geralmente, COVs tem uma maior reatividade incremental sob condições relativamente altas de $\mathrm{NO}_{\mathrm{x}}$ (baixo $\mathrm{COV} / \mathrm{NO}_{\mathrm{x}}$ ) e tem uma reatividade muito menor ou até negativa sob condições onde o $\mathrm{NO}_{x}$ é o limitante (alta COV/NO ) (Carter, 1994).

Devido a toda esta complexidade envolvida na determinação das escalas de reatividade é que se faz necessário estudos específicos destas escalas para diferentes regiões, já que as concentrações individuais dos COVs podem variar significantemente de um local para outro, assim como as relações COV/NO Além disso, deve-se lembrar que as atmosferas urbanas brasileiras apresentam uma composição de COVs um pouco diferente das atmosferas ao redor do mundo devido a uma série de fatores como: elevado uso de álcool etílico e GNV (gás natural veicular) como combustível veicular, diferente composição química do óleo diesel e diferente tecnologia dos motores a diesel e mais recentemente, a entrada do biodiesel no mercado. 


\section{6 - Justificativa do trabalho}

É fato notório que as ações antrópicas, ao longo do tempo, vêm alterando a composição química da atmosfera terrestre através da emissão dos mais variados poluentes, sobretudo, em áreas industriais e urbanas.

Conforme a legislação, poluente atmosférico é qualquer forma de matéria ou energia com intensidade e quantidade, concentração, tempo ou características em desacordo com os níveis estabelecidos, e que tornem ou possam tornar o ar: impróprio, nocivo ou ofensivo à saúde; inconveniente ao bem-estar público; danoso aos materiais, à fauna e flora; prejudicial à segurança, ao uso e gozo da propriedade e às atividades normais da comunidade (CONAMA, 1990).

Muitos são os compostos lançados no ar que afetam o ambiente e a saúde humana. A emissão de óxidos de nitrogênio e enxofre que causam a chuva ácida, os CFCs que destroem a camada de ozônio, o gás carbônico que contribui para o aquecimento do planeta, os hidrocarbonetos, grupo no qual estão inseridos compostos reconhecidamente carcinogênicos, dentre outros. Outro poluente comumente encontrado em atmosferas urbanas é o ozônio, substância que será objeto de estudo deste trabalho.

O ozônio é um poluente atmosférico nocivo. Seu efeito é mais prejudicial para as crianças, idosos e pessoas que apresentam problemas respiratórios préexistentes, porém, ele afeta também pessoas fortes e saudáveis. Experimentos realizados com pessoas voluntárias demonstraram que o ozônio produz irritação passageira do sistema respiratório, produzindo tosse, irritação da garganta e do nariz, respiração ofegante e dor no peito durante a respiração profunda. Assim, mesmo quando saudáveis, alguns jovens apresentaram esses sintomas enquanto realizavam exercícios ao ar livre, como andar de bicicleta ou correr, durante os episódios de smog. Um efeito esperado é uma diminuição na resistência às doenças infecciosas devido à destruição dos tecidos pulmonares. Muitos cientistas defendem que a exposição crônica a altos níveis de ozônio urbano leva ao envelhecimento prematuro dos tecidos pulmonares, pois como se sabe, o ozônio ataca prontamente substâncias que contenham em sua estrutura ligações $\mathrm{C}=\mathrm{C}$, tais como as que se encontram nos tecidos dos pulmões (Baird, 1995).

Em experimento realizado com ratos, onde os mesmos permaneceram em ambientes com concentrações controladas de ozônio, foi possível observar que a 
exposição prolongada ao ozônio pode danificar o aparelho respiratório, contribuindo para o desenvolvimento de doenças e aumentando o risco de câncer nesses animais. Os autores ressaltam que os resultados não podem simplesmente ser extrapolados para as condições humanas, principalmente porque os ratos respiram apenas pelo nariz, enquanto os humanos respiram também pela boca, indicando a necessidade de pesquisas adicionais (Wagner et al., 2003).

O ozônio também provoca efeitos maléficos sobre as culturas agrícolas devido a sua capacidade de atacar as plantas. O ozônio reage com o gás eteno que é emitido pelas plantas, gerando radicais livres que causam danos aos tecidos vegetais. A taxa de fotossíntese diminui pela ação do ozônio. Prejuízos de grande intensidade foram registrados em várias partes do mundo com relação a cultivos agrícolas que crescem em regiões ricas em ozônio.

Em atmosferas urbanas como a da Região Metropolitana de São Paulo (RMSP), a emissão de origem veicular responde por mais de $90 \%$ dos poluentes lançados na mesma (CETESB, 2007). Durante muito tempo acreditou-se que a poluição gerada por automóveis era consideravelmente menor que a poluição industrial. Fato que só foi desmentido a partir dos anos 80 , quando se observou que a contribuição dos poluentes gerados pelos automóveis era a fonte majoritária para as grandes cidades (Corrêa, 2003).

Uma vez constatada a gravidade da poluição gerada pelos veículos, os órgãos ambientais nacionais iniciaram seus esforços na tentativa de minimizar essas emissões. No ano de 1986 foi publicada a Resolução n 18/86 do CONAMA - Conselho Nacional do Meio Ambiente, que estabeleceu o PROCONVE Programa de Controle da Poluição do Ar por Veículos Automotores.

Desde que foi implantado, o Programa reduziu a emissão de poluentes de veículos novos em cerca de $97 \%$, por meio da limitação progressiva da emissão de poluentes, através da introdução de tecnologias como catalisador, injeção eletrônica de combustível e melhorias nos combustíveis automotivos (CETESB, 2007).

Em contrapartida a frota de veículos na Região Metropolitana de São Paulo cresceu consideravelmente desde a década de 80 até hoje. Como pode ser verificado na Figura 1.8 a frota duplicou no período de 14 anos, apresentando um leve decréscimo em 2005, em função de uma atualização do banco de dados de 
veículos registrados, realizada pela PRODESP, que resultou na retirada de um grande número de veículos, principalmente os mais antigos, anteriores a 1980.

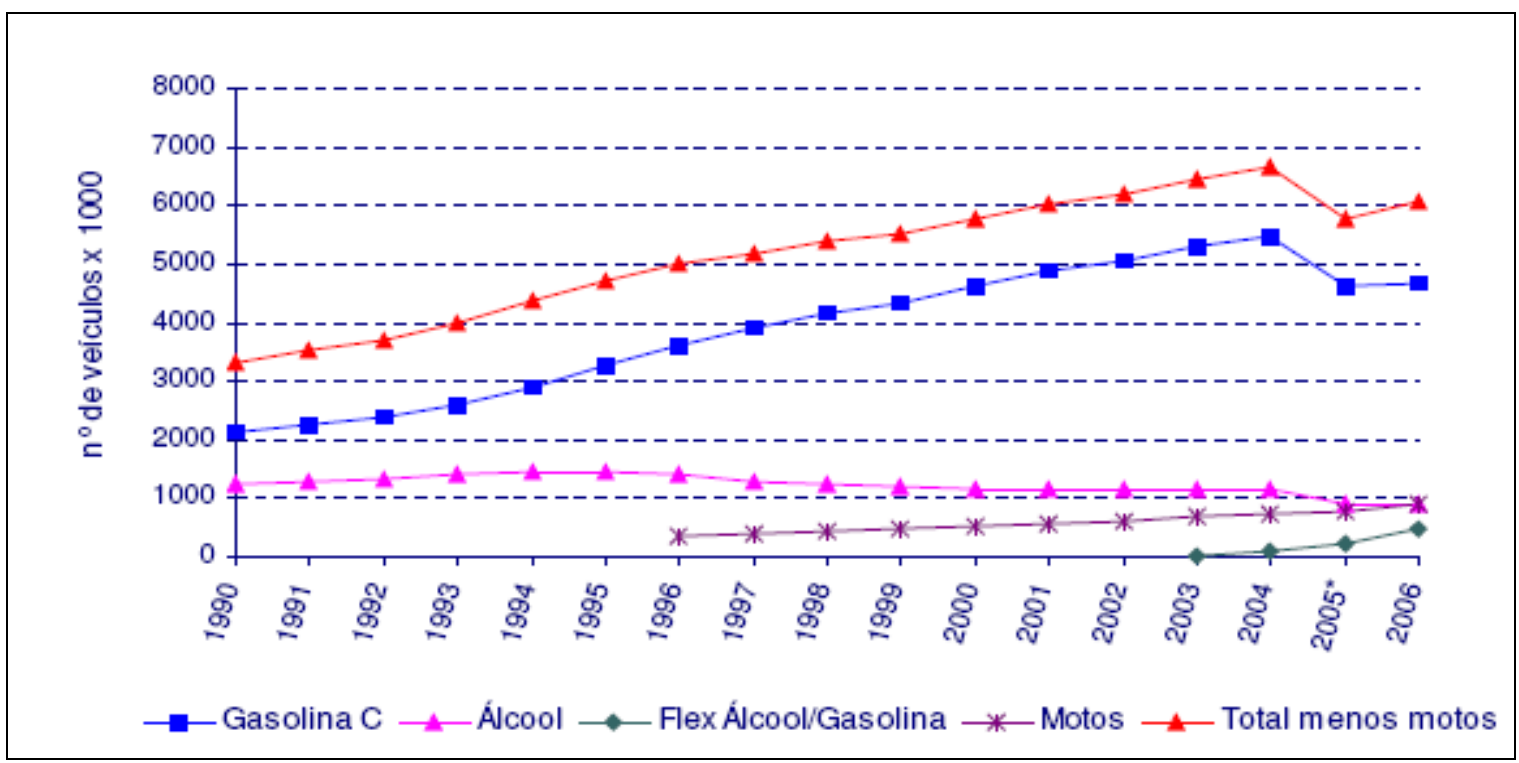

(*) A redução do número de veículos registrados se deve à atualização do banco de dados, realizada pela PRODESP (Fonte: PRODESP)

Figura 1.8 - Evolução da frota de veículos automotores leves na RMSP.

Segundo dados da CETESB, as melhorias tecnológicas realizadas nos veículos associadas ao processo de combustão e uso de catalisadores, além da melhoria na qualidade dos combustíveis, conseguiram contrabalancear o grande aumento na frota de veículos no que diz respeito à emissão de poluentes atmosféricos. Na Figura 1.9, são apresentados os fatores da emissão média de CO das frotas de veículos a gasolina C (gasolina contendo $22 \%$ de álcool anidro e 500 ppm de enxofre (massa)) e a álcool.

Pode-se notar um decréscimo significativo dos fatores para veículos movidos a gasolina $C$, no entanto, o mesmo não ocorre para os veículos a álcool, embora representem uma fração bem menor que a dos veículos a gasolina $\mathrm{C}$, sua frota se constitui, em sua maioria, de veículos mais antigos, em crescente deterioração, o que a leva a emitir cada vez mais.

É importante lembrar que apesar dessas consideráveis reduções nas emissões de $\mathrm{CO}$ e também de outros poluentes, como $\mathrm{NO}_{x}$ e Hidrocarbonetos, ainda são freqüentes os dias em que a concentração de ozônio na RMSP ultrapassa os padrões nacionais de qualidade do ar (CETESB, 2007). Enquanto o número de ultrapassagens do padrão para CO na RMSP caiu de 18 para 1 de 1999 até 2005, o número de ultrapassagens para ozônio caiu de 109 para 51 no 
mesmo período, ou seja, apesar de ter ocorrido uma considerável diminuição no número de ultrapassagens para ozônio, ainda não ocorreu uma diminuição tão significativa como dos demais poluentes. Além disso, deve-se salientar que as variações nas condições meteorológicas também interferem na formação de ozônio, como por exemplo, a nebulosidade, que reduz a incidência de radiação solar e dificulta a formação deste poluente (CETESB, 2007).

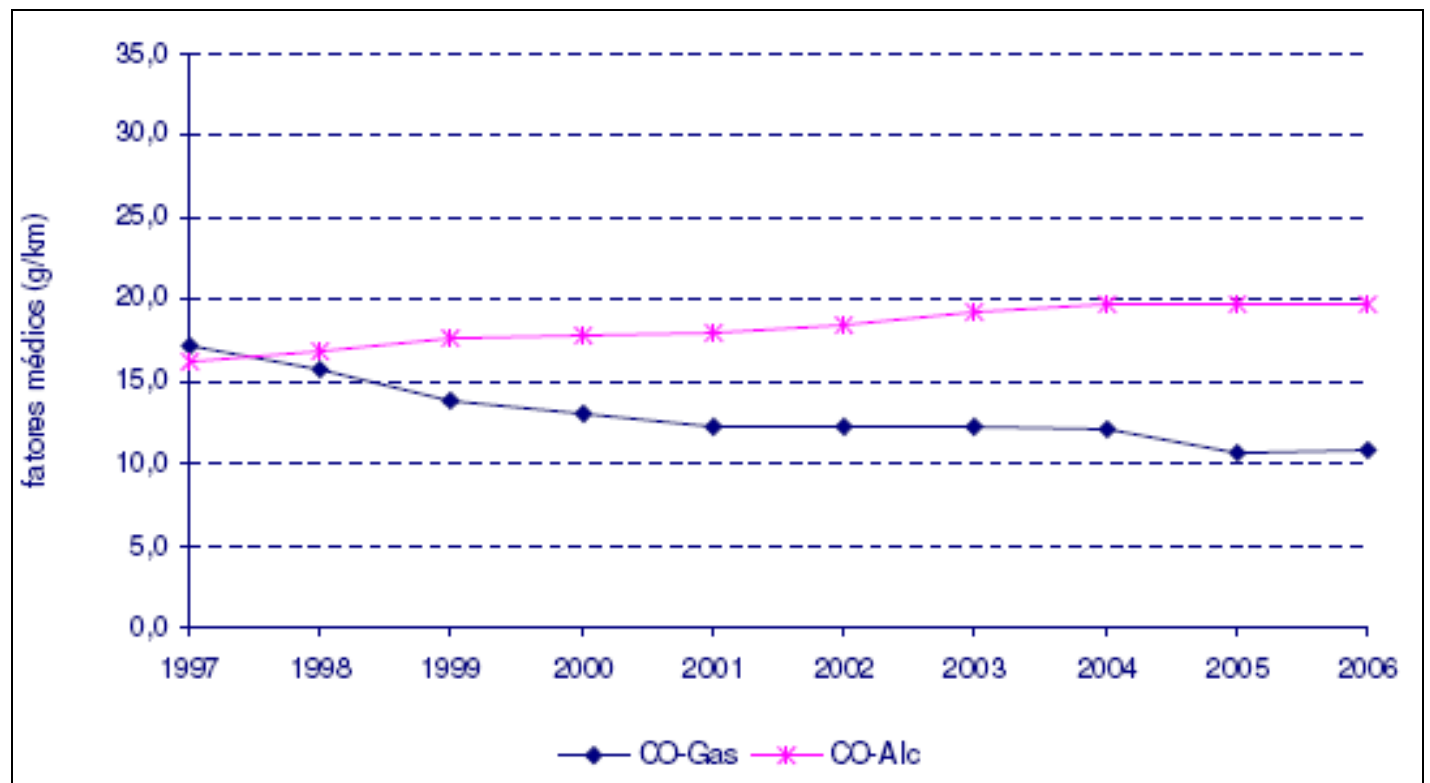

Figura 1.9 - Evolução dos fatores médios de emissão de CO dos veículos movidos a álcool e a gasolina C da RMSP.

A Figura 1.10 apresenta a distribuição da qualidade do ar por ozônio no período de 2001 a 2006, considerando sete estações de monitoramento. A análise não indica uma tendência clara de redução das concentrações e eventuais reduções observadas como na freqüência de Inadequada e Má, podem refletir variações das condições meteorológicas entre os anos (CETESB, 2007).

As concentrações observadas em São Paulo são comparáveis com aquelas existentes atualmente na Europa e as ocorrências de ozônio sofrem influência direta das condições meteorológicas ocorridas durante o período, não representando necessariamente reduções de emissões dos precursores deste poluente (CETESB, 2007). 


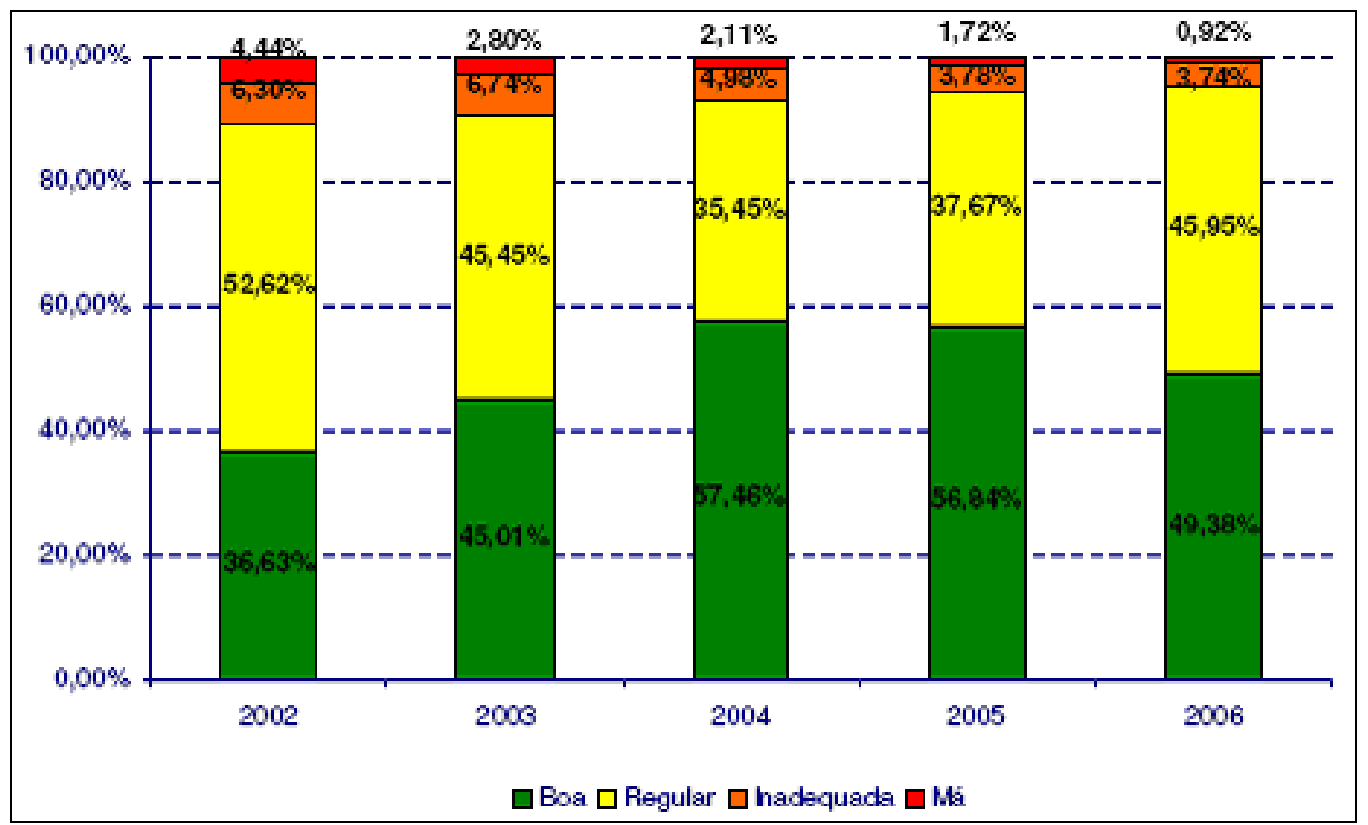

Figura 1.10- $\mathrm{O}_{3}$ : Distribuição Percentual da Qualidade do Ar Período de 2001 a 2006. Base: Estações Santana, Moóca, Ibirapuera, Diadema, Santo Amaro, Santo André-Capuava e Mauá.

Diante da dificuldade em se reduzir os níveis de ozônio na RMSP, assim como, em outros grandes conglomerados urbanos, faz-se necessário um estudo detalhado de quais os principais precursores deste poluente para assim subsidiar a elaboração de possíveis legislações que venham a ser propostas na tentativa de minimizar este problema.

\section{7 - Caracterização da região de estudo}

A Região Metropolitana de São Paulo (RMSP) está localizada a $23^{\circ} \mathrm{S}$ e $46^{\circ} \mathrm{W}$, na porção sudeste do Brasil. Possui uma área de $8.051 \mathrm{~km}^{2} \mathrm{com}$ uma população superior a 19 milhões de habitantes, distribuída em uma área urbanizada e de maneira desordenada em $1.747 \mathrm{~km}^{2}$ dessa área. O sítio urbano situa-se, praticamente, na Bacia Sedimentar de São Paulo, cujo principal vale é o do Rio Tietê, orientado no sentido leste-oeste, com uma altitude média de 720 metros e uma extensa planície de inundação. Essa bacia é cercada ao norte pela Serra da Cantareira, também orientada no sentido leste-oeste e com altitudes que atingem até 1.200 metros e a leste-sul pelo reverso da Serra do Mar com altitudes que, em geral, ultrapassam os 800 metros. Está distante cerca de $45 \mathrm{~km}$ do Oceano Atlântico. A Região Metropolitana de São Paulo (Figura 1.11) ocupa 
cerca de $0,1 \%$ do território brasileiro e é o terceiro maior conglomerado urbano do mundo, responsável por 1/6 do PIB nacional (CETESB, 2007).

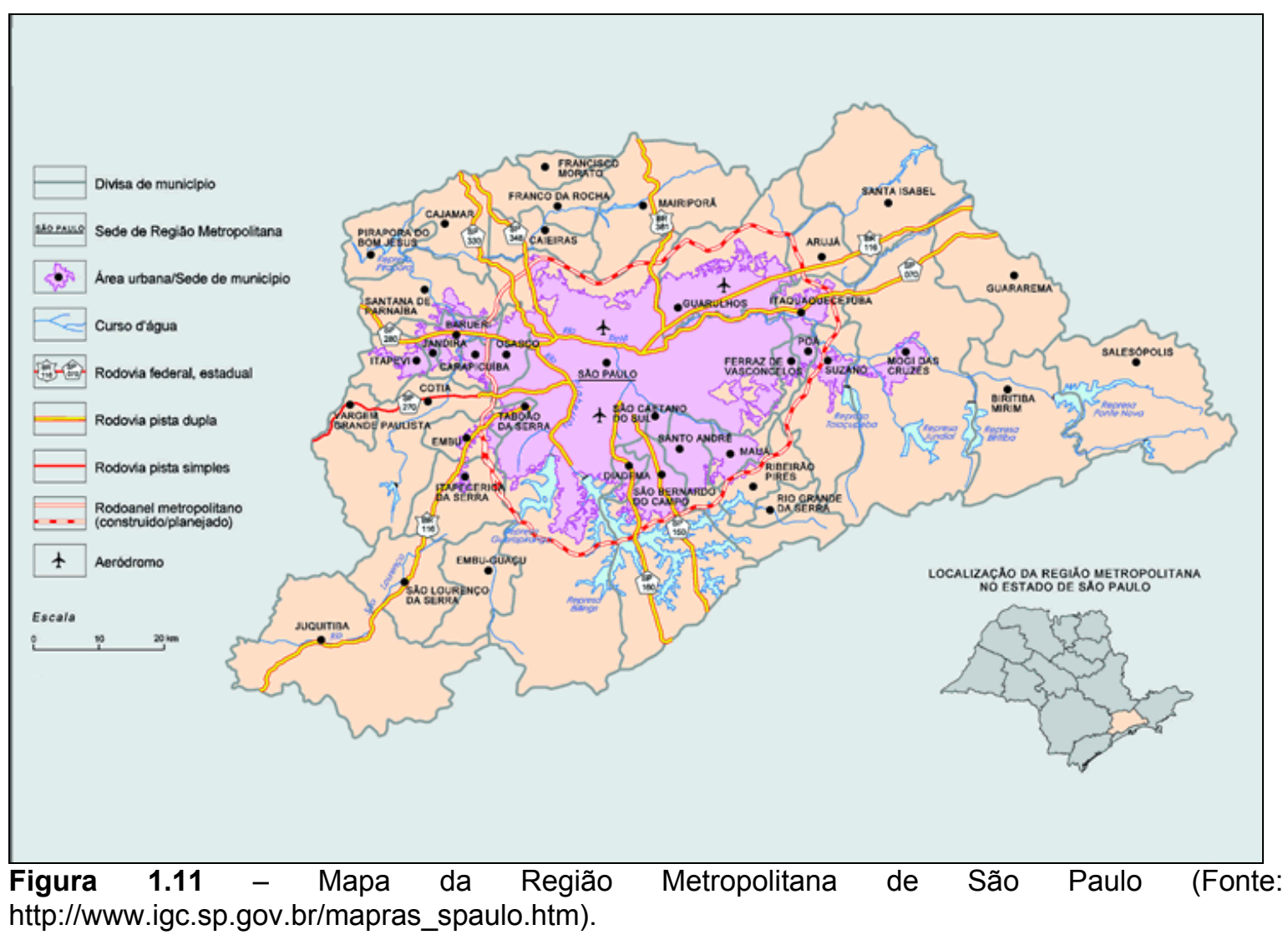

A região possui cerca de 2000 indústrias de alto potencial poluidor e uma frota registrada de aproximadamente 7,3 milhões de veículos, sendo 6,0 milhões de veículos do ciclo Otto, 430 mil veículos a diesel e 870 mil motos, frota esta que representa cerca de 1/5 do total nacional. De acordo com as estimativas de 2006, essas fontes de poluição são responsáveis pelas emissões para a atmosfera, dos seguintes poluentes: 1,48 milhão de t/ano de monóxido de carbono (CO), 358,1 mil t/ano de hidrocarbonetos $(\mathrm{HC}), 331$ mil t/ano de óxidos de nitrogênio $\left(\mathrm{NO}_{\mathrm{x}}\right), 29$ mil t/ano de material particulado total (MP) e 9,1 mil t/ano de óxidos de enxofre $\left(\mathrm{SO}_{\mathrm{x}}\right)$. Desses totais os veículos são responsáveis por $97 \%$ das emissões de CO, $97 \%$ de $\mathrm{HC}, 96 \% \mathrm{NO}_{x}, 40 \%$ de MP e 35\% de $\mathrm{SO}_{\mathrm{x}}$. Na Figura 1.12 é possível verificar a notável extensão da ocupação urbana da Região Metropolitana de São Paulo. 


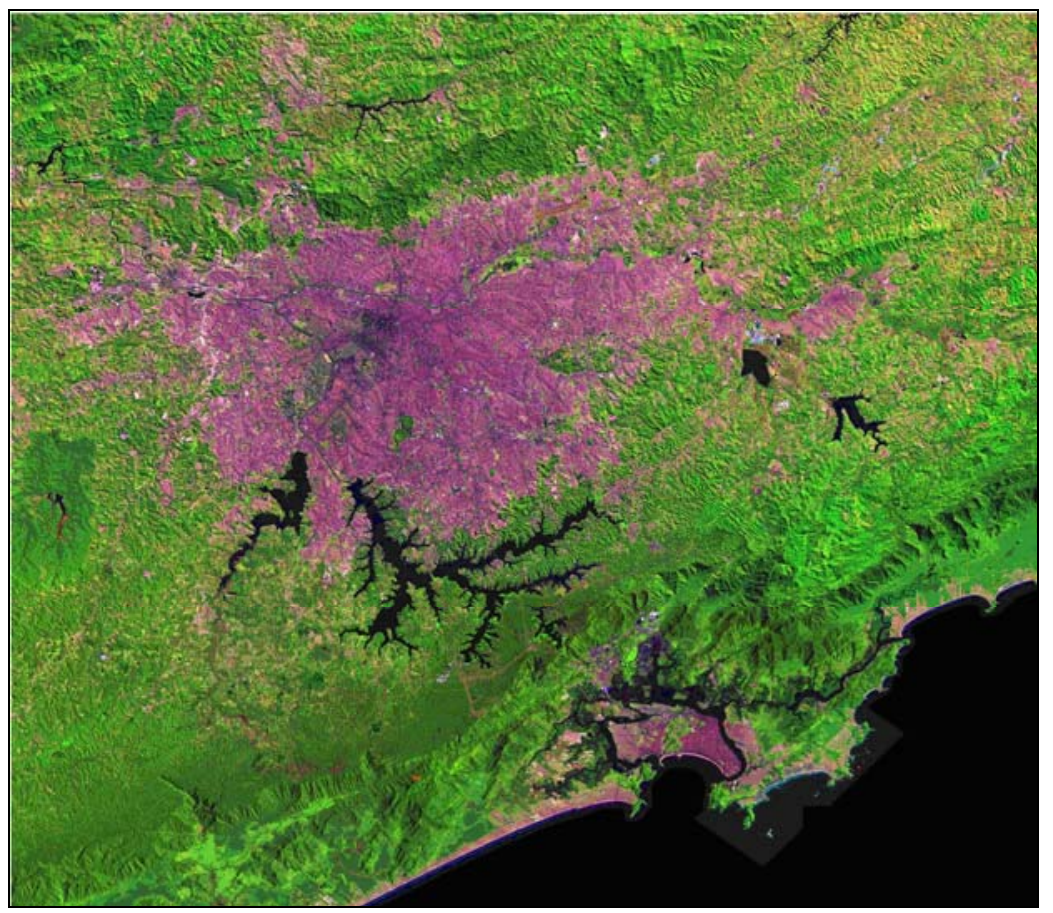

Figura 1.12 - Mosaico de composições das imagens TM do satélite LANDSAT-5 mostrando a notável extensão da ocupação urbana na região. (Fonte: IGBP e http://www.cdbrasil.cnpm.embrapa.br).

Deve-se lembrar ainda que o Brasil é o único país no mundo que conta com uma frota veicular que utiliza etanol em larga escala como combustível, gerando assim uma composição química da atmosfera muito particular, comparativamente com outras grandes cidades no mundo. Na frota atual da RMSP, os veículos movidos a etanol hidratado representam $12,3 \%$ e os movidos a gasool (mistura 22\% de etanol e $78 \%$ de gasolina), representam $65 \%$. O álcool etílico, considerando suas formas anidra e hidratada, corresponde a $47,5 \%$ do combustível consumido, segundo dados de consumo. Os veículos do tipo "flexfuel" (bi-combustível), lançados recentemente no mercado, correspondem a 6,1\%, as motocicletas representam $11,0 \%$ e os veículos movidos a diesel representam $5,6 \%$ da frota. Deve-se também destacar que a frota da RMSP é bastante antiga, sendo que cerca de 53,3\% desta é anterior a 1996 (CETESB, 2007). 


\section{2 - Objetivos}

- Implantar o modelo matemático OZIPR e SAPRC no Laboratório de Química Atmosférica (LQA) do IPEN.

- Realizar um levantamento sobre o inventário de emissões para a cidade de São Paulo e suas atualizações.

- Utilizar os modelos OZIPR e SAPRC para determinar a escala de reatividade incremental de ozônio para a cidade de São Paulo, a fim de prover dados que auxiliem a elaboração de estratégias para a redução de ozônio.

- Determinar escalas de reatividade incremental para COVs para as diferentes estações do ano, a fim de verificar se a diferença sazonal na especiação dos COVs reflete em mudanças na escala de reatividade.

- Simular a formação de ozônio em atmosferas com diferentes valores de emissão de poluentes a fim de encontrar estratégias para a diminuição das concentrações de ozônio na cidade de São Paulo. 


\section{3 - Metodologia}

\section{1 - Obtenção dos dados de emissões de poluentes}

Os valores de emissões para $\mathrm{CO}, \mathrm{NO}_{x}$ e COVs devem ser inseridos no modelo usando-se a unidade $\mathrm{kg} \cdot \mathrm{km}^{-2} \cdot \mathrm{h}^{-1}$. Para a obtenção destes valores foi tomado como base a estimativa de emissão anual de CO divulgada pela CETESB em 2006 em seu Relatório de Qualidade do Ar. Segundo este relatório, são emitidos por ano 1.503 .000 toneladas de CO na RMSP. Segundo o mesmo relatório, a RMSP possui uma área urbanizada de $1747 \mathrm{~km}^{2}$. Para se efetuar os cálculos de emissões horárias foi considerado um ano com 313 dias, descontando-se os domingos, pelo fato de haver pouca circulação de veículos nestes dias. Para cada dia foram consideradas 18 horas com efetiva circulação de veículos.

$$
1.503 .000 \frac{\text { ton }}{\text { ano }} \times \frac{1000 \mathrm{~kg}}{1 \text { ton }} \times \frac{1}{1.747 \mathrm{~km}^{2}} \times \frac{1 \text { ano }}{313 \text { dias }} \times \frac{1 \text { dia }}{18 \mathrm{~h}}=153 \mathrm{~kg} . \mathrm{km}^{-2} \cdot \mathrm{h}^{-1}
$$

Uma vez determinados os valores de emissões médias horárias para $\mathrm{CO}$, os valores para $\mathrm{NO}_{x}$ e COVs foram determinados utilizando-se a razão ambiental, já que os dados de emissão para $\mathrm{NO}_{x}$ e COVs divulgados pela CETESB parecem não corresponder à realidade, conforme demonstrado por Vivanco e Andrade (2005). Neste estudo, o modelo eureliano de qualidade do ar CIT (California Institute of Technology) foi utilizado para simular um episódio de poluição atmosférica na RMSP. O modelo foi alimentado com os dados de emissão oficiais providos pela CETESB e com dados de emissão calculados a partir das razões $\mathrm{NO}_{x} / \mathrm{CO}$ e COV/CO provenientes de medições ambientais entre 7:00 e 8:00h no período de julho e agosto de 1999. As concentrações de $\mathrm{O}_{3}$ e $\mathrm{NO}$ previstas pelo modelo CIT se aproximaram mais das medidas reais quando foram utilizados os dados de emissão revisados, invés dos dados oficiais da CETESB, sugerindo que as emissões de $\mathrm{NO}_{x}$ e COVs estariam respectivamente 0,5 vezes menores e 1,2 vezes maiores que as estimativas da CETESB.

Neste trabalho, as razões $\mathrm{NO}_{x} / \mathrm{CO}$ e $\mathrm{COV} / \mathrm{CO}$ foram determinadas através das concentrações ambientais destes poluentes, tomando-se a média entre 6:00 e 9:00h durante todo o ano de 2006, admitindo que neste horário os processos 
fotoquímicos não interferem significantemente na concentração destes poluentes. Para a determinação da razão $\mathrm{COV} / \mathrm{NO}_{x}$ não foi considerada a concentração de metano.

Para razão de $\mathrm{NO}_{\mathrm{x}} / \mathrm{CO}=0,09 \quad \mathrm{O}$ valor da Emissão Média $=14 \mathrm{~kg} \cdot \mathrm{km}^{-2} \cdot \mathrm{h}^{-1}$ de $\mathrm{NO}_{\mathrm{x}}$ Para razão de COV/CO $=0,25$ O valor da Emissão Media $=38 \mathrm{~kg} \cdot \mathrm{km}^{-2} \cdot \mathrm{h}^{-1}$ de COVs

\section{2 - Metodologia das medidas de poluentes}

Conforme abordado anteriormente, alguns dados de entrada do modelo OZIPR são as concentrações iniciais de $\mathrm{CO}, \mathrm{NO}_{\mathrm{x}}$ e $\mathrm{COVs}$, assim como as concentrações individuais de cada COV presente na mistura. São necessários também dados horários da concentração de $\mathrm{CO}, \mathrm{NO}_{\mathrm{x}}$ e $\mathrm{O}_{3}$ para se ajustar o modelo comparando-se esses dados com os valores obtidos por simulação.

Para as medidas de concentração de $\mathrm{CO}, \mathrm{NO}_{x}$ e $\mathrm{O}_{3}$ foram utilizados os valores medidos pela Rede Telemétrica da CETESB, que utiliza monitores automáticos de tempo real da Thermo Environmental Instruments (TEI) Inc. Já as medidas de COVs foram realizadas através de análises cromatográficas pelo LQA e pela CETESB.

Para as simulações realizadas neste trabalho foram utilizadas medidas de poluentes de dois locais diferentes. Foi realizada uma campanha de amostragem de COVs durante os meses de agosto e setembro de 2006 na Faculdade de Saúde Pública da USP, localizada na Av. Dr. Arnaldo, onde existe também uma estação da CETESB com monitores automáticos de $\mathrm{CO}$ e $\mathrm{NO}_{\mathrm{x}}$. Além disso, nesta campanha a CETESB realizou medidas de formaldeído e acetaldeído, COVs não monitorados nas análises rotineiras do LQA. A outra campanha foi realizada durante todo o ano de 2006 pelo LQA, coletando-se amostras duas vezes por semana entre as 7:00 e 9:00 horas na parte mais alta do Ipen, local que corresponde ao ponto mais alto da Cidade Universitária.

\subsection{1 - Monitor de CO}

Foi utilizado um analisador Gas Filter Correlation CO, Modelo TEI 48C. Este monitor de se baseia no princípio de que o monóxido de carbono (CO) absorve radiação infravermelha em um determinado comprimento de onda $(4,6$ 
$\mu \mathrm{m})$. A amostra de ar é submetida a um feixe de radiação infravermelha em uma câmara de comprimento em torno de $30-40 \mathrm{~cm}$. Uma série de espelhos é utilizada para quadruplicar o caminho ótico e desta maneira melhorar a sensibilidade do instrumento (Pretto, 2005).

Para minimizar o efeito dos interferentes, como a água, que absorve radiação infravermelha muito próximo da faixa de interesse, o monitor possui um sistema que alterna a passagem da radiação ora por uma câmara contendo CO, ora por uma câmara contendo $\mathrm{N}_{2}$. Quando a radiação emitida passa pela câmara de $\mathrm{CO}$, produz um feixe de referência, que não foi atenuado pelo CO presente na amostra, mas sim pelos outros compostos que absorvem no comprimento de onda especificado. Ao passar pelo filtro de $\mathrm{N}_{2}$, o qual é transparente à radiação infravermelha, o feixe produzido é atenuado por todos os compostos presentes na amostra que absorvem a luz nesse comprimento de onda, incluindo o CO. A diferença entre o feixe de referência e da medida permite obter a concentração de CO da amostra. O esquema de funcionamento do monitor de CO está mostrado na Figura 3.1.

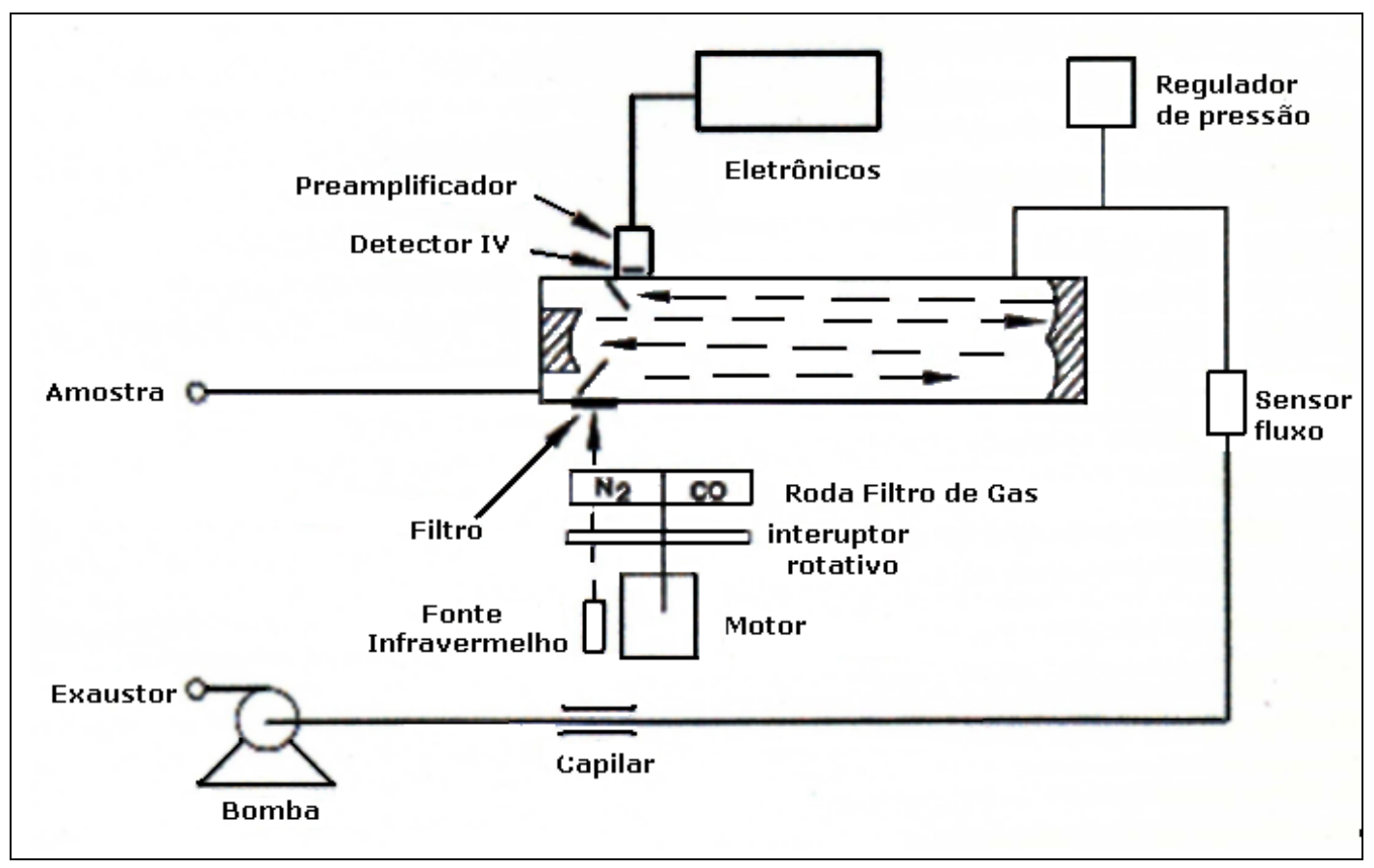

Figura 3.1 - Esquema de funcionamento do analisador de CO por correlação de filtro de gás. 


\subsection{2 - Monitor de $\mathrm{NO}-\mathrm{NO}_{2}-\mathrm{NO}_{x}$}

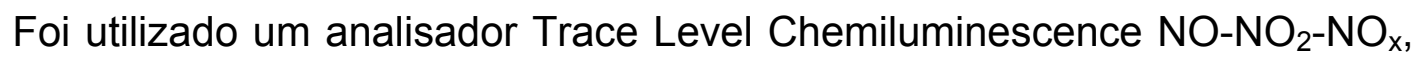
modelo TEI 42CTL. Este se baseia no princípio da reação do óxido nítrico (NO) com o ozônio $\left(\mathrm{O}_{3}\right)$, que produz moléculas de $\mathrm{NO}_{2}$ em estado eletrônico excitado. Quando estas moléculas de $\mathrm{NO}_{2}$ decaem para um estado de menor energia emitem luz no infravermelho, com uma intensidade linear proporcional à concentração de NO segundo a reação 3.1 .

$$
\mathrm{NO}+\mathrm{O}_{3} \longrightarrow \mathrm{NO}_{2}{ }^{*}+\mathrm{O}_{2}
$$

Para se determinar a concentração de $\mathrm{NO}_{x}$, o ar passa alternadamente por um redutor de $\mathrm{NO}_{2}$ para $\mathrm{NO}$. Todo $\mathrm{NO}_{2}$ é convertido então a $\mathrm{NO}$, por meio de um conversor de molibdênio aquecido a $325^{\circ} \mathrm{C}$. A concentração de $\mathrm{NO}$ determinada neste caso, corresponde na verdade à concentração de $\mathrm{NO}_{x}$. Através da diferença entre as duas leituras $\left(\mathrm{NO}\right.$ e $\left.\mathrm{NO}_{x}\right)$, obtemos a concentração de $\mathrm{NO}_{2}$. Um esquema do funcionamento do monitor de $\mathrm{NO}_{x}$ está apresentado na Figura 3.2.

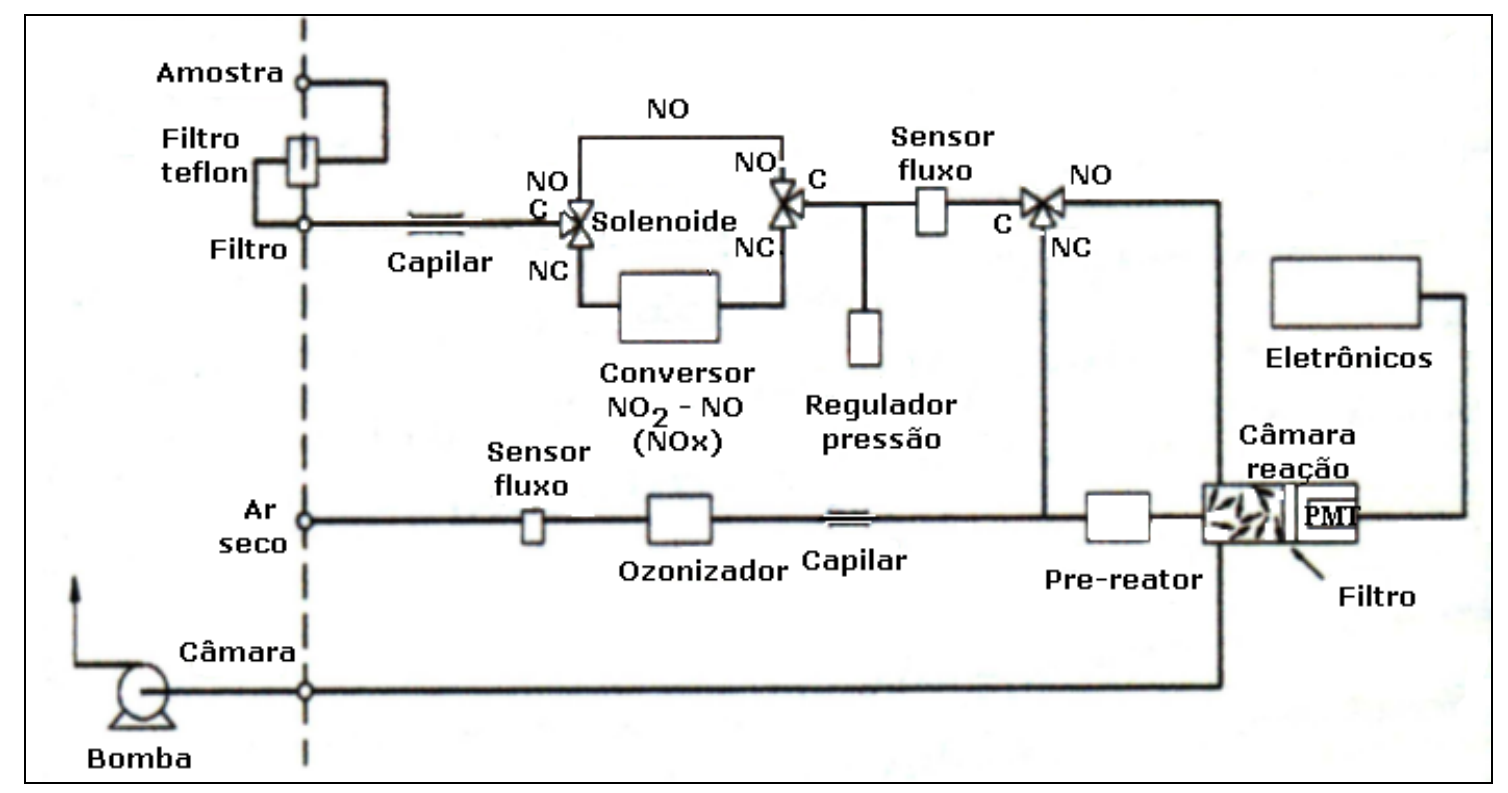

Figura 3.2 - Esquema de funcionamento do analisador de $\mathrm{NO}-\mathrm{NO}_{2}-\mathrm{NO}_{x}$ por quimiluminescência.

\subsection{3 - Monitor de ozônio}

Foi utilizado um analisador UV Photometric $\mathrm{O}_{3}$, Modelo TEI 49C. Este monitor está baseado no princípio de que moléculas de $\mathrm{O}_{3}$ absorvem luz ultravioleta no comprimento de onda de $254 \mathrm{~nm}$. A concentração de ozônio 
existente é diretamente proporcional à quantidade de luz ultravioleta absorvida, conforme descreve a lei de Lambert-Beer na Equação 3.1:

$$
\frac{\mathrm{I}}{\mathrm{I}_{0}}=\mathrm{e}^{-\mathrm{KLC}}
$$

Onde:

$K=$ Coeficiente de absorção molecular, $308 \mathrm{~cm}^{-1}$ (a $0^{\circ} \mathrm{C}$ e 1 atmosfera)

$L=$ Comprimento da célula $(\mathrm{cm})$

$C=$ Concentração de ozônio em partes por milhão (ppm)

$I$ = Intensidade da luz UV da amostra com ozônio (amostra de gás)

$I_{0}=$ Intensidade da luz UV da amostra sem ozônio (gás de referência)

Um esquema do funcionamento do monitor de ozônio pode ser visualizado na Figura 3.3.

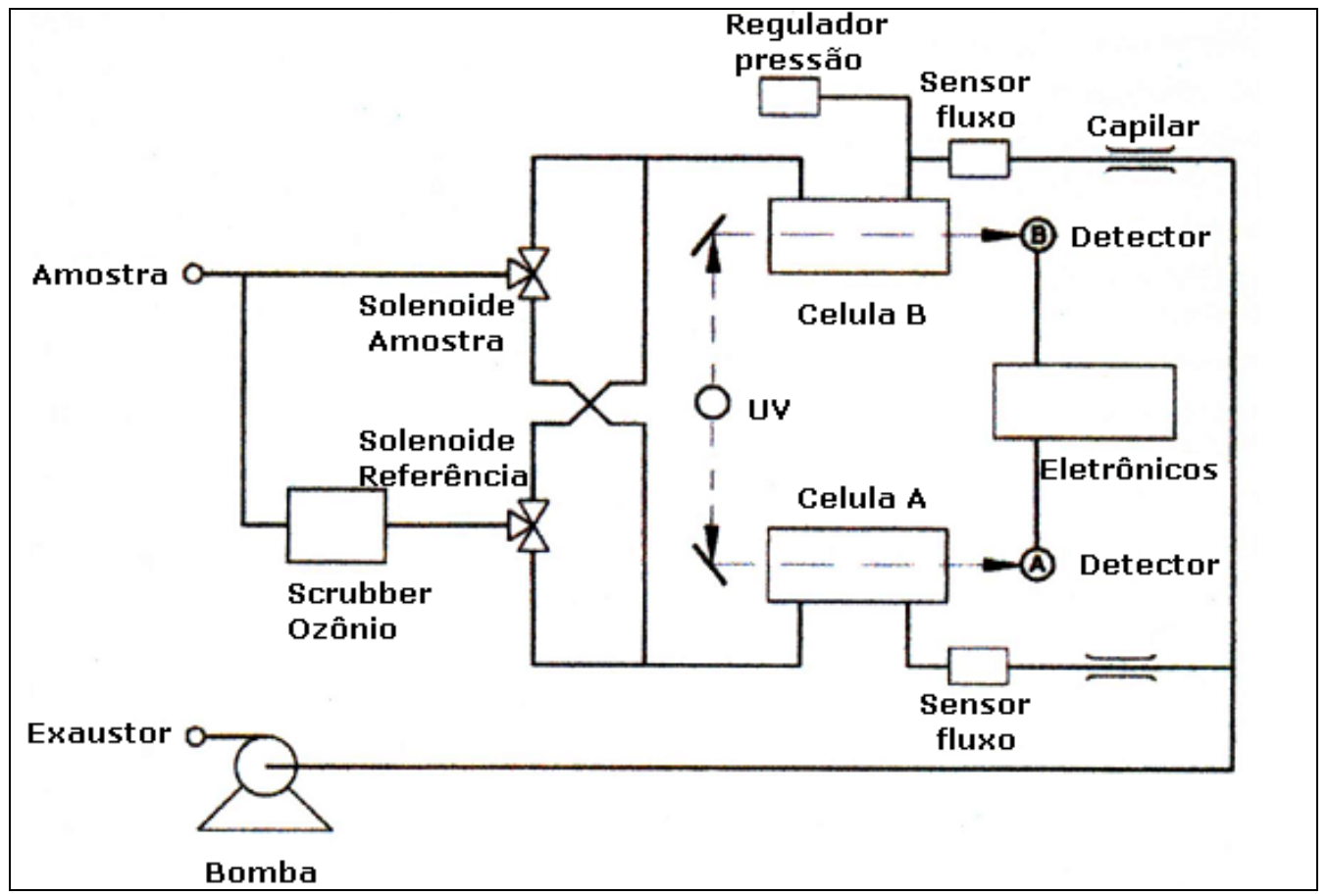

Figura 3.3 - Esquema de funcionamento do analisador de $\mathrm{O}_{3}$.

Neste monitor, o ar a ser analisado passa previamente através de um filtro de Teflon, para retirar o material particulado. A determinação da concentração de ozônio é realizada por diferença entre a leitura de um ar isento de ozônio (gás referência) e o ar atmosférico. Para tal, o equipamento utiliza duas válvulas solenóides para alternar a passagem do ar de referência $\left(I_{0}\right)$ e atmosférico pelas duas câmaras de leitura. Para a obtenção do ar de referência, o ar a ser analisado passa por um removedor de ozônio, a fim de eliminar por completo o ozônio da 
amostra e segue para o detector. As válvulas solenóides alternam o gás de referência e a amostra entre as células A e B, a cada 10 segundos. As intensidades da luz ultravioleta de cada célula são medidas pelos detectores $A$ e B. O analisador determina a concentração de ozônio pela diferença de leitura entre as duas células e calcula a média dos dois detectores para obter a concentração de ozônio.

\subsection{4 - Análise de COVs - Hidrocarbonetos}

A metodologia de amostragem dos hidrocarbonetos utilizada neste trabalho foi baseada nos métodos TO-14 e TO-15 da U.S. Environmental Protection Agency (EPA) (U.S.EPA, 1999a; 1999b), que consistem na amostragem realizada em canisters seguido de pré-concentração criogênica da amostra e posterior análise por cromatografia gasosa com diversos detectores. Esta técnica permite medir concentrações muito pequenas de uma grande variedade de compostos presentes no ambiente.

Os canisters são recipientes esféricos de aço inoxidável, com superfície interna eletropolida, que dá uma característica inerte ao amostrador. Esses canisters foram previamente limpos em um sistema de limpeza que emprega ciclos de vácuo e vapor d'água com aquecimento em ambas as etapas. Cada ciclo tem duração de uma hora. Este processo de limpeza é finalizado deixando o canister em alto-vácuo, de forma que uma vez aberta a sua válvula, ocorre a entrada do ar que se deseja amostrar, apenas necessitando controlar de fluxo para a integração do tempo de amostragem desejado. Restritores de fluxo foram utilizados para permitir uma passagem gradual do ar ambiente, e assim, coletar as amostras períodos de duas em duas horas.

Finalizadas as amostragens, a válvula do canister era fechada. Posteriormente, os canisters amostrados foram levados ao Laboratório de Química Atmosférica (LQA) do IPEN para serem realizadas as análises químicas. Um esquema e uma foto do sistema de amostragem com canisters e o sistema de limpeza dos canisters, utilizado neste trabalho, pode ser visualizado na Figura 3.4. 


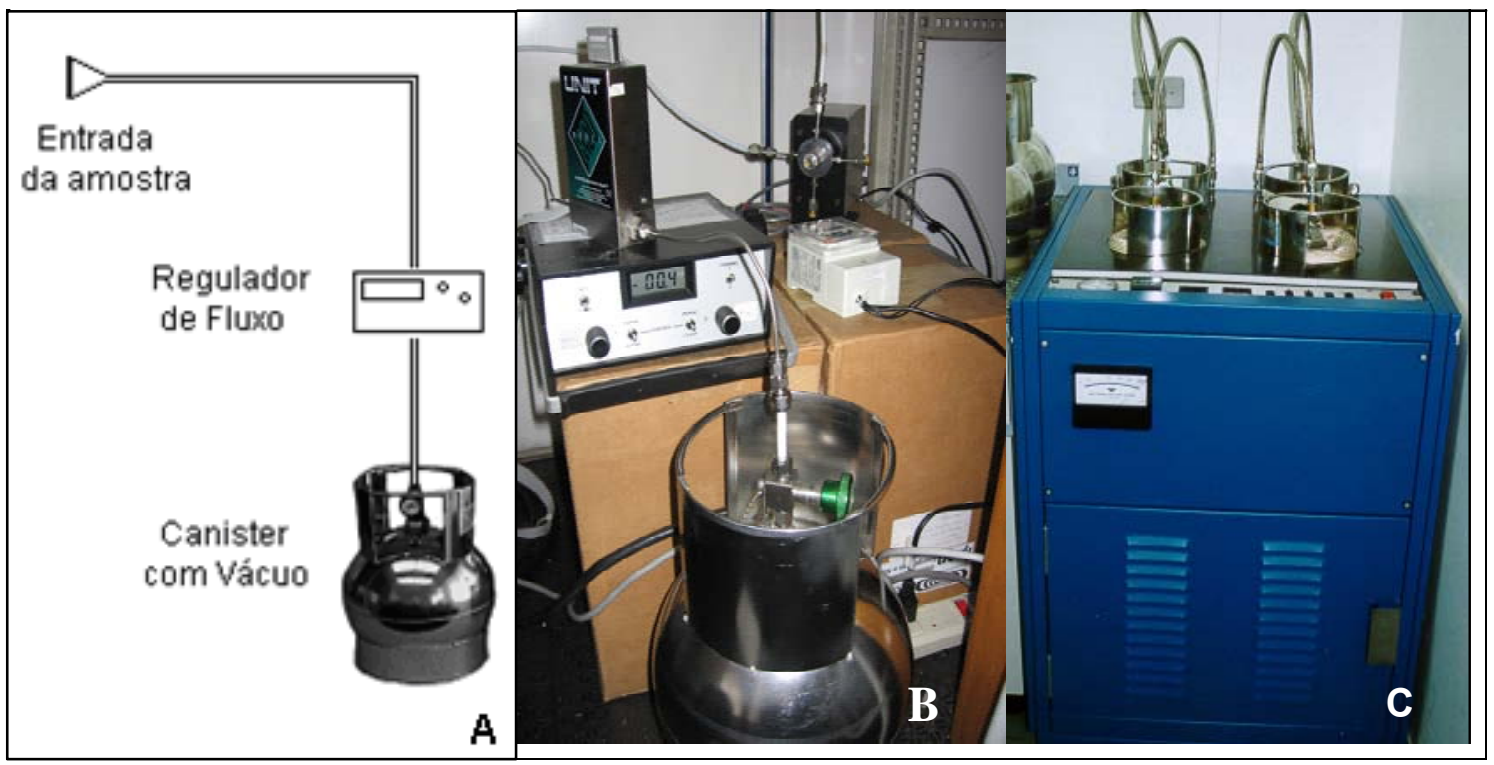

Figura 3.4 - [a]: Esquema da amostragem com canister, [b]: Foto de uma amostragem com canister dentro da Estação Cerqueira Cesar da CETESB e [c]: Foto do sistema de limpeza utilizado neste trabalho.

A análise é realizada conectando-se a válvula do canister a uma válvula posicionada no injetor do cromatógrafo e o ar amostrado no canister é retirado com auxílio de uma bomba de vácuo (Figura 3.5).

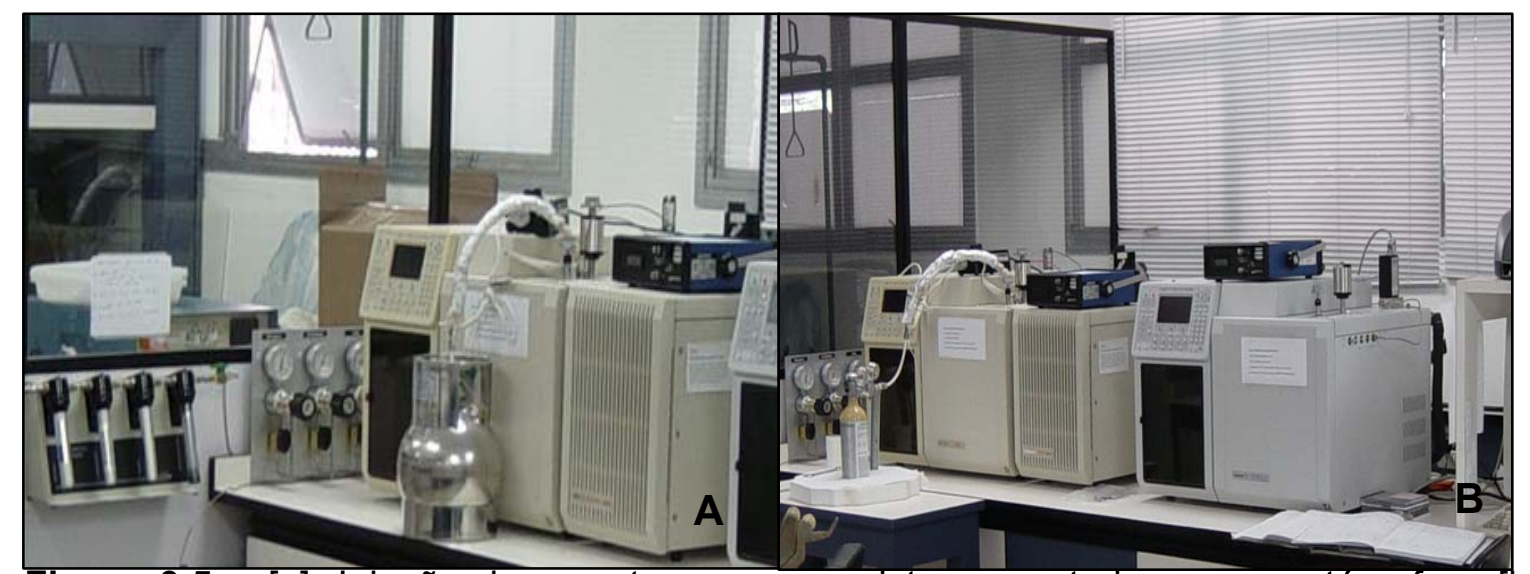

Figura 3.5 - [a]: Injeção da amostra com o canister conectado ao cromatógrafo e [b]: Cilindro de padrão conectado ao cromatógrafo. (Pretto, 2005).

Isso permitirá a entrada de quantidade conhecida do ar amostrado para dentro de um loop, onde será efetuada a pré-concentração criogênica da amostra. $\mathrm{Na}$ pré-concentração, a amostra passa por um tubo de aço inox de $9 \mathrm{~cm}$ de comprimento, empacotado com pérolas de vidro de 60/80 mesh. Estas são silanizadas para evitar que ocorra a adsorção dos compostos no vidro. Durante a passagem da amostra pelo tudo pré-concentrador, este está imerso em nitrogênio 
liquido a uma temperatura de $-180^{\circ} \mathrm{C}$. Após a pré-concentração a amostra é enviada à coluna cromatográfica pelo processo de aquecimento $\left(200^{\circ} \mathrm{C}\right)$ e carregada pelo gás de arraste Hélio. Ocorre então o processo de separação dos COVs individuais e posterior detecção. Utiliza-se um detector de espectrometria de massas (DEM) e um detector de ionização de chama (DIC), sendo que o primeiro tem a função de identificar os picos e o outro de quantificá-los.

\subsection{5 - Análise de COVs - Aldeídos}

Para as análises de formaldeído e acetaldeído foi utilizada a norma TO-11 da U.S. EPA (U.S.EPA, 1997), que consiste na realização de amostragens em cartuchos de sílica, revestidos com resina C-18 e impregnados com solução de 2,4-dinitrofenilhidrazina (DNPH). Durante essa amostragem, as carbonilas são convertidas nas respectivas hidrazonas provenientes da DNPH, como descrito na Figura 3.6.

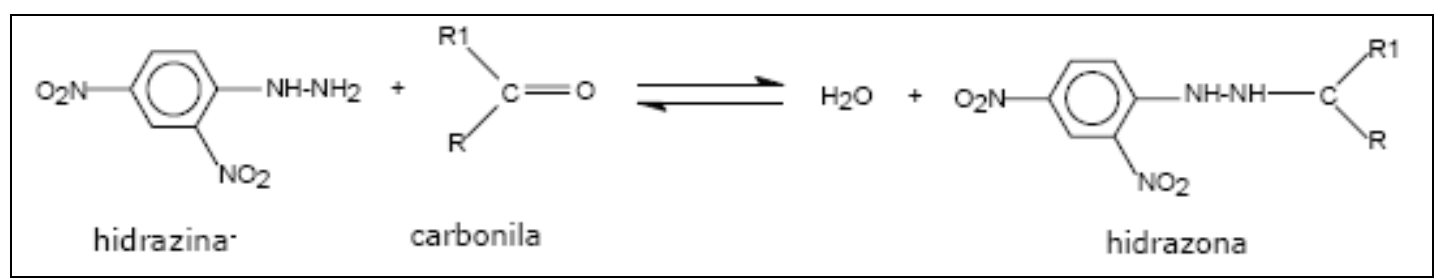

Figura 3.6 - Conversão da hidrazina em carbonilas-hidrazonas.

Os cartuchos são amostrados à vazão de 1,0 litro por minuto, pelo período de duas horas. As hidrazonas formadas são extraídas com acetonitrila e analisadas por cromatografia líquida de alta eficiência (HPLC), fazendo-se uso de uma coluna $\mathrm{C} 18$ para promover a separação. Em seguida, faz-se a detecção das mesmas por ultravioleta na faixa dos $360 \mathrm{~nm}$. 


\section{4 - Simulação da Região Metropolitana de São Paulo}

Neste trabalho foram montados cinco casos base para se determinar a escala de reatividade incremental para ozônio e realizar simulações variando-se os valores de emissão de $\mathrm{NO}_{\mathrm{x}}$ e COVs.

Para o primeiro caso base foram utilizados os dados de COVs obtidos durante uma campanha realizada em conjunto pelo Laboratório de Química Atmosférica (LQA-IPEN) e pela CETESB na Faculdade de Saúde Pública da USP, na primavera de 2006. Nesta campanha a CETESB mediu as concentrações de formaldeído e acetaldeído, enquanto o LQA mediu os demais hidrocarbonetos.

Nos outros quatro casos base foram utilizados dados de COVs analisados pelo LQA durante todo o ano de 2006, amostrados na Cidade Universitária. Esses casos base representam a média das medidas de COVs para as quatro estações do ano: verão, outono, inverno e primavera. Como não estavam disponíveis dados de formaldeído e acetaldeído nesta campanha, foram utilizados nas simulações os valores médios destes poluentes obtidos na campanha realizada na Faculdade de Saúde Pública (FSP) da USP em conjunto com a CETESB nos meses de agosto e setembro de 2006.

$\mathrm{Em}$ todos os casos base foram ainda adicionados valores de etanol e metanol obtidos por Colón et al. (2001) em um estudo da CETESB em conjunto com a US-EPA sobre compostos orgânicos voláteis associados às emissões veiculares na atmosfera urbana de São Paulo.

\section{1 - Caso base da Faculdade de Saúde Pública da USP}

Para este caso base, foram utilizadas as concentrações medianas de COVs dos oito dias estudados em Agosto e Setembro de 2006, com medidas de hidrocarbonetos e aldeídos. Os dias estudados com medidas simultâneas de hidrocarbonetos e aldeídos foram: 10/08/06; 15/08/06; 16/08/06; 17/08/06; 14/09/06; 15/09/06; 27/09/06 e 28/09/06, sendo todos dias sem chuva e com pouca cobertura de nuvens. $O$ modelo foi alimentado com a mediana dos dados de concentrações iniciais e emissões horárias de $\mathrm{CO}, \mathrm{NO}_{\mathrm{x}}$ e COVs; dados horários de temperatura, umidade relativa do ar e altura da camada de mistura e especiação dos COVs. 
Para os dados de concentrações iniciais de $\mathrm{CO}, \mathrm{NO}_{\mathrm{x}}$ e COVs foram utilizados os valores medianos do período compreendido entre 6:00 e 9:00 h dos meses de Agosto e Setembro. Os valores para $\mathrm{NO}_{\mathrm{x}}$ e $\mathrm{CO}$ foram obtidos pelos monitores automáticos da estação Cerqueira César da CETESB. Para os valores de COVs, foram utilizadas as concentrações de hidrocarbonetos medidas pelo LQA do IPEN e os aldeídos medidos pela CETESB, somados aos valores de etanol e metanol obtidos por Colón et al. (2001). Os referidos valores podem ser observados na Tabela 4.1.

Tabela 4.1 - Concentrações iniciais de COVs, $\mathrm{NO}_{x}$ e CO, para a Faculdade de Saúde Publica da USP.

\begin{tabular}{|c|c|}
\hline Composto ou Grupo & Concentração Inicial \\
\hline $\mathrm{COV}$ & $1,24 \mathrm{ppmC}$ \\
\hline $\mathrm{NO}_{\mathrm{x}}$ & $0,12 \mathrm{ppm}$ \\
\hline $\mathrm{CO}$ & $1,15 \mathrm{ppm}$ \\
\hline
\end{tabular}

Os dados horários de temperatura e umidade relativa do ar foram obtidos pelos monitores automáticos da estação Pinheiros da CETESB, já que a estação Cerqueira César não realiza medição de parâmetros meteorológicos. Além disso, a estação Pinheiros é a estação que se encontra mais próxima da estação Cerqueira César. Os dados de altura da camada de mistura foram obtidos junto ao Laboratório de Aplicações Ambientais de Lasers do Centro de Lasers e Aplicações (CLA - IPEN) e passaram por um ajuste que será detalhado adiante. Os valores de parâmetros meteorológicos são mostrados na Tabela 4.2. A figura 4.1 mostra o exemplo de um gráfico da CLP obtido através do sistema de sensoriamento Lidar (Light Detection and Ranging).

Tabela 4.2 - Valores de Temperatura, Umidade Relativa do Ar e Altura da Camada de Mistura para o caso base Faculdade de Saúde Pública.

\begin{tabular}{|c|c|c|c|}
\hline Hora & ${\text { Temp. }\left({ }^{\circ} \mathrm{C}\right)}$ & UR (\%) & Alt. Cam. Mist. (m) \\
\hline $6: 00$ & 15 & 76,3 & 300 \\
\hline $7: 00$ & 15 & 77,2 & 500 \\
\hline $8: 00$ & 15 & 77,7 & 530 \\
\hline $9: 00$ & 17 & 74,3 & 650 \\
\hline $10: 00$ & 19 & 64,5 & 750 \\
\hline $11: 00$ & 21 & 56,1 & 900 \\
\hline $12: 00$ & 23 & 50,2 & 1000 \\
\hline $13: 00$ & 24 & 45,4 & 1080 \\
\hline $14: 00$ & 25 & 42,6 & 1150 \\
\hline $15: 00$ & 25 & 41,6 & 1350 \\
\hline $16: 00$ & 24 & 42,6 & 1300 \\
\hline $17: 00$ & 23 & 45,5 & 700 \\
\hline $18: 00$ & 22 & 50,0 & 300 \\
\hline
\end{tabular}




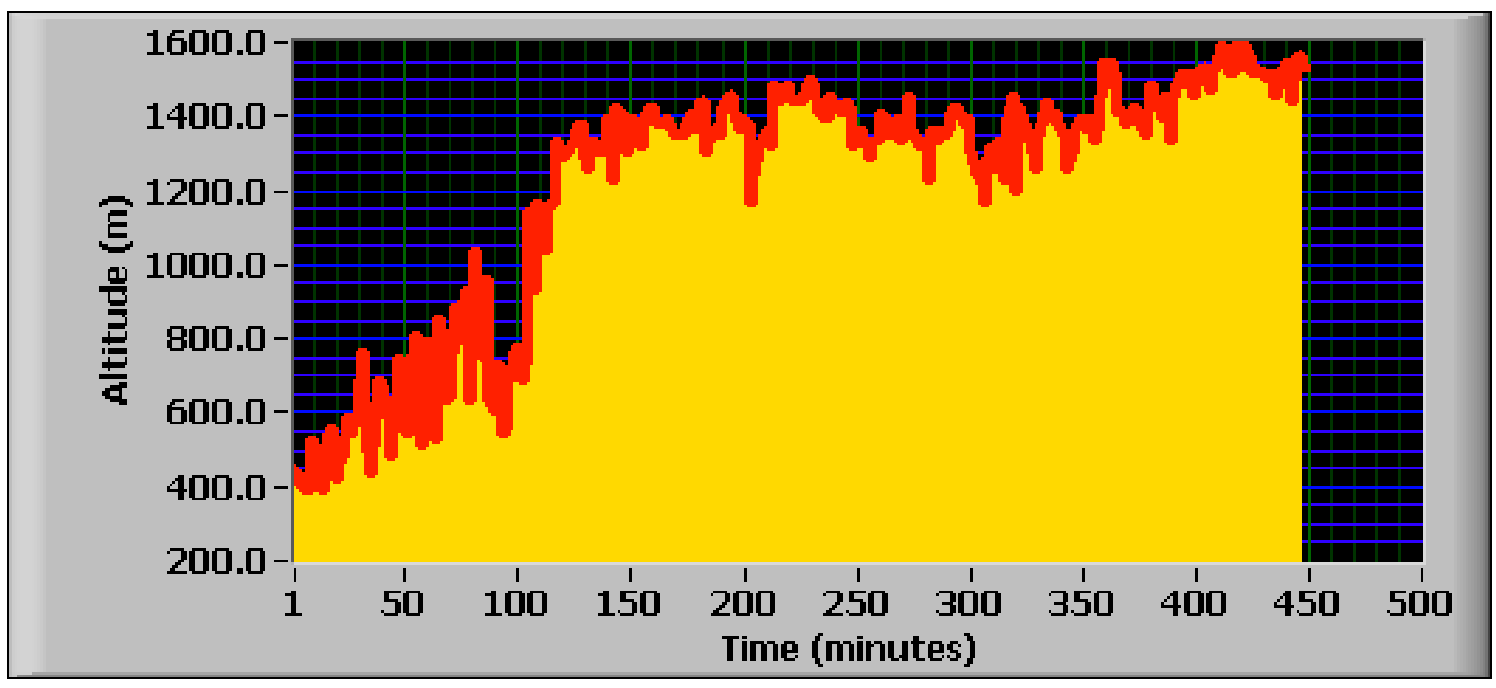

Figura 4.1 - Exemplo de um gráfico da evolução da CLP obtido através do sistema Lidar.

Com os dados de concentração de COVs foi realizado o agrupamento dos mesmos, conforme explicado no Capítulo 1.4.2. A Tabela 4.3 e a Figura 4.2 mostram a distribuição dos COVs amostrados no período estudado entre Agosto e Setembro de 2006, agrupados por função orgânica. A Tabela 4.4 mostra o agrupamento dos COVs segundo metodologia do Modelo Químico SAPRC.

Tabela 4.3 - Porcentagem de COVs agrupados por função orgânica - caso base FSP.

\begin{tabular}{|c|c|}
\hline Função & $\mathbf{( \% )}$ \\
\hline Alcanos & 48,8 \\
\hline Alcenos & 25,4 \\
\hline Aromáticos & 13,0 \\
\hline Aldeídos & 12,8 \\
\hline
\end{tabular}

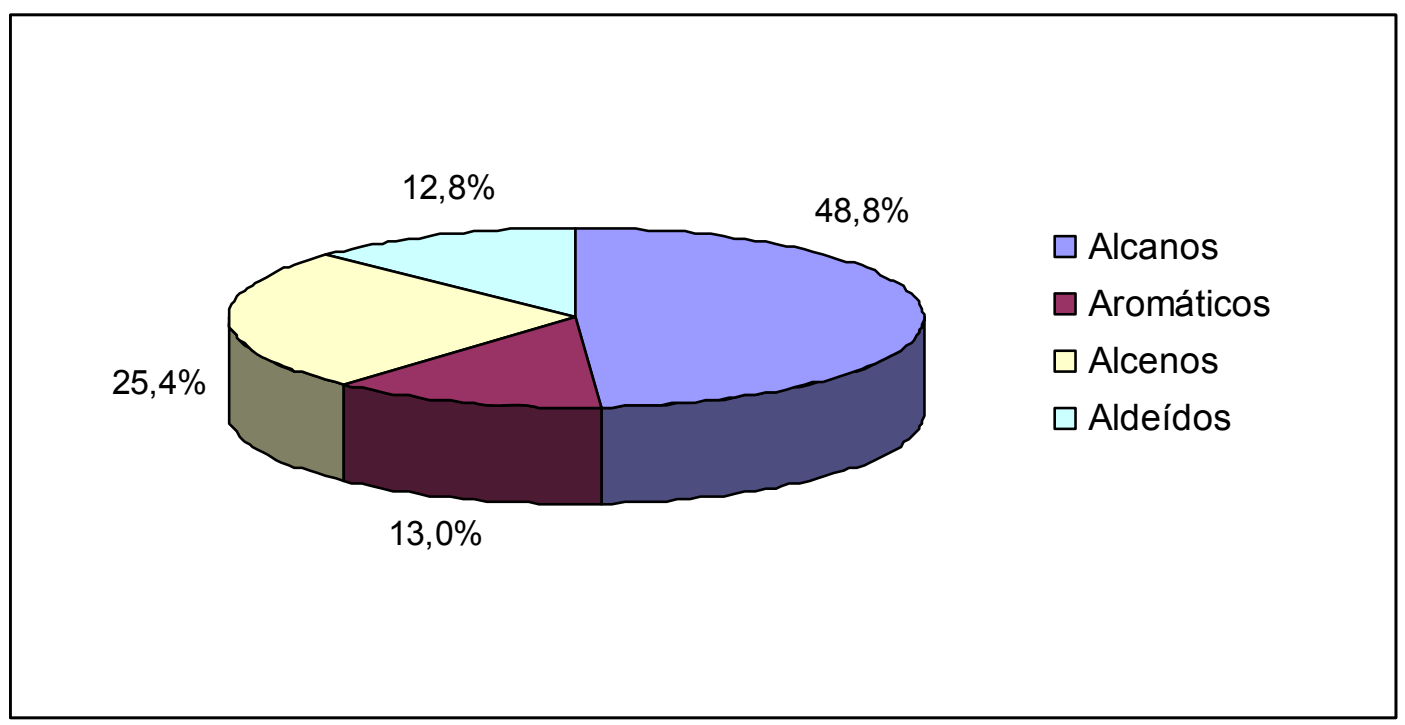

Figura 4.2 - Porcentagem de COVs agrupados por função orgânica para o caso base Faculdade de Saúde Publica. 
Tabela 4.4 - Agrupamento dos COVs para os 8 dias amostrados em Agosto e Setembro de 2006 na Faculdade de Saúde Publica da USP, segundo metodologia SAPRC.

\begin{tabular}{|c|c|c|c|c|}
\hline GRUPOS & DESCRIÇÃO & ppmC totais & Fração & No Médio C $^{\circ}$ \\
\hline ALK 1 & $1^{\circ}$ grupo de alcanos & 0,019 & 0,0149 & 2,000 \\
\hline ALK 2 & $2^{\circ}$ grupo de alcanos & 0,017 & 0,0137 & 3,000 \\
\hline ALK 3 & $3^{\circ}$ grupo de alcanos & 0,026 & 0,0207 & 4,042 \\
\hline ALK 4 & $4^{\circ}$ grupo de alcanos & 0,090 & 0,0722 & 5,469 \\
\hline ALK 5 & $5^{\circ}$ grupo de alcanos & 0,053 & 0,0430 & 7,834 \\
\hline OLE 1 & $1^{\circ}$ grupo de alcenos & 0,027 & 0,0217 & 4,009 \\
\hline OLE 2 & $2^{\circ}$ grupo de alcenos & 0,039 & 0,0312 & 4,886 \\
\hline ARO 1 & $1^{\circ}$ grupo de aromáticos & 0,045 & 0,0363 & 7,210 \\
\hline ARO 2 & $2^{\circ}$ grupo de aromáticos & 0,051 & 0,0414 & 8,564 \\
\hline TERP & Terpenos & 0,001 & 0,0005 & 10,000 \\
\hline HCHO & Formaldeído & 0,006 & 0,0046 & 1,000 \\
\hline CCHO & Acetaldeído & 0,012 & 0,0097 & 2,000 \\
\hline ETHENE & Eteno & 0,015 & 0,0122 & 2,000 \\
\hline MEOH & Metanol & 0,011 & 0,0085 & 1,000 \\
\hline ETOH & Etanol & 0,828 & 0,6664 & 2,000 \\
\hline ISOPRENE & Isopreno & 0,004 & 0,0029 & 5,000 \\
\hline
\end{tabular}

\subsection{1 - Validação do simulador}

Após carregar o simulador com todos os dados citados anteriormente, foi feito o ajuste para que este reproduzisse as concentrações reais de CO medidas pelo monitor automático. Este procedimento inicial é na verdade um ajuste do caso base. A razão de se escolher o CO para este ajuste deve-se à sua baixa reatividade, logo, um poluente essencialmente primário, caracterizando-se assim as emissões.

É importante lembrar que os dados de emissões obtidos são valores médios e que as emissões variam muito ao longo do dia, em função principalmente, da variação do número de veículos nas ruas e das condições meteorológicas. Por isso há a necessidade de se ajustar esses valores.

Ao rodar o simulador, este gera um arquivo com as concentrações horárias dos poluentes desejados. Os resultados de concentração horária de CO obtidos pelo simulador foram comparados com os valores médios para o mês de setembro de 2006 medidos na Estação Cerqueira César da CETESB.

Em função da discrepância entre os valores simulados e medidos foram realizados ajustes nas emissões horárias de CO de modo a aproximar ao máximo estes valores, sempre mantendo fixo o valor médio das emissões.

Após realizar o melhor ajuste possível alterando somente as emissões horárias de $\mathrm{CO}$, passou-se ao ajuste dos valores de altura de camada de mistura. O simulador foi alimentado com valores médios de alguns dias do mês de Agosto 
de 2006. Como a altura da camada de mistura influencia diretamente a concentração de poluentes, estes valores foram ajustados de modo a obter a melhor aproximação possível entre os valores medidos e simulados de concentração de CO. A Figura 4.3 mostra o resultado dos valores simulados comparados com a média dos valores medidos para o período em questão após os ajustes citados.

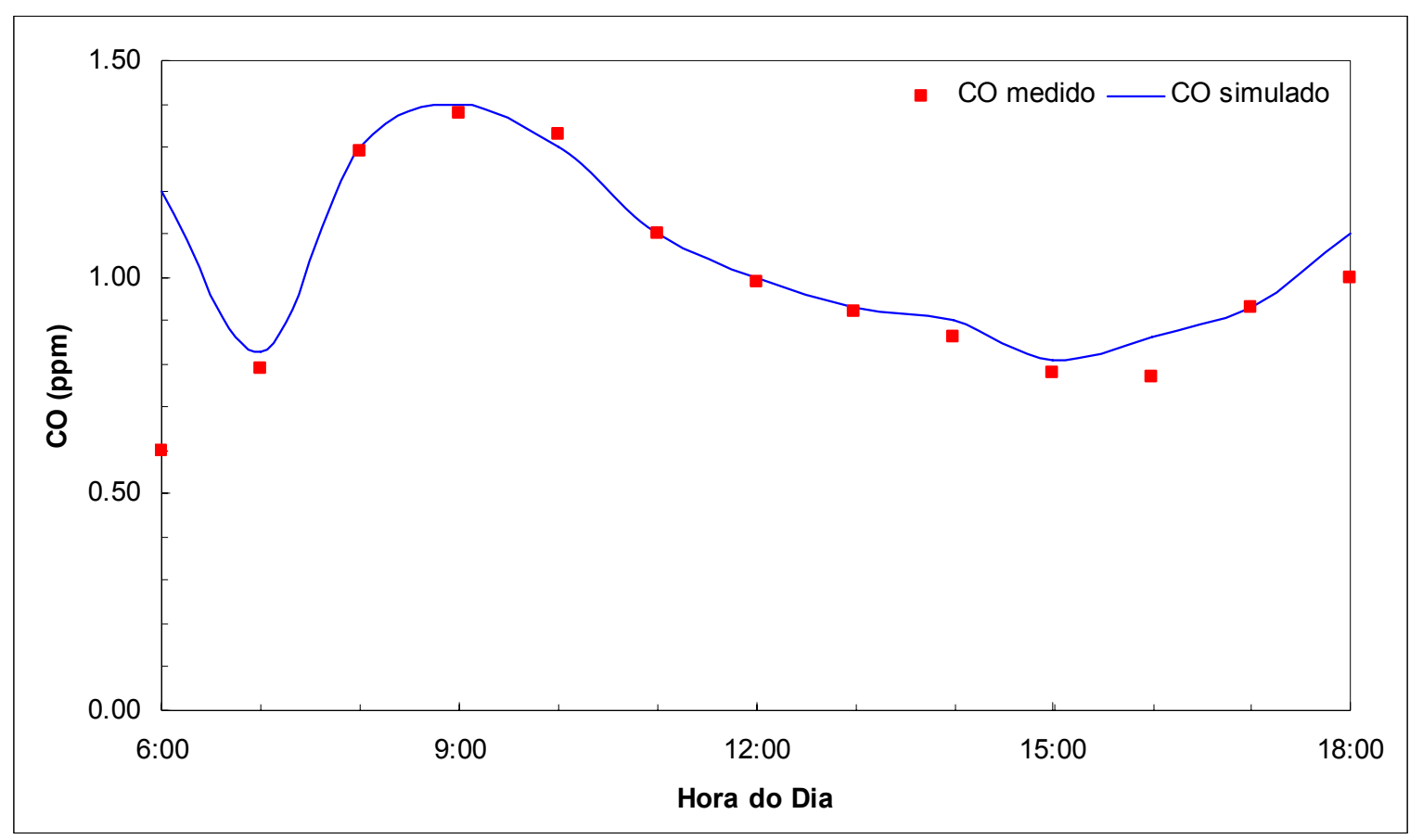

Figura 4.3 - Comparação dos valores simulados para o caso base com os valores médios obtidos para a concentração de CO para período em questão na Estação Cerqueira César.

Na montagem dos próximos casos base partiu-se dos valores de emissão de $\mathrm{CO}$ e altura de camada de mistura ajustados neste caso base. As emissões de CO não foram mais alteradas e o ajuste foi realizado apenas variando a altura da camada de mistura, de modo a reproduzir na simulação as concentrações de CO medidas nos monitores automáticos para o período em questão.

Após realizado o ajuste do perfil de $\mathrm{CO}$ simulado contra os dados experimentais médios, ajustou-se o perfil do $\mathrm{NO}_{\mathrm{x}}$. A razão $\mathrm{NO}_{\mathrm{x}} / \mathrm{CO}$, assim como, a razão COVs/CO não foi mantida fixa ao longo do dia em virtude da estratificação da frota, que varia ao longo do dia. Nesta etapa foi realizado um ajuste nas emissões horárias de modo a reproduzir as medidas reais, porém, sempre mantendo constante a média diária. Um pequeno ajuste nas taxas de deposição deste poluente também foi realizado. A Figura 4.4 mostra o resultado dos valores 
simulados comparados com a média dos valores medidos para o período em questão após os ajustes citados.

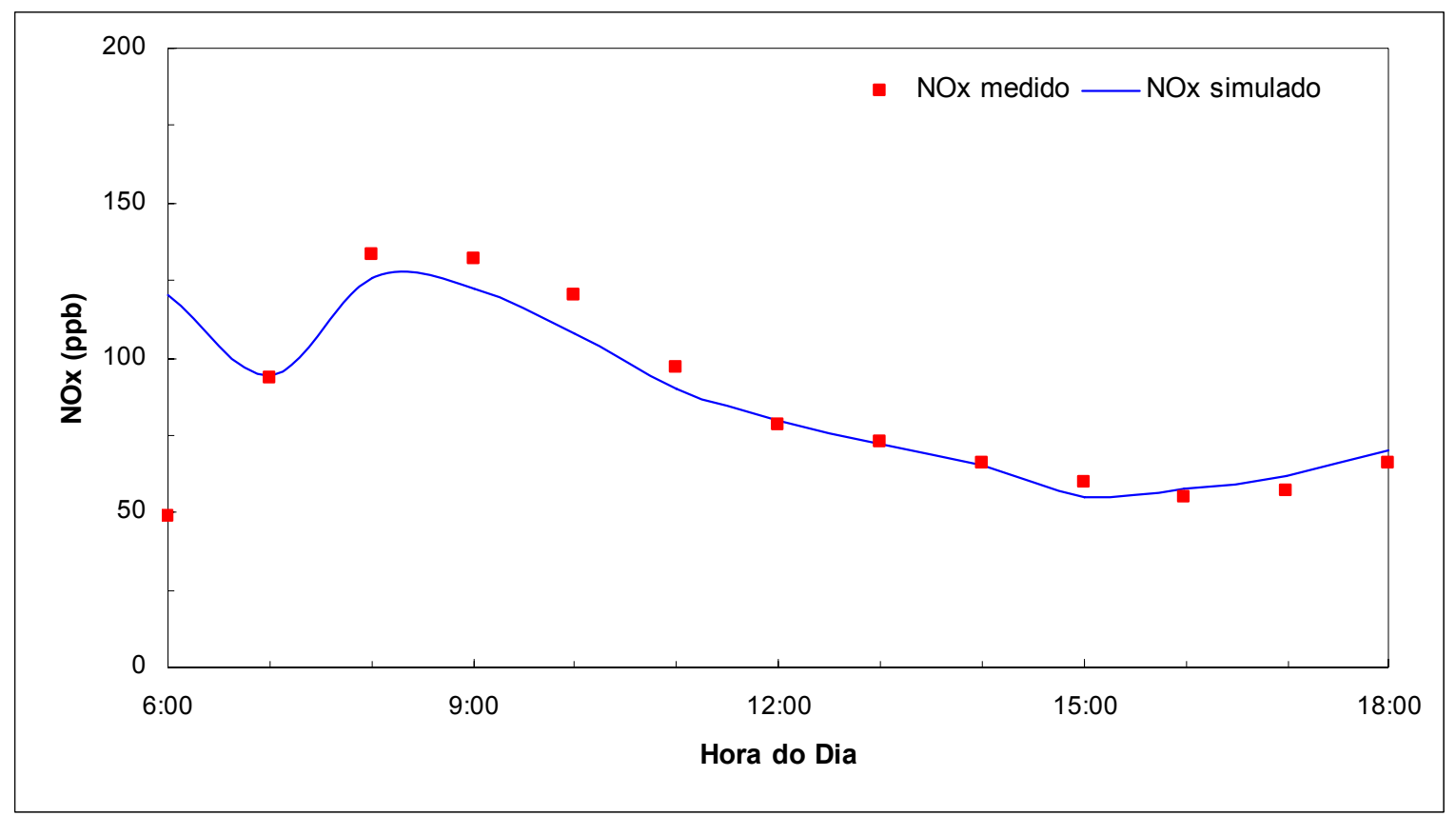

Figura 4.4 - Comparação dos valores simulados para o caso base com os valores médios obtidos para a concentração de $\mathrm{NO}_{x}$ no período estudado na Estação Cerqueira César.

Uma vez realizados os ajustes para $\mathrm{CO}$ e $\mathrm{NO}_{\mathrm{x}}$, o caso base fica então bem próximo do estágio final. O passo seguinte é ajustar as emissões horárias de COVs. Como o simulador não disponibiliza dados de concentração horária de COVs, este ajuste deve ser feito através do perfil de ozônio. Um pequeno ajuste nas taxas de deposição de ozônio também foi realizado para que o perfil de ozônio ficasse o mais próximo possível dos dados experimentais. As taxas de deposição utilizadas neste trabalho, assim como todos os outros dados de entrada do simulador podem ser visualizadas no Anexo $A$.

A estação Cerqueira César não conta com monitores automáticos de ozônio, logo, foi realizada então uma comparação entre os valores médios de concentração de ozônio de quatro estações: Pinheiros, Parque D. Pedro II, Santana e Santo Amaro, apresentado na Figura 4.5. Observa-se que a concentração de ozônio na estação Pinheiros registra valores abaixo das demais e também do perfil do simulador. A explicação mais provável para este fato é que como o ozônio demora em média 3 horas para ser produzido na atmosfera, este poluente atinge maiores concentrações em locais mais afastados das fontes de emissão de seus precursores. Como a estação Pinheiros está localizada muito 
próxima às vias de tráfego, acaba por registrar valores que não correspondem à situação mediana da cidade de São Paulo. Para as demais Estações da CETESB analisadas, o valor simulado ficou muito próximo, pois as demais Estações estão localizadas em locais altos e/ou distantes do trafego.

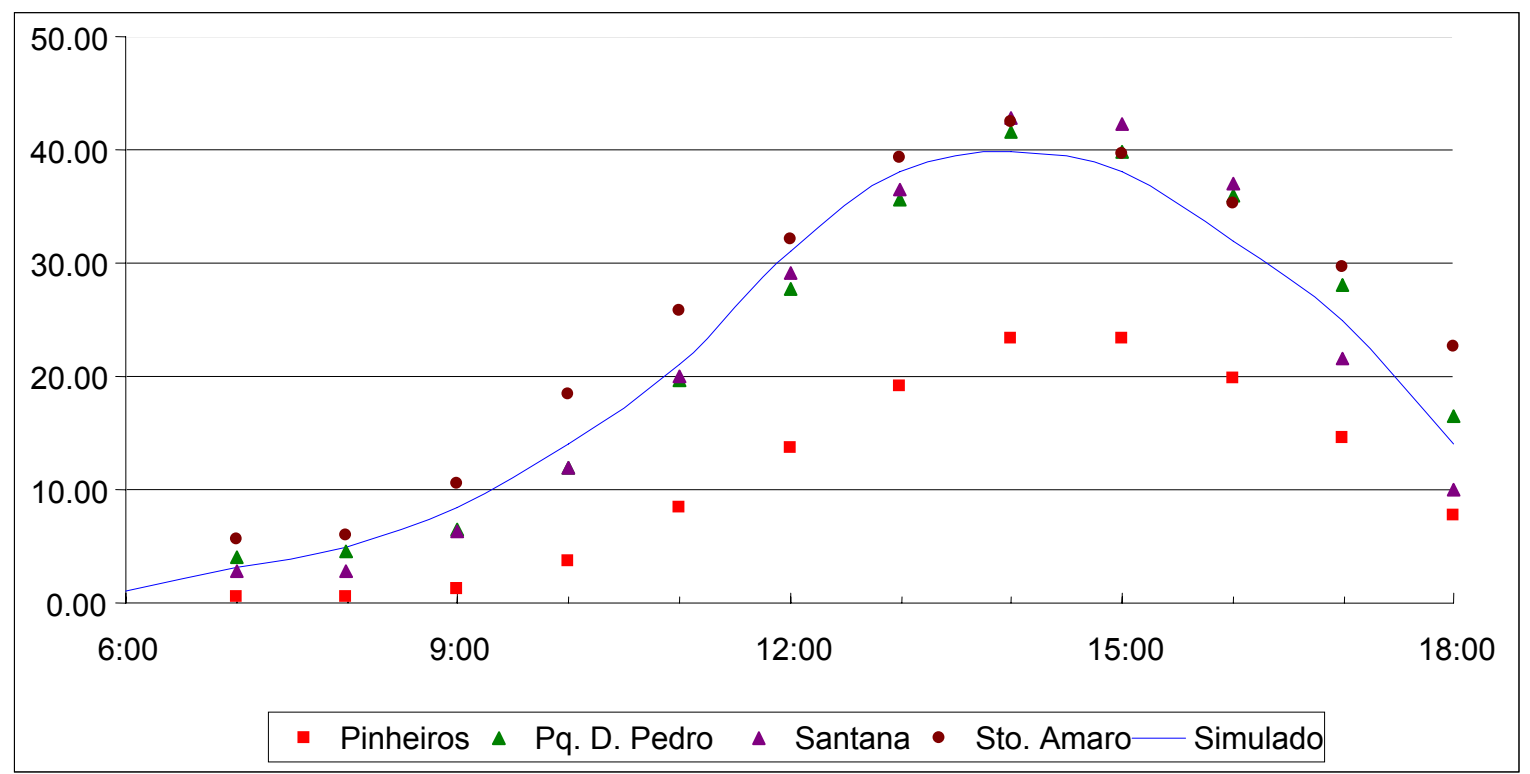

Figura 4.5 - Comparação dos valores simulados para o caso base com os valores médios obtidos para a concentração de $\mathrm{O}_{3}$ no período de agosto e setembro de 2006 para 4 estações da RMSP.

Na Tabela 4.5 estão apresentados os valores de emissões horárias para $\mathrm{CO}, \mathrm{NO}_{\mathrm{x}}$ e $\mathrm{O}_{3}$ após todos os ajustes realizados no modelo. Estes foram os valores finais utilizados nas simulações realizadas neste estudo.

Tabela 4.5 - Valores de emissões horárias para $\mathrm{CO}, \mathrm{NO}_{\mathrm{x}}$ e $\mathrm{O}_{3}$.

\begin{tabular}{|c|c|c|c|}
\hline \multirow{2}{*}{ Hora } & \multicolumn{3}{|c|}{ Emissões $\mathbf{( k g} / \mathbf{k m}^{\mathbf{2}} \mathbf{~}$} \\
\cline { 2 - 4 } & $\mathbf{C O}$ & $\mathbf{N O}_{\mathbf{x}}$ & COV \\
\hline $06: 00$ & 122 & 21 & 31 \\
\hline $07: 00$ & 380 & 41 & 105 \\
\hline $08: 00$ & 322 & 25 & 90 \\
\hline $09: 00$ & 102 & 8 & 24 \\
\hline $10: 00$ & 102 & 8 & 24 \\
\hline $11: 00$ & 102 & 8 & 24 \\
\hline $12: 00$ & 62 & 4 & 14 \\
\hline $13: 00$ & 82 & 6 & 19 \\
\hline $14: 00$ & 112 & 8 & 26 \\
\hline $15: 00$ & 127 & 11 & 30 \\
\hline $16: 00$ & 132 & 12 & 31 \\
\hline $17: 00$ & 132 & 12 & 31 \\
\hline $18: 00$ & 212 & 20 & 48 \\
\hline
\end{tabular}


De posse destes ajustes, o simulador torna-se uma ferramenta muito poderosa para a simulação dos mais diversos cenários. Pode-se, por exemplo, simular como irá variar o ozônio em função da alteração na concentração de um COV específico ou em função da alteração nas emissões totais dos COVs e dos $\mathrm{NO}_{\mathrm{x}}$. Pode-se também inferir cenários, como: problemas meteorológicos, eficácia do rodízio de veículos, influência da entrada de um novo combustível no mercado, etc.

\subsection{2 - Determinação da escala de reatividade incremental}

Segundo a metodologia proposta na documentação da versão mais recente do modelo de trajetórias OZIPR (Tonnesen, 2000) para a determinação da escala de reatividade incremental de COVs, deve-se fazer um acréscimo e um decréscimo de $0,2 \%$ dos COVs totais a cada COV de interesse.

Sendo a concentração média total de COVs de 1243 ppbC encontrada na campanha da primavera de 2006, cada COV encontrado na atmosfera da RMSP teve, portanto, sua concentração aumentada em 2,49 ppbC $(0,2 \%$ dos COVs totais) e executou-se o simulador para verificar a alteração no máximo de ozônio. Foi determinada então a reatividade incremental positiva (IR+).

$$
\begin{aligned}
& \mathrm{IR}+=\frac{\left[\mathrm{O}_{3}+\right]-\left[\mathrm{O}_{3}\right]_{\text {base }}}{[\mathrm{COV}+]-[\mathrm{COV}]_{\text {inicial }}} \\
& \text { onde: }\left[\mathrm{O}_{3}+\right]=\text { máximo de ozônio após } \\
& \text { incremento de COV. } \\
& {[\mathrm{COV}+]=\text { concentração de COV após }}
\end{aligned}
$$

Em seguida cada COV teve sua concentração diminuída em 2,49 ppbC e a alteração no máximo de ozônio determinou a reatividade incremental negativa (IR-).

$$
\begin{aligned}
\text { IR- }=\frac{\left[\mathrm{O}_{3^{-}}\right]-\left[\mathrm{O}_{3}\right]_{\text {base }}}{[\mathrm{COV}-]-[\mathrm{COV}]_{\text {inicial }}} \quad \text { onde: }\left[\mathrm{O}_{3^{-}}\right]=\begin{array}{c}
\text { máximo de ozônio após } \\
\text { decréscimo de COV. }
\end{array} \\
{[\mathrm{COV}-] \begin{array}{c}
\text { concentração de COV após } \\
\text { decréscimo. }
\end{array} }
\end{aligned}
$$

Finalmente, a média entre os valores de IR+ e IR- forneceram os valores de reatividade incremental (IR) para cada COV encontrado na RMSP.

$\mathrm{IR}=\frac{\mathrm{IR}++\mathrm{IR}-}{2}$ 
É importante lembrar que cada alteração realizada na concentração individual de um COV faz com que toda a especiação dos COVs se altere também, portanto, a cada nova simulação é necessário corrigir os valores referentes à fração do grupo de COV.

\section{2 - Casos base das amostragens realizadas na Cidade Universitária}

Com os dados de COVs obtidos durante todo o ano de $2006 \mathrm{em}$ amostragens realizadas na Cidade Universitária foram montados quatro casos base, um para cada estação do ano, a fim de se verificar se a diferença sazonal na especiação dos COVs reflete uma significativa alteração na escala de reatividade incremental para COVs, assim como determinar se estratégias de redução das emissões totais de COVs e/ou $\mathrm{NO}_{x}$ se mostram uma alternativa interessante para reduzir os níveis de ozônio na RMSP em qualquer época do ano.

\subsection{1 - Caso base verão}

Para a montagem do caso base do verão foram utilizadas as médias das concentrações dos gases traço do período de 21 de dezembro de 2005 a 19 de março de 2006. Para os valores de concentrações iniciais de COVs foram utilizados valores médios do período das 6:00 às 9:00 horas para toda a estação medidos pelo LQA na Cidade Universitária. Os dias de amostragem deste período foram: 21/12/05, 28/12/05, 05/01/06, 11/01/06, 12/01/06, 18/01/06, 24/01/06, 31/01/06, 03/02/06, 07/02/06, 09/02/06, 16/02/06, 21/02/06, 24/02/06, 02/03/06, 07/03/06, 10/03/06, 13/03/06 e 16/03/06. Os valores de concentração inicial de $\mathrm{NO}_{x}$ e $\mathrm{CO}$ foram obtidos a partir da estação Pinheiros da CETESB. A Tabela 4.6 apresenta os referidos valores.

Tabela 4.6 - Concentrações iniciais de COVs, $\mathrm{NO}_{x}$ e CO, para a Cidade Universitária e Estação Pinheiros da CETESB para o verão de 2006.

\begin{tabular}{|c|c|}
\hline Composto ou Grupo & Concentração Inicial \\
\hline $\mathrm{COV}$ & $1,10 \mathrm{ppmC}$ \\
\hline $\mathrm{NO}_{\mathrm{x}}$ & $0,09 \mathrm{ppm}$ \\
\hline $\mathrm{CO}$ & $1,22 \mathrm{ppm}$ \\
\hline
\end{tabular}

Os dados horários de temperatura e umidade relativa do ar foram obtidos pelos monitores automáticos da Estação Pinheiros da CETESB e representam 
valores médios para a estação em questão. A Tabela 4.7 apresenta os valores de parâmetros meteorológicos para o verão de 2006.

Os dados de altura da camada de mistura apresentados nesta tabela são o resultado do ajuste realizado na ocasião de validação do simulador. Conforme dito anteriormente, para efetuar o ajuste da concentração de CO foram realizados acertos nos valores de altura da camada de mistura a partir dos dados do caso base anterior, já que os valores horários de emissão de CO foram mantidos idênticos ao do caso base anterior.

Tabela 4.7 - Valores de Temperatura, Umidade Relativa do Ar e Altura da Camada de Mistura para o caso base verão.

\begin{tabular}{|c|c|c|c|}
\hline Hora & Temp. $\left({ }^{\circ} \mathrm{C}\right)$ & UR (\%) & Alt. Cam. Mist. $(\mathrm{m})$ \\
\hline $6: 00$ & 20 & 83,5 & 300 \\
\hline $7: 00$ & 20 & 83,5 & 450 \\
\hline $8: 00$ & 21 & 80,8 & 510 \\
\hline $9: 00$ & 22 & 74,9 & 750 \\
\hline $10: 00$ & 23 & 67,2 & 800 \\
\hline $11: 00$ & 25 & 59,0 & 1000 \\
\hline $12: 00$ & 27 & 63,7 & 1200 \\
\hline $13: 00$ & 27 & 50,4 & 1250 \\
\hline $14: 00$ & 28 & 49,1 & 1350 \\
\hline $15: 00$ & 28 & 48,7 & 1400 \\
\hline $16: 00$ & 28 & 49,6 & 1350 \\
\hline $17: 00$ & 27 & 54,4 & 700 \\
\hline $18: 00$ & 26 & 59,8 & 300 \\
\hline
\end{tabular}

Com os dados de concentração de COVs foi realizado o agrupamento dos mesmos, conforme explicado no Capítulo 1.4.2. A Tabela 4.8 e a Figura 4.6 mostram a distribuição dos COVs durante o verão de 2006 agrupados por função orgânica. A Tabela 4.9 mostra o agrupamento dos COVs segundo metodologia do Modelo Químico SAPRC.

Tabela 4.8 - Porcentagem de COVs para o caso base verão agrupados por função orgânica.

\begin{tabular}{|c|c|}
\hline Função & $\mathbf{( \% )}$ \\
\hline Alcanos & 45,5 \\
\hline Alcenos & 26,0 \\
\hline Aromáticos & 10,0 \\
\hline Aldeídos & 18,5 \\
\hline
\end{tabular}




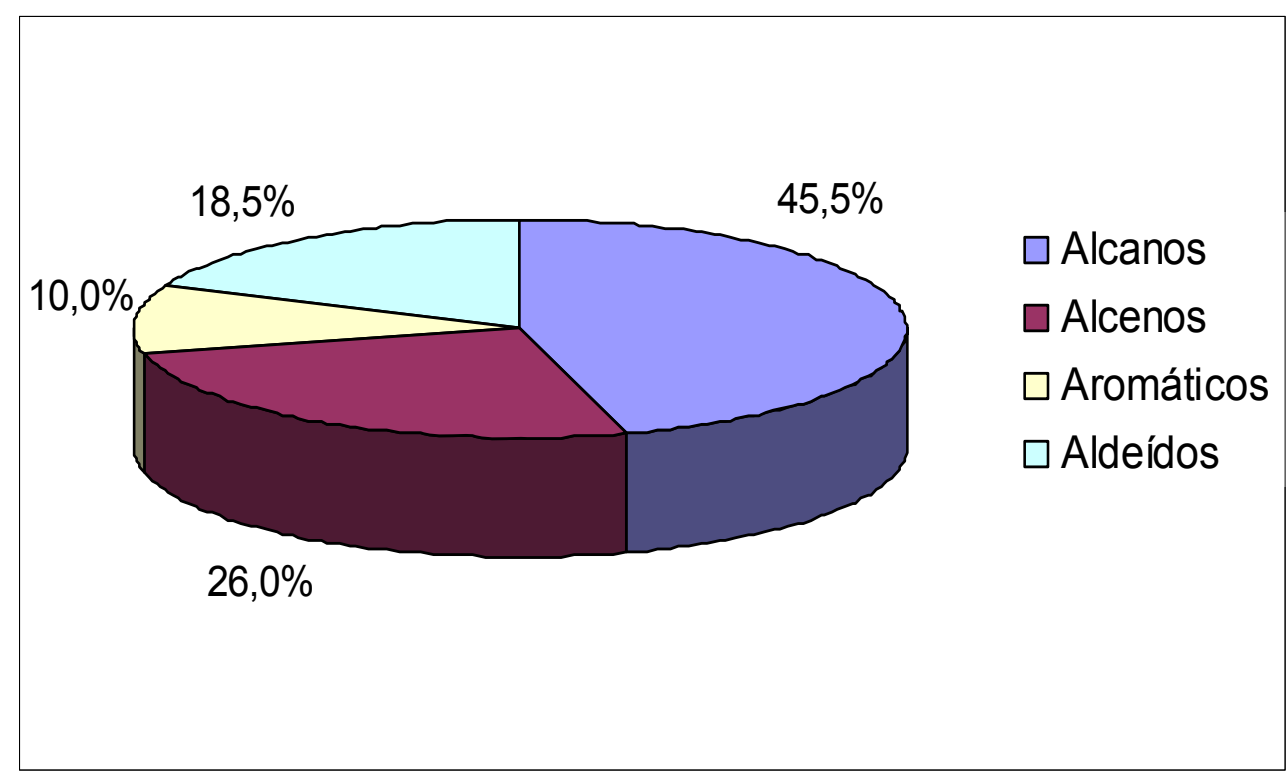

Figura 4.6 - Porcentagem de COVs para o caso base verão agrupados por função orgânica.

Tabela 4.9 - Agrupamento dos COVs para o caso base verão 2006, segundo metodologia SAPRC.

\begin{tabular}{|c|c|c|c|c|}
\hline GRUPOS & DESCRIÇÃO & ppmC totais & Fração & $\mathbf{N}^{\circ}$ Médio C \\
\hline ALK 1 & $1^{\circ}$ grupo de alcanos & 0,005 & 0,0049 & 2,000 \\
\hline ALK 2 & $2^{\circ}$ grupo de alcanos & 0,011 & 0,0097 & 3,000 \\
\hline ALK 3 & $3^{\circ}$ grupo de alcanos & 0,030 & 0,0273 & 4,000 \\
\hline ALK 4 & $4^{\circ}$ grupo de alcanos & 0,068 & 0,0617 & 5,524 \\
\hline ALK 5 & $5^{\circ}$ grupo de alcanos & 0,023 & 0,0212 & 7,708 \\
\hline OLE 1 & $1^{\circ}$ grupo de alcenos & 0,029 & 0,0265 & 3,997 \\
\hline OLE 2 & $2^{\circ}$ grupo de alcenos & 0,013 & 0,0118 & 4,535 \\
\hline ARO 1 & $1^{\circ}$ grupo de aromáticos & 0,030 & 0,0270 & 7,185 \\
\hline ARO 2 & $2^{\circ}$ grupo de aromáticos & 0,019 & 0,0168 & 8,450 \\
\hline TERP & Terpenos & 0,001 & 0,0005 & 10,000 \\
\hline HCHO & Formaldeído & 0,006 & 0,0052 & 1,000 \\
\hline CCHO & Acetaldeído & 0,012 & 0,0109 & 2,000 \\
\hline ETHENE & Eteno & 0,010 & 0,0094 & 2,000 \\
\hline MEOH & Metanol & 0,011 & 0,0096 & 1,000 \\
\hline ETOH & Etanol & 0,828 & 0,7535 & 2,000 \\
\hline ISOPRENE & Isopreno & 0,004 & 0,0038 & 5,000 \\
\hline
\end{tabular}

Conforme realizado na montagem do caso base anterior, após carregar o simulador com todos os dados citados, passou-se à etapa de validação do simulador. Foram realizados acertos nos valores de altura da camada de mistura para ajustar o perfil de CO. A Figura 4.7 mostra o resultado dos perfis de CO simulado e medido durante o verão de 2006 pela Estação Pinheiros da CETESB após realizados os devidos ajustes. 


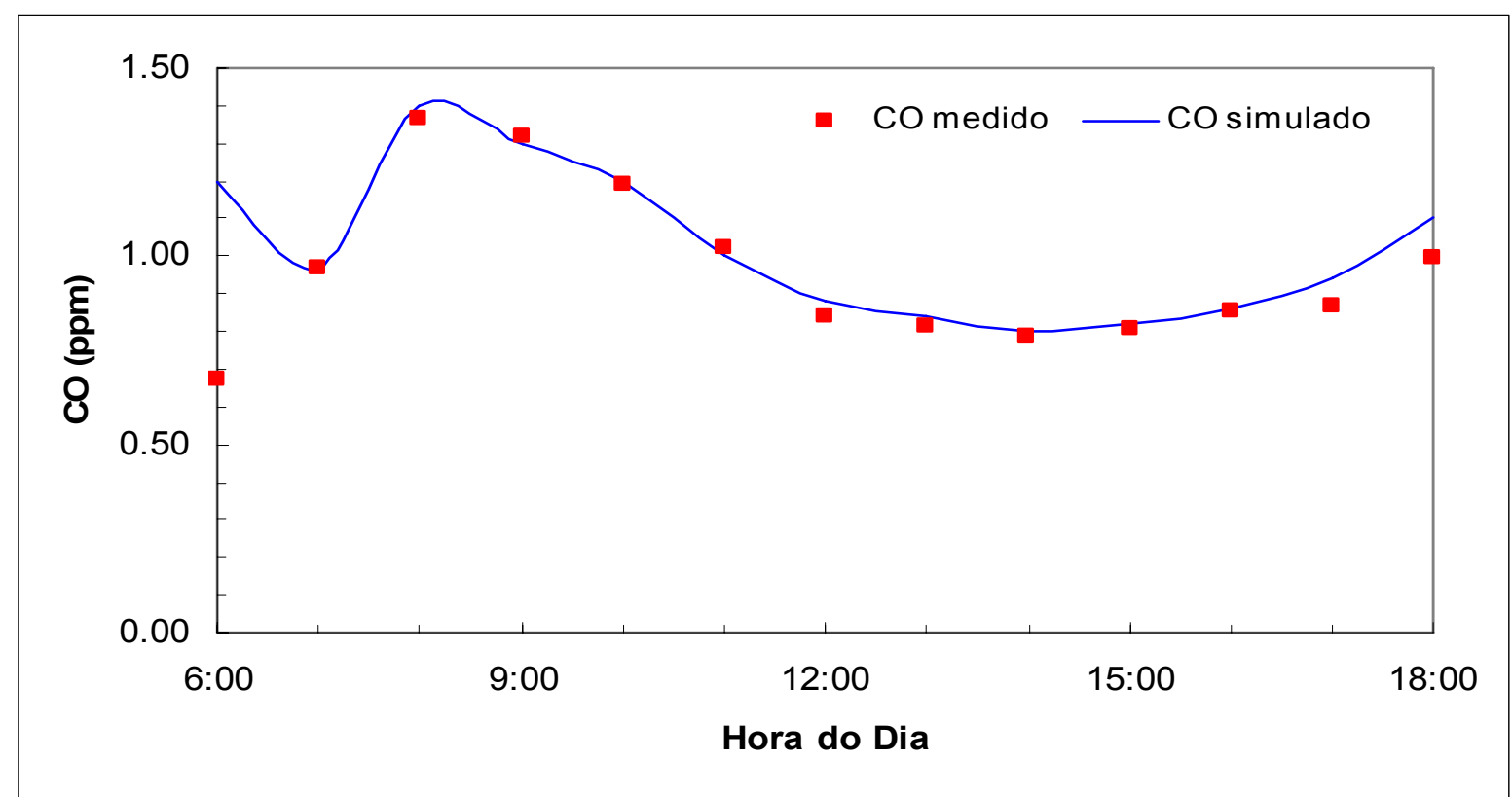

Figura 4.7 - Comparação dos valores simulados para o caso base com os valores médios obtidos para a concentração de CO no verão de 2006 na Estação Pinheiros.

Em seguida, um pequeno ajuste nas emissões horárias e nas taxas de deposição de $\mathrm{NO}_{\mathrm{x}}$ foram realizadas para conseguir a melhor aproximação possível entre os dados medidos e simulados. A Figura 4.8 apresenta os perfis de $\mathrm{NO}_{x}$ para o verão de 2006.

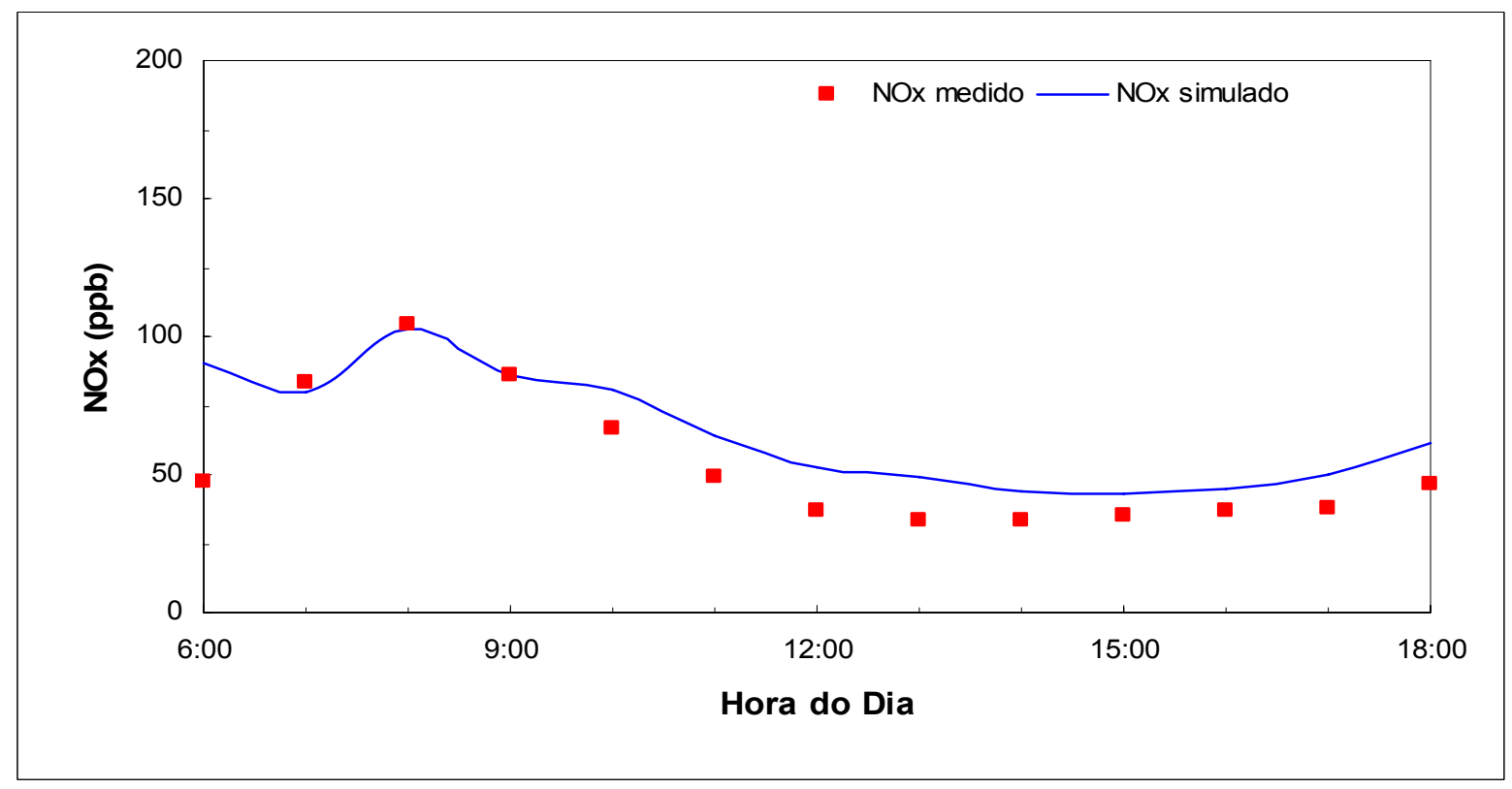

Figura 4.8 - Comparação dos valores simulados para o caso base com os valores médios obtidos para a concentração de $\mathrm{NO}_{x}$ no verão de 2006 na Estação Pinheiros.

Assim como na montagem do caso base anterior, os valores simulados para ozônio ficaram bastante acima do medido na Estação Pinheiros, desta forma 
foi considerado ajustado o perfil de ozônio que se aproximasse de um valor médio entre as quatro estações analisadas. A comparação entre o perfil de ozônio simulado e o perfil das quatro estações analisadas para o verão de 2006 pode ser vista na Figura 4.9.

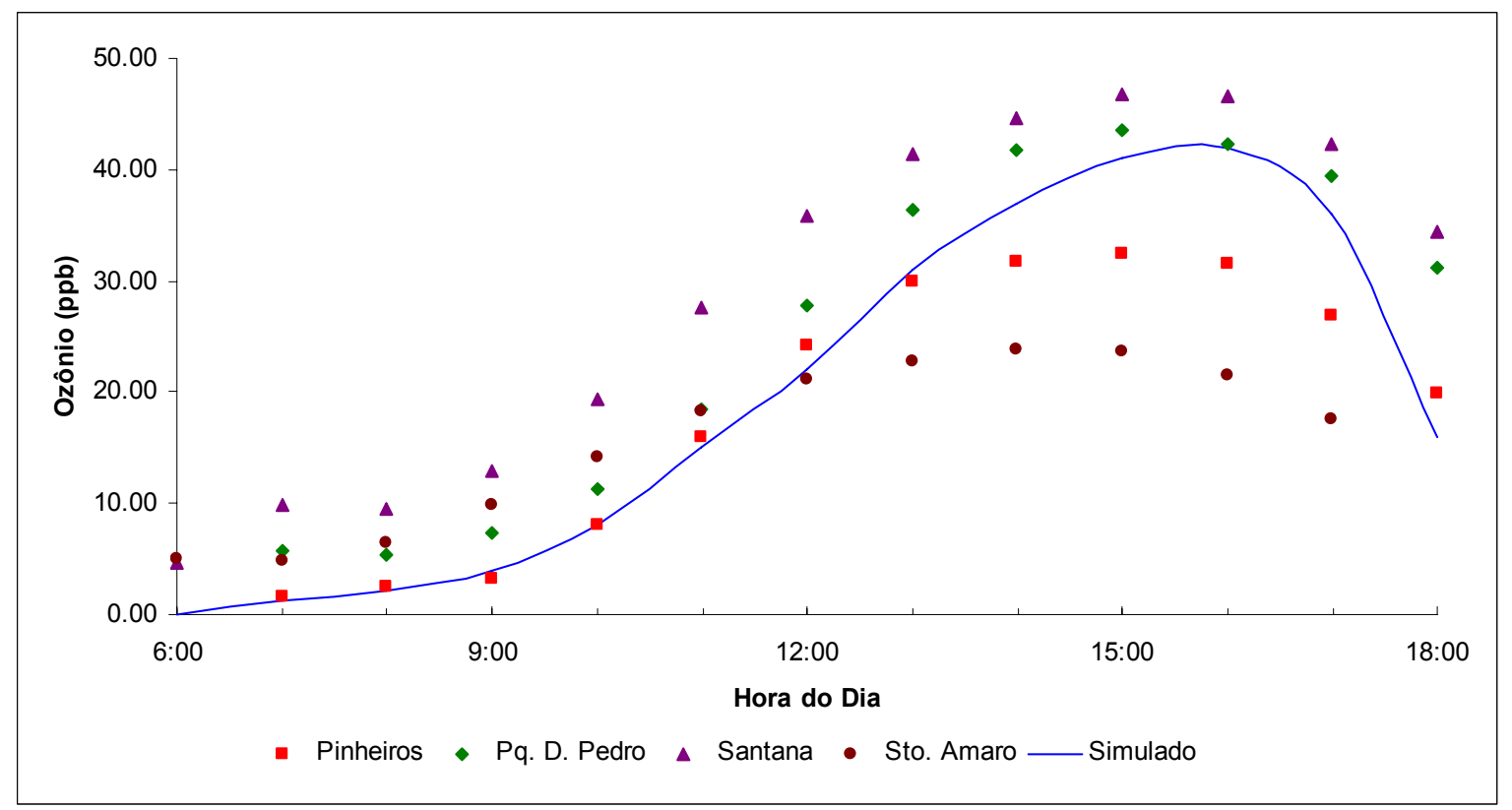

Figura 4.9 - Comparação dos valores simulados para o caso base com os valores médios obtidos para a concentração de $\mathrm{O}_{3}$ no verão de 2006 para 4 estações da RMSP.

\subsection{2 - Caso base outono}

Para a montagem do caso base do outono foram utilizadas as médias das concentrações dos gases traço do período de 20 de março a 20 de junho de 2006. Os dias de amostragem de COVs para este período foram: 23/03/06, 28/03/06, 30/03/06, 03/04/06, 07/04/06, 11/04/06, 13/04/06, 20/04/06, 25/04/06, 27/04/06, 03/05/06, 05/05/06, 11/05/06, 19/05/06, 23/05/06, 26/05/06, 29/05/06, 01/06/06, 05/06/06, 09/06/06, 13/06/06, 16/06/06 e 19/06/06. Os valores de concentrações iniciais de COVs, $\mathrm{NO}_{\mathrm{x}}$ e $\mathrm{CO}$ foram obtidos de forma idêntica ao caso base do verão e podem ser visualizados na Tabela 4.10 .

Tabela 4.10 - Concentrações iniciais de COVs, $\mathrm{NO}_{x}$ e $\mathrm{CO}$, para a Cidade Universitária e Estação Pinheiros da CETESB para o outono de 2006.

\begin{tabular}{|c|c|}
\hline Composto ou Grupo & Concentração Inicial \\
\hline $\mathrm{COV}$ & $1,09 \mathrm{ppmC}$ \\
\hline $\mathrm{NO}_{\mathrm{x}}$ & $0,11 \mathrm{ppm}$ \\
\hline $\mathrm{CO}$ & $1,31 \mathrm{ppm}$ \\
\hline
\end{tabular}

A obtenção dos dados horários de temperatura e umidade relativa do ar, assim como os ajustes para os valores de altura de camada de mistura foram 
obtidos da mesma forma que no caso base anterior. A Tabela 4.11 apresenta os valores de parâmetros meteorológicos para o outono de 2006.

Tabela 4.11 - Valores de Temperatura, Umidade Relativa do Ar e Altura da Camada de Mistura para o caso base outono.

\begin{tabular}{|c|c|c|c|}
\hline Hora & Temp. $\left({ }^{\circ} \mathrm{C}\right)$ & UR (\%) & Alt. Cam. Mist. $(\mathrm{m})$ \\
\hline $6: 00$ & 16 & 82,9 & 300 \\
\hline $7: 00$ & 16 & 83,3 & 400 \\
\hline $8: 00$ & 16 & 82,1 & 500 \\
\hline $9: 00$ & 18 & 77,3 & 700 \\
\hline $10: 00$ & 19 & 68,2 & 800 \\
\hline $11: 00$ & 21 & 59,9 & 900 \\
\hline $12: 00$ & 22 & 54,4 & 1100 \\
\hline $13: 00$ & 23 & 50,3 & 1150 \\
\hline $14: 00$ & 24 & 47,7 & 1200 \\
\hline $15: 00$ & 24 & 47,2 & 1300 \\
\hline $16: 00$ & 24 & 48,5 & 1270 \\
\hline $17: 00$ & 23 & 52,1 & 700 \\
\hline $18: 00$ & 21 & 59,1 & 300 \\
\hline
\end{tabular}

A Tabela 4.12 e a Figura 4.10 mostram a distribuição dos COVs durante o outono de 2006 agrupados por função orgânica. A Tabela 4.13 mostra o agrupamento dos COVs segundo metodologia do Modelo Químico SAPRC.

Tabela 4.12 - Porcentagem de COVs para o caso base outono agrupados por função orgânica.

\begin{tabular}{|c|c|}
\hline Função & $\mathbf{( \% )}$ \\
\hline Alcanos & 48,2 \\
\hline Alcenos & 23,0 \\
\hline Aromáticos & 9,7 \\
\hline Aldeídos & 19,0 \\
\hline
\end{tabular}

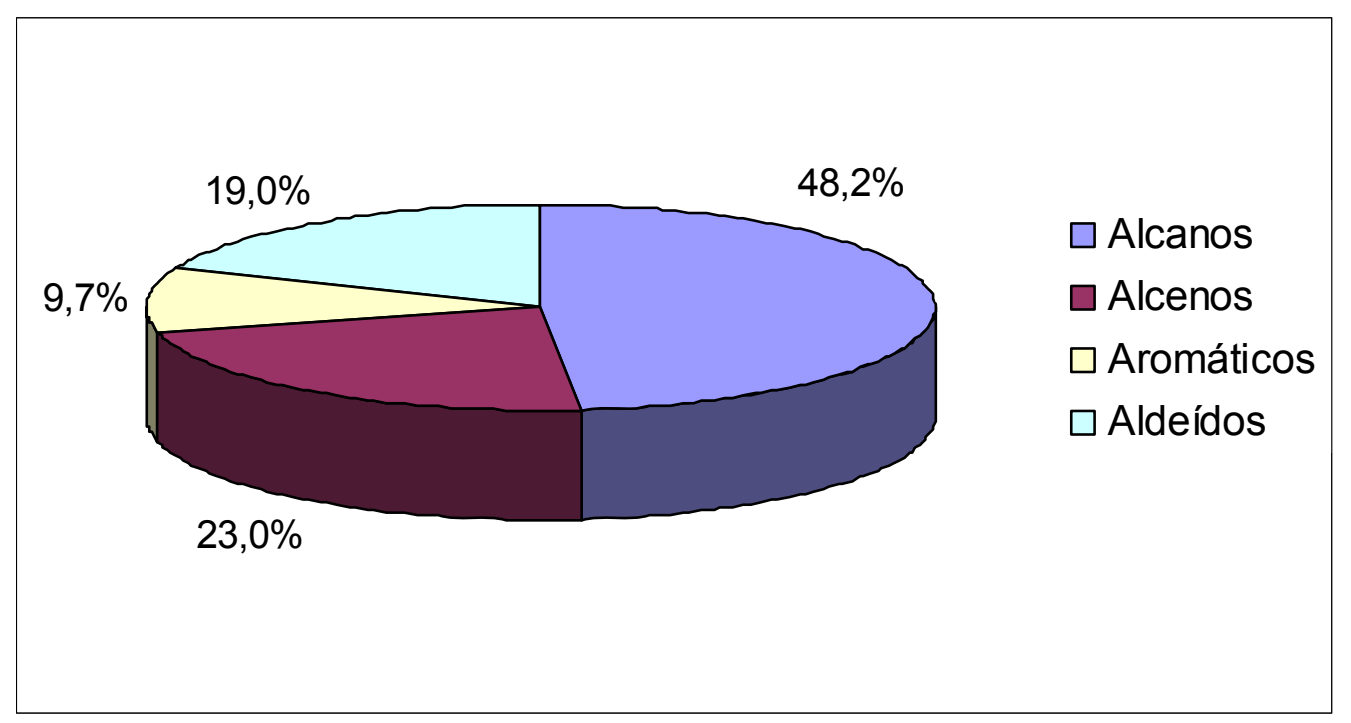

Figura 4.10 - Porcentagem de COVs para o caso base outono agrupados por função orgânica. 
Tabela 4.13 - Agrupamento dos COVs para o caso base outono 2006, segundo metodologia SAPRC.

\begin{tabular}{|c|c|c|c|c|}
\hline GRUPOS & DESCRIÇÃO & ppmC totais & Fração & N $^{\circ}$ Médio C \\
\hline ALK 1 & $1^{\circ}$ grupo de alcanos & 0,006 & 0,0058 & 2,000 \\
\hline ALK 2 & $2^{\circ}$ grupo de alcanos & 0,012 & 0,0108 & 3,000 \\
\hline ALK 3 & $3^{\circ}$ grupo de alcanos & 0,029 & 0,0267 & 4,000 \\
\hline ALK 4 & $4^{\circ}$ grupo de alcanos & 0,068 & 0,0622 & 5,594 \\
\hline ALK 5 & $5^{\circ}$ grupo de alcanos & 0,023 & 0,0212 & 7,436 \\
\hline OLE 1 & $1^{\circ}$ grupo de alcenos & 0,019 & 0,0177 & 3,809 \\
\hline OLE 2 & $2^{\circ}$ grupo de alcenos & 0,017 & 0,0159 & 4,584 \\
\hline ARO 1 & $1^{\circ}$ grupo de aromáticos & 0,028 & 0,0260 & 7,257 \\
\hline ARO 2 & $2^{\circ}$ grupo de aromáticos & 0,017 & 0,0154 & 8,227 \\
\hline TERP & Terpenos & 0,000 & 0,0003 & 10,000 \\
\hline HCHO & Formaldeído & 0,006 & 0,0053 & 1,000 \\
\hline CCHO & Acetaldeído & 0,012 & 0,0110 & 2,000 \\
\hline ETHENE & Eteno & 0,010 & 0,0092 & 2,000 \\
\hline MEOH & Metanol & 0,011 & 0,0097 & 1,000 \\
\hline ETOH & Etanol & 0,828 & 0,7602 & 2,000 \\
\hline ISOPRENE & Isopreno & 0,003 & 0,0025 & 5,000 \\
\hline
\end{tabular}

Passou-se então para a etapa de ajuste dos perfis de $\mathrm{CO}, \mathrm{NO}_{\mathrm{x}}$ e $\mathrm{O}_{3} . \mathrm{O}$ perfil de CO foi ajustado através de acertos nos valores de altura da camada de mistura (Figura 4.11).

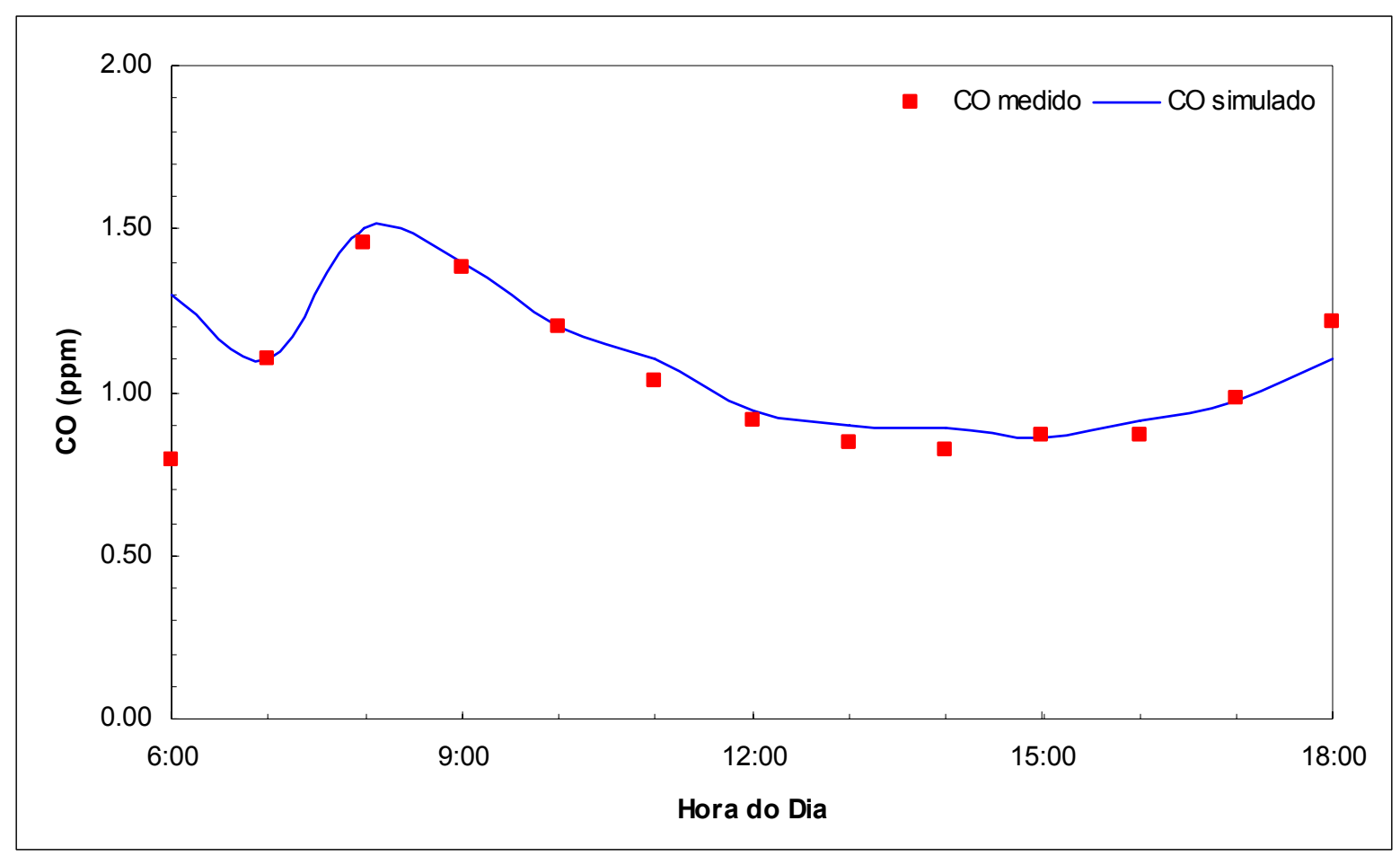

Figura 4.11 - Comparação dos valores simulados para o caso base com os valores médios obtidos para a concentração de CO no outono de 2006 na Estação Pinheiros. 
Ajustes nas emissões horárias e nas taxas de deposição de $\mathrm{NO}_{x}$ foram realizados para se obter uma melhor aproximação entre os valores medidos e simulados. As Figuras 4.12 e 4.13 apresentam os resultados dos perfis de $\mathrm{NO}_{\mathrm{x}} \mathrm{e}$ $\mathrm{O}_{3}$ simulados e medidos durante o outono de 2006.

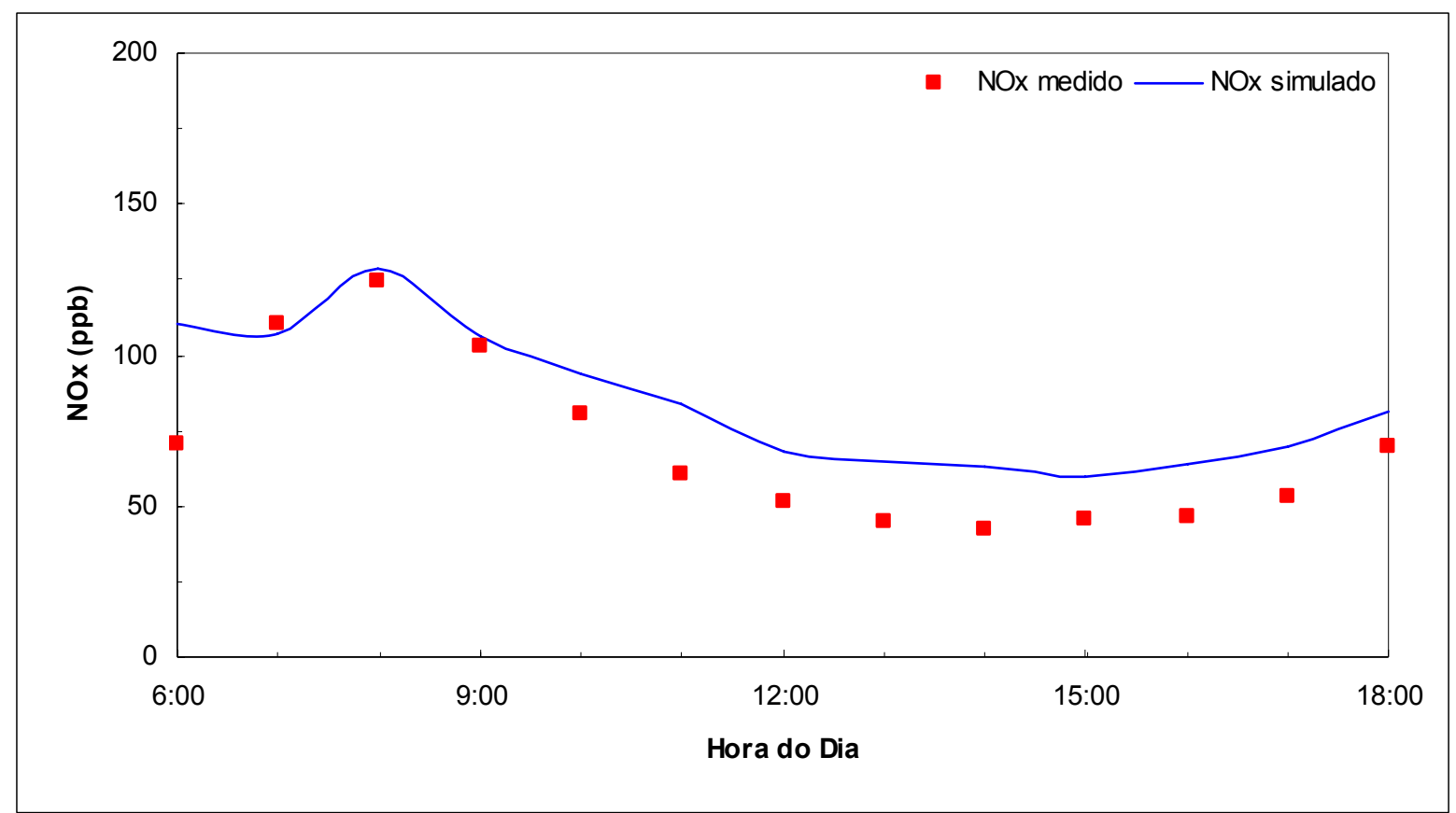

Figura 4.12 - Comparação dos valores simulados para o caso base com os valores médios obtidos para a concentração de $\mathrm{NO}_{x}$ no outono de 2006 na Estação Pinheiros.

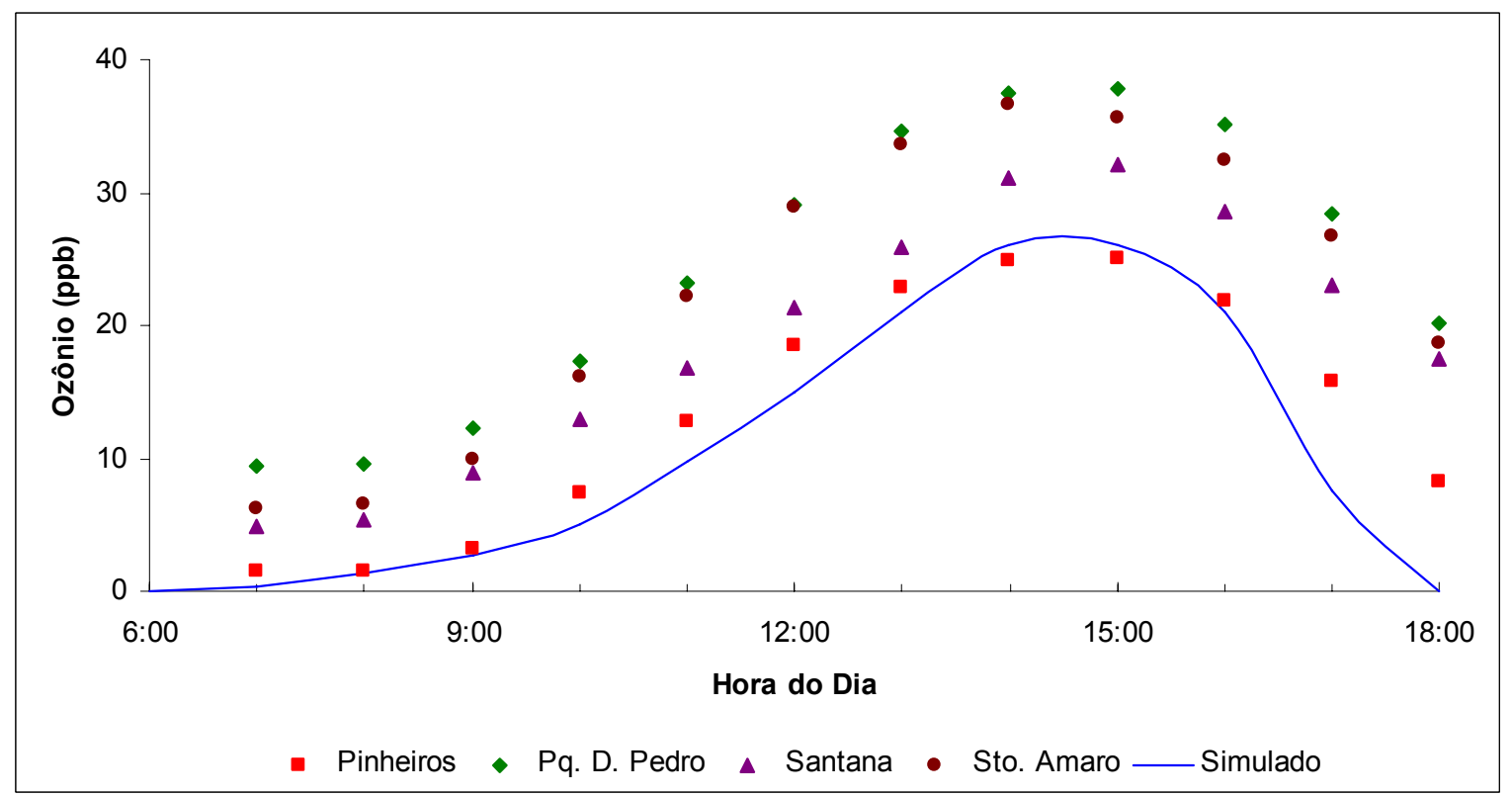

Figura 4.13 - Comparação dos valores simulados para o caso base com os valores médios obtidos para a concentração de $\mathrm{O}_{3}$ no outono de 2006 para 4 estações da RMSP. 
Para os ajustes no perfil de $\mathrm{O}_{3}$ também foram realizados acertos nas taxas de emissão horárias de COVs. Apesar de todos os acertos realizados não foi possível obter um perfil de $\mathrm{O}_{3}$ simulado que representasse a média das quatro estações analisadas, como nos casos base anteriores. Para este caso base 0 perfil de $\mathrm{O}_{3}$ simulado ficou muito próximo do perfil medido na Estação Pinheiros e um pouco abaixo da média das quatro estações.

\subsection{3 - Caso base inverno}

Para a montagem do caso base do inverno foram utilizadas as médias das concentrações dos gases traço do período de 21 de junho a 22 de setembro de 2006. Os dias de amostragem de COVs para este período foram: 22/06/06, 27/06/06, 29/06/06, 03/07/06, 06/07/06, 12/07/06, 14/07/06, 17/07/06, 20/07/06, 24/07/06, 27/07/06, 01/08/06, 04/08/06, 07/08/06, 23/08/06, 29/08/06, 01/09/06, 06/09/06 e 12/09/06. Os valores de concentrações iniciais de COVs, $\mathrm{NO}_{\mathrm{x}}$ e CO foram obtidos de forma idêntica ao caso base anterior e podem ser visualizados na Tabela 4.14.

Tabela 4.14 - Concentrações iniciais de COVs, $\mathrm{NO}_{x}$ e $\mathrm{CO}$, para a Cidade Universitária e Estação Pinheiros da CETESB para o inverno de 2006.

\begin{tabular}{|c|c|}
\hline Composto ou Grupo & Concentração Inicial \\
\hline $\mathrm{COV}$ & $1,29 \mathrm{ppmC}$ \\
\hline $\mathrm{NO}_{\mathrm{x}}$ & $0,22 \mathrm{ppm}$ \\
\hline $\mathrm{CO}$ & $2,07 \mathrm{ppm}$ \\
\hline
\end{tabular}

Comparando-se as concentrações de $\mathrm{NO}_{x}$ e $\mathrm{CO}$ medidas no inverno com as outras estações, nota-se que no inverno há uma concentração cerca de duas vezes maior que nas demais. Este fato se deve provavelmente à menor altura da camada de mistura encontrada no inverno aliada às condições de pouca movimentação das massas de ar que ocorrem nesta estação, dificultando assim a dispersão dos poluentes. No entanto, ao analisar as concentrações de COVs, nota-se um aumento no inverno bem menos significativo, na faixa de $20 \%$, a possível explicação para este fato é que a diminuição das emissões evaporativas nesta estação, contrabalanceia as piores condições de dispersão dos poluentes.

A obtenção dos dados horários de temperatura e umidade relativa do ar, assim como, os ajustes para os valores de altura de camada de mistura foram obtidos da mesma forma que no caso base anterior. A Tabela 4.15 apresenta os valores de parâmetros meteorológicos para o inverno de 2006. 
Tabela 4.15 - Valores de Temperatura, Umidade Relativa do Ar e Altura da Camada de Mistura para o caso base inverno.

\begin{tabular}{|c|c|c|c|}
\hline Hora & Temp. $\left({ }^{\circ} \mathrm{C}\right)$ & UR (\%) & Alt. Cam. Mist. $(\mathrm{m})$ \\
\hline $6: 00$ & 14 & 78,7 & 270 \\
\hline $7: 00$ & 14 & 79,7 & 330 \\
\hline $8: 00$ & 14 & 80,3 & 360 \\
\hline $9: 00$ & 16 & 78,0 & 480 \\
\hline $10: 00$ & 18 & 68,6 & 550 \\
\hline $11: 00$ & 20 & 58,0 & 810 \\
\hline $12: 00$ & 22 & 51,2 & 950 \\
\hline $13: 00$ & 24 & 46,1 & 1040 \\
\hline $14: 00$ & 25 & 42,8 & 1200 \\
\hline $15: 00$ & 25 & 41,0 & 1250 \\
\hline $16: 00$ & 25 & 40,9 & 1100 \\
\hline $17: 00$ & 24 & 43,1 & 700 \\
\hline $18: 00$ & 21 & 48,3 & 300 \\
\hline
\end{tabular}

A Tabela 4.16 e a Figura 4.14 mostram a distribuição dos COVs durante o inverno de 2006 agrupados por função orgânica. A Tabela 4.17 mostra o agrupamento dos COVs segundo metodologia do Modelo Químico SAPRC.

Tabela 4.16 - Porcentagem de COVs para o caso base inverno agrupados por função orgânica.

\begin{tabular}{|c|c|}
\hline Função & $\mathbf{( \% )}$ \\
\hline Alcanos & 45,5 \\
\hline Alcenos & 29,5 \\
\hline Aromáticos & 13,8 \\
\hline Aldeídos & 11,2 \\
\hline
\end{tabular}

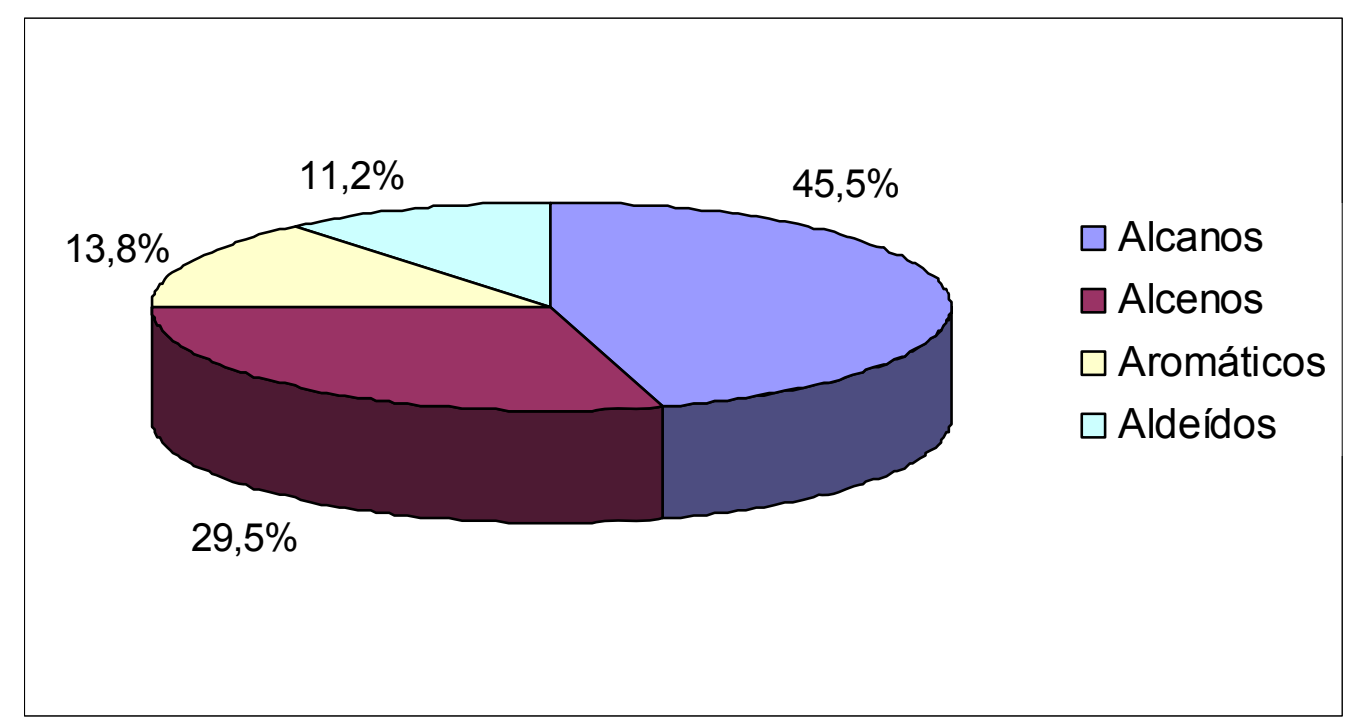

Figura 4.14 - Porcentagem de COVs para o caso base inverno agrupados por função orgânica. 
Tabela 4.17 - Agrupamento dos COVs para o caso base inverno 2006, segundo metodologia SAPRC.

\begin{tabular}{|c|c|c|c|c|}
\hline GRUPOS & DESCRIÇÃO & ppmC totais & Fração & $\mathbf{N}^{\circ}$ Médio C \\
\hline ALK 1 & $1^{\circ}$ grupo de alcanos & 0,013 & 0,0099 & 2,000 \\
\hline ALK 2 & $2^{\circ}$ grupo de alcanos & 0,027 & 0,0212 & 3,000 \\
\hline ALK 3 & $3^{\circ}$ grupo de alcanos & 0,037 & 0,0290 & 4,000 \\
\hline ALK 4 & $4^{\circ}$ grupo de alcanos & 0,085 & 0,0661 & 5,437 \\
\hline ALK 5 & $5^{\circ}$ grupo de alcanos & 0,052 & 0,0399 & 7,717 \\
\hline OLE 1 & $1^{\circ}$ grupo de alcenos & 0,044 & 0,0342 & 3,769 \\
\hline OLE 2 & $2^{\circ}$ grupo de alcenos & 0,039 & 0,0302 & 4,688 \\
\hline ARO 1 & $1^{\circ}$ grupo de aromáticos & 0,056 & 0,0434 & 7,206 \\
\hline ARO 2 & $2^{\circ}$ grupo de aromáticos & 0,056 & 0,0431 & 8,512 \\
\hline TERP & Terpenos & 0,002 & 0,0014 & 10,000 \\
\hline HCHO & Formaldeído & 0,006 & 0,0044 & 1,000 \\
\hline CCHO & Acetaldeído & 0,012 & 0,0093 & 2,000 \\
\hline ETHENE & Eteno & 0,022 & 0,0168 & 2,000 \\
\hline MEOH & Metanol & 0,011 & 0,0082 & 1,000 \\
\hline ETOH & Etanol & 0,828 & 0,6406 & 2,000 \\
\hline ISOPRENE & Isopreno & 0,003 & 0,0024 & 5,000 \\
\hline
\end{tabular}

Os ajustes dos perfis de $\mathrm{CO}, \mathrm{NO}_{\mathrm{x}}$ e $\mathrm{O}_{3}$ foram realizados de forma idêntica ao realizado no caso base outono. $\mathrm{O}$ perfil do $\mathrm{O}_{3}$ para este caso base se assemelhou ao caso base da FSP, ficando bastante acima das medidas da estação Pinheiros, porém, próximo às outras estações. Nas Figuras 4.15, $4.16 \mathrm{e}$ 4.17 podem ser vistos respectivamente os resultados dos perfis de $\mathrm{CO}, \mathrm{NO}_{\mathrm{x}} \mathrm{e} \mathrm{O}_{3}$ simulados e medidos durante o inverno de 2006.

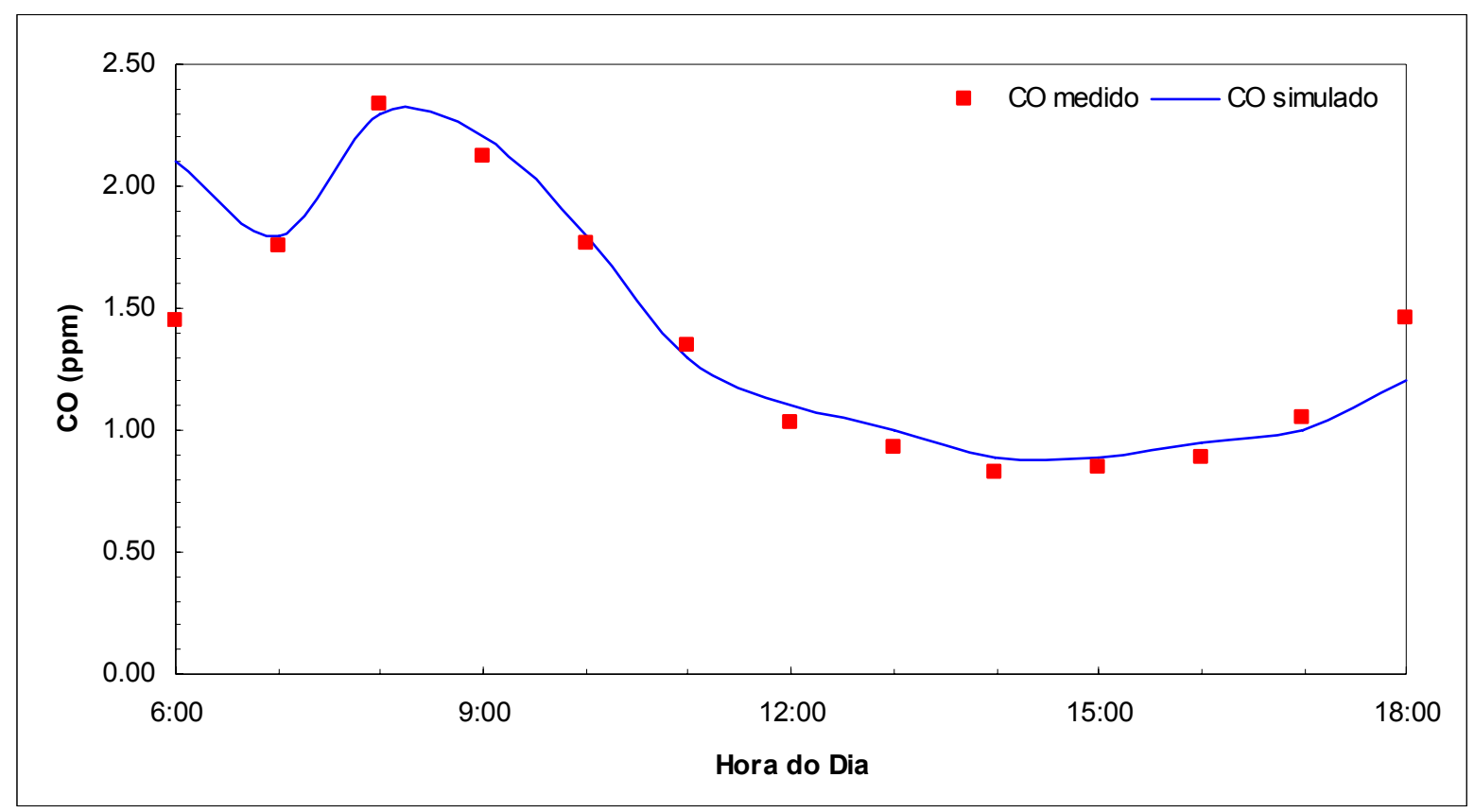

Figura 4.15 - Comparação dos valores simulados para o caso base com os valores médios obtidos para a concentração de CO no inverno de 2006 na Estação Pinheiros. 


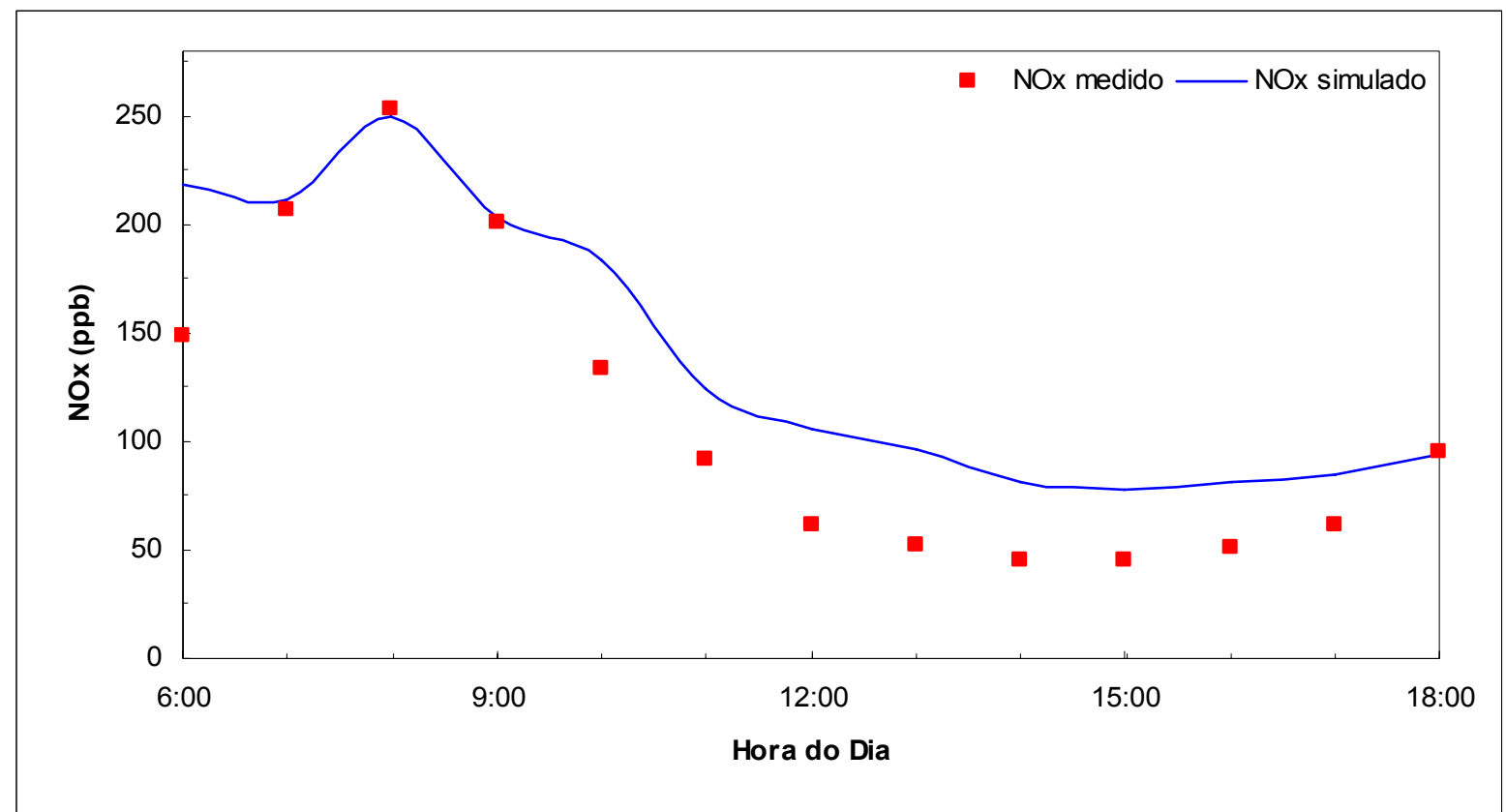

Figura 4.16 - Comparação dos valores simulados para o caso base com os valores médios obtidos para a concentração de $\mathrm{NO}_{\mathrm{x}}$ no inverno de 2006 na Estação Pinheiros.

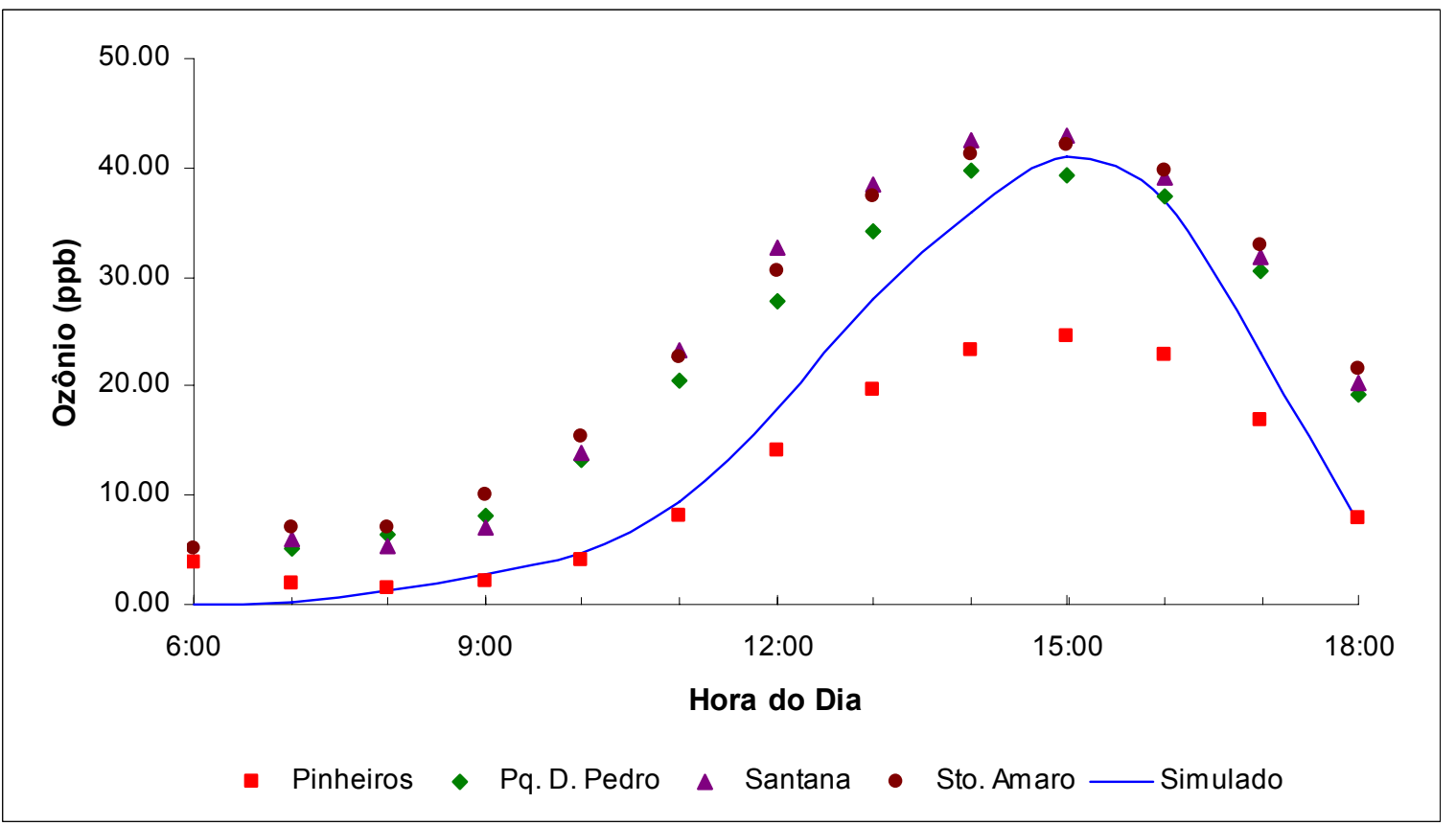

Figura 4.17 - Comparação dos valores simulados para o caso base com os valores médios obtidos para a concentração de $\mathrm{O}_{3}$ no inverno de 2006 para 4 estações da RMSP.

\subsection{4 - Caso base primavera}

Para a montagem do caso base do inverno foram utilizadas as médias das concentrações dos gases traço do período de 23 de setembro a 22 de dezembro de 2006. Os dias de amostragem de COVs para este período foram: 29/09/06, 03/10/06, 05/10/06, 10/10/06, 13/10/06, 17/10/06, 24/10/06, 26/10/06, 30/10/06, 08/11/06, 10/11/06, 14/11/06, 04/12/06, 07/12/06, 13/12/06, 15/12/06 e 19/12/06. 
Os valores de concentrações iniciais de COVs, $\mathrm{NO}_{x}$ e $\mathrm{CO}$ foram obtidos de forma idêntica aos casos base anteriores e podem ser visualizados na Tabela 4.18.

Tabela 4.18 - Concentrações iniciais de $\mathrm{COVs}, \mathrm{NO}_{x}$ e $\mathrm{CO}$, para a Cidade Universitária e Estação Pinheiros da CETESB para a primavera de 2006.

\begin{tabular}{|c|c|}
\hline Composto ou Grupo & Concentração Inicial \\
\hline $\mathrm{COV}$ & $1,11 \mathrm{ppmC}$ \\
\hline $\mathrm{NO}_{\mathrm{x}}$ & $0,08 \mathrm{ppm}$ \\
\hline $\mathrm{CO}$ & $1,03 \mathrm{ppm}$ \\
\hline
\end{tabular}

A obtenção dos dados horários de temperatura e umidade relativa do ar, assim como os ajustes para os valores de altura de camada de mistura foram obtidos da mesma forma que nos casos base anteriores. A Tabela 4.19 apresenta os valores de parâmetros meteorológicos para a primavera de 2006.

Tabela 4.19 - Valores de Temperatura, Umidade Relativa do Ar e Altura da Camada de Mistura para o caso base primavera.

\begin{tabular}{|c|c|c|c|}
\hline Hora & Temp. $\left({ }^{\circ} \mathrm{C}\right)$ & UR (\%) & Alt. Cam. Mist. $(\mathrm{m})$ \\
\hline $6: 00$ & 18 & 85,1 & 300 \\
\hline $7: 00$ & 18 & 81,9 & 450 \\
\hline $8: 00$ & 19 & 81,1 & 700 \\
\hline $9: 00$ & 20 & 77,1 & 900 \\
\hline $10: 00$ & 21 & 71,1 & 1000 \\
\hline $11: 00$ & 23 & 65,0 & 1100 \\
\hline $12: 00$ & 24 & 59,7 & 1250 \\
\hline $13: 00$ & 26 & 55,2 & 1300 \\
\hline $14: 00$ & 26 & 52,0 & 1350 \\
\hline $15: 00$ & 26 & 50,1 & 1450 \\
\hline $16: 00$ & 26 & 52,6 & 1400 \\
\hline $17: 00$ & 25 & 56,2 & 1100 \\
\hline $18: 00$ & 23 & 61,2 & 600 \\
\hline
\end{tabular}

A Tabela 4.20 e a Figura 4.18 mostram a distribuição dos COVs durante a primavera de 2006 agrupados por função orgânica. A Tabela 4.21 mostra o agrupamento dos COVs segundo metodologia do Modelo Químico SAPRC.

Tabela 4.20 - Porcentagem de COVs para o caso base primavera agrupados por função orgânica.

\begin{tabular}{|c|c|}
\hline Função & $(\mathbf{\%})$ \\
\hline Alcanos & 39,7 \\
\hline Alcenos & 25,1 \\
\hline Aromáticos & 15,7 \\
\hline Aldeídos & 19,6 \\
\hline
\end{tabular}




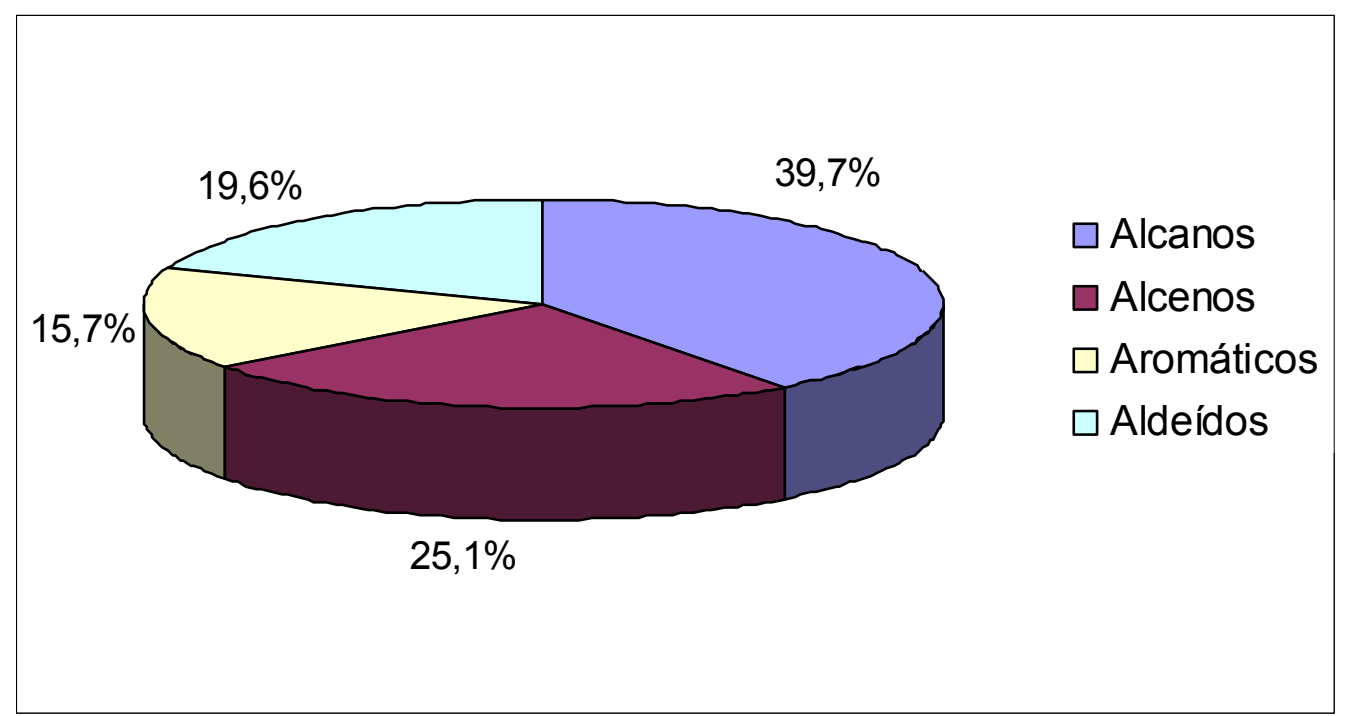

Figura 4.18 - Porcentagem de COVs para o caso base primavera agrupados por função orgânica.

Tabela 4.21 - Agrupamento dos COVs para o caso base primavera 2006, segundo metodologia SAPRC.

\begin{tabular}{|c|c|c|c|c|}
\hline GRUPOS & DESCRIÇÃO & ppmC totais & Fração & No Médio C $^{\circ}$ \\
\hline ALK 1 & $1^{\circ}$ grupo de alcanos & 0,006 & 0,0052 & 2,000 \\
\hline ALK 2 & $2^{\circ}$ grupo de alcanos & 0,010 & 0,0092 & 3,000 \\
\hline ALK 3 & $3^{\circ}$ grupo de alcanos & 0,018 & 0,0159 & 4,000 \\
\hline ALK 4 & $4^{\circ}$ grupo de alcanos & 0,049 & 0,0438 & 5,652 \\
\hline ALK 5 & $5^{\circ}$ grupo de alcanos & 0,038 & 0,0344 & 8,664 \\
\hline OLE 1 & $1^{\circ}$ grupo de alcenos & 0,020 & 0,0182 & 3,882 \\
\hline OLE 2 & $2^{\circ}$ grupo de alcenos & 0,022 & 0,0203 & 4,520 \\
\hline ARO 1 & $1^{\circ}$ grupo de aromáticos & 0,032 & 0,0293 & 7,271 \\
\hline ARO 2 & $2^{\circ}$ grupo de aromáticos & 0,042 & 0,0383 & 8,729 \\
\hline TERP & Terpenos & 0,001 & 0,0008 & 10,000 \\
\hline HCHO & Formaldeído & 0,006 & 0,0052 & 1,000 \\
\hline CCHO & Acetaldeído & 0,012 & 0,0108 & 2,000 \\
\hline ETHENE & Eteno & 0,008 & 0,0074 & 2,000 \\
\hline MEOH & Metanol & 0,011 & 0,0096 & 1,000 \\
\hline ETOH & Etanol & 0,828 & 0,7486 & 2,000 \\
\hline ISOPRENE & Isopreno & 0,003 & 0,0028 & 5,000 \\
\hline
\end{tabular}

Os ajustes dos perfis de $\mathrm{CO}, \mathrm{NO}_{x}$ e $\mathrm{O}_{3}$ foram realizados de forma idêntica aos ajustes anteriores. O comportamento do perfil de ozônio simulado para a primavera seguiu a mesma tendência observada para os outros casos base, com exceção ao do outono. Nas Figuras $4.19,4.20$ e 4.21 podem ser vistos respectivamente os resultados dos perfis de $\mathrm{CO}, \mathrm{NO}_{\mathrm{x}}$ e $\mathrm{O}_{3}$ simulados e medidos durante a primavera de 2006. 


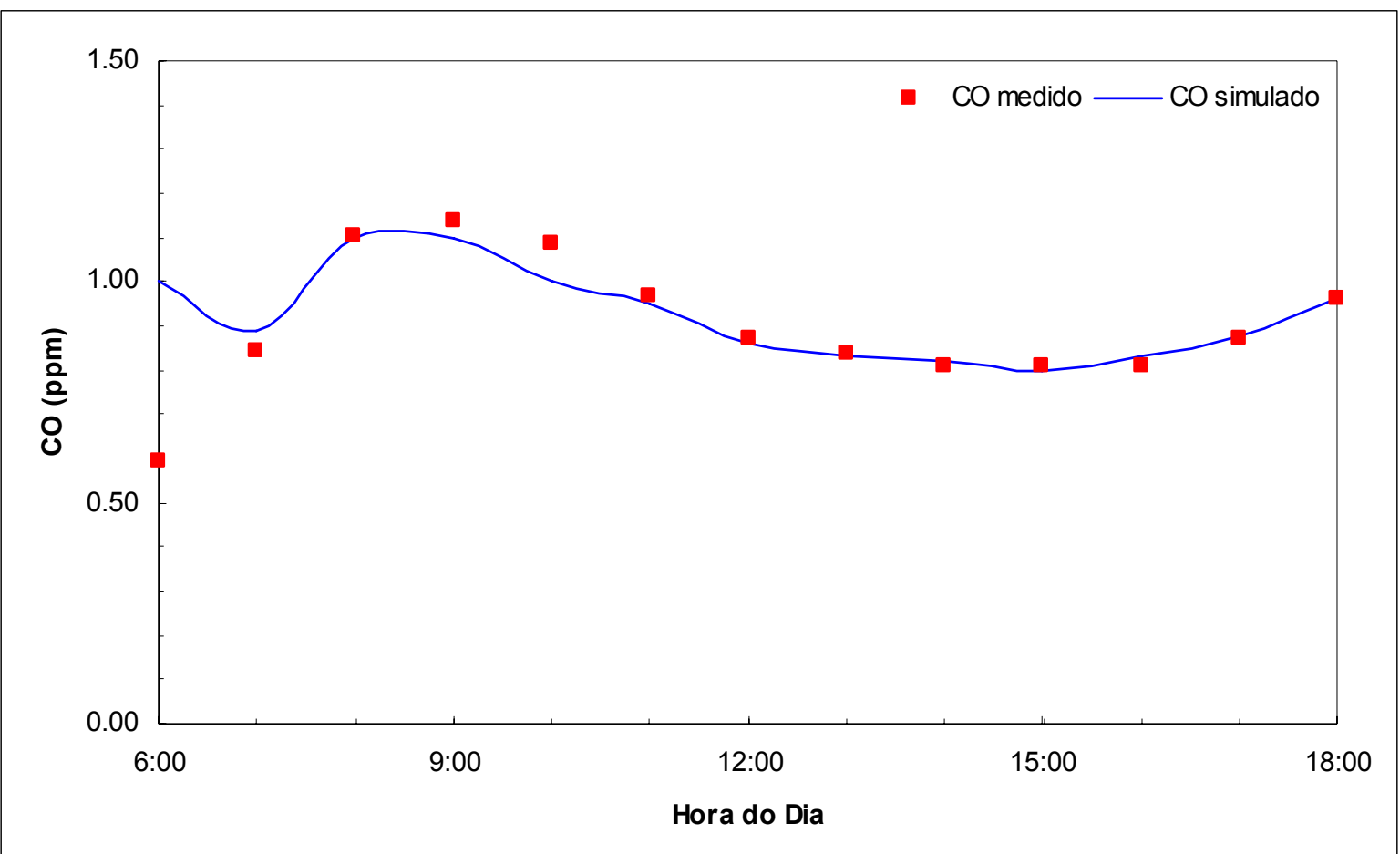

Figura 4.19 - Comparação dos valores simulados para o caso base com os valores médios obtidos para a concentração de CO na primavera de 2006 na Estação Pinheiros.

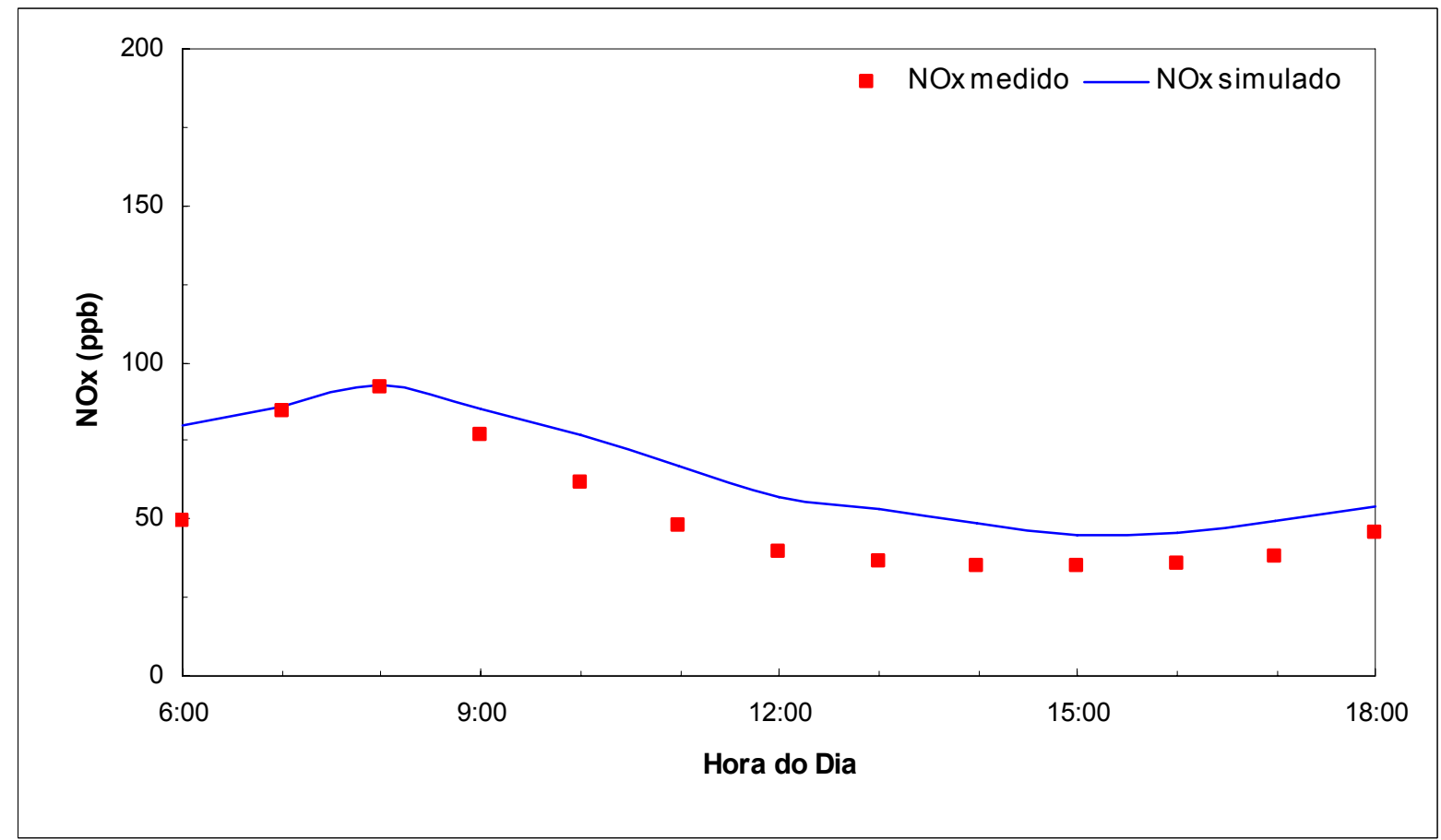

Figura 4.20 - Comparação dos valores simulados para o caso base com os valores médios obtidos para a concentração de $\mathrm{NO}_{x}$ na primavera de 2006 na Estação Pinheiros. 


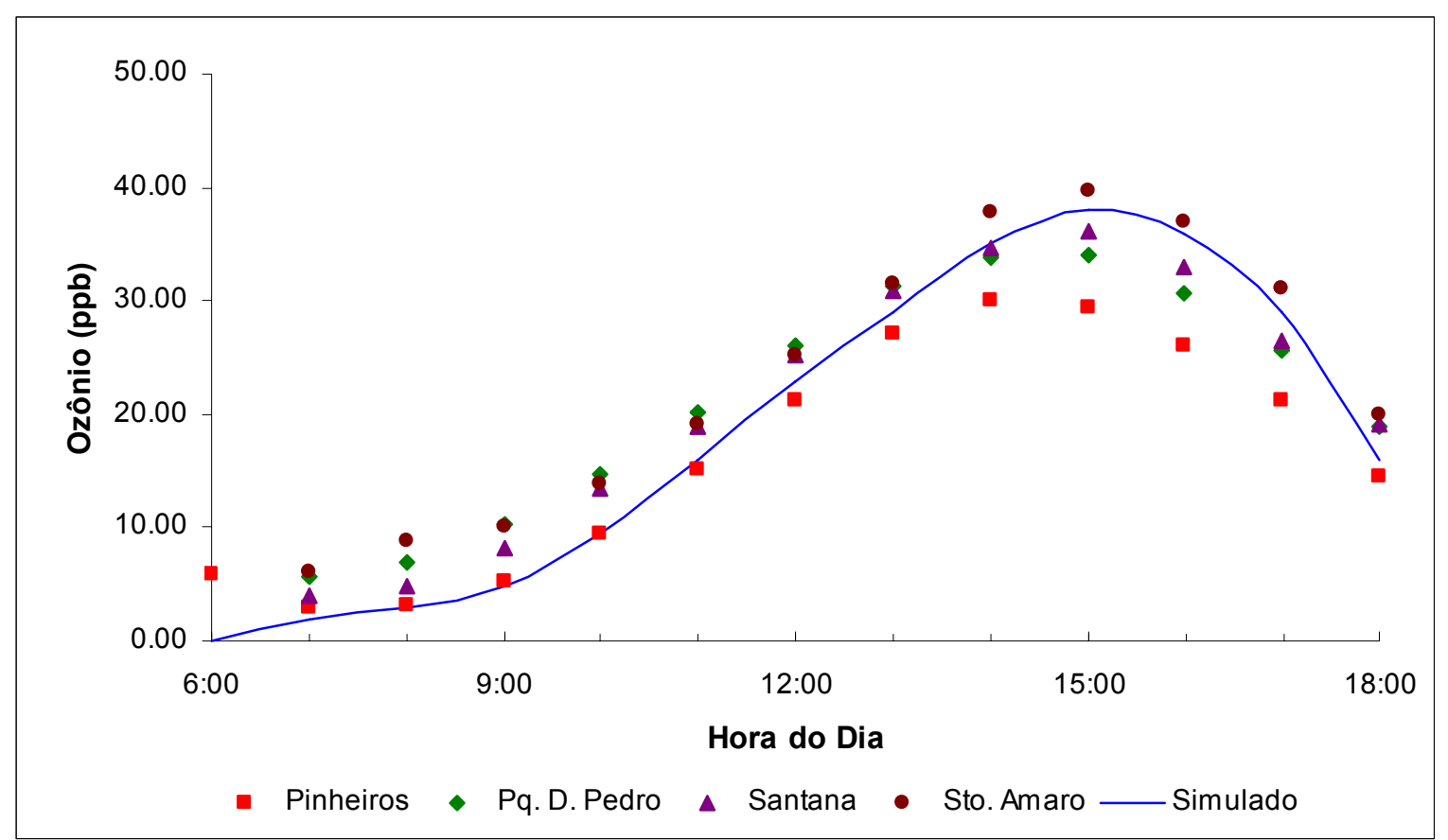

Figura 4.21 - Comparação dos valores simulados para o caso base com os valores médios obtidos para a concentração de $\mathrm{O}_{3}$ na primavera de 2006 para 4 estações da RMSP.

\section{3 - Simulações}

Para todos os casos base montados foram determinadas escalas de reatividade incremental, conforme metodologia descrita anteriormente. Foram realizadas também simulações para se verificar se reduções nas emissões totais de COVs e/ou de $\mathrm{NO}_{x}$ seriam eficazes para a diminuição do ozônio. Nestas simulações as emissões horárias de COV e $\mathrm{NO}_{\mathrm{x}}$ foram diminuídas em 5, 10, 20 e $30 \%$ independe e simultaneamente. Com os dados de saída do simulador foram construídos gráficos de isopletas a fim de se entender melhor a formação de ozônio na cidade de São Paulo e determinar se essa formação é controlada pelos COVs ou pelos $\mathrm{NO}_{\mathrm{x}}$. 


\section{5 - Resultados e Discussões}

\section{1 - Simulações de redução nas emissões}

A fim de se verificar a eficácia na redução de ozônio pelas reduções das emissões totais de COVs e/ou de $\mathrm{NO}_{\mathrm{x}}$ foram realizadas simulações nas quais estes poluentes tiveram suas emissões horárias diminuídas em 5, 10, 20 e 30\% independente e simultaneamente. Os resultados destas simulações podem ser visualizados nas Tabelas 5.1, 5.2, 5.3, 5.4 e 5.5 .

Tabela 5.1 - Variação do ozônio em função da diminuição das emissões horárias de COVs totais e $\mathrm{NO}_{x}$ para o caso base verão.

\begin{tabular}{|c|c|c|c|}
\hline & \multicolumn{3}{|c|}{ Variação de $\mathbf{O}_{\mathbf{3}}$ (\%) } \\
\hline Diminuição das emissões & COVs & NO $_{\mathbf{x}}$ & COVs e NO $_{\mathbf{x}}$ \\
\hline $5 \%$ & $-6,17$ & $+7,40$ & $+0,57$ \\
\hline $10 \%$ & $-12,22$ & $+16,01$ & $+1,38$ \\
\hline $20 \%$ & $-23,22$ & $+35,70$ & $+1,73$ \\
\hline $30 \%$ & $-33,14$ & $+61,12$ & $+3,08$ \\
\hline
\end{tabular}

Tabela 5.2 - Variação do ozônio em função da diminuição das emissões horárias de COVs totais e $\mathrm{NO}_{x}$ para o caso base outono.

\begin{tabular}{|c|c|c|c|}
\hline & \multicolumn{3}{|c|}{ Variação de $\mathbf{O}_{\mathbf{3}}(\%)$} \\
\hline Diminuição das emissões & COVs & $\mathbf{N O}_{\mathbf{x}}$ & COVs e NO $\mathbf{x}_{\mathbf{x}}$ \\
\hline $5 \%$ & $-7,18$ & $+6,08$ & $+0,68$ \\
\hline $10 \%$ & $-13,67$ & $+13,07$ & $+1,80$ \\
\hline $20 \%$ & $-25,30$ & $+31,08$ & $+2,65$ \\
\hline $30 \%$ & $-35,80$ & $+50,57$ & $+3,04$ \\
\hline
\end{tabular}

Tabela 5.3 - Variação do ozônio em função da diminuição das emissões horárias de COVs totais e $\mathrm{NO}_{x}$ para o caso base inverno.

\begin{tabular}{|c|c|c|c|}
\hline & \multicolumn{3}{|c|}{ Variação de $\mathbf{O}_{\mathbf{3}}(\%)$} \\
\hline Diminuição das emissões & $\mathbf{C O V s}$ & $\mathbf{N O}_{\mathbf{x}}$ & COVs e NO $_{\mathbf{x}}$ \\
\hline $5 \%$ & $-8,41$ & $+5,85$ & $+0,42$ \\
\hline $10 \%$ & $-16,37$ & $+13,45$ & $+1,74$ \\
\hline $20 \%$ & $-30,61$ & $+27,46$ & $+2,04$ \\
\hline $30 \%$ & $-42,40$ & $+44,58$ & $+2,87$ \\
\hline
\end{tabular}

Tabela 5.4 - Variação do ozônio em função da diminuição das emissões horárias de COVs totais e $\mathrm{NO}_{\mathrm{x}}$ para o caso base primavera.

\begin{tabular}{|c|c|c|c|}
\hline & \multicolumn{3}{|c|}{ Variação de $\mathbf{O}_{\mathbf{3}}(\%)$} \\
\hline Diminuição das emissões & $\mathbf{C O V s}$ & $\mathbf{N O}_{\mathbf{x}}$ & COVs e NO $_{\mathbf{x}}$ \\
\hline $5 \%$ & $-5,72$ & $+7,16$ & $+1,03$ \\
\hline $10 \%$ & $-10,42$ & $+15,49$ & $+2,37$ \\
\hline $20 \%$ & $-21,50$ & $+35,30$ & +5.44 \\
\hline $30 \%$ & $-30,27$ & $+60,51$ & $+8,71$ \\
\hline
\end{tabular}


Tabela 5.5 - Variação do ozônio em função da diminuição das emissões horárias de COVs totais e $\mathrm{NO}_{x}$ para o caso base Faculdade de Saúde Pública.

\begin{tabular}{|c|c|c|c|}
\hline & \multicolumn{3}{|c|}{ Variação de $\mathbf{O}_{\mathbf{3}}(\%)$} \\
\hline Diminuição das emissões & COVs & $\mathbf{N O}_{\mathbf{x}}$ & COVs e NO \\
\hline $5 \%$ & $-6,09$ & $+7,10$ & $+0,38$ \\
\hline $10 \%$ & $-12,00$ & $+15,51$ & $+0,76$ \\
\hline $20 \%$ & $-23,85$ & $+33,88$ & $+0,85$ \\
\hline $30 \%$ & $-32,79$ & $+56,64$ & $+2,10$ \\
\hline
\end{tabular}

Os resultados destas simulações mostram que uma diminuição nas taxas de emissão de $\mathrm{NO}_{x}$ não seria uma estratégia eficaz para a redução dos níveis de ozônio, pelo contrário, esta redução acarretaria numa elevação das concentrações de ozônio. Uma redução de $5 \%$ nas emissões de $\mathrm{NO}_{x}$, representaria um aumento em torno de 6 a $7 \%$ nos níveis de ozônio, dependendo da época do ano.

A diminuição de ambos os precursores simultaneamente também não se mostra uma alternativa eficaz, pois embora a variação do ozônio nestas condições seja pouco significativa, ela também ocorre no sentido do aumento do ozônio. Ao se diminuir as emissões destes dois poluentes em $30 \%$, se verifica um acréscimo na produção de ozônio de cerca de dois por cento nas simulações para a Faculdade de Saúde Pública e um acréscimo que varia de três a nove por cento para as simulações da Cidade Universitária.

Já uma redução nas emissões totais de COVs, se mostra uma alternativa muito interessante, sendo que uma diminuição de $5 \%$ dos COVs totais levaria a uma redução em torno de 6 a $8 \%$ na concentração de ozônio e para se conseguir uma redução entre 30 e 42\% nos níveis de ozônio, em função da época do ano, seria necessária uma diminuição na faixa de $30 \%$ nas taxas de emissão dos covs.

Conforme abordado no Capítulo 1 , em atmosferas com razão COV/NO menor que 5,5 , os $\mathrm{NO}_{\mathrm{x}}$ reagem preferencialmente com os radicais hidroxila, retirando-os do sistema e retardando a formação do $\mathrm{O}_{3}$. Nestas condições, a diminuição das concentrações de $\mathrm{NO}_{x}$ faz aumentar a formação de $\mathrm{O}_{3}$, pois com menos $\mathrm{NO}_{x}$ na atmosfera, os $\mathrm{OH}^{\bullet}$ passam a reagir com os COVs para formar radicais peróxido que irão permitir a formação líquida de $\mathrm{O}_{3}$ através da restauração das moléculas de $\mathrm{NO}_{2}$ na atmosfera. Este fato não seria coerente para explicar os resultados de simulação para a cidade de São Paulo deste trabalho, onde a diminuição das emissões de $\mathrm{NO}_{x}$ resultaram numa elevação nos 
níveis de $\mathrm{O}_{3}$, pois a razão $\mathrm{COV} / \mathrm{NO}_{\mathrm{x}}$ encontrada para esta região é em torno de 11 . No entanto é importante lembrar que esta alta razão $\mathrm{COV} / \mathrm{NO}_{\mathrm{x}}$ se dá principalmente pela alta concentração de etanol, que representa cerca de $70 \%$ do total dos COVs e não é um composto importante na formação de $\mathrm{O}_{3}$. Calculandose a razão COV/NO ${ }_{x}$ sem o etanol, encontraríamos um valor em torno de 3,5 e desta forma, as simulações deste trabalho estariam de acordo com as informações encontradas na literatura.

Os dados de variação percentual do ozônio em função da diminuição das emissões de $\mathrm{NO}_{\mathrm{x}}$ e COVs, para as quatro estações do ano, apresentados anterioromente na forma de tabela, podem ser também observados na Figura 5.1.

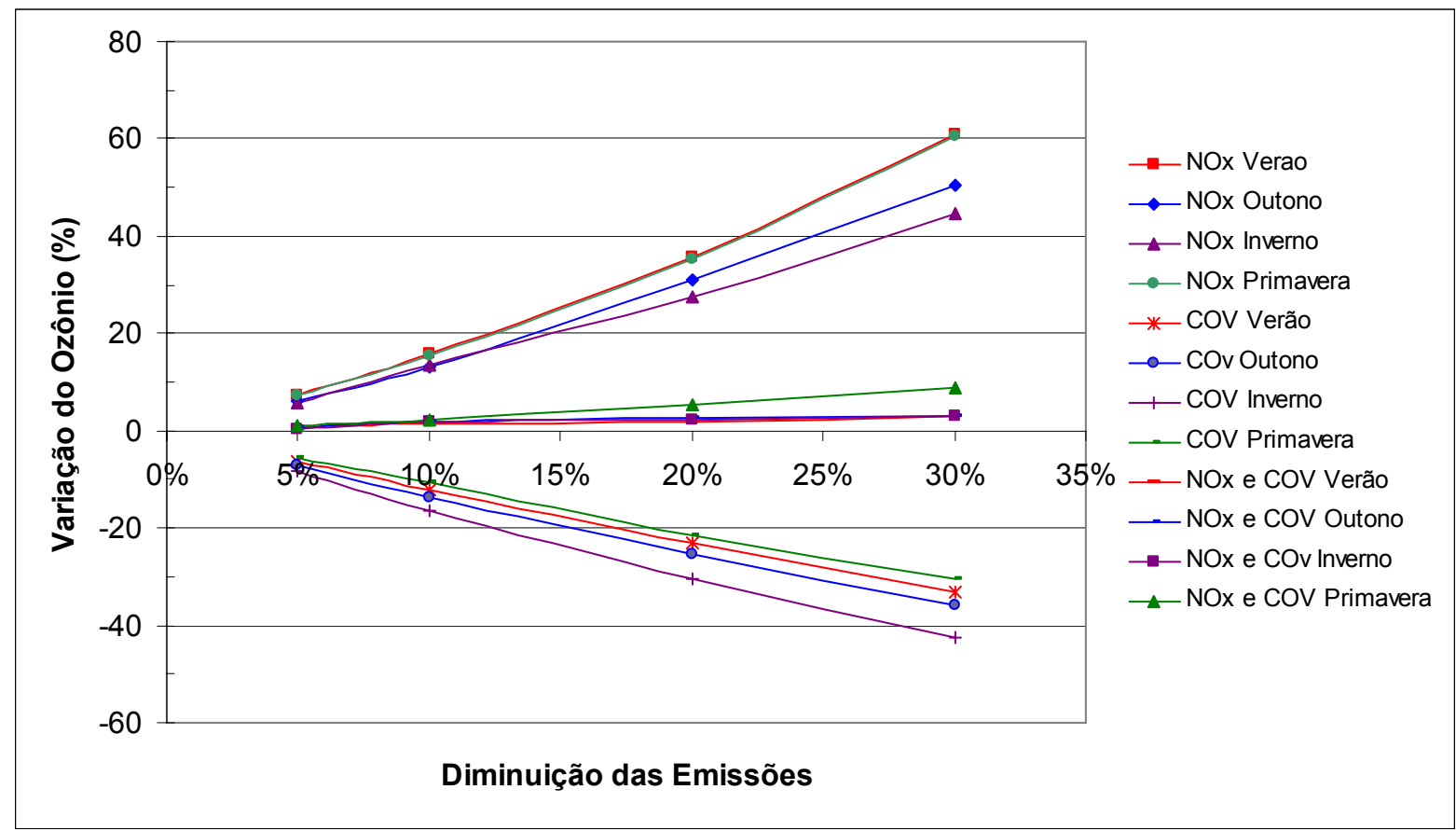

Figura 5.1 - Variação percentual de ozônio em função da diminuição das emissões de $\mathrm{NO}_{\mathrm{x}} \mathrm{e}$ COVs para as quatro estações do ano.

Analisando-se esta figura, observa-se que a redução nas emissões de COVs se mostra mais eficiente para reduzir o $\mathrm{O}_{3}$ no inverno e menos eficiente nas estações primavera e verão. Estes dados sugerem que, na primavera e verão, a formação de $\mathrm{O}_{3}$ é fortemente controlada pela incidência de radiação solar, pois nestas épocas, o ângulo de inclinação da Terra favorece a incidência desta radiação. Além disso, nestas estações a atmosfera se encontra mais limpa, com menor concentração de aerossóis se comparado ao inverno, onde as inversões térmicas concentram estes poluentes, que por sua vez filtram a luz do Sol. Por 
estes motivos, a redução dos COVs na primavera e verão não surte um efeito tão grande na redução do $\mathrm{O}_{3}$. Já no inverno, onde a incidência de radiação solar é menor e a presença de aerossóis na atmosfera maior, esta redução de emissão dos COVs se mostra bem mais significativa para reduzir o $\mathrm{O}_{3}$.

De forma semelhante, quando é analisada a redução das emissões de $\mathrm{NO}_{\mathrm{x}}$, nota-se que ocorre um aumento na produção de $\mathrm{O}_{3}$ mais acentuado no verão e primavera e um aumento menos significativo no inverno. Novamente, os dados sugerem que no inverno a produção de $\mathrm{O}_{3}$ é fortemente limitada pela menor incidência de radiação solar. Embora a retirada dos $\mathrm{NO}_{x}$ do sistema favoreça a formação de $\mathrm{O}_{3}$, o baixo índice de radiação que atinge a Terra nesta estação limita o aumento deste poluente. Já nas estações verão e primavera, onde esta radiação é muito mais abundante, o aumento na produção de $\mathrm{O}_{3}$ é bem mais significativo.

Análises das isopletas geradas a partir dos casos base Faculdade de Saúde Publica e das quatro estações para a Cidade Universitária, que podem ser visualizadas na Figura 5.2, reforçam os resultados acima, mostrando que na região onde se encontra a concentração de ozônio nestas simulações, um aumento dos COVs proporciona um aumento de ozônio e uma diminuição dos COVs, diminuição no ozônio. Já em relação aos $\mathrm{NO}_{x}$ a situação é inversa, o aumento dos $\mathrm{NO}_{\mathrm{x}}$ diminui o ozônio e a diminuição dos mesmos, aumenta os níveis de ozônio. Estes resultados estão de acordo com os apresentados por Andrade et al. (2006), onde foi utilizado o modelo eureliano de qualidade do ar CIT (California Institute of Technology) para simular situações de redução de COVs que resultaram em redução nas concentrações de ozônio. Pode-se observar também que essa tendência para a formação de ozônio é independente da época do ano, e, portanto, da especiação dos COVs, sendo regida pela razão entre os COVs totais e os $\mathrm{NO}_{x}$.

A análise da relação $\mathrm{COV} / \mathrm{NO}_{\mathrm{x}}$ para a RMSP mostra uma razão bastante alta entre estes dois poluentes, em torno de 11. Este fato é bastante curioso, pois difere de outro grande centro urbano brasileiro. Segundo Corrêa (2003), a razão $\mathrm{COV} / \mathrm{NO}_{\mathrm{x}}$ para a cidade do Rio de Janeiro fica em torno de 8. Já a razão encontrada na RMSP se assemelha mais com as encontradas em cidades dos Estados Unidos, que apresentam valores sempre acima de 8. 


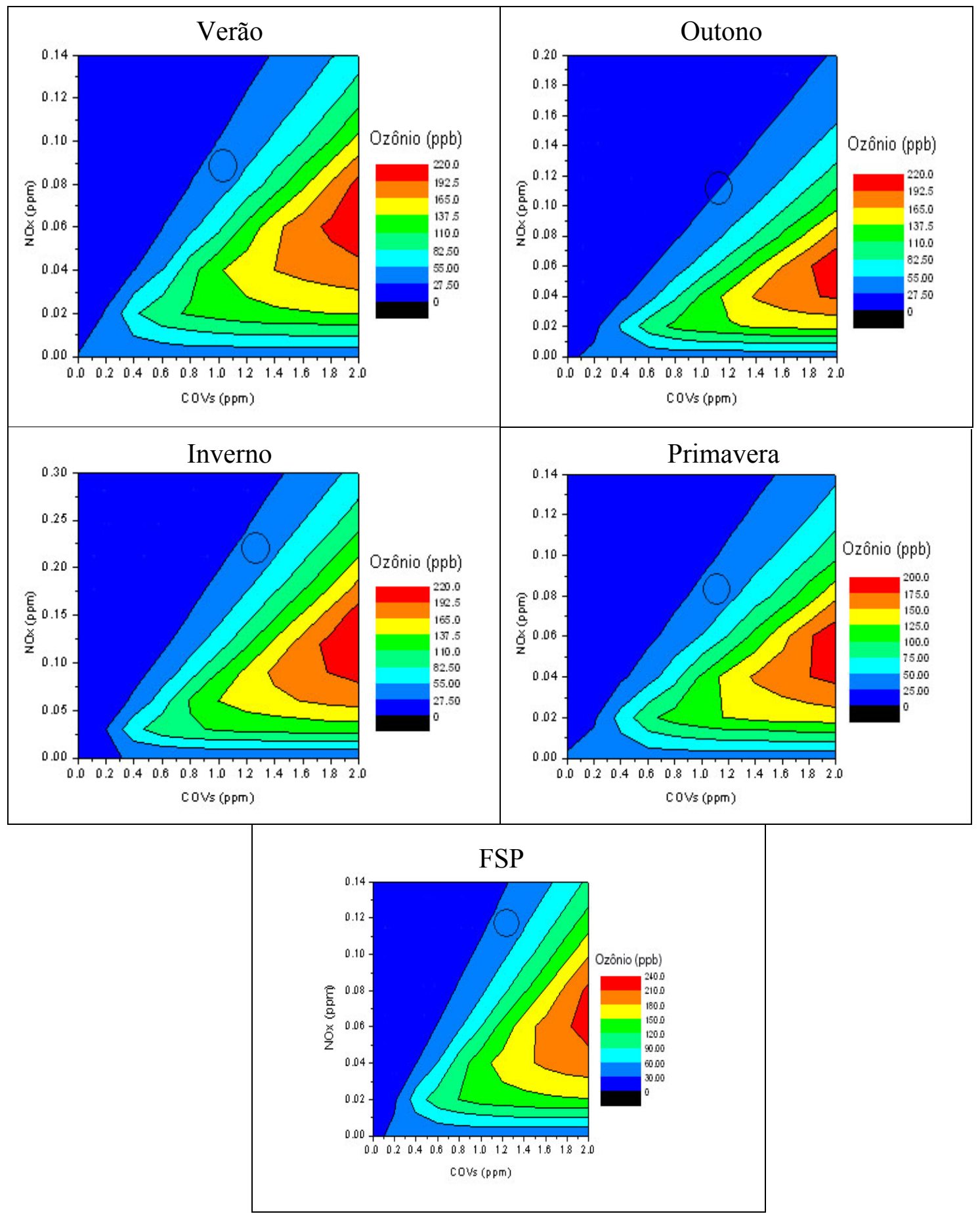

Figura 5.2- Isopletas de ozônio (em ppb) para diversas concentrações de COVs e NOx, para os cinco casos base construídos. A região com um círculo situa a condição atual da cidade de São Paulo para cada caso base.

Esta alta razão $\mathrm{COV} / \mathrm{NO}_{\mathrm{x}}$ encontrada na RMSP sugere uma atmosfera onde a formação de ozônio é controlada pelos COVs. Em ambientes, como o mostrado pelo exemplo ilustrado na Figura 1.6, alterações nas concentrações de COVs não refletem em mudanças significativas nas concentrações de ozônio, no 
entanto mudanças nas concentrações de $\mathrm{NO}_{x}$ propiciam alterações no mesmo sentido nas concentrações de ozônio.

Porém, as análises das isopletas produzidas para a RMSP em conjunto com as simulações de redução de emissões nos mostram que apesar da alta razão $\mathrm{COV} / \mathrm{NO}_{x}$, a atmosfera da RMSP se encontra em uma situação onde alterações nas concentrações de COVs refletem sim uma mudança na concentração de ozônio e alterações nas concentrações de $\mathrm{NO}_{x}$ resultam em alterações nas concentrações de ozônio no sentido inverso, ou seja, a diminuição na concentração de $\mathrm{NO}_{x}$ faz aumentar o ozônio e vice-versa.

Uma possível explicação, tanto para a diferença entre as razões COV/NO encontradas em São Paulo e no Rio de Janeiro, quanto para a diferença na tendência de formação de ozônio observada ao se comparar as isopletas produzidas para a RMSP com as encontradas na literatura, pode ser encontrada no fato da RMSP possuir concentrações elevadíssimas de etanol.

Segundo dados de Corrêa (2003), é encontrada na cidade do Rio de Janeiro uma concentração média de etanol de 19,9 ppbV, dado que diverge muito da concentração média de 414,0 ppbV encontrado para São Paulo por Cólon et al. (2001) e utilizado neste trabalho. Muito provavelmente esta diferença nas medidas de etanol entre essas duas cidades, somada ao fato do etanol representar cerca de $70 \%$ do total dos COVNM, para a RMSP é que faz surgir essa diferença entre as razões $\mathrm{COV} / \mathrm{NO}_{\mathrm{x}}$ para as duas cidades. É importamte lembrar que a metodologia utilizada por Cólon é a de amostragem em canisters e a utilizada por Corrêa é a de amostragem em cartuchos. No entanto, estudos de Corrêa (2003) mostraram boa correlação entre análises de etanol com amostragens em canisters e com cartuchos, tornando difícil uma explicação para os altos valores encontrados por Cólon na RMSP, utilizando canisters.

No que diz respeito à comparação entre as isopletas produzidas neste trabalho e as encontradas na literatura, reside também na alta concentração de etanol para a RMSP uma possível explicação para este fato. Sendo o Brasil, único país do mundo a utilizar etanol como combustível em larga escala, isto explica as altas concentrações deste poluente na RMSP quando comparadas a outros centros urbanos, como Los Angeles com valor médio de 17,7 ppbV (Lonneman,1998) e Osaka com 20,0 (Nguyen, 1999). Esta alta concentração de etanol faz com que a razão $\mathrm{COV} / \mathrm{NO}_{\mathrm{x}}$ fique alta, mas não representa as situações 
de formação de ozônio encontradas em isopletas na literatura, devido ao etanol ser um composto pouco importante na formação de ozônio.

\section{2 - Escalas de reatividade incremental}

A fim de se determinar quais os COVs mais importantes na formação de ozônio e se há diferença sazonal para esses compostos, os COVs de cada caso base foram ordenados em função de suas reatividades, conforme metodologia descrita anteriormente.

\subsection{1 - Escala de reatividade incremental Caso base FSP}

A Figura 5.3 apresenta o gráfico com os trinta principais precursores de ozônio na atmosfera de São Paulo para o caso base da FSP.

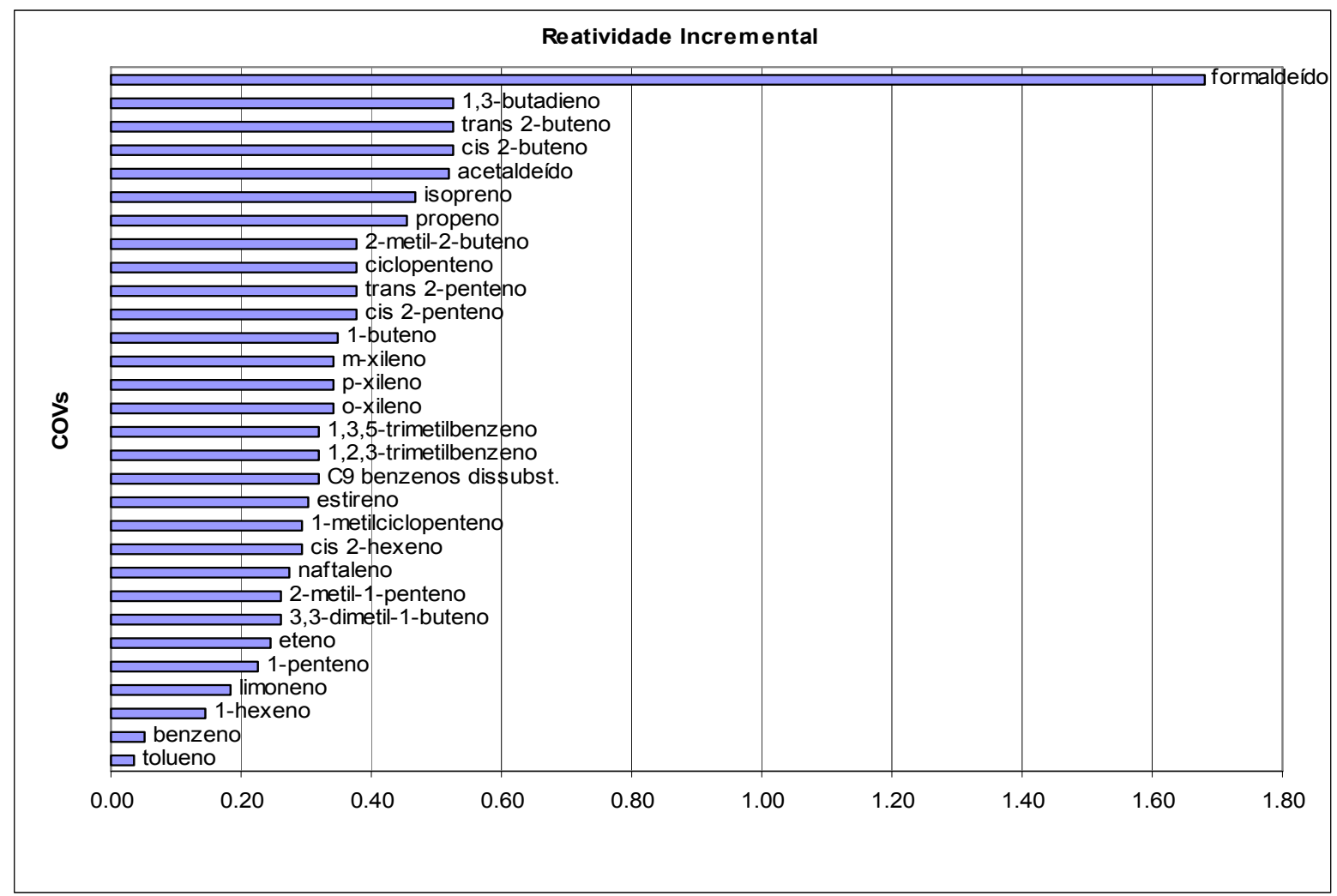

Figura 5.3 - Reatividade Incremental ( $p p b$ de $\mathrm{O}_{3} / \mathrm{pppC}$ de COV) para os 30 principais precursores de ozônio na atmosfera de São Paulo - caso base Faculdade de Saúde Pública.

Observa-se que os cinco principais compostos formadores de ozônio para este caso base são: formaldeído, 1,3-butadieno, trans 2-buteno, cis 2-buteno e acetaldeído, sendo que o formaldeído apresenta um potencial de formação de ozônio mais de três vezes maior que o segundo composto da escala, 
demonstrando a importância do monitoramento constante de compostos oxigenados nesta região.

Apesar da mistura de COVs possuir cerca de $49 \%$ de compostos alcanos, nenhum alcano é encontrado entre os principais precursores de ozônio. Este grupo de compostos só começa a aparecer a partir da $32^{a}$ posição na escala com o cicloexano, sendo este, o único composto com valor de reatividade incremental positiva, todos os demais alcanos apresentam valores negativos. A Tabela 5.6 apresenta a lista completa de todos os COVs encontrados ordenados pelo potencial de formação de ozônio.

Tabela 5.6 - Resultados do cálculo da reatividade incremental (IR) para o caso base Faculdade de Saúde Publica. Valores de IR em ppb de $\mathrm{O}_{3} / \mathrm{ppbC}$ de COV.

\begin{tabular}{|c|c|c|c|c|c|}
\hline Espécie & Conc. (ppbV) & Conc. (ppbC) & IR - & IR+ & IR \\
\hline formaldeído & 5,75 & 5,75 & 1,8182 & 1,5447 & 1,6814 \\
\hline cis 2-buteno & 0,92 & 3,68 & 0,5511 & 0,5028 & 0,5270 \\
\hline trans 2-buteno & 0,97 & 3,88 & 0,5511 & 0,5028 & 0,5270 \\
\hline 1,3-butadieno & 0,81 & 3,24 & 0,5511 & 0,5028 & 0,5270 \\
\hline acetaldeído & 6,01 & 12,01 & 0,5310 & 0,5109 & 0,5209 \\
\hline isopreno & 0,90 & 3,60 & 0,5189 & 0,4183 & 0,4686 \\
\hline propeno & 2,79 & 8,37 & 0,4505 & 0,4586 & 0,4545 \\
\hline cis 2-penteno & 0,68 & 3,40 & 0,3982 & 0,3580 & 0,3781 \\
\hline trans 2-penteno & 1,06 & 5,30 & 0,3982 & 0,3580 & 0,3781 \\
\hline ciclopenteno & 0,64 & 3,20 & 0,3982 & 0,3580 & 0,3781 \\
\hline 2-metil-2-buteno & 1,20 & 6,00 & 0,3982 & 0,3580 & 0,3781 \\
\hline 1-buteno & 3,03 & 12,13 & 0,3459 & 0,3540 & 0,3500 \\
\hline o-xileno & 0,75 & 6,00 & 0,3821 & 0,3017 & 0,3419 \\
\hline p-xileno & 1,60 & 12,81 & 0,3821 & 0,3017 & 0,3419 \\
\hline m-xileno & 0,73 & 5,84 & 0,3821 & 0,3017 & 0,3419 \\
\hline 1,2,3-trimetilbenzeno & 0,42 & 3,78 & 0,3339 & 0,3057 & 0,3198 \\
\hline 1,3,5-trimetilbenzeno & 0,52 & 4,68 & 0,3339 & 0,3057 & 0,3198 \\
\hline C9 benzenos dissubst. & 1,44 & 12,97 & 0,3339 & 0,3057 & 0,3198 \\
\hline estireno & 0,20 & 1,60 & - & 0,3017 & 0,3017 \\
\hline cis 2-hexeno & 0,52 & 3,12 & 0,3258 & 0,2615 & 0,2936 \\
\hline 1-metilciclopenteno & 0,63 & 3,75 & 0,3258 & 0,2615 & 0,2936 \\
\hline naftaleno & 0,38 & 3,80 & 0,2896 & 0,2615 & 0,2755 \\
\hline 3,3-dimetil-1-buteno & 0,40 & 2,40 & - & 0,2615 & 0,2615 \\
\hline 2-metil-1-penteno & 0,14 & 0,84 & - & 0,2615 & 0,2615 \\
\hline eteno & 7,61 & 15,21 & 0,2655 & 0,2253 & 0,2454 \\
\hline 1-penteno & 0,86 & 4,30 & 0,2574 & 0,1931 & 0,2253 \\
\hline limoneno & 0,06 & 0,60 & - & 0,1850 & 0,1850 \\
\hline 1-hexeno & 0,36 & 2,16 & - & 0,1448 & 0,1448 \\
\hline benzeno & 1,14 & 6,84 & 0,0603 & 0,0442 & 0,0523 \\
\hline tolueno & 3,59 & 25,14 & 0,0442 & 0,0282 & 0,0362 \\
\hline etilbenzeno & 1,25 & 10,01 & 0,0282 & 0,0121 & 0,0201 \\
\hline cicloexano & 0,84 & 5,04 & 0,0121 & $-0,0040$ & 0,0040 \\
\hline n-propilbenzeno & 0,24 & 2,16 & - & $-0,0040$ & $-0,0040$ \\
\hline indano & 0,11 & 0,99 & - & $-0,0040$ & $-0,0040$ \\
\hline 2-metilexano & 0,55 & 3,85 & 0,0040 & $-0,0121$ & $-0,0040$ \\
\hline n-heptano & 0,84 & 5,88 & 0,0040 & $-0,0121$ & $-0,0040$ \\
\hline 3-metilexano & 0,64 & 4,48 & 0,0040 & $-0,0121$ & $-0,0040$ \\
\hline metilciclohexano & 0,71 & 4,97 & 0,0040 & $-0,0121$ & $-0,0040$ \\
\hline
\end{tabular}


Tabela 5.6 - Resultados do cálculo da reatividade incremental (IR) para o caso base Faculdade de Saúde Publica. Valores de IR em ppb de $\mathrm{O}_{3} / \mathrm{ppbC}$ de COV (continuação).

\begin{tabular}{|c|c|c|c|c|c|}
\hline 1,3-dimetilciclopentano & 0,20 & 1,40 & - & $-0,0121$ & $-0,0121$ \\
\hline 2,3-dimetilpentano & 0,22 & 1,54 & - & $-0,0121$ & $-0,0121$ \\
\hline etilciclopentano & 0,24 & 1,68 & - & $-0,0121$ & $-0,0121$ \\
\hline C7 cicloalcanos & 0,22 & 1,54 & - & $-0,0121$ & $-0,0121$ \\
\hline 2-metileptano & 0,32 & 2,56 & $-0,0080$ & $-0,0201$ & $-0,0141$ \\
\hline n-octano & 0,40 & 3,20 & $-0,0080$ & $-0,0201$ & $-0,0141$ \\
\hline 2,3,4,-trimetilpentano & 0,06 & 0,48 & - & $-0,0201$ & $-0,0201$ \\
\hline 3-metileptano & 0,18 & 1,44 & - & $-0,0201$ & $-0,0201$ \\
\hline 1,3-dimetilcicloexano & 0,22 & 1,76 & - & $-0,0201$ & $-0,0201$ \\
\hline etilcicloexano & 0,19 & 1,52 & - & $-0,0201$ & $-0,0201$ \\
\hline n-nonano & 0,35 & 3,15 & $-0,0161$ & $-0,0322$ & $-0,0241$ \\
\hline 1,1,3-trimetilcilcoexano & 0,15 & 1,35 & - & $-0,0322$ & $-0,0322$ \\
\hline iso-pentano & 5,83 & 29,17 & $-0,0241$ & $-0,0402$ & $-0,0322$ \\
\hline n-pentano & 2,41 & 12,06 & $-0,0241$ & $-0,0402$ & $-0,0322$ \\
\hline alcanos C5 ramificados & 1,30 & 6,50 & $-0,0241$ & $-0,0402$ & $-0,0322$ \\
\hline ciclopentano & 0,56 & 2,80 & $-0,0241$ & $-0,0402$ & $-0,0322$ \\
\hline n-decano & 0,29 & 2,90 & $-0,0241$ & $-0,0402$ & $-0,0322$ \\
\hline 2-metilpentano & 1,74 & 10,45 & $-0,0322$ & $-0,0483$ & $-0,0402$ \\
\hline n-hexano & 1,10 & 6,60 & $-0,0322$ & $-0,0483$ & $-0,0402$ \\
\hline metilciclopentano & 1,50 & 9,01 & $-0,0322$ & $-0,0483$ & $-0,0402$ \\
\hline 3-metilpentano & 1,26 & 7,56 & $-0,0322$ & $-0,0483$ & $-0,0402$ \\
\hline 2,3-dimetilbutano & 0,58 & 3,48 & $-0,0322$ & $-0,0483$ & $-0,0402$ \\
\hline n-undecano & 0,25 & 2,53 & $-0,0362$ & $-0,0483$ & $-0,0422$ \\
\hline metanol & 10,61 & 10,61 & $-0,0322$ & $-0,0603$ & $-0,0463$ \\
\hline n-butano & 4,19 & 16,77 & $-0,0442$ & $-0,0603$ & $-0,0523$ \\
\hline iso-butano & 2,10 & 8,40 & $-0,0442$ & $-0,0603$ & $-0,0523$ \\
\hline 2,4 dimetilpentano & 0,18 & 1,26 & - & $-0,0563$ & $-0,0563$ \\
\hline n-dodecano & 0,18 & 2,16 & - & $-0,0603$ & $-0,0603$ \\
\hline 2,2,4-trimetilpentano & 0,10 & 0,80 & - & $-0,0644$ & $-0,0644$ \\
\hline propano & 5,67 & 17,02 & $-0,0603$ & $-0,0764$ & $-0,0684$ \\
\hline 2,2-dimetilbutano & 0,09 & 0,54 & - & $-0,0764$ & $-0,0764$ \\
\hline etano & 9,28 & 18,55 & $-0,0724$ & $-0,0845$ & $-0,0784$ \\
\hline etanol & 414,24 & 828,47 & $-0,0764$ & $-0,1046$ & $-0,0905$ \\
\hline
\end{tabular}

\subsection{2 - Escala de reatividade incremental Caso base Cidade Universitária - Verão}

A Figura 5.4 apresenta os 30 principais precursores de ozônio para o caso base da Cidade Universitária no verão.

Pode-se observar que os cinco precursores com maior reatividade para a formação de ozônio são: formaldeído, acetaldeído, propeno, isopreno e trans 2buteno. Neste caso base os aldeídos aparecem com maior destaque ainda que no caso anterior, ocupando a $1^{\mathrm{a}}$ e $2^{\mathrm{a}}$ posições na escala, seguidos pelos alcenos, aromáticos, e por fim, os alcanos. Este último grupo que aqui também se apresenta como grupo majoritário (45\%) começa a surgir na escala a partir da posição 23, e apesar dos baixos valores de reatividade incremental, apenas os últimos seis compostos são negativos. 


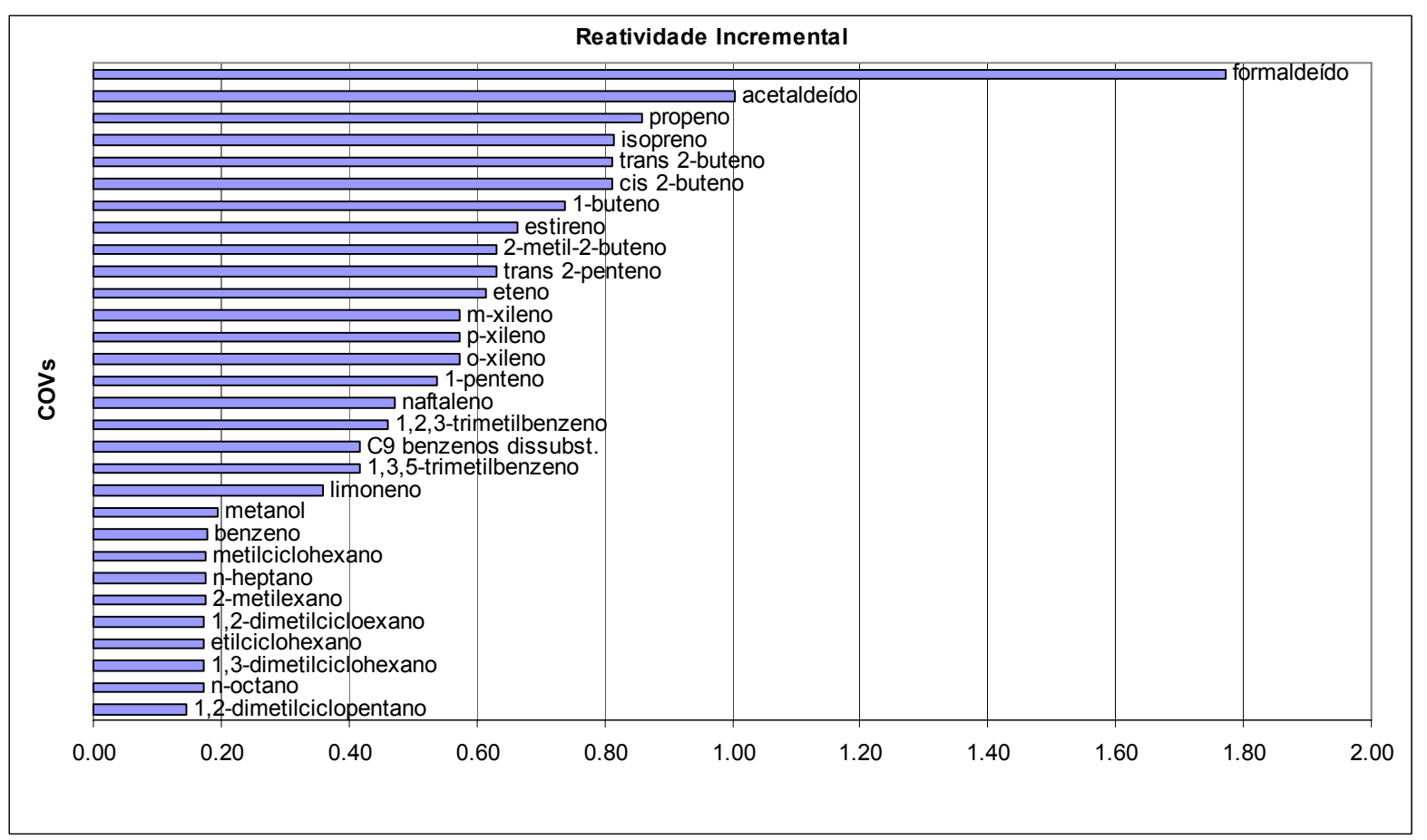

Figura 5.4 - Reatividade Incremental (ppb de $\mathrm{O}_{3} / \mathrm{pppC}$ de COV) para os 30 principais precursores de ozônio na atmosfera de São Paulo - caso base Cidade Universitária - Verão.

\section{$\mathrm{Na}$ Tabela 5.7 pode ser visualizada a lista completa dos COVs encontrados} neste período, ordenados por seus potenciais de formação de ozônio.

Tabela 5.7 - Resultados do cálculo da reatividade incremental (IR) para o caso base verão. Valores de IR em ppb de $\mathrm{O}_{3} / \mathrm{ppbC}$ de COV.

\begin{tabular}{|c|c|c|c|c|c|}
\hline Espécie & Conc. $(\mathbf{p p b V})$ & Conc. $(\mathbf{p p b C})$ & $\mathbf{I R}-$ & $\mathbf{I R +}$ & $\mathbf{I R}$ \\
\hline formaldeído & 5,75 & 5,75 & 1,8455 & 1,7000 & 1,7727 \\
\hline acetaldeído & 6,01 & 12,01 & 0,9591 & 1,0500 & 1,0045 \\
\hline propeno & 2,94 & 8,83 & 0,8409 & 0,8773 & 0,8591 \\
\hline isopreno & 0,83 & 4,15 & 0,7636 & 0,8682 & 0,8159 \\
\hline cis 2-buteno & 0,72 & 2,88 & 0,8545 & 0,7682 & 0,8114 \\
\hline trans 2-buteno & 0,79 & 3,16 & 0,8545 & 0,7682 & 0,8114 \\
\hline 1-buteno & 3,28 & 13,13 & 0,7682 & 0,7091 & 0,7386 \\
\hline estireno & 0,07 & 0,56 & - & 0,6636 & 0,6636 \\
\hline trans 2-penteno & 0,56 & 2,80 & 0,5727 & 0,6909 & 0,6318 \\
\hline 2-metil-2-buteno & 0,83 & 4,15 & 0,5727 & 0,6909 & 0,6318 \\
\hline eteno & 5,17 & 10,33 & 0,6455 & 0,5818 & 0,6136 \\
\hline o-xileno & 0,33 & 2,64 & 0,4818 & 0,6636 & 0,5727 \\
\hline p-xileno & 0,68 & 5,44 & 0,4818 & 0,6636 & 0,5727 \\
\hline m-xileno & 0,28 & 2,24 & 0,4818 & 0,6636 & 0,5727 \\
\hline 1-penteno & 1,12 & 5,60 & 0,4909 & 0,5818 & 0,5364 \\
\hline naftaleno & 0,07 & 0,70 & - & 0,4727 & 0,4727 \\
\hline 1,2,3-trimetilbenzeno & 0,46 & 4,14 & 0,5045 & 0,4182 & 0,4614 \\
\hline 1,3,5-trimetilbenzeno & 0,14 & 1,26 & - & 0,4182 & 0,4182 \\
\hline C9 benzenos dissubst. & 0,17 & 1,53 & - & 0,4182 & 0,4182 \\
\hline limoneno & 0,06 & 0,60 & - & 0,3591 & 0,3591 \\
\hline metanol & 10,6 & 10,60 & 0,1955 & 0,1955 & 0,1955 \\
\hline benzeno & 0,68 & 4,08 & 0,1500 & 0,2091 & 0,1795 \\
\hline 2-metilexano & 0,34 & 2,38 & 0,2045 & 0,1455 & 0,1750 \\
\hline n-heptano & 0,62 & 4,34 & 0,2045 & 0,1455 & 0,1750 \\
\hline metilcicloexano & 0,41 & 2,87 & 0,2045 & 0,1455 & 0,1750 \\
\hline
\end{tabular}


Tabela 5.7 - Resultados do cálculo da reatividade incremental (IR) para o caso base verão. Valores de IR em ppb de $\mathrm{O}_{3} / \mathrm{ppbC}$ de COV (continuação).

\begin{tabular}{|c|c|c|c|c|c|}
\hline n-octano & 0,26 & 2,08 & - & 0,1727 & 0,1727 \\
\hline 1,3-dimetilcicloexano & 0,09 & 0,72 & - & 0,1727 & 0,1727 \\
\hline etilcicloexano & 0,02 & 0,16 & - & 0,1727 & 0,1727 \\
\hline 1,2-dimetilcicloexano & 0,03 & 0,24 & - & 0,1727 & 0,1727 \\
\hline 1,3-dimetilciclopentano & 0,15 & 1,05 & - & 0,1455 & 0,1455 \\
\hline 2,3-dimetilpentano & 0,06 & 0,42 & - & 0,1455 & 0,1455 \\
\hline 3-metilexano & 0,29 & 2,03 & - & 0,1455 & 0,1455 \\
\hline etilciclopentano & 0,04 & 0,28 & - & 0,1455 & 0,1455 \\
\hline 1,2-dimetilciclopentano & 0,24 & 1,68 & - & 0,1455 & 0,1455 \\
\hline tolueno & 2,62 & 18,35 & 0,1636 & 0,0864 & 0,1250 \\
\hline etilbenzeno & 0,61 & 4,88 & 0,0455 & 0,2000 & 0,1227 \\
\hline 1,1,3-trimetilcilcohexano & 0,07 & 0,63 & - & 0,1000 & 0,1000 \\
\hline n-nonano & 0,2 & 1,80 & - & 0,1000 & 0,1000 \\
\hline 1,3,5-trimetilcilcoexano & 0,03 & 0,27 & - & 0,1000 & 0,1000 \\
\hline 1-hexeno & 0,26 & 1,56 & - & 0,0864 & 0,0864 \\
\hline etanol & 414,24 & 828,47 & 0,0273 & 0,0955 & 0,0614 \\
\hline n-decano & 0,13 & 1,30 & - & 0,0591 & 0,0591 \\
\hline n-undecano & 0,09 & 0,99 & - & 0,0591 & 0,0591 \\
\hline iso-pentano & 3,48 & 17,41 & $-0,0091$ & 0,0955 & 0,0432 \\
\hline n-pentano & 2,28 & 11,41 & $-0,0091$ & 0,0955 & 0,0432 \\
\hline alcanos C5 ramificados & 0,70 & 3,50 & $-0,0091$ & 0,0955 & 0,0432 \\
\hline iso-propilbenzeno & 0,26 & 2,34 & 0,1045 & $-0,0636$ & 0,0205 \\
\hline etano & 2,70 & 5,40 & 0,0455 & $-0,0227$ & 0,0114 \\
\hline propano & 3,56 & 10,69 & $-0,0500$ & 0,0591 & 0,0045 \\
\hline iso-butano & 3,78 & 15,13 & $-0,0227$ & $-0,1000$ & $-0,0614$ \\
\hline n-butano & 3,72 & 14,89 & $-0,0227$ & $-0,1000$ & $-0,0614$ \\
\hline 2-metilpentano & 1,78 & 8,89 & $-0,0409$ & $-0,1409$ & $-0,0909$ \\
\hline 3-metilpentano & 1,63 & 8,16 & $-0,0409$ & $-0,1409$ & $-0,0909$ \\
\hline n-hexano & 2,78 & 16,69 & $-0,0409$ & $-0,1409$ & $-0,0909$ \\
\hline metilciclopentano & 0,30 & 1,80 & - & $-0,1409$ & $-0,1409$ \\
\hline & & & & & \\
\hline
\end{tabular}

\subsection{3 - Escala de reatividade incremental Caso base Cidade Universitária - Outono}

A Figura 5.5 apresenta o gráfico com os trinta principais precursores de ozônio na atmosfera de São Paulo para o caso base da Cidade Universitária no outono. Neste caso base, novamente temos formaldeído e acetaldeído ocupando as duas primeiras posições na escala, desta vez, seguidos por isopreno, trans e cis 2-buteno. A exemplo dos casos base anteriores há uma predominância de alcanos, representando quase a metade com COVs, porém os compostos deste grupo não ocupam posições de destaque, sendo o n-decano o primeiro do grupo na escala na $27^{a}$ posição. A Tabela 5.8 apresenta a lista completa de todos os COVs encontrados ordenados pelo potencial de formação de ozônio. 


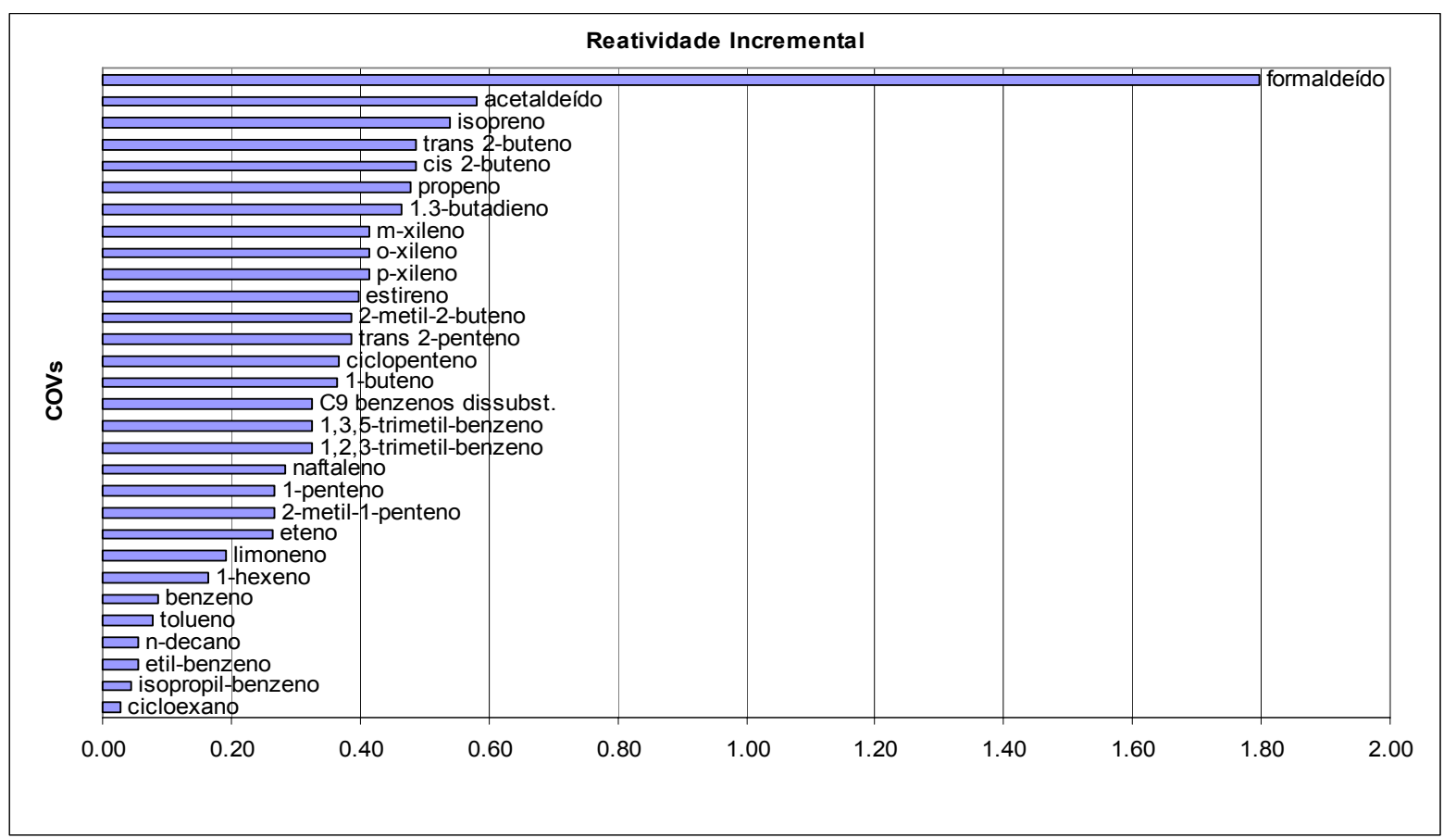

Figura 5.5 - Reatividade Incremental (ppb de $\mathrm{O}_{3} / \mathrm{pppC}$ de COV) para os 30 principais precursores de ozônio na atmosfera de São Paulo - caso base Cidade Universitária - Outono.

Tabela 5.8 - Resultados do cálculo da reatividade incremental (IR) para o caso base outono. Valores de IR em ppb de $\mathrm{O}_{3} / \mathrm{ppbC}$ de COV.

\begin{tabular}{|c|c|c|c|c|c|}
\hline Espécie & Conc. $(\mathbf{p p b V})$ & Conc. $(\mathbf{p p b C})$ & $\mathbf{I R}-$ & $\mathbf{I R +}$ & $\mathbf{I R}$ \\
\hline formaldeído & 5,75 & 5,75 & 1,8349 & 1,7615 & 1,7982 \\
\hline acetaldeído & 6,01 & 12,01 & 0,5963 & 0,5642 & 0,5803 \\
\hline isopreno & 0,54 & 2,70 & 0,5642 & 0,5138 & 0,5390 \\
\hline cis 2-buteno & 0,63 & 2,52 & 0,5092 & 0,4633 & 0,4862 \\
\hline trans 2-buteno & 0,73 & 2,92 & 0,5092 & 0,4633 & 0,4862 \\
\hline propeno & 2,26 & 6,78 & 0,4862 & 0,4679 & 0,4771 \\
\hline 1,3-butadieno & 0,51 & 2,04 & - & 0,4633 & 0,4633 \\
\hline o-xileno & 0,36 & 2,88 & 0,4312 & 0,3991 & 0,4151 \\
\hline m-xileno & 0,34 & 2,72 & 0,4312 & 0,3991 & 0,4151 \\
\hline p-xileno & 0,82 & 6,56 & 0,4312 & 0,3991 & 0,4151 \\
\hline estireno & 0,13 & 1,04 & - & 0,3991 & 0,3991 \\
\hline trans 2-penteno & 0,69 & 3,45 & 0,4083 & 0,3670 & 0,3876 \\
\hline 2-metil-2-buteno & 0,82 & 4,10 & 0,4083 & 0,3670 & 0,3876 \\
\hline ciclopenteno & 0,39 & 1,95 & - & 0,3670 & 0,3670 \\
\hline 1-buteno & 2,39 & 9,57 & 0,3853 & 0,3440 & 0,3647 \\
\hline 1,2,3-trimetilbenzeno & 0,18 & 1,62 & - & 0,3257 & 0,3257 \\
\hline 1,3,5-trimetillbenzeno & 0,05 & 0,45 & - & 0,3257 & 0,3257 \\
\hline C9 benzenos dissubst. & 0,15 & 1,35 & - & 0,3257 & 0,3257 \\
\hline naftaleno & 0,02 & 0,20 & - & 0,2844 & 0,2844 \\
\hline 1-penteno & 0,57 & 2,85 & 0,2661 & 0,2661 & 0,2661 \\
\hline 2-metil-1-penteno & 0,05 & 0,30 & - & 0,2661 & 0,2661 \\
\hline eteno & 5,03 & 10,05 & 0,2890 & 0,2385 & 0,2638 \\
\hline limoneno & 0,03 & 0,30 & - & 0,1927 & 0,1927 \\
\hline 1-hexeno & 0,02 & 0,12 & - & 0,1651 & 0,1651 \\
\hline benzeno & 0,63 & 3,78 & 0,1101 & 0,0596 & 0,0849 \\
\hline tolueno & 2,35 & 16,46 & 0,1147 & 0,0413 & 0,0780 \\
\hline n-decano & 0,12 & 1,20 & - & 0,0550 & 0,0550 \\
\hline etilbenzeno & 0,64 & 5,12 & 0,0826 & 0,0275 & 0,0550 \\
\hline Iso-propilbenzeno & 0,33 & 2,97 & 0,0688 & 0,0183 & 0,0436 \\
\hline cicloexano & 0,63 & 3,78 & 0,0505 & 0,0046 & 0,0275 \\
\hline & & & & & \\
\hline
\end{tabular}


Tabela 5.8 - Resultados do cálculo da reatividade incremental (IR) para o caso base outono. Valores de IR em ppb de $\mathrm{O}_{3} / \mathrm{ppbC}$ de COV (continuação).

\begin{tabular}{|c|c|c|c|c|c|}
\hline n-heptano & 0,47 & 3,29 & 0,0413 & $-0,0046$ & 0,0183 \\
\hline 3-metilexano & 0,33 & 2,31 & 0,0413 & $-0,0046$ & 0,0183 \\
\hline metilcicloexano & 0,39 & 2,73 & 0,0413 & $-0,0046$ & 0,0183 \\
\hline 1,1,3-trimeti-cilcoexano & 0,04 & 0,36 & - & 0,0138 & 0,0138 \\
\hline n-octano & 0,22 & 1,76 & - & 0,0138 & 0,0138 \\
\hline n-nonano & 0,19 & 1,71 & - & 0,0138 & 0,0138 \\
\hline 1,3-dimetilcicloexano & 0,07 & 0,56 & - & 0,0138 & 0,0138 \\
\hline etilcicloexano & 0,05 & 0,40 & - & 0,0138 & 0,0138 \\
\hline C8 cicloalcanos & 0,04 & 0,32 & - & 0,0138 & 0,0138 \\
\hline 2,3-dimetilbutano & 0,15 & 0,90 & - & 0,0046 & 0,0046 \\
\hline iso-pentano & 3,10 & 15,51 & 0,0229 & $-0,0229$ & 0,0000 \\
\hline n-pentano & 1,65 & 8,25 & 0,0229 & $-0,0229$ & 0,0000 \\
\hline alcanos C5 ramificados & 0,75 & 3,75 & 0,0229 & $-0,0229$ & 0,0000 \\
\hline 2-metilpentano & 1,16 & 6,96 & $-0,0138$ & 0,0046 & $-0,0046$ \\
\hline metilciclopentano & 1,00 & 6,00 & $-0,0138$ & 0,0046 & $-0,0046$ \\
\hline 1,3-dimetilciclopentano & 0,12 & 0,84 & - & $-0,0046$ & $-0,0046$ \\
\hline 2-metilexano & 0,12 & 0,84 & - & $-0,0046$ & $-0,0046$ \\
\hline 2,3-dimetilpentano & 0,07 & 0,49 & - & $-0,0046$ & $-0,0046$ \\
\hline etilciclopentano & 0,07 & 0,49 & - & $-0,0046$ & $-0,0046$ \\
\hline C7 cicloalcanos & 0,18 & 1,26 & - & $-0,0046$ & $-0,0046$ \\
\hline 3-metilpentano & 1,29 & 7,74 & $-0,0138$ & 0,0046 & $-0,0046$ \\
\hline n-hexano & 3,11 & 18,67 & $-0,0138$ & 0,0046 & $-0,0046$ \\
\hline propano & 3,92 & 11,77 & 0,0046 & $-0,0505$ & $-0,0229$ \\
\hline metanol & 10,60 & 10,60 & $-0,0183$ & $-0,0321$ & $-0,0252$ \\
\hline etano & 3,18 & 6,36 & $-0,0046$ & $-0,0642$ & $-0,0344$ \\
\hline n-butano & 3,41 & 13,65 & $-0,0275$ & $-0,0413$ & $-0,0344$ \\
\hline iso-butano & 3,87 & 15,49 & $-0,0275$ & $-0,0413$ & $-0,0344$ \\
\hline n-undecano & 0,08 & 0,77 & - & $-0,0367$ & $-0,0367$ \\
\hline etanol & 414,24 & 828,47 & $-0,0138$ & $-0,0688$ & $-0,0413$ \\
\hline & & & & &
\end{tabular}

\subsection{4 - Escala de reatividade incremental Caso base Cidade Universitária - Inverno}

Na Figura 5.6 é possível vizualizar o gráfico com os 30 principais precursores de ozônio para o caso base da Cidade Universitária no inverno. Os cinco primeiros compostos para esta escala são: formaldeído, acetaldeído, isopreno, 1,3-butadieno e trans 2-buteno, sendo que o formaldeído apresenta um potencial de formação de ozônio quase quatro vezes maior que o acetaldeído, segundo composto da escala. A ordem de reatividade por função orgânica também é mantida nesta escala com a diferença de todos os alcanos apresentarem valores negativos. A escala completa para este caso base é apresentada na Tabela 5.9. 


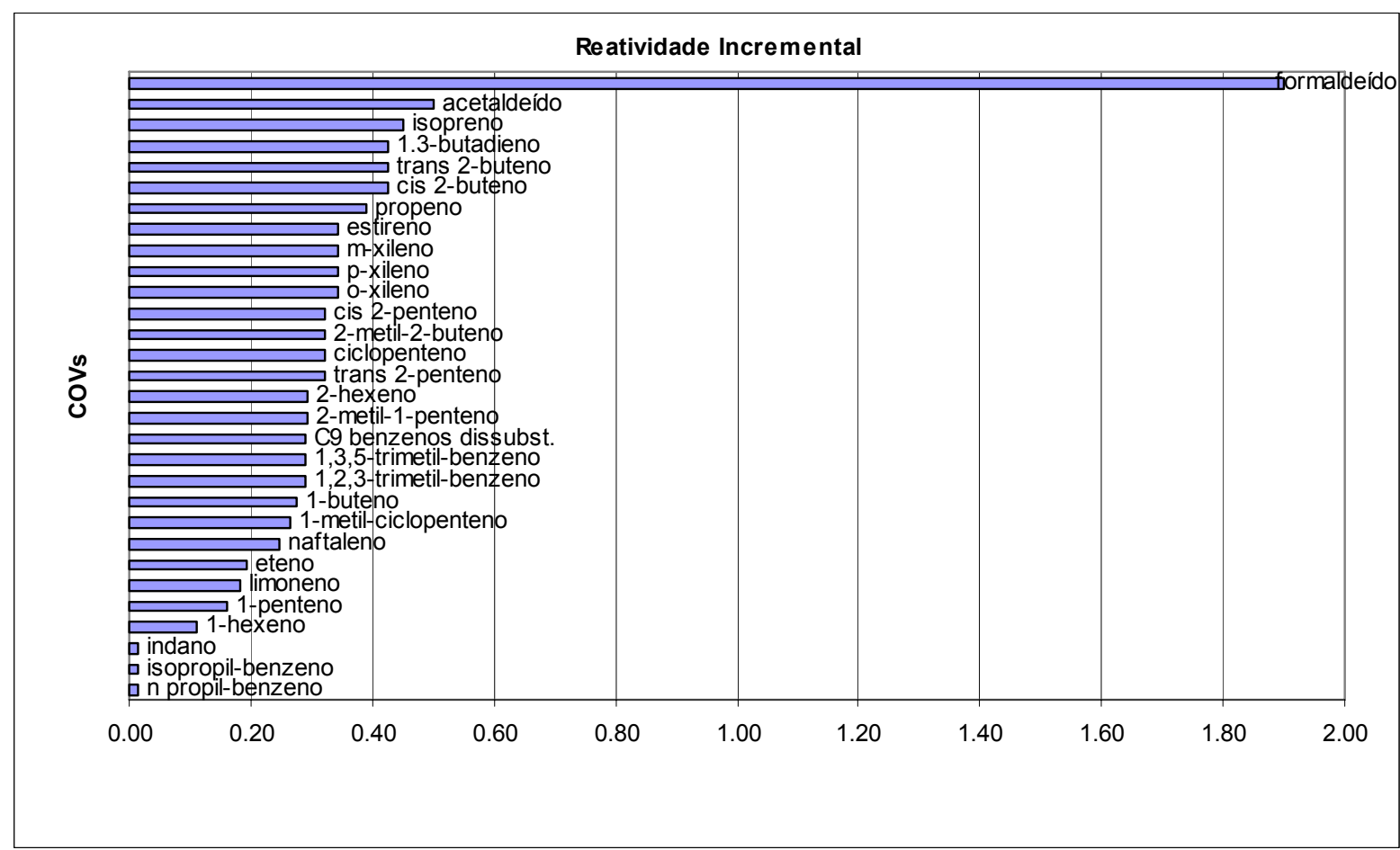

Figura 5.6 - Reatividade Incremental ( $p p b$ de $\mathrm{O}_{3} / \mathrm{pppC}$ de COV) para os 30 principais precursores de ozônio na atmosfera de São Paulo - caso base Cidade Universitária - Inverno.

Tabela 5.9 - Resultados do cálculo da reatividade incremental (IR) para o caso base inverno. Valores de IR em ppb de $\mathrm{O}_{3} / \mathrm{ppbC}$ de COV.

\begin{tabular}{|c|c|c|c|c|c|}
\hline Espécie & Conc. $(\mathbf{p p b V})$ & Conc. $(\mathbf{p p b C})$ & $\mathbf{I R}-$ & $\mathbf{I R +}$ & $\mathbf{I R}$ \\
\hline formaldeído & 5,75 & 5,75 & 1,9614 & 1,8417 & 1,9015 \\
\hline acetaldeído & 6,01 & 12,01 & 0,4440 & 0,5598 & 0,5019 \\
\hline isopreno & 0,62 & 3,10 & 0,3977 & 0,5058 & 0,4517 \\
\hline cis 2-buteno & 1,33 & 5,32 & 0,3707 & 0,4826 & 0,4266 \\
\hline trans 2-buteno & 1,52 & 6,08 & 0,3707 & 0,4826 & 0,4266 \\
\hline 1,3-butadieno & 1,01 & 4,04 & 0,3707 & 0,4826 & 0,4266 \\
\hline propeno & 5,88 & 17,65 & 0,3320 & 0,4479 & 0,3900 \\
\hline o-xileno & 0,83 & 6,64 & 0,2896 & 0,3977 & 0,3436 \\
\hline p-xileno & 1,84 & 14,73 & 0,2896 & 0,3977 & 0,3436 \\
\hline m-xileno & 0,69 & 5,52 & 0,2896 & 0,3977 & 0,3436 \\
\hline estireno & 0,38 & 3,04 & 0,2896 & 0,3977 & 0,3436 \\
\hline trans 2-penteno & 1,12 & 5,60 & 0,2664 & 0,3784 & 0,3224 \\
\hline ciclopenteno & 0,52 & 2,60 & 0,2664 & 0,3784 & 0,3224 \\
\hline 2-metil-2-buteno & 1,18 & 5,90 & 0,2664 & 0,3784 & 0,3224 \\
\hline cis 2-penteno & 0,59 & 2,95 & 0,2664 & 0,3784 & 0,3224 \\
\hline 2-metil-1-penteno & 0,20 & 1,20 & - & 0,2934 & 0,2934 \\
\hline 2-hexeno & 0,34 & 2,04 & - & 0,2934 & 0,2934 \\
\hline 1,2,3-trimetilbenzeno & 0,43 & 3,87 & 0,2394 & 0,3398 & 0,2896 \\
\hline 1,3,5-trimetilbenzeno & 0,57 & 5,13 & 0,2394 & 0,3398 & 0,2896 \\
\hline C9 benzenos dissubst. & 1,57 & 14,14 & 0,2394 & 0,3398 & 0,2896 \\
\hline 1-buteno & 5,25 & 21,01 & 0,2162 & 0,3320 & 0,2741 \\
\hline 1-metilciclopenteno & 0,56 & 3,35 & 0,2355 & 0,2934 & 0,2645 \\
\hline naftaleno & 0,27 & 2,70 & 0,2046 & 0,2896 & 0,2471 \\
\hline eteno & 10,84 & 21,67 & 0,1390 & 0,2510 & 0,1950 \\
\hline limoneno & 0,18 & 1,80 & - & 0,1815 & 0,1815 \\
\hline 1-penteno & 0,74 & 3,70 & 0,1042 & 0,2201 & 0,1622 \\
\hline 1-hexeno & 0,31 & 1,86 & - & 0,1120 & 0,1120 \\
\hline n-propilbenzeno & 0,21 & 1,89 & - & 0,0154 & 0,0154 \\
\hline iso-propilbenzeno & 0,08 & 0,72 & - & 0,0154 & 0,0154 \\
\hline & & & & & \\
\hline
\end{tabular}


Tabela 5.9 - Resultados do cálculo da reatividade incremental (IR) para o caso base inverno. Valores de IR em ppb de $\mathrm{O}_{3} / \mathrm{ppbC}$ de COV (continuação).

\begin{tabular}{|c|c|c|c|c|c|}
\hline indano & 0,13 & 1,17 & - & 0,0154 & 0,0154 \\
\hline benzeno & 1,20 & 7,20 & $-0,0425$ & 0,0618 & 0,0097 \\
\hline tolueno & 4,84 & 33,90 & $-0,0579$ & 0,0463 & $-0,0058$ \\
\hline 1,3-dimetilciclopentano & 0,19 & 1,33 & - & $-0,0154$ & $-0,0154$ \\
\hline 2,3-dimetilpentano & 0,16 & 1,12 & - & $-0,0154$ & $-0,0154$ \\
\hline etilciclopentano & 0,18 & 1,26 & - & $-0,0154$ & $-0,0154$ \\
\hline C7 cicloalcanos & 0,37 & 2,59 & - & $-0,0154$ & $-0,0154$ \\
\hline etilbenzeno & 1,40 & 11,21 & $-0,0734$ & 0,0309 & $-0,0212$ \\
\hline 2,3,4-trimetilpentano & 0,06 & 0,48 & - & $-0,0232$ & $-0,0232$ \\
\hline 2-metileptano & 0,20 & 1,76 & - & $-0,0232$ & $-0,0232$ \\
\hline 3-metileptano & 0,13 & 1,20 & - & $-0,0232$ & $-0,0232$ \\
\hline 1,3-dimetilcicloexano & 0,18 & 1,44 & - & $-0,0232$ & $-0,0232$ \\
\hline etilcicloexano & 0,17 & 1,36 & - & $-0,0232$ & $-0,0232$ \\
\hline C8 cicloalcanos & 0,05 & 0,40 & - & $-0,0232$ & $-0,0232$ \\
\hline ciclopentano & 0,43 & 2,15 & - & $-0,0270$ & $-0,0270$ \\
\hline 1,1,3-trimetilcilcoexano & 0,13 & 1,17 & - & $-0,0270$ & $-0,0270$ \\
\hline 2,3-dimetilbutano & 0,36 & 2,16 & - & $-0,0347$ & $-0,0347$ \\
\hline 2,4-dimetilpentano & 0,03 & 0,21 & - & $-0,0425$ & $-0,0425$ \\
\hline n-undecano & 0,23 & 2,53 & - & $-0,0425$ & $-0,0425$ \\
\hline 2,2,4-trimetilpentano & 0,08 & 0,64 & - & $-0,0502$ & $-0,0502$ \\
\hline n-dodecano & 0,07 & 0,84 & - & $-0,0502$ & $-0,0502$ \\
\hline cicloexano & 0,87 & 5,22 & $-0,0965$ & $-0,0077$ & $-0,0521$ \\
\hline 2-metilexano & 0,53 & 3,71 & $-0,1042$ & $-0,0154$ & $-0,0598$ \\
\hline n-heptano & 0,90 & 6,30 & $-0,1042$ & $-0,0154$ & $-0,0598$ \\
\hline 3-metilexano & 0,55 & 4,41 & $-0,1042$ & $-0,0154$ & $-0,0598$ \\
\hline metilcicloexano & 0,71 & 4,97 & $-0,1042$ & $-0,0154$ & $-0,0598$ \\
\hline n-octano & 0,39 & 3,12 & $-0,0965$ & $-0,0232$ & $-0,0598$ \\
\hline n-nonano & 0,36 & 3,24 & $-0,1158$ & $-0,0270$ & $-0,0714$ \\
\hline n-decano & 0,31 & 3,10 & $-0,1236$ & $-0,0347$ & $-0,0792$ \\
\hline iso-pentano & 5,58 & 27,92 & $-0,1429$ & $-0,0270$ & $-0,0849$ \\
\hline n-pentano & 2,57 & 12,86 & $-0,1429$ & $-0,0270$ & $-0,0849$ \\
\hline alcanos $\mathrm{C} 5$ ramificados & 1,33 & 6,65 & $-0,1429$ & $-0,0270$ & $-0,0849$ \\
\hline metanol & 10,61 & 10,61 & $-0,1429$ & $-0,0347$ & $-0,0888$ \\
\hline 2-metil-pentano & 1,95 & 11,71 & $-0,1467$ & $-0,0347$ & $-0,0907$ \\
\hline 3-metil-pentano & 1,36 & 8,16 & $-0,1467$ & $-0,0347$ & $-0,0907$ \\
\hline n-hexano & 1,36 & 8,16 & $-0,1467$ & $-0,0347$ & $-0,0907$ \\
\hline metilciclopentano & 0,80 & 4,80 & $-0,1467$ & $-0,0347$ & $-0,0907$ \\
\hline n-butano & 6,37 & 25,49 & $-0,1544$ & $-0,0463$ & $-0,1004$ \\
\hline iso-butano & 2,99 & 11,97 & $-0,1544$ & $-0,0463$ & $-0,1004$ \\
\hline propano & 9,15 & 27,44 & $-0,1660$ & $-0,0579$ & $-0,1120$ \\
\hline etanol & 414,24 & 828,47 & $-0,1699$ & $-0,0734$ & $-0,1216$ \\
\hline etano & 6,41 & 12,81 & $-0,1776$ & $-0,0656$ & $-0,1216$ \\
\hline
\end{tabular}

\subsection{5 - Escala de reatividade incremental Caso base Cidade Universitária - Primavera}

A Figura 5.7 mostra o gráfico com os 30 principais precursores de ozônio para o caso base da Cidade Universitária na primavera. 


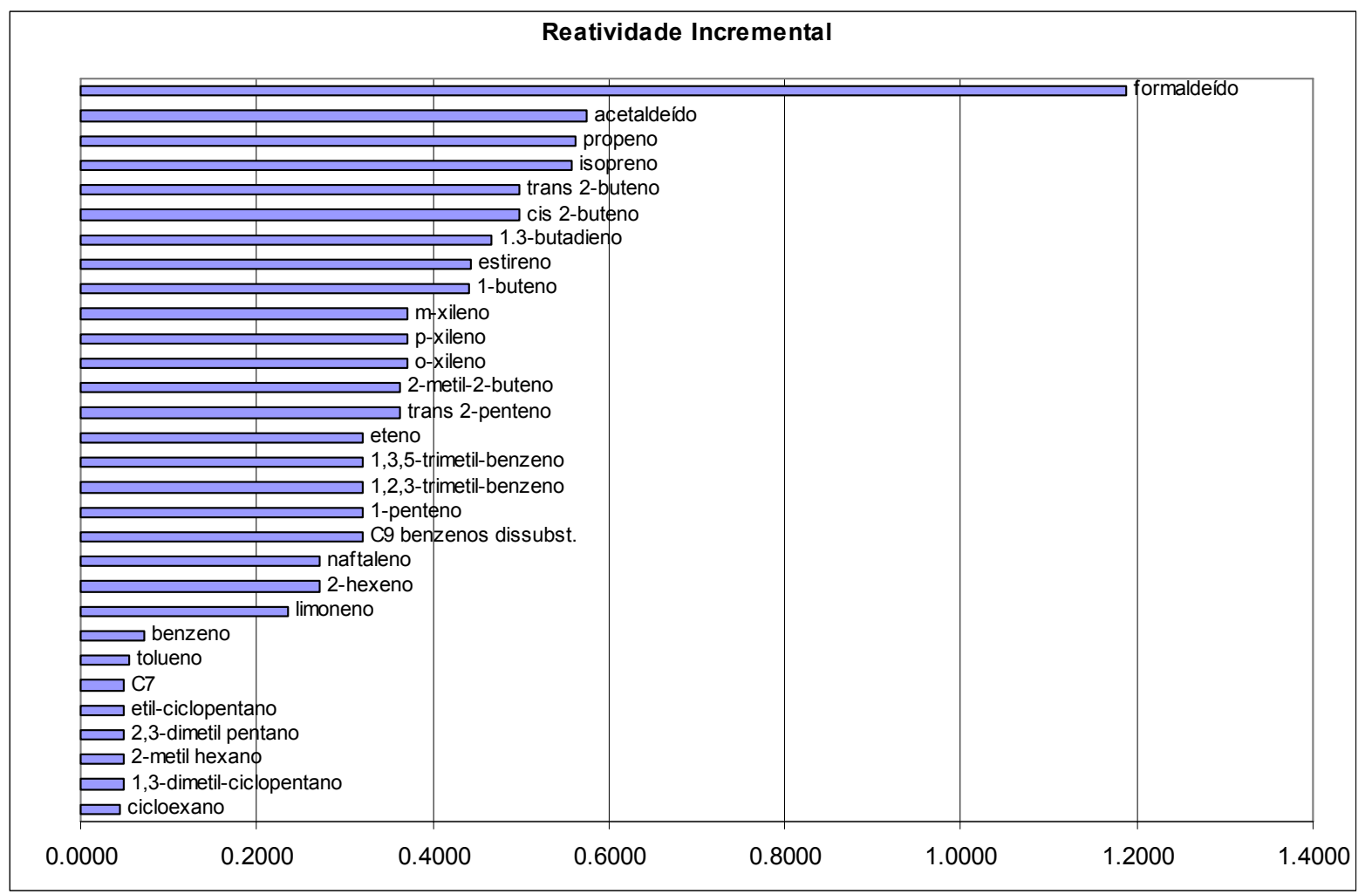

Figura 5.7 - Reatividade Incremental (ppb de $\mathrm{O}_{3} / \mathrm{pppC}$ de COV) para os 30 principais precursores de ozônio na atmosfera de São Paulo - caso base Cidade Universitária - Primavera.

Novamente formaldeído e acetaldeído lideram o ranking dos compostos precursores de ozônio com o primeiro apresnetando um valor de reatividade incremental duas vezes maior que o segundo. Em seguida aparecem: propeno, isopreno e trans 2-buteno. Nesta escala o primeiro alcano a aparecer é o etilciclopentano na $26^{a}$ posição e a partir da $46^{a}$ posição os compostos apresentam valores de IR negativos. A escala completa para este caso base é apresentada na Tabela 5.10.

Tabela 5.10 - Resultados do cálculo da reatividade incremental (IR) para o caso base primavera. Valores de IR em ppb de $\mathrm{O}_{3} / \mathrm{ppbC}$ de COV.

\begin{tabular}{|c|c|c|c|c|c|}
\hline Espécie & Conc. $(\mathbf{p p b V})$ & Conc. $(\mathbf{p p b C})$ & $\mathbf{I R}-$ & $\mathbf{I R +}$ & IR \\
\hline formaldeído & 5,75 & 5,75 & 1,1900 & 1,1855 & 1,1878 \\
\hline acetaldeído & 6,01 & 12,01 & 0,4977 & 0,6516 & 0,5747 \\
\hline propeno & 1,46 & 4,38 & 0,5113 & 0,6109 & 0,5611 \\
\hline isopreno & 0,63 & 3,15 & 0,4796 & 0,6380 & 0,5588 \\
\hline cis 2-buteno & 0,48 & 1,92 & - & 0,4977 & 0,4977 \\
\hline trans 2-buteno & 0,55 & 2,20 & - & 0,4977 & 0,4977 \\
\hline 1,3-butadieno & 2,17 & 8,68 & 0,4344 & 0,4977 & 0,4661 \\
\hline estireno & 0,09 & 0,72 & - & 0,4434 & 0,4434 \\
\hline 1-buteno & 3,43 & 13,73 & 0,4208 & 0,4615 & 0,4412 \\
\hline o-xileno & 0,52 & 4,16 & 0,2986 & 0,4434 & 0,3710 \\
\hline p-xileno & 0,98 & 7,84 & 0,2986 & 0,4434 & 0,3710 \\
\hline m-xileno & 0,42 & 3,36 & 0,2986 & 0,4434 & 0,3710 \\
\hline trans 2-penteno & 0,66 & 3,30 & 0,3439 & 0,3801 & 0,3620 \\
\hline 2-metil-2-buteno & 0,86 & 4,30 & 0,3439 & 0,3801 & 0,3620 \\
\hline
\end{tabular}


Tabela 5.10 - Resultados do cálculo da reatividade incremental (IR) para o caso base primavera. Valores de IR em ppb de $\mathrm{O}_{3} / \mathrm{ppbC}$ de COV (continuação).

\begin{tabular}{|c|c|c|c|c|c|}
\hline 1-penteno & 0,40 & 2,00 & - & 0,3213 & 0,3213 \\
\hline 1,2,3-trimetilbenzeno & 0,48 & 4,32 & 0,2489 & 0,3937 & 0,3213 \\
\hline 1,3,5-trimetilbenzeno & 0,58 & 5,22 & 0,2489 & 0,3937 & 0,3213 \\
\hline eteno & 4,09 & 8,18 & 0,2489 & 0,3937 & 0,3213 \\
\hline C9 benzenos dissubst. & 1,35 & 12,16 & 0,2489 & 0,3937 & 0,3213 \\
\hline 2-hexeno & 0,34 & 2,04 & - & 0,2715 & 0,2715 \\
\hline naftaleno & 0,46 & 4,60 & 0,1991 & 0,3439 & 0,2715 \\
\hline limoneno & 0,09 & 0,90 & - & 0,2353 & 0,2353 \\
\hline benzeno & 0,90 & 5,40 & 0,0588 & 0,0860 & 0,0724 \\
\hline tolueno & 2,27 & 15,90 & 0,0407 & 0,0679 & 0,0543 \\
\hline 1,3-dimetilciclopentano & 0,06 & 0,42 & - & 0,0498 & 0,0498 \\
\hline 2-metilexano & 0,29 & 2,03 & - & 0,0498 & 0,0498 \\
\hline 2,3-dimetilpentano & 0,05 & 0,35 & - & 0,0498 & 0,0498 \\
\hline etilciclopentano & 0,07 & 0,49 & - & 0,0498 & 0,0498 \\
\hline C7 cicloalcanos & 0,17 & 1,19 & - & 0,0498 & 0,0498 \\
\hline cicloexano & 0,57 & 3,42 & 0,0317 & 0,0588 & 0,0452 \\
\hline 2-metileptano & 0,10 & 0,72 & - & 0,0362 & 0,0362 \\
\hline 3-metileptano & 0,03 & 0,24 & - & 0,0362 & 0,0362 \\
\hline n-octano & 0,21 & 1,68 & - & 0,0362 & 0,0362 \\
\hline 1,3-dimetilcicloexano & 0,04 & 0,32 & - & 0,0362 & 0,0362 \\
\hline etilcicloexano & 0,11 & 0,88 & - & 0,0362 & 0,0362 \\
\hline C8 cicloalcanos & 0,01 & 0,08 & - & 0,0362 & 0,0362 \\
\hline n-heptano & 0,48 & 3,36 & 0,0181 & 0,0498 & 0,0339 \\
\hline 3-metilexano & 0,36 & 2,52 & 0,0181 & 0,0498 & 0,0339 \\
\hline metilciclohexano & 0,36 & 2,52 & 0,0181 & 0,0498 & 0,0339 \\
\hline etilbenzeno & 1,01 & 8,08 & 0,0181 & 0,0498 & 0,0339 \\
\hline n-propilbenzeno & 0,22 & 1,98 & - & 0,0317 & 0,0317 \\
\hline iso-propilbenzeno & 0,05 & 0,45 & - & 0,0317 & 0,0317 \\
\hline indano & 0,07 & 0,63 & - & 0,0317 & 0,0317 \\
\hline n-nonano & 0,34 & 3,06 & $-0,0045$ & 0,0498 & 0,0226 \\
\hline 1,1,3-trimetilcilcohexano & 0,11 & 0,99 & - & 0,0226 & 0,0226 \\
\hline n-decano & 0,43 & 4,30 & $-0,0181$ & 0,0090 & $-0,0045$ \\
\hline iso-pentano & 1,24 & 6,20 & $-0,0226$ & 0,0000 & $-0,0113$ \\
\hline n-pentano & 1,52 & 7,60 & $-0,0226$ & 0,0000 & $-0,0113$ \\
\hline alcanos C5 ramificados & 0,72 & 3,60 & $-0,0226$ & 0,0000 & $-0,0113$ \\
\hline n-undecano & 0,50 & 5,50 & $-0,0317$ & 0,0000 & $-0,0158$ \\
\hline n-hexano & 1,96 & 11,77 & $-0,0362$ & $-0,0090$ & $-0,0226$ \\
\hline 3-metil-pentano & 1,22 & 7,32 & $-0,0362$ & $-0,0090$ & $-0,0226$ \\
\hline metil ciclopentano & 1,55 & 9,31 & $-0,0362$ & $-0,0090$ & $-0,0226$ \\
\hline 2,3-dimetilbutano & 0,38 & 2,28 & $-0,0362$ & $-0,0090$ & $-0,0226$ \\
\hline 2,4-dimetilpentano & 0,05 & 0,35 & - & $-0,0226$ & $-0,0226$ \\
\hline n-dodecano & 0,33 & 3,96 & $-0,0407$ & $-0,0136$ & $-0,0271$ \\
\hline metanol & 10,61 & 10,61 & $-0,1041$ & 0,0362 & $-0,0339$ \\
\hline 2,2,4-trimetilpentano & 0,01 & 0,08 & - & $-0,0362$ & $-0,0362$ \\
\hline n-butano & 2,93 & 11,73 & $-0,0588$ & $-0,0317$ & $-0,0452$ \\
\hline iso-butano & 1,48 & 5,92 & $-0,0588$ & $-0,0317$ & $-0,0452$ \\
\hline propano & 3,40 & 10,21 & $-0,0814$ & $-0,0543$ & $-0,0679$ \\
\hline etano & 2,86 & 5,72 & $-0,0950$ & $-0,0679$ & $-0,0814$ \\
\hline etanol & 414,24 & 828,47 & $-0,1629$ & $-0,0226$ & $-0,0928$ \\
\hline
\end{tabular}

É importante lembrar que para os compostos cuja concentração é menor que $0,2 \%$ dos COVs totais não é possível calcular a IR-, pois iria gerar uma 
concentração negativa para os mesmos. Nestes casos foi calculada apenas a IR+, cujo valor corresponde também a IR, já que não é possível calcular a média.

\subsection{6 - Comparação entre as escalas de reatividade incremental}

Analisando-se as tabelas de reatividade incremental nota-se uma grande ocorrência de alcanos com valores negativos, ou seja, um acréscimo na concentração destes compostos implicaria na redução das concentrações de ozônio na cidade de São Paulo. Isto ocorre pelo fato destes compostos serem saturados e, portanto, pouco reativos. O entendimento do mecanismo SAPRC faz supor que essa diminuição nos níveis de ozônio ocorre não pelo fato dos alcanos interferirem na produção deste poluente, mas sim pelo fato de que um aumento na concentração de um composto faz diminuir a fração relativa aos grupos mais reativos e esta diminuição é que leva à queda nas concentrações de ozônio. O mesmo ocorre com o etanol, composto muito abundante na atmosfera da RMSP, porém de pouca importância para a formação de ozônio dentro do mecanismo.

Essa pouca importância do etanol se dá um função do mecanismo só possuir uma das quatro reações importantes para este poluente. $O$ etanol possui quatro vias de reação na atmosfera: com o radical hidroxila, radical hidroperóxido, com o nitrito e a reação fotoquímica. Destas, somente a constante de velocidade da reação com o radical hidroxila é conhecida, e portanto, esta é a única reação do etanol dentro do mecanismo. Comparando-se as constantes de velocidade que podem ser consultas no Anexo B (Modelo Químico SAPRC) - do formaldeído, principal composto formador de ozônio para todos os casos base deste trabalho, com a do etanol, nota-se que a do etanol é apenas cerca de um terço menor que a do formaldeído, e conseqüentemente, se o mecanismo fosse implementado com as demais reações para o etanol, a importância deste composto na formação do ozônio tenderia a aumentar.

A análise das tabelas leva a perceber também que dentre os compostos com menores valores de IR, não há muita variação ao se comparar as quatro estações do ano, com a diferença da estação verão apresentar poucos alcanos com valores negativos. De qualquer forma esses alcanos apresentam valores muito próximos de zero, tendo pouca importância na produção de ozônio. Para as 
outras três estações, o etanol e os alcanos com até quatro carbonos: etano, propano, n-butano e iso-butano sempre apresentam valores negativos.

No que diz respeito aos principais precursores de ozônio para a RMSP, ao se comparar as escalas para as quatro estações do ano, percebe-se que de forma geral, estas escalas seguem a seguinte seqüência: aldeídos, alcenos, aromáticos, em seguida intercalam-se outros alcenos e aromáticos menos reativos, e por fim, os alcanos. A tabela 5.11 apresenta quais são os alcenos e aromáticos considerados por este trabalho como mais ou menos reativos. Existe uma pequena variação com relação aos compostos que representam estes grupos em função da diferença na especiação e concentração dos COVs nas diferentes estações. Por exemplo, na primavera, outono e inverno, o composto 1,3-butadieno se encontra entre os alcenos mais reativos e no verão este composto não aparece na escala, pois não foi encontrado na atmosfera durante toda a estação.

Tabela 5.11 - Especificação dos alcenos e aromáticos mais e menos reativos segundo simulações deste trabalho.

\begin{tabular}{|c|c|c|c|}
\hline \multicolumn{2}{|c|}{ Alcenos } & \multicolumn{2}{c|}{ Aromáticos } \\
\hline Mais Reativos & Menos Reativos & Mais Reativos & Menos Reativos \\
\hline propeno & eteno & o-xileno & benzeno \\
\hline isopreno & cis 2-penteno & m-xileno & tolueno \\
\hline cis 2-buteno & trans 2-penteno & p-xileno & etilbenzeno \\
\hline trans 2-buteno & 1-penteno & estireno & 1,2,3-trimetilbenzeno \\
\hline 1-buteno & 2-metil-2-buteno & - & 1,3,5-trimetilbenzeno \\
\hline 1,3-butadieno & ciclopenteno & - & C9 benzenos dissubst. \\
\hline- & 1-hexeno & - & iso-propilbenzeno \\
\hline- & 2-hexeno & - & n-propilbenzeno \\
\hline- & 2-metil-1-penteno & - & indano \\
\hline- & 1-metilciclopenteno & - & naftaleno \\
\hline
\end{tabular}

Ao analisar somente os dez principais COVs precursores de ozônio para a cidade de São Paulo, observa-se que os compostos formaldeído, acetaldeído, propeno, isopreno, cis e trans 2-buteno são os únicos encontrados nas quatro estações. Os compostos orto, meta e para xilenos também aparecem com bastante freqüência, porém, para o caso base verão, não se encontram entre os dez principais. Isso mostra que há pouca variação entre as escalas de reatividade para as diferentes estações, e quando elas existem, são pequenas: os compostos trocam de posições, mas sem que exista uma diferença muito significativa entre a posição do mesmo composto em diferentes estações. 
É importante atentar para o fato de que o isopreno, composto encontrado sempre entre os cinco principais precursores de ozônio, é emitido na atmosfera tanto por fontes antrópicas, quanto por fontes naturais. Em um estudo de simulação para a cidade de São Paulo, onde foram utilizados valores de emissão de isopreno e monoterpenos obtidos por Zimmerman et al. (1988) para a floresta Amazônica, mostraram que as emissões biogênicas podem contribuir para o aumento da concentração de $\mathrm{O}_{3}$ em torno de $15 \%$ (Martins et al., 2006). O que reforça a necessidade de estudos mais detalhados sobre as parcelas de contribuições antrópicas e naturais nas emissões de isopreno.

Formaldeído, acetaldeído, propeno, isopreno, cis e trans 2-buteno também se encontram entre os dez principais precursores de ozônio na escala de reatividade desenvolvida para o caso base da Faculdade de Saúde Pública. Nesta escala o acetaldeído é encontrado na $5^{\mathrm{a}}$ posição e não na $2^{\mathrm{a}}$ como nos outros casos base.

Comparando-se os valores de reatividade incremental produzidos para a cidade de São Paulo com valores propostos por Carter (Anexo C), nota-se uma diferença muito grande em alguns dos principais compostos da escala, sobretudo para os aldeídos. O formaldeído e acetaldeído, principais compostos formadores de ozônio segundo valores deste trabalho, na escala proposta por Carter não apresentam posições de tanto destaque. O formaldeído irá aparecer somente depois dos principais alcenos e o acetaldeído apenas depois de alguns compostos aromáticos. Esta diferença pode se dar em função da diferença de concentração destes compostos na cidade de São Paulo, em comparação com outras cidades do mundo, pelo fato do uso de álcool etílico como combustível e como aditivo na gasolina, o que não é comum em outros países.

Entre os principais alcenos a diferença é mais amena, porém também existe. Os compostos propeno e isopreno, por exemplo, que nas escalas deste trabalho, se encontram sempre entre os cinco principais precursores, na escala de Carter, se encontram entre os vinte principais. Fato semelhante também ocorre ao se analisar os xilenos. 


\section{6 - CONCLUSÕES}

A análise das escalas de reatividade incremental produzidas neste trabalho, para as quatro estações do ano na cidade de São Paulo, nos mostra que os compostos formaldeído e acetaldeído são os principais precursores de ozônio para esta região, estando no topo de todas as escalas.

Embora os compostos que compõem os grupos variem de uma estação para outra, de forma geral as escalas de reatividade apresentam a seguinte seqüência: [aldeídos] > [alcenos] > [aromáticos] > [alcenos e aromáticos menos reativos] > [alcanos]. O alto potencial de formação de ozônio apresentado pelos aldeídos e alcenos é explicado em função da instabilidade destes compostos por apresentarem ligações insaturadas. Os aromáticos também apresentam alto potencial de formação de ozônio, em função da instabilidade do anel benzênico. Os compostos com pouca importância na formação de ozônio são os alcanos, altamente estáveis por serem saturados.

Os compostos encontrados com mais freqüência entre os dez principais precursores de ozônio na RMSP nas escalas de reatividade das quatro estações do ano são: formaldeído, acetaldeído, propeno, isopreno, cis e trans 2-buteno, logo, são compostos cujas reduções nas emissões constituiriam uma estratégia eficiente para reduzir os níveis de ozônio. Já a redução nas emissões dos alcanos e do etanol teria pouquíssima ou até nenhuma importância para a redução do ozônio.

Estas informações podem ser usadas, por exemplo, para pautar a formulação de novos combustíveis, já que a gasolina utilizada no Brasil apresenta por volta de $45 \%$ em volume de compostos aromáticos e $30 \%$ de olefinas. Estes dados servem também como parâmetro para a elaboração de futuras legislações que venham surgir na tentativa de se diminuir efetivamente os COVs de maior impacto na formação de ozônio, assim como, nos mostra a necessidade de estudos mais freqüentes sobre a concentração de compostos oxigenados na RMSP.

O presente trabalho mostra também a importância de se determinar a escala de reatividade de COVs para a região de interesse, ao invés de simplesmente buscar na literatura escalas desenvolvidas para outras cidades. Fatores como parâmetros meteorológicos, especiação dos COVs, taxas de 
emissão de poluentes e razão $\mathrm{COV} / \mathrm{NO}_{\mathrm{x}}$ podem variar muito de um local para outro e conseqüentemente produzir escalas de reatividade com significativas diferenças.

A análise dos resultados das simulações com redução nas emissões de $\mathrm{NO}_{x}$ e/ou COVs em conjunto com a análise das isopletas produzidas para a RMSP mostra que outra alternativa para reduzir os níveis de ozônio nesta região é a redução das emissões totais de COVs. As simulações indicam que uma redução de $30 \%$ nas emissões de COVs totais resultaria numa redução nas concentrações de ozônio que iria variar entre 30 e 42\%, dependendo da época do ano. Pode-se concluir também que essa estratégia se mostra eficiente independentemente da estação do ano em questão. Por outro lado, diminuir as emissões de $\mathrm{NO}_{x}$ faria aumentar as concentrações de ozônio.

A observação das isopletas ratificam as conclusões acima, mostrando que na região onde se encontra a concentração de ozônio na RMSP, o aumento dos COVs resultaria em aumento do ozônio e diminuição dos COVs, diminuição do ozônio. Para os $\mathrm{NO}_{x}$ ocorre exatamente o inverso, ao aumentar a concentração destes poluentes o ozônio diminui e ao diminuir a concentração dos $\mathrm{NO}_{x}$, o ozônio aumenta.

Pode-se concluir também que a RMSP apresenta uma alta razão COV/NO por volta de 11. No entanto, esta alta razão é proporcionada por uma elevadíssima concentração de um composto pouco reativo para a produção de ozônio, o etanol. Esta alta razão em função da alta concentração de um composto pouco reativo, que comumente não é encontrado em níveis tão altos em atmosferas de outras cidades do mundo, faz surgir um gráfico de isopletas bastante incomum e reforça a necessidade de estudos pontuais com dados da região de interesse para se elaborar estratégias de controle das concentrações de ozônio. 


\section{7 - Referências bibliográficas}

ANDRADE, M.F.; SÁNCHEZ-CCOYLLO, O.R.; YNOUE, R.Y.; MARTINS, L.D. Impacts of ozone precursor limitation and meteorological variables on ozone concentration in São Paulo, Brazil. Atmospheric Environment, v.40. p. S552S562, 2006.

ATKINSON, R. Atmospheric chemistry of VOCs and NOx. Atmospheric Environment, v.34, p. 2063-2101, 2000.

BAIRD, C. Química Ambiental. 2 ed. Porto Alegre: Artmed Editora, 1995.

BRAGA, B.; HESPANHOL, I.; CONEJO, J.G.L.; BARROS, M.T.L.; SPENCER, M.; PORTO, M.; NUCCl, N.; JULIANO, N.; EIGER, S.; Introdução à Engenharia Ambiental, 1ed. São Paulo Prentice Hall, 2002. 305p. ISBN 85-97918-0502.

BRASSEUR, G.P.; ORLANDO, J.J.; TYNDALL, G.S. Atmospheric Chemistry and Global Change. New York: Oxford University Press, Inc, 1999.

CARTER, W.P.L. A detailed mechanism for the gas-phases atmospheric reactions of organic compounds, Atmospheric Environment, v. 24 A, p. 481-518, 1990.

CARTER, W.P.L. Development of ozone reactivity scales for volatile organic compounds, Journal of the Air and Waste Management Association. v. 44. p. 881-899, 1994.

CARTER, W.P.L. VOC Reactivity Data (Excel format) as of February 5, 2003. Disponível em: <http://pah.cert.ucr.edu/ carter/reactdat.htm>. Acesso em 20/agosto/2007.

CETESB, 2006, Relatório de Qualidade do Ar no Estado de São Paulo - 2005, série ISSN 0103-4103.

CETESB, 2006, Relatório Operação Inverno - 2006, série ISSN 0103-4103.

CETESB, 2007, Relatório de Qualidade do Ar no Estado de São Paulo - 2006, série ISSN 0103-4103.

CETESB - COMPANHIA DE TECNOLOGIA DE SANEAMENTO AMBIENTAL. Proconve.

Disponível em: <http://www.cetesb.sp.gov.br/Ar/emissoes/proconve.asp>. Acesso em 20/maio/2007.

COLÓN, M.; PLEIL, J.D.; HARTLAGE, T.A; GUARDANI, M. L.; MARTINS, M.H. Survey of volatile organic compounds associated with automotive emissions in the urban airshed of São Paulo, Brazil. Atmospheric Environment, v.35. p. 40174031, 2001. 
CONAMA - CONSELHO NACIONAL DE MEIO AMBIENTE.

Resolução Nº 003 de 28 de junho de 1990.

Disponível em: <http://www.mma.gov.br/port/conama/res/res90/res0390.html>. Acesso em 16/ago/2007.

CORREAA, S.M. Qualidade do ar na cidade do Rio de Janeiro: sinergia entre simulação e monitoramento. 2003. Tese de Doutorado - Universidade Federal do Rio de Janeiro, Rio de Janeiro.

DARNALL, K.R.; LLOYD, A.C.; WINER, A.M.; PITTS, J.N. Reactivity Scale for Atmospheric Hydrocarbons Based on Reaction with Hydroxyl Radical. Environ. Sci. Technol, v.10, p. 692-696, 1976.

FINLAYSON-PITTS, B.J e PITTS, J.N. Chemistry of the Upper and Lower Atmosphere. San Diego: Academic Press, 2000.

GERY, M.W.; CROUSE, R.R. User's Guide for Executing OZIPR, U.S. Environmental Protection Agency, Research Triangle Park, N.C., EPA9D2196NASA, 1990.

HARE, F.K. Atmospheric Sciences, In: HENRY, J.G. e HEINKE, G.W. (Ed.). Environmental Science and Engineering. New Jersey, USA: Prentice-Hall, 1996. p. 216.

LONNEMAN, W.A. Comparison of hydrocarbon composition in Los Angeles for the year 1968 and 1997. Proceedings of the EPA/AWMA Symposium on Measurement of Toxic and Related Air Pollutants, Cary, NC. Air \& Waste Management Association, p. 356-365, 1998.

MARTINS, L.D.; VASCONCELLOS, P.C.; CARVALHO, L.R.F.; ANDRADE, M.F. Estimated impact of biogenic hydrocarbon emissions on photochemical oxidant formation in São Paulo during two periods of the winters of 1999-2000. Revista Brasileira de Meteorologia, v.21, n.2. p. 190-200, 2006.

NGUYEN, H.T.; FUJIO, Y.; TAKENAKA, N. A new method for determining the concentration of atmospheric alcohols using the nitrite formation reaction. Analytica Chimica Acta, v.402. p. 233-239, 1999.

PRETTO, A. O estudo do comportamento dos gases-traço $\mathrm{O}_{3}, \mathrm{NO}_{\mathbf{x}}, \mathrm{CO}, \mathrm{SO}_{2}$ e de COVs na atmosfera da cidade de São Paulo. São Paulo, 2005. Tese de Doutorado - Instituito de Pesquisas Energéticas e Nucleares, São Paulo.

ROELOFS, G.J.; E LELIEVELD, J. Model study of the influence of crosstropopause $\mathrm{O}_{3}$ transports on tropospheric $\mathrm{O}_{3}$ levels. Tellus, v. B 49, p. 38-55, 1997. 
SEINFELD, J.H. e PANDIS, S.P. Atmospheric Chemistry and Physics: from air pollution to climate change. New York, USA: John Wiley \& Sons Inc., 1998. p. 20-111, 140-152, 234- 330, 766-775, 1098.

STULL, R.B. Mean Boundary Layer Characteristics. In: An Introduction to Boundary Layer Meteorology. Boston, EUA: Kluwer Academic Publishers, 1991. cap.1, p. 2-26.

TONNESEN, G. S. User's Guide for Executing OZIPR Version 2.0. 2000, North Caroline, USEPA.

U.S.EPA, 1999a. Compendium Method TO-14A - Determination of Volatile Organic Compounds (VOCs) in Ambient Air Using Specially Prepared Canisters with Subsequent Analysis by Gas Chromatography, Center for Environmental Research Information, 2 ed., Cincinnati, OH 45268, EPA/625/R-96/010b.

U.S.EPA, 1999b. Compendium Method TO-15A - Determination of Volatile Organic Compounds (VOCs) in Air Collected in Specially-Prepared Canisters And Analyzed by Gas Chromatography/ Mass Spectrometry, Center for Environmental Research Information, 2 ed., Cincinnati, OH 45268, EPA/625/R-96/010b.

U.S.EPA. Compendium Method TO-11A. Determination of Formaldehyde in Ambient Air Using Adsorbent Cartridge Followed by High Performance Liquid Chromatography (HPLC). EPA-625/R-96/010b. Cincinnati, OH: U.S. Environmental Protection Agency, 1997.

VIVANCO, M.G. e ANDRADE, M.F. Validation of the emission inventory in the São Paulo Metropolitan Area of Brazil, based on ambient concentrations ratios of $\mathrm{CO}$, NMOG and $\mathrm{NO}_{\mathrm{x}}$ and on a photochemical model. Atmospheric Environment, v.40. p. 1189-1198, 2006.

WAGNER, J.G.; VAN DYKEN, S.J.; WIERENGA, J.R.; HOTCHKISS, J.A.; HARKEMA, J.R. Ozone Exposure Enhances Endotoxin-Induced Mucous Cell Metaplasia in Rat Pulmonary Airways. Toxicol. Sci., v.74 (2), p. 437-446, 2003.

WUEBBLES, D.J.; BRASSEUR, G.P.; RODHE, H. Changes in the Chemical Composition of the Atmosphere and Potential Impacts, In: Brasseur, G.P.; Prinn, R.G.; Pszenny, A.A.P. (Ed.). Atmospheric Chemistry in a Changing World - An Integration and Synthesis of a Decade of Tropospheric Chemistry Research. Berlin, Germany: Springer, 2003. p. 4-6, 15-16.

ZIMMERMAN, P.R.; GREENBERG, J.P.; WESTERG, C. Measurements of atmospheric hydrocarbons and biogenic emission fluxes in the Amazon boundary layer. J. Geophys. Res., v.93, p.1407-1416, 1988. 
ANEXO A - Dados de entrada do Modelo OZIPR.

\section{ENTRADA.INP}

! Arquivo principal de entrada dos dados

! Dados para FSP

! Modificado por Sergio Machado em Janeiro de 2005

!

@saprc05.mec \{arquivo com o mecanismo\}

@saprc05.zen \{arquivo para calcular as constantes fotoquímicas\}

@boundary.rea \{arquivo com as especiações\}

@deposita.dat \{arquivo com as deposições e transporte\}

@meteorol.dat \{arquivo com a meteorologia\}

@emissoes.dat \{arquivo com as emissões\}

!@ekma.dat \{arquivo para calculos EKMA\}

!@isopleta.dat \{arquivo para calculo da isopleta 11x11\}

!@mir.dat \{arquivo para calculos MIR\}

TITLE > Agosto setembro $2006<$ ate 72 caracteres $\}$

IRR = TIME;

!O comando IRR coloca no arquivo de saida as taxas de reacao horarias, entradas, emissões,

!deposicoes, Conc inicial e final, produzido, consumido de cada especie

!CMP; \{gera um arquivo *.cmp com o mecanismo fotoquimico\}

!PA_OUTPUT; \{gera um arquivo com balancos de O3, O, NOy e radicais\}

MODIFY>

WIDTH $=80 ; \quad$ \{numero de colunas para o arquivo de saida

ACCURACY $=0.003 ; \quad$ toleancia da rotina Gear de integracao

TENSION $=0.1 ; \quad$ \{fator para as funcoes de ajuste hiperbolico $\}$ $<$

PLACE>

CITY = SAO PAULO, SP; $\{$ ate 24 caracteres

LATITUDE $=-23.550$, \{latidude em graus norte

LONGITUDE $=46.630$, \{longitude em graus oeste $\}$

TZone $=3.1$, fuso de Greenwich\}

YEAR $=2006$,

MONTH $=8$,

DIA $=31$

$<$

TIME> 0600, 1800 \{inicio e fim da simulacao\}

$<$

CALCULATE>

VOC $=1.24 ;\{$ conc inicial de $\mathrm{VOC}$ em ppmC $\}$

NOX $=0.12 ;$ \{conc inicial de NOx em ppm\}

$\mathrm{CO}=1.15 ;\{$ conc inicial de $\mathrm{CO}$ em ppm $\}$

FILE[4] = O3, NO, NO2, CO;

!existem diversos outros comandos que podem ser obtidos no manual $<$

END. 
BOUNDARY.REA

\begin{tabular}{|c|c|c|c|c|}
\hline \multicolumn{5}{|c|}{$\begin{array}{l}\text { BOUNDARY > } \\
\text { REACTIVITY = }\end{array}$} \\
\hline \multicolumn{2}{|c|}{ ! especies ou grupo } & fracao $($ soma=1) & aloft VOC & transported VOC \\
\hline ALK1 & $=$ & 0.0149 & 0.000 & 0.016853 \\
\hline ALK2 & $=$ & 0.0137 & 0.000, & 0.023871 \\
\hline ALK3 & $=$ & 0.0207 & 0.000, & 0.026410 \\
\hline ALK4 & $=$ & 0.0722 & 0.000, & 0.033844, \\
\hline ALK5 & $=$ & 0.0430, & 0.000, & 0.017935, \\
\hline OLE1 & $=$ & 0.0217 & 0.000, & 0.010832 \\
\hline OLE2 & $=$ & 0.0312 & 0.000, & 0.011956, \\
\hline ARO1 & $=$ & 0.0363 & 0.000 & 0.012992, \\
\hline ARO2 & $=$ & 0.0414 & 0.000, & 0.016424, \\
\hline $\mathrm{RCHO}$ & $=$ & 0.0000 & 0.000 & 0.002811 \\
\hline MEK & $=$ & 0.0000 & 0.000, & 0.001097, \\
\hline TERP & $=$ & 0.0005 & 0.000, & 0.000697, \\
\hline $\mathrm{HCHO}$ & $=$ & 0.0046, & 0.000, & 0.007923, \\
\hline $\mathrm{MEOH}$ & $=$ & 0.0085 & 0.000, & 0.000000 \\
\hline $\mathrm{CCHO}$ & $=$ & 0.0097 & 0.000, & 0.004773, \\
\hline ETHENE & $=$ & 0.0122 & 0.000, & 0.013463, \\
\hline ETOH & $=$ & 0.6664 & 0.000 & 0.002811 \\
\hline ACET & $=$ & 0.0000, & 0.000, & 0.003086, \\
\hline ISOP & $=$ & 0.0029, & 0.000, & 0.001299; \\
\hline
\end{tabular}




\section{DEPOSITA.DAT}

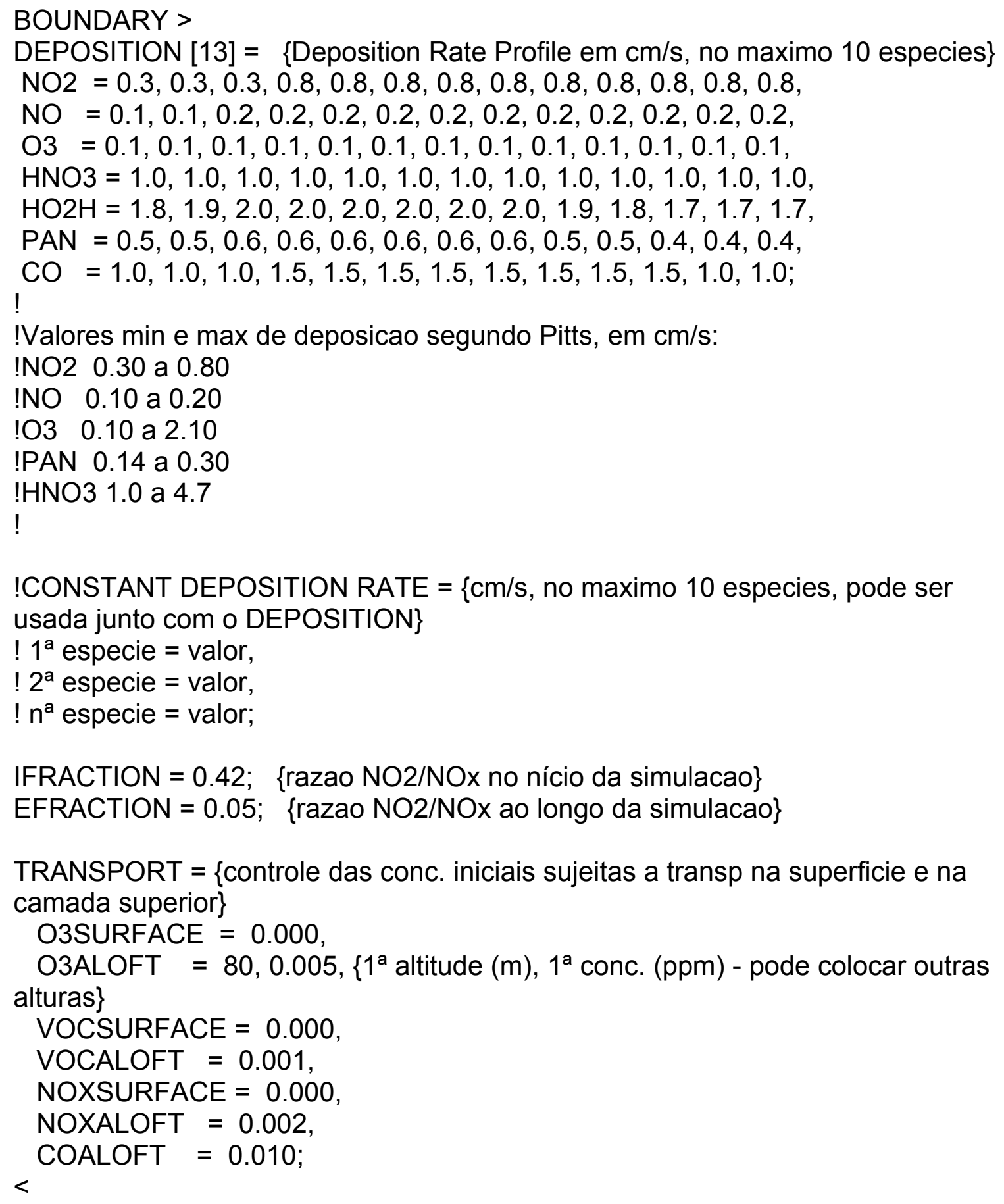

!CONSTANT DEPOSITION RATE $=\{\mathrm{cm} / \mathrm{s}$, no maximo 10 especies, pode ser usada junto com o DEPOSITION $\}$

$! 1^{\text {a }}$ especie $=$ valor

$! 2^{\mathrm{a}}$ especie $=$ valor

$! \mathrm{n}^{\mathrm{a}}$ especie $=$ valor;

IFRACTION = 0.42; $\{$ razao NO2/NOx no nício da simulacao $\}$

EFRACTION $=0.05 ; \quad$ razao NO2/NOx ao longo da simulacao $\}$

TRANSPORT $=$ \{controle das conc. iniciais sujeitas a transp na superficie e na camada superior $\}$

O3SURFACE $=0.000$

O3ALOFT $=80,0.005,\left\{1^{\mathrm{a}}\right.$ altitude $(\mathrm{m}), 1^{\mathrm{a}}$ conc. $(\mathrm{ppm})$ - pode colocar outras alturas\}

VOCSURFACE $=0.000$,

VOCALOFT $=0.001$

NOXSURFACE $=0.000$,

NOXALOFT $=0.002$,

COALOFT $=0.010$

$<$ 


\section{METEOROL.DAT}

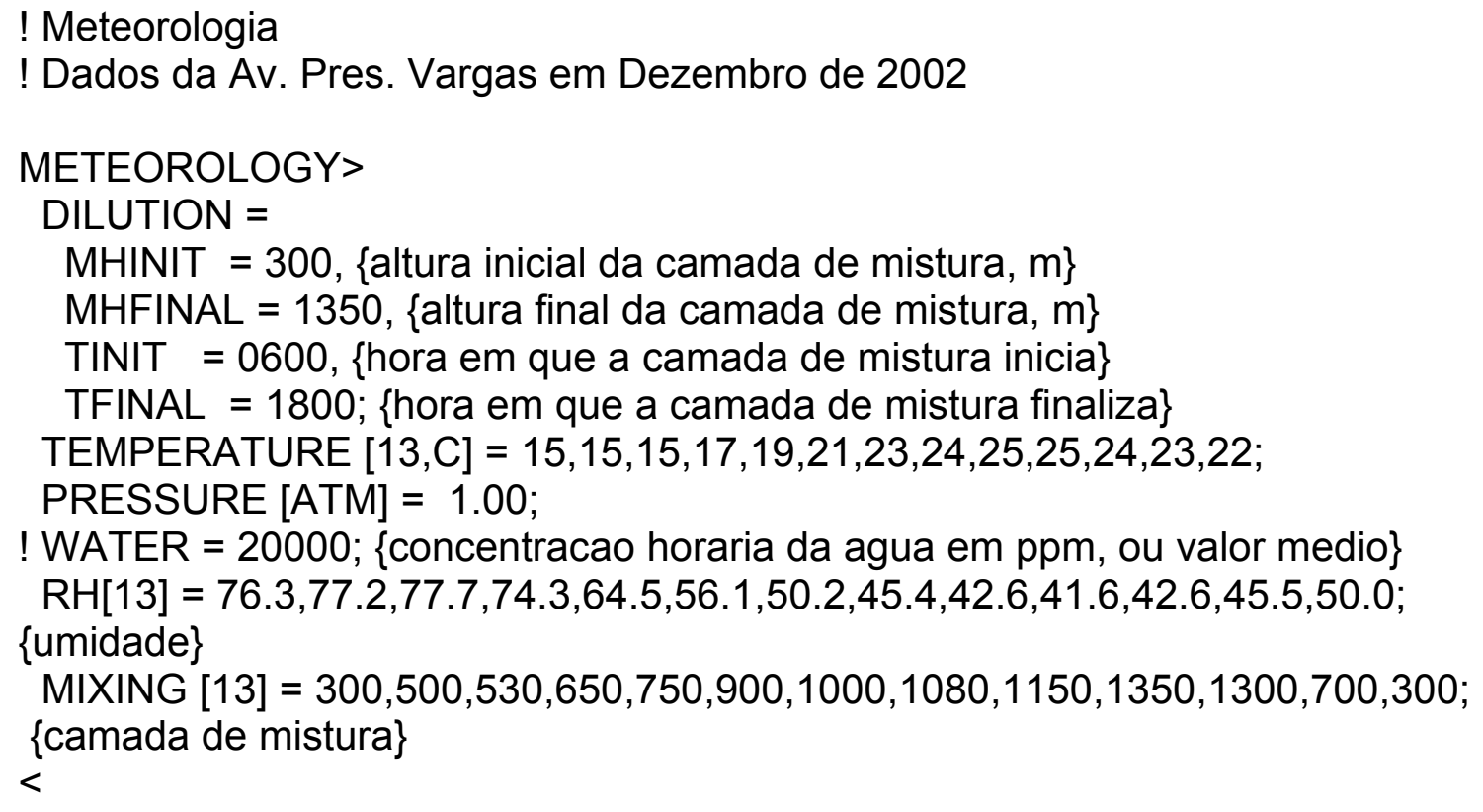




\section{EMISSOES.DAT}

MASS [13] $>\left\{1^{\circ}\right.$ valor $=$ concentracao inicial, demais valores $=$ emissões em $\mathrm{kg} \cdot \mathrm{Km}-2 \cdot \mathrm{h}-1\}$

$\operatorname{VOC}[14.50]=1.24$

$31,105,90,24,24,24,14,19,26,30,31,31,48$, $\mathrm{NOX}[46.00]=0.12$,

$21.0,41.0,25.0,8.0,8.0,8.0,4.0,6.0,8.0,11.0,12.0,12.0,20.0$, CO $[28.00]=1.15$,

$122,380,322,102,102,102,62,82,112,127,132,132,212 ;$

!podem ser colocadas atá 10 especies emissoras. [massa molecular] opcional para VOC, NOX e CO

$<$ 


\section{SAPRC05.ZEN}

ZENI>

! Photo Rates at OZIPR Zenith Angles from HEJs JSPECTRA and FLX2RATE programs.

! SAPRC 1999

! Created by Flux2JTable Version C1.0.02 Built on build on Dec 23 1999 06:57:33

! JRates are for Stdzamed.fts Thu Dec 30 11:55:18 1999

! CSQY Source is c:/backup/Projects/EPA-Mechs/jvalues/UNC/Csqy/ for NO2, NO3, O3, HONO, $\mathrm{H} 2 \mathrm{O} 2, \mathrm{HCHO}$

! CSQY Source is c:/backup/Projects/EPA-Mechs/jvalues/SAPRC/Csqy/ for all other species !

$\begin{array}{lllllllllll}\text { !zenith angles } & 0 & 10 & 20 & 30 & 40 & 50 & 60 & 70 & 78 & 86\end{array}$

L1 \{NO2_to_O3P\}: $\quad 0.5604, \quad 0.5560,0.5421,0.5182,0.4806,0.4211,0.3276, \quad 0.1939, \quad 0.0744,0.0029$;

L2 \{NO3 to NO\}: $\quad 1.05850,1.05480,1.0454,1.0289,1.0039,0.9644,0.8949, \quad 0.7670,0.5831,0.2417$;

L3 \{NO3_to_NO2\}: $\quad 12.8027,12.7536,12.6260,12.4013,12.0585,11.511,10.5474,8.7929,6.352,2.1738$;

L4 \{HONO_to_OH\}: $\quad 0.1076,0.1067,0.1040,0.0991,0.0914,0.0793,0.0603,0.0339,0.0116,0.0003 ;$

L5 $\left\{\mathrm{HONO}^{-}\right.$to $\left.\mathrm{NO} 2\right\}: \quad 0.0139,0.0137,0.0132,0.0124,0.0112,0.0093,0.0066,0.0032,0.0009,0.0001$;

L6 \{O3_to_O1D*1000\}: $3.0544,2.9464,2.6481,2.1872,1.6046,0.9795,0.4305, \quad 0.0999,0.0113,0.0001$;

L7 \{O3_to_O3P*1000\}: $\quad 30.4793,30.3114,29.8659,29.1036,27.9694,26.2878,23.6872,19.6263,14.6048,6.0885$.

L8 $\{\mathrm{H} 2 \mathrm{O} 2$ to_OH*1000\}: $0.4753,0.4665,0.4420,0.4015,0.3432,0.2649, \quad 0.1680,0.0696,0.0158,0.0003$;

L9 $\{\mathrm{COOH}\}:-\quad 0.3479, \quad 0.3419, \quad 0.325, \quad 0.2969, \quad 0.2562, \quad 0.2008,0.1306,0.0567,0.0138,0.0002$;

$\mathrm{L} 10\{\mathrm{C} 2 \mathrm{CHO}\}: \quad 1.2995,1.2666,1.1768,1.0324,0.8346,0.5912,0.3276,0.1087,0.0185,0.0002 ;$

L11 \{HCHO_to_HO2*1000\}: 2.1272, 2.084, 1.9645, 1.7683, 1.4869, 1.1152, $0.6711,0.2501, \quad 0.048,0.0006$;

$\mathrm{L} 12\left\{\mathrm{HCHO}^{-}\right.$to $\left.\mathrm{H}^{*}{ }^{1000}\right\}: 2.9062,2.8659,2.7491,2.5507,2.2509,1.8176,1.2267,0.5528,0.1359,0.0024 ;$

L13 $\left\{\mathrm{CCHO} \mathrm{R}^{*} 1000\right\}$ : $\quad 0.3906,0.3796,0.3496,0.3018,0.2376,0.1613,0.0832,0.0242,0.0034,0.0001$;

L14 $\left.\mathrm{BZCHO}^{*} 1000\right\}: \quad 53.433,52.849, \quad 51.110,48.135,43.539,36.643, \quad 26.577,13.754,4.193, \quad 0.0974$;

L15 \{ACETONE*1000\}: $\quad 0.0400, \quad 0.0387, \quad 0.0351, \quad 0.0294, \quad 0.0222,0.0141, \quad 0.0067, \quad 0.0017,0.0002, \quad 0.0001$;

L16 \{GLY_ABS\}: $\quad 0.1522, \quad 0.1514, \quad 0.149,0.1448, \quad 0.1383, \quad 0.1277,0.1096, \quad 0.0794, \quad 0.0441, \quad 0.0051$;

L17 \{GLYR\}: $\quad 7.6728,7.5844,7.3237,6.8848,6.2268,5.2622, \quad 3.8982, \quad 2.1614,0.7735,0.0251 ;$

L18 $\{$ BACL_ADJ*1000\}: 15.9296, 15.8111, 15.4409, 14.8047, 13.8098, 12.2309, 9.7176, 6.0143, 2.4937, 0.1155 ;

L19 \{ACROLEIN*1000\}: 28.7407, 28.4061, 27.4152, 25.7219, 23.1116, 19.228, 13.652, 6.7735, 1.9289, 0.0405 ;

L20 \{IC3ONO2*1000\}: $\quad 0.2141, \quad 0.2087, \quad 0.194, \quad 0.1704, \quad 0.138, \quad 0.0982, \quad 0.0549, \quad 0.0185, \quad 0.0032, \quad 0.0001$;

L21 $\left\{\mathrm{HNO3}^{*} 1000\right\}: \quad 0.0319, \quad 0.0309, \quad 0.0283, \quad 0.024,0.0185,0.0121, \quad 0.006, \quad 0.0016,0.0002,0.0001$;

L22 $\{$ HO2NO2*1000\}: $\quad 0.4225,0.4125,0.3849,0.3404,0.2787,0.2015, \quad 0.1154,0.0402,0.0072,0.0001$;

L23 \{MEK-UNC*1000\}: $\quad 0.3051, \quad 0.2972, \quad 0.2757, \quad 0.2412, \quad 0.1940, \quad 0.1364, \quad 0.0746, \quad 0.0242, \quad 0.0040, \quad 0.0001$;

!!!L23 \{KETONE\}: $\quad 0.0009, \quad 0.0009, \quad 0.0008,0.0007, \quad 0.0006, \quad 0.0004,0.0002, \quad 0.0001, \quad 0.0001, \quad 0.0001$;

L24 $\{$ MGLY ABS\}: $\quad 172.7295,171.7641,168.9548,164.0819,156.3877,143.8667,122.4825,87.1828,46.7259$,

4.8029;

L25 \{MGLY_ADJ*1000\}: 9.3927, 9.2950, 9.0028, 8.5092, 7.7627, 6.6506, 5.0291, 2.8806, 1.0742, 0.0389 ; 
ANEXO B - Mecanismo Químico SAPRC

\section{Nomenclatura:}

CCHO - acetaldeído

$\mathrm{RCHO}$ - propionaldeído e demais aldeídos superiores agrupados

PAN - nitrato de peroxi acetila

PPN - nitrato de peroxi propionila e análogos

ACET - acetona

MEK - metil etil cetona

$\mathrm{RNO}_{3}$ - nitratos orgânicos agrupados

GLY - glioxal

GPAN - análogos PAN formados do glioxal

MGLY - metil glioxal

PHEN - fenol

CRES - cresol

AFG1 - produtos de fragmentação aromáticos desconhecidos

AFG2 - produtos de fragmentação aromáticos desconhecidos de alquil benzenos

ETHE - eteno

ISOP - isopreno

$\mathrm{OH}$ - radical hidroxila

BZO - radicais fenoxila

M - ar

$\mathrm{RO}_{2}$ - radical alquil peroxila

$\mathrm{RCO}_{3}$ - radical peroxi acetila

$\mathrm{RO}_{2} \mathrm{R}$ - radical que representa a conversão $\mathrm{NO} \rightarrow \mathrm{NO}_{2}$ formando radicais $\mathrm{HO}_{2}$

$\mathrm{RO}_{2} \mathrm{~N}$ - radical que representa o consumo de $\mathrm{NO}$ e a formação de $\mathrm{RNO}_{3}$

$\mathrm{RO}_{2} \mathrm{XN}$ - radical que representa reações terminais de NO

$\mathrm{RO}_{2} \mathrm{NP}$ - radical que representa o consumo de $\mathrm{NO}$ e formação de nitro-aromáticos

$\mathrm{R}_{2} \mathrm{O}_{2}$ - radical que representa uma conversão extra de $\mathrm{NO} \rightarrow \mathrm{NO}_{2}$

Representação das Constantes de Velocidade:

\begin{tabular}{|l|l|}
\hline $\mathrm{k}=\mathrm{A}$ & $\mathrm{A}$ \\
\hline $\mathrm{k}=\mathrm{A} \times(\mathrm{T} / 300)^{\mathrm{B}}$ & $\mathrm{A}^{\wedge} \mathrm{B}$ \\
\hline $\mathrm{k}=\mathrm{A} \times \exp (-\mathrm{C} / \mathrm{T})$ onde $\mathrm{C}=\mathrm{E}_{2} / \mathrm{RT}$ & $\mathrm{A} @ \mathrm{C}$ \\
\hline $\mathrm{k}=\mathrm{A} \times(\mathrm{T} / 300)^{\mathrm{B}} \times \exp (-\mathrm{C} / \mathrm{T})$ & $\mathrm{A}^{\wedge} \mathrm{B} @ \mathrm{C}$ \\
\hline
\end{tabular}


Reações fotolíticas $L n->L$ se refere a uma tabela específica de taxas de reações que são multiplicadas pelo ângulo zênite.

\begin{tabular}{|c|c|}
\hline \multicolumn{2}{|c|}{ Química Inorgânica } \\
\hline $\mathrm{NO}_{2} \rightarrow \mathrm{NO}+\mathrm{O}$ & $0.016667 / \mathrm{L} 1$ \\
\hline $\mathrm{O}+\mathrm{O}_{2}+\mathrm{M} \rightarrow \mathrm{O}_{3}+\mathrm{M}$ & $7.9 \mathrm{E}+4^{\wedge}-2.3$ \\
\hline $\mathrm{NO}+\mathrm{O}_{3} \rightarrow \mathrm{NO}_{2}+\mathrm{O}_{2}$ & $2.0 \mathrm{E}-12 @ 1401$ \\
\hline $\mathrm{O}+\mathrm{NO}_{2} \rightarrow \mathrm{NO}+\mathrm{O}_{2}$ & $6.5 \mathrm{E}-12 @-120$ \\
\hline $\mathrm{O}+\mathrm{NO}_{2} \rightarrow \mathrm{NO}_{3}$ & $9.075 \mathrm{E}-32^{\wedge}-2$ \& $2.2 \mathrm{E}-11$ \\
\hline $\mathrm{NO}+\mathrm{NO}+\mathrm{O}_{2} \rightarrow 2.0^{*} \mathrm{NO}_{2}$ & $1.71 \mathrm{E}-20 @-529$ \\
\hline \multicolumn{2}{|c|}{ Fotólise do Ozônio } \\
\hline $\mathrm{O}_{3} \rightarrow \mathrm{O}+\mathrm{O}_{2}$ & $0.016667 \mathrm{E}-03 / \mathrm{R} 3$ \\
\hline $\mathrm{O}_{3} \rightarrow \mathrm{O}_{1} \mathrm{D}+\mathrm{O}_{2}$ & $0.016667 \mathrm{E}-03 / \mathrm{R} 4$ \\
\hline $\mathrm{O}_{1} \mathrm{D}+\mathrm{M} \rightarrow \mathrm{O}+\mathrm{M}$ & $4.774 E+8 @-126$. \\
\hline $\mathrm{O}_{1} \mathrm{D}+\mathrm{H}_{2} \mathrm{O} \rightarrow 2.0^{*} \mathrm{OH}$ & $2.2 \mathrm{E}-10$ \\
\hline $\mathrm{O}_{3}+\mathrm{OH} \rightarrow \mathrm{HO}_{2}+\mathrm{O}_{2}$ & $1.6 \mathrm{E}-12 @ 942$ \\
\hline $\mathrm{O}_{3}+\mathrm{HO}_{2} \rightarrow \mathrm{OH}+\mathrm{O}_{2}$ & $1.1 \mathrm{E}-14 @ 501$ \\
\hline \multicolumn{2}{|c|}{ Química do $\mathrm{NO}_{3}$} \\
\hline $\mathrm{NO}_{2}+\mathrm{O}_{3} \rightarrow \mathrm{NO}_{3}$ & $1.4 \mathrm{E}-13 @ 2502$ \\
\hline $\mathrm{NO}_{3} \rightarrow \mathrm{NO}$ & $0.016667 /$ R1 \\
\hline $\mathrm{NO}_{3} \rightarrow \mathrm{NO}_{2}+\mathrm{O}$ & $0.016667 / R 2$ \\
\hline $\mathrm{NO}+\mathrm{NO}_{3} \rightarrow 2.0 * \mathrm{NO}_{2}$ & $1.7 E-11 @-150$ \\
\hline $\mathrm{NO}_{2}+\mathrm{NO}_{3} \rightarrow \mathrm{NO}+\mathrm{NO}_{2}+\mathrm{O}_{2}$ & $2.5 \mathrm{E}-14 @ 1229$ \\
\hline $\mathrm{NO}_{2}+\mathrm{NO}_{3} \rightarrow \mathrm{N}_{2} \mathrm{O}_{5}$ & $2.2 \mathrm{E}-30^{\wedge}-4.3 \& 1.5 \mathrm{E}-12^{\wedge}-0.5$ \\
\hline $\mathrm{N}_{2} \mathrm{O}_{5} \rightarrow \mathrm{NO}_{2}+\mathrm{NO}_{3}$ & $1.1 \mathrm{E}-27 @-11202 * \mathrm{E} 9$ \\
\hline $\mathrm{N}_{2} \mathrm{O}_{5}+\mathrm{H}_{2} \mathrm{O} \rightarrow 2.0^{*} \mathrm{HNO}_{3}$ & $1.0 \mathrm{E}-21$ \\
\hline \multicolumn{2}{|c|}{ Química do HONO } \\
\hline $\mathrm{NO}+\mathrm{OH} \rightarrow \mathrm{HONO}$ & $7.04 \mathrm{E}-31^{\wedge}-2.6 \& 1.5 \mathrm{E}-11^{\wedge}-0.5$ \\
\hline $\mathrm{HONO} \rightarrow \mathrm{NO}+\mathrm{OH}$ & $2.85 \mathrm{E}-03 / \mathrm{L} 1$ \\
\hline \multicolumn{2}{|c|}{ Química do $\mathrm{HO}_{2}$} \\
\hline $\mathrm{NO}+\mathrm{HO}_{2} \rightarrow \mathrm{NO}_{2}+\mathrm{OH}$ & $3.7 \mathrm{E}-12 @-242$ \\
\hline $\mathrm{NO}_{2}+\mathrm{HO}_{2} \rightarrow \mathrm{HNO}_{4}$ & $1.8 \mathrm{E}-31^{\wedge}-3.2 \& 4.7 \mathrm{E}-12^{\wedge}-1.4$ \\
\hline $\mathrm{HNO}_{4} \rightarrow \mathrm{NO}_{2}+\mathrm{HO}_{2}$ & $2.1 \mathrm{E}-27 @-10900 * \mathrm{E} 28$ \\
\hline $\mathrm{HNO}_{4}+\mathrm{OH} \rightarrow \mathrm{NO}_{2}$ & $1.3 \mathrm{E}-12 @-380$ \\
\hline \multicolumn{2}{|c|}{ OH ( química de "terminação") } \\
\hline $\mathrm{NO}_{2}+\mathrm{OH} \rightarrow \mathrm{HNO}_{3}$ & $2.6 \mathrm{E}-30^{\wedge}-3.2 \& 2.41 \mathrm{E}-11^{\wedge}-1.3$ \\
\hline
\end{tabular}




\begin{tabular}{|c|c|}
\hline $\mathrm{HNO}_{3}+\mathrm{OH} \rightarrow \mathrm{NO}_{3}$ & 5.45E-15@-832 \\
\hline $\mathrm{HNO}_{3} \rightarrow \mathrm{NO}_{2}+\mathrm{OH}$ & $0.016667 E-03 / R 9$ \\
\hline $\mathrm{OH}+\mathrm{HO}_{2} \rightarrow \mathrm{H}_{2} \mathrm{O}+\mathrm{O}_{2}$ & $4.6 \mathrm{E}-11 @-230$ \\
\hline \multicolumn{2}{|l|}{$\mathrm{HO}_{2}$ (química de "terminação") } \\
\hline $\mathrm{HO}_{2}+\mathrm{HO}_{2} \rightarrow \mathrm{H}_{2} \mathrm{O}_{2}$ & $2.2 \mathrm{E}-13 @-619$ \\
\hline $\mathrm{HO}_{2}+\mathrm{HO}_{2}+\mathrm{M} \rightarrow \mathrm{H}_{2} \mathrm{O}_{2}+\mathrm{M}$ & $4.73 \mathrm{E}-14 @-982$ \\
\hline $\mathrm{O}_{2}+\mathrm{HO}_{2}+\mathrm{H}_{2} \mathrm{O} \rightarrow \mathrm{H}_{2} \mathrm{O}_{2}+\mathrm{H}_{2} \mathrm{O}+\mathrm{O}_{2}$ & $3.1 \mathrm{E}-34 @-2820$ \\
\hline $\mathrm{HO}_{2}+\mathrm{HO}_{2}+\mathrm{H}_{2} \mathrm{O} \rightarrow \mathrm{H}_{2} \mathrm{O}_{2}+\mathrm{H}_{2} \mathrm{O}+\mathrm{O}_{2}$ & $6.60 \mathrm{E}-35$ @ -3182 \\
\hline $\mathrm{NO}_{3}+\mathrm{HO}_{2} \rightarrow \mathrm{HNO}_{3}+\mathrm{O}_{2}$ & $2.20 \mathrm{E}-13 @-619$ \\
\hline $\mathrm{NO}_{3}+\mathrm{HO}_{2}+\mathrm{M} \rightarrow \mathrm{HNO}_{3}+\mathrm{M}+\mathrm{O}_{2}$ & $4.73 \mathrm{E}-14$ @ -982 \\
\hline $\mathrm{O}_{3}+\mathrm{HO}_{2}+\mathrm{H}_{2} \mathrm{O} \rightarrow \mathrm{HNO}_{3}+\mathrm{H}_{2} \mathrm{O}+\mathrm{O}_{2}$ & $3.1 \mathrm{E}-34 @-2818$ \\
\hline $\mathrm{NO}_{3}+\mathrm{HO}_{2}+\mathrm{H}_{2} \mathrm{O} \rightarrow \mathrm{HNO}_{3}+\mathrm{H}_{2} \mathrm{O}+\mathrm{O}_{2}$ & $6.60 \mathrm{E}-35 @-3182$ \\
\hline $\mathrm{H}_{2} \mathrm{O}_{2} \rightarrow 2^{*} \mathrm{OH}$ & $0.016667 \mathrm{E}-03 / \mathrm{R} 6$ \\
\hline $\mathrm{H}_{2} \mathrm{O}_{2}+\mathrm{OH} \rightarrow \mathrm{HO}_{2}+\mathrm{H}_{2} \mathrm{O}$ & $3.3 \mathrm{E}-12 @ 200$ \\
\hline \multicolumn{2}{|l|}{ Química do CO } \\
\hline $\mathrm{CO}+\mathrm{OH} \rightarrow \mathrm{HO}_{2}$ & $2.4 \mathrm{E}-13$ \\
\hline \multicolumn{2}{|c|}{ Fim da química inorgânica (40 reaçôes) } \\
\hline \multicolumn{2}{|l|}{ Química dos Operadores } \\
\hline $\mathrm{RO}_{2} \mathrm{R}+\mathrm{NO} \rightarrow \mathrm{NO}_{2}+\mathrm{HO}_{2}$ & $4.2 \mathrm{E}-12 @-180$ \\
\hline $\mathrm{RO}_{2} \mathrm{R}+\mathrm{HO}_{2} \rightarrow \mathrm{XOOH}$ & $3.40 \mathrm{E}-13 @-800$ \\
\hline $\mathrm{RO}_{2} \mathrm{R}+\mathrm{RO}_{2} \rightarrow 0.5^{*} \mathrm{HO}_{2}+\mathrm{RO}_{2}$ & $1.0 \mathrm{E}-15$ \\
\hline $\mathrm{RO}_{2} \mathrm{R}+\mathrm{CCO}_{3} \rightarrow 0.5^{*} \mathrm{HO}_{2}+0.5^{*} \mathrm{HCHO}+\mathrm{CO}_{2}$ & $1.86 \mathrm{E}-12 @-530$ \\
\hline $\mathrm{RO}_{2} \mathrm{R}+\mathrm{PCO}_{3} \rightarrow 0.5^{*} \mathrm{HO}_{2}+0.5^{*} \mathrm{CCHO}+\mathrm{CO}_{2}+\mathrm{XR}$ & $1.86 \mathrm{E}-12 @-530$ \\
\hline $\mathrm{R}_{2} \mathrm{O}_{2}+\mathrm{NO} \rightarrow \mathrm{NO}_{2}$ & $4.2 \mathrm{E}-12 @-180$ \\
\hline $\mathrm{R}_{2} \mathrm{O}_{2}+\mathrm{HO}_{2} \rightarrow$ & $3.40 \mathrm{E}-13 @-800$ \\
\hline $\mathrm{R}_{2} \mathrm{O}_{2}+\mathrm{RO}_{2} \rightarrow \mathrm{RO}_{2}$ & $1.0 \mathrm{E}-15$ \\
\hline $\mathrm{R}_{2} \mathrm{O}_{2}+\mathrm{CCO}_{3} \rightarrow 0.5^{*} \mathrm{HO}_{2}+0.5^{*} \mathrm{HCHO}$ & $1.86 \mathrm{E}-12 @-530$ \\
\hline $\mathrm{R}_{2} \mathrm{O}_{2}+\mathrm{PCO}_{3} \rightarrow 0.5^{*} \mathrm{HO}_{2}+0.5^{*} \mathrm{CCHO}$ & $1.86 \mathrm{E}-12 @-530$ \\
\hline $\mathrm{RO}_{2} \mathrm{~N}+\mathrm{NO} \rightarrow \mathrm{RNO}_{3}$ & $4.2 \mathrm{E}-12 @-180$ \\
\hline $\mathrm{RO}_{2} \mathrm{~N}+\mathrm{HO}_{2} \rightarrow \mathrm{XOOH}+\mathrm{MEK}+1.5^{*} \mathrm{XC}$ & $3.40 \mathrm{E}-13 @-800$ \\
\hline $\mathrm{RO}_{2} \mathrm{~N}+\mathrm{RO}_{2} \rightarrow \mathrm{RO}_{2}+0.5^{*} \mathrm{HO}_{2}+\mathrm{MEK}+1.5^{*} \mathrm{XC}$ & $1.0 \mathrm{E}-15$ \\
\hline $\mathrm{RO}_{2} \mathrm{~N}+\mathrm{CCO}_{3} \rightarrow 0.5^{*} \mathrm{HO}_{2}+0.5^{*} \mathrm{HCHO}+\mathrm{MEK}+1.5^{*} \mathrm{XC}$ & $1.86 \mathrm{E}-12 @-530$ \\
\hline $\mathrm{RO}_{2} \mathrm{~N}+\mathrm{PCO}_{3} \rightarrow 0.5^{*} \mathrm{HO}_{2}+0.5^{*} \mathrm{CCHO}+\mathrm{MEK}+1.5^{*} \mathrm{XC}$ & $1.86 \mathrm{E}-12 @-530$ \\
\hline $\mathrm{RO}_{2}+\mathrm{NO} \rightarrow \mathrm{NO}$ & $4.2 \mathrm{E}-12 @-180$ \\
\hline $\mathrm{RO}_{2}+\mathrm{HO}_{2} \rightarrow \mathrm{HO}_{2}$ & $3.4 \mathrm{E}-13 @-800$ \\
\hline
\end{tabular}




\begin{tabular}{|c|c|}
\hline $\mathrm{RO}_{2}+\mathrm{RO}_{2} \rightarrow$ & $1.0 \mathrm{E}-15$ \\
\hline $\mathrm{RO}_{2}+\mathrm{CCO}_{3} \rightarrow \mathrm{CCO}_{3}$ & $1.86 \mathrm{E}-12 @-530$ \\
\hline $\mathrm{RO}_{2}+\mathrm{PCO}_{3} \rightarrow \mathrm{PCO}_{3}$ & $1.86 \mathrm{E}-12 @-530$ \\
\hline $\mathrm{XOOH} \rightarrow \mathrm{HO}_{2}+\mathrm{OH} 1.02 / 60$ & $0.017 \mathrm{E}-03 / \mathrm{R} 7$ \\
\hline $\mathrm{XOOH}+\mathrm{OH} \rightarrow \mathrm{OH}$ & $1.18 \mathrm{E}-12 @-128$ \\
\hline $\mathrm{XOOH}+\mathrm{OH} \rightarrow \mathrm{RO}_{2} \mathrm{R}+\mathrm{RO}_{2}$ & $1.79 \mathrm{E}-12 @-219$ \\
\hline \multicolumn{2}{|c|}{ Fim da química de operadores (23 reações) } \\
\hline \multicolumn{2}{|c|}{ Química do Formaldeído (7 reações) } \\
\hline $\mathrm{HCHO} \rightarrow 2 * \mathrm{HO}_{2}+\mathrm{CO}$ & $0.016667 \mathrm{E}-03 / \mathrm{R} 8$ \\
\hline $\mathrm{HCHO} \rightarrow \mathrm{CO}+\mathrm{H}_{2}$ & $0.016667 \mathrm{E}-03 / \mathrm{R9}$ \\
\hline $\mathrm{HCHO}+\mathrm{OH} \rightarrow \mathrm{HO}_{2}+\mathrm{CO}$ & $1.125 \mathrm{E}-12 \wedge 2 @-648$ \\
\hline $\mathrm{HCHO}+\mathrm{NO}_{3} \rightarrow \mathrm{HNO}_{3}+\mathrm{HO}_{2}+\mathrm{CO}$ & $2.8 \mathrm{E}-12 @ 2518$ \\
\hline $\mathrm{HCHO}+\mathrm{HO}_{2} \rightarrow \mathrm{HCO}_{3}$ & $9.70 \mathrm{E}-15 @-625$ \\
\hline $\mathrm{HCO}_{3} \rightarrow \mathrm{HO}_{2}+\mathrm{HCHO}$ & $2.4 \mathrm{E} 12 @ 7000$ \\
\hline $\mathrm{HCO}_{3}+\mathrm{NO} \rightarrow \mathrm{NO}_{2}+\mathrm{HO}_{2}+\mathrm{XC}$ & $4.2 \mathrm{E}-12 @-180$ \\
\hline \multicolumn{2}{|c|}{ Química do Acetaldeído (3 reaçôes) } \\
\hline $\mathrm{CCHO}+\mathrm{OH} \rightarrow \mathrm{CCO}_{3}$ & $5.55 \mathrm{E}-12 @-311$ \\
\hline $\mathrm{CCHO} \rightarrow \mathrm{CO}+\mathrm{HCHO}+\mathrm{HO}_{2}+\mathrm{RO}_{2} \mathrm{R}+\mathrm{RO}_{2}$ & $0.016667 \mathrm{E}-03 / \mathrm{R} 10$ \\
\hline $\mathrm{CCHO}+\mathrm{NO}_{3} \rightarrow \mathrm{HNO}_{3}+\mathrm{CCO}_{3}$ & $1.4 \mathrm{E}-12 @ 1861$ \\
\hline \multicolumn{2}{|c|}{ Química do radical Peroxi acetil (6 reações) } \\
\hline \multicolumn{2}{|c|}{\begin{tabular}{l|l}
$\mathrm{CCO}_{3}+\mathrm{NO} \rightarrow \mathrm{NO}_{2}+\mathrm{HCHO}+\mathrm{RO}_{2} \mathrm{R}+\mathrm{RO}_{2}$ & $5.1 \mathrm{E}-12 @-200$
\end{tabular}} \\
\hline \multicolumn{2}{|l|}{$\mathrm{CCO}_{3}+\mathrm{NO}_{2} \rightarrow \mathrm{PAN}$} \\
\hline \multicolumn{2}{|l|}{$\mathrm{CCO}_{3}+\mathrm{HO}_{2} \rightarrow \mathrm{XOOH}+\mathrm{HCHO}$} \\
\hline \multicolumn{2}{|l|}{$\mathrm{CCO}_{3}+\mathrm{PCO}_{3} \rightarrow 2 * \mathrm{RO}_{2} \mathrm{R}+\mathrm{HCHO}+\mathrm{CCHO}+2^{*} \mathrm{RO}_{2}$} \\
\hline \multicolumn{2}{|l|}{$\mathrm{CCO}_{3}+\mathrm{CCO}_{3} \rightarrow 2 * \mathrm{RO}_{2} \mathrm{R}+2 * \mathrm{HCHO}+2 * \mathrm{RO}_{2}$} \\
\hline $\mathrm{PAN} \rightarrow \mathrm{NO}_{2}+\mathrm{CCO}_{3}$ & $\begin{array}{l}6.3 \mathrm{E}-2 @ 12785 \& 2.2 \mathrm{E} 16 @ 9 \\
13435 \& 0.27\end{array}$ \\
\hline \multicolumn{2}{|c|}{ Química dos aldeídos sup. (propionaldeido PPN e análogos) (3 reaçôes) } \\
\hline $\mathrm{RCHO}+\mathrm{OH} \rightarrow \mathrm{PCO}_{3}$ & $8.50 \mathrm{E}-12 @-252$ \\
\hline $\mathrm{RCHO} \rightarrow \mathrm{CO}+\mathrm{CCHO}+\mathrm{HO}_{2}+\mathrm{RO}_{2} \mathrm{R}+\mathrm{RO}_{2}$ & $0.016667 \mathrm{E}-03 / \mathrm{R} 11$ \\
\hline $\mathrm{RCHO}+\mathrm{NO}_{3} \rightarrow \mathrm{HNO}_{3}+\mathrm{PCO}_{3}$ & $1.4 \mathrm{E}-12 @ 1861$ \\
\hline \multicolumn{2}{|c|}{ Química do radical Peroxipropil (5 reaçôes) } \\
\hline $\mathrm{PCO}_{3}+\mathrm{NO} \rightarrow \mathrm{NO}_{2}+\mathrm{CCHO}+\mathrm{RO}_{2} \mathrm{R}+\mathrm{RO}_{2}$ & $5.1 \mathrm{E}-12 @-200$ \\
\hline $\mathrm{PCO}_{3}+\mathrm{NO}_{2} \rightarrow \mathrm{PPN}$ & $1.95 \mathrm{E}-28^{\wedge}-4 \& 8.4 \mathrm{E}-12 \& 0.27$ \\
\hline $\mathrm{PCO}_{3}+\mathrm{HO}_{2} \rightarrow \mathrm{XOOH}+\mathrm{CCHO}$ & $3.40 \mathrm{E}-13 @-800$ \\
\hline
\end{tabular}




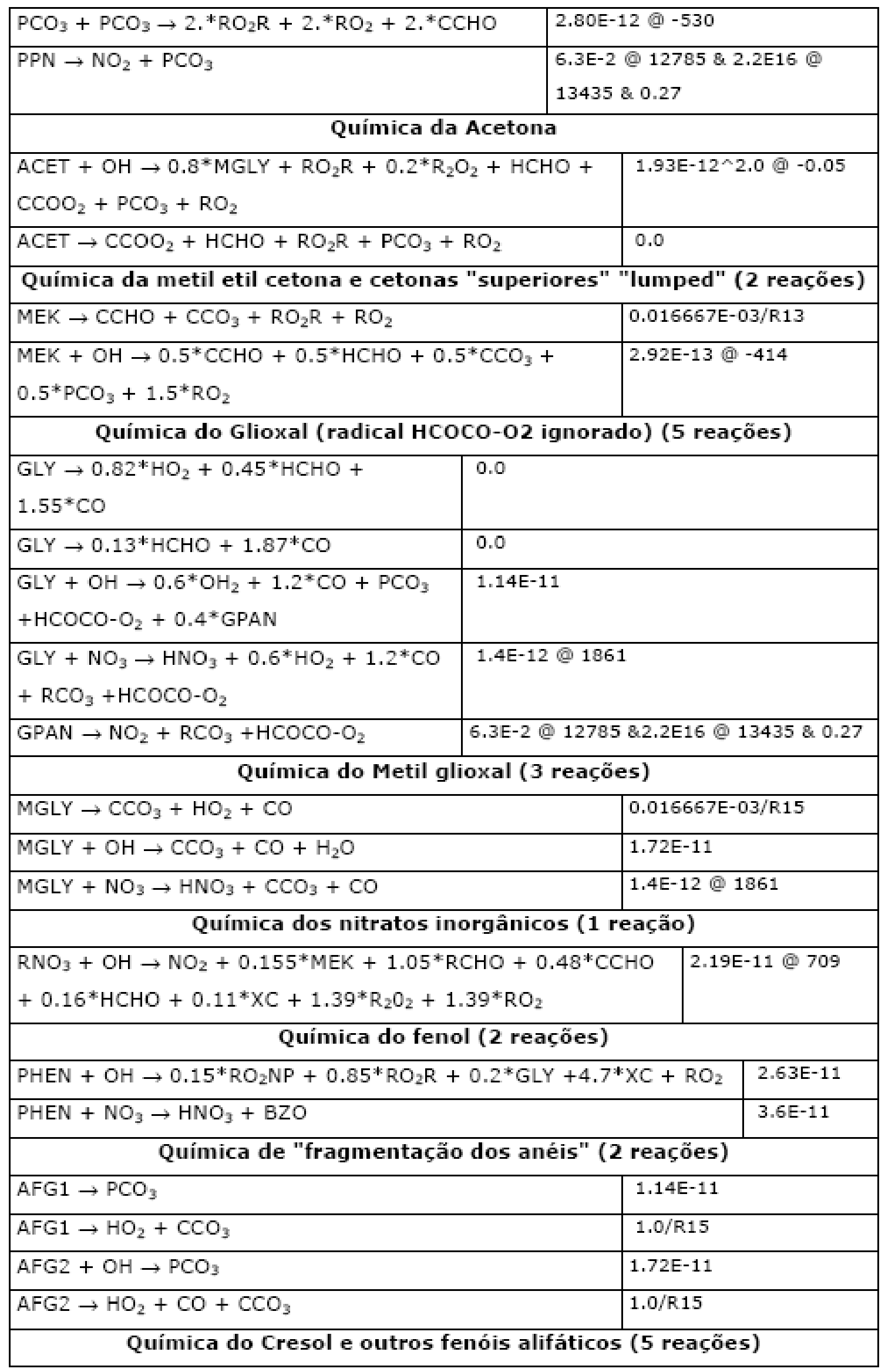




\begin{tabular}{|c|c|c|c|}
\hline \multicolumn{2}{|l|}{$\begin{array}{l}\mathrm{CRES}+\mathrm{OH} \rightarrow 0.20 * \mathrm{MGLY}+0.15^{*} \mathrm{RO}_{2} \mathrm{~N}+0.85^{*} \mathrm{RO}_{2} \mathrm{R}+\mathrm{RO}_{2}+ \\
0.075^{*} \mathrm{CRES}+5.5^{*} \mathrm{XC}\end{array}$} & \multicolumn{2}{|c|}{$4.2 \mathrm{E}-11$} \\
\hline \multicolumn{2}{|l|}{$\mathrm{CRES}+\mathrm{NO}_{3} \rightarrow \mathrm{HNO}_{3}+\mathrm{BZO}+\mathrm{XC}$} & \multicolumn{2}{|c|}{$2.1 \mathrm{E}-11$} \\
\hline \multicolumn{2}{|l|}{$\mathrm{BZO}+\mathrm{NO}_{2} \rightarrow \mathrm{RNO}_{3}+0.5^{*} \mathrm{CRES}+2.5^{*} \mathrm{XC}$} & \multicolumn{2}{|c|}{$1.3 \mathrm{E}-11 @-300$} \\
\hline \multicolumn{2}{|l|}{$\mathrm{BZO}+\mathrm{HO}_{2} \rightarrow 0.5^{*} \mathrm{CRES}+2.5^{*} \mathrm{XC}$} & \multicolumn{2}{|c|}{$3.40 \mathrm{E}-13 @-800$} \\
\hline \multicolumn{2}{|l|}{$\mathrm{BZO} \rightarrow 0.5^{*} \mathrm{CRES}+2.5^{*} \mathrm{XC}$} & \multicolumn{2}{|c|}{$1.0 \mathrm{E}-3$} \\
\hline \multicolumn{4}{|c|}{ Química explicita de álcoois e MTBE (3 reaçôes) } \\
\hline $\mathrm{MEOH}+\mathrm{OH} \rightarrow \mathrm{HO}_{2}+\mathrm{HCHO}$ & \multicolumn{3}{|c|}{$5.75 \mathrm{E}-13 \wedge 2 @-148$} \\
\hline $\mathrm{ETOH}+\mathrm{OH} \rightarrow \mathrm{CCHO}+\mathrm{HO}_{2}$ & \multicolumn{3}{|c|}{$3.24 \mathrm{E}-12$} \\
\hline $\begin{array}{l}\text { MTBE }+\mathrm{OH} \rightarrow 0.41 * \mathrm{MEK}+0.39 * \mathrm{HCHO}+2.87 * \mathrm{XC}+ \\
0.37 * \mathrm{R}_{2} \mathrm{O}_{2}+0.98 * \mathrm{RO}_{2} \mathrm{R}+0.02 * \mathrm{RO}_{2} \mathrm{~N}+1.37 * \mathrm{RO}_{2}\end{array}$ & \multicolumn{3}{|c|}{$2.8 \mathrm{E}-12$} \\
\hline \multicolumn{4}{|c|}{ Química explicita do metano, acetileno, propano (3 reações) } \\
\hline $\mathrm{CH}_{4}+\mathrm{OH} \rightarrow \mathrm{HCHO}+\mathrm{RO}_{2} \mathrm{R}+\mathrm{RO}_{2}$ & \multicolumn{3}{|c|}{$6.255 \mathrm{E}-13^{\wedge} 2 @ 1283$} \\
\hline $\begin{array}{l}\mathrm{PROP}+\mathrm{OH} \rightarrow 0.961^{*} \mathrm{RO}_{2} \mathrm{R}+0.039^{*} \mathrm{RO}_{2} \mathrm{~N}+0.303^{*} \mathrm{RCHO} \\
+0.658^{*} \mathrm{ACET}\end{array}$ & \multicolumn{3}{|c|}{$1.22 \mathrm{E}-12$} \\
\hline $\begin{array}{l}\mathrm{ACEY}+\mathrm{OH} \rightarrow 0.7^{*} \mathrm{MGLY}+0.3^{*} \mathrm{HO}_{2}+0.7^{*} \mathrm{RO}_{2} \mathrm{R}+ \\
0.7^{*} \mathrm{RO}_{2}\end{array}$ & \multicolumn{3}{|c|}{ 1.7E-12 } \\
\hline \multicolumn{4}{|c|}{ Inicio da química dos compostos orgânicos primários agrupados } \\
\hline \multicolumn{4}{|c|}{ Química de alcanos (2 reações) } \\
\hline \multicolumn{2}{|l|}{$\begin{array}{l}\mathrm{ALK1}+\mathrm{OH} \rightarrow 0.918^{*} \mathrm{RO}_{2} \mathrm{R}+0.082^{*} \mathrm{RO}_{2} \mathrm{~N}+0.0 * \mathrm{HO}_{2}+ \\
0.576 * \mathrm{R}_{2} \mathrm{O}_{2}+1.576^{*} \mathrm{RO}_{2}+0.069 * \mathrm{HCHO}+0.352 * \mathrm{CCHO}+ \\
0.199 * \mathrm{RCHO}+0.599^{*} \mathrm{MEK}+0.00 * \mathrm{CO}+0.534^{*} \mathrm{XC}\end{array}$} & \multicolumn{2}{|c|}{$3.8996 \mathrm{E}-12$} \\
\hline \multicolumn{2}{|l|}{$\begin{array}{l}\mathrm{ALK} 2+\mathrm{OH} \rightarrow 0.763^{*} \mathrm{RO}_{2} \mathrm{R}+0.237^{*} \mathrm{RO}_{2} \mathrm{~N}+0.0 * \mathrm{HO}_{2}+ \\
0.945^{*} \mathrm{R}_{2} \mathrm{O}_{2}+1.945^{*} \mathrm{RO}_{2}+0.056^{*} \mathrm{HCHO}+0.054^{*} \mathrm{CCHO}+ \\
0.241^{*} \mathrm{RCHO}+1.110^{*} \mathrm{MEK}+0.043^{*} \mathrm{CO}+1.129 * \mathrm{XC}\end{array}$} & \multicolumn{2}{|c|}{$8.2057 \mathrm{E}-12$} \\
\hline \multicolumn{4}{|l|}{ Química do eteno (etileno) (4 reações) } \\
\hline $\mathrm{ETHE}+\mathrm{OH} \rightarrow 1.56^{*} \mathrm{HCHO}+0.22^{*} \mathrm{CCHO}+\mathrm{RO}_{2} \mathrm{R}+\mathrm{RO}_{2}$ & \multicolumn{3}{|c|}{$2.15 \mathrm{E}-12 @-411$} \\
\hline $\mathrm{ETHE}+\mathrm{O}_{3} \rightarrow \mathrm{HCHO}+0.12 * \mathrm{HO}_{2}+0.44 * \mathrm{CO}+0.56 * \mathrm{XC}$ & \multicolumn{3}{|c|}{$1.2 \mathrm{E}-14 @ 2634$} \\
\hline $\mathrm{ETHE}+\mathrm{O} \rightarrow \mathrm{HCHO}+\mathrm{HO}_{2}+\mathrm{CO}+\mathrm{RO}_{2} \mathrm{R}+\mathrm{RO}_{2}$ & \multicolumn{3}{|c|}{$1.04 \mathrm{E}-11 @ 792$} \\
\hline $\mathrm{ETHE}+\mathrm{NO}_{3} \rightarrow \mathrm{NO}_{2}+2.0^{*} \mathrm{HCHO}+\mathrm{R}_{2} \mathrm{O}_{2}+\mathrm{RO}_{2}$ & \multicolumn{3}{|c|}{$3.7 E-12 @ 2925$} \\
\hline \multicolumn{4}{|l|}{ Química dos Alcenos (12 reaçôes) } \\
\hline \multicolumn{3}{|c|}{$\begin{array}{l}\text { OLE1 }+\mathrm{OH} \rightarrow 0.914^{*} \mathrm{HCHO}+0.312^{*} \mathrm{CCHO}+0.601^{*} \mathrm{RCHO}+0.0^{*} \mathrm{MEK} \\
+0.914^{*} \mathrm{RO}_{2} \mathrm{R}+0.086^{*} \mathrm{RO}_{2} \mathrm{~N}+\mathrm{RO}_{2}+0.416^{*} \mathrm{XC}\end{array}$} & $3.054 \mathrm{E}-11$ \\
\hline \multicolumn{3}{|c|}{$\begin{array}{l}\text { OLE } 1+\mathrm{O}_{3} \rightarrow 0.551^{*} \mathrm{HCHO}+0.270^{*} \mathrm{CCHO}+0.329^{*} \mathrm{RCHO}+ \\
0.186^{*} \mathrm{MEK}+0.0^{*} \mathrm{MGLY}+0.295^{*} \mathrm{CO}+0.000^{*} \mathrm{CCO}_{3}+0.000^{*} \mathrm{PCO}_{3}+\end{array}$} & $1.167 \mathrm{E}-17$ \\
\hline
\end{tabular}




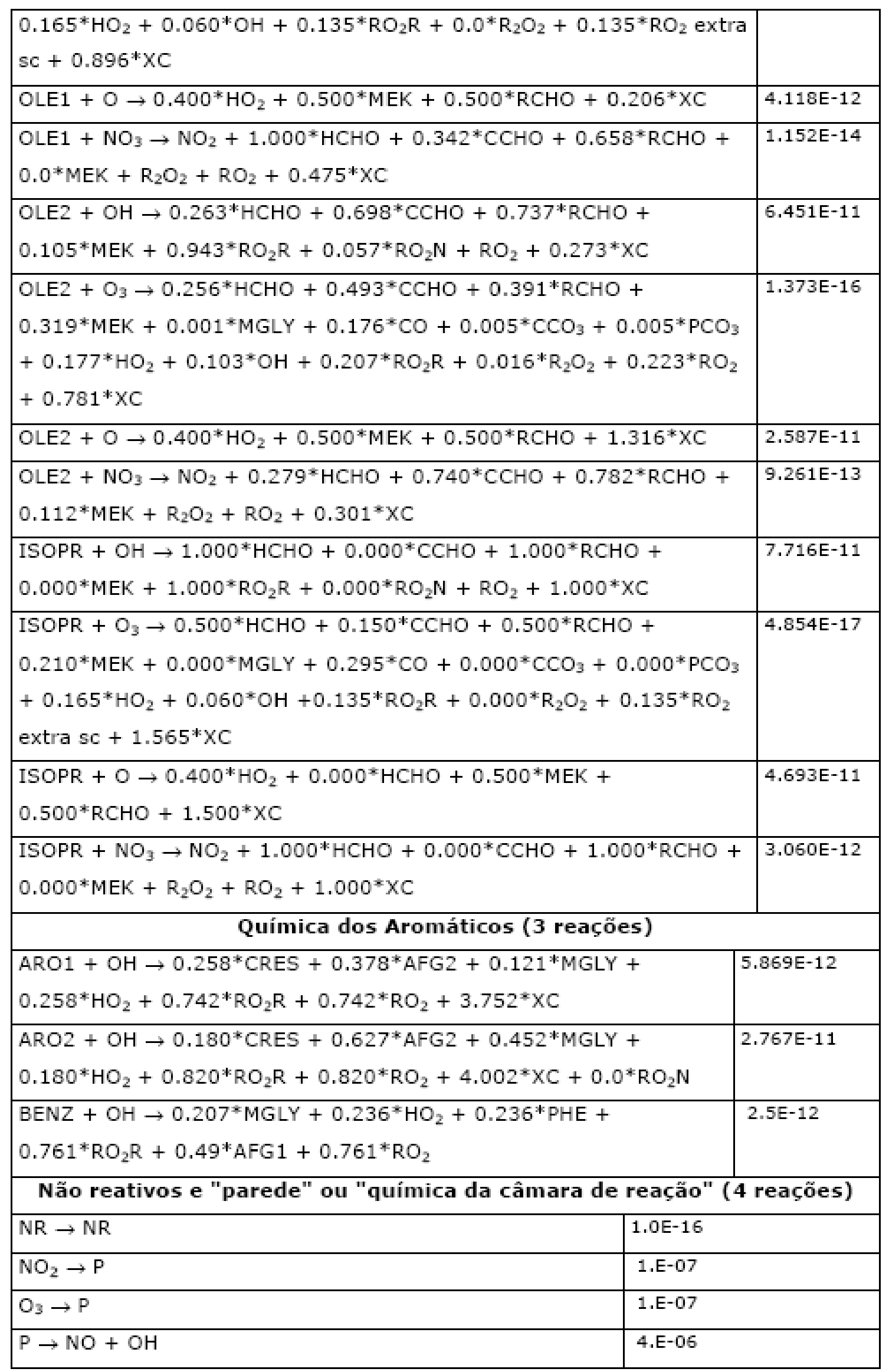


ANEXO C - Escala de Reatividade Incremental Máxima (MIR) desenvolvida por Carter, 2003. (valores de reatividade em gramas de ozônio por grama de COV).

\begin{tabular}{|c|c|c|c|c|c|}
\hline & Composto & MIR & & Composto & MIR \\
\hline 1 & 2-Methyl-2-Butene & 14,45 & 339 & 2-(2-Ethylhexyloxy) ethanol & 1,71 \\
\hline 2 & Glyoxal & 14,22 & 340 & 1-Methoxy-2-Propyl Acetate & 1,70 \\
\hline 3 & Trans 3-Methyl-2-Hexene & 14,17 & 341 & Ethanol & 1,69 \\
\hline 4 & 1-Methyl cyclopentene & 13,95 & 342 & 2,5-Dimethyl Hexane & 1,68 \\
\hline 5 & trans-2-Butene & 13,91 & 343 & Iso-Pentane & 1,67 \\
\hline 6 & 1,3-Butadiene & 13,58 & 344 & Branched C5 Alkanes & 1,67 \\
\hline 7 & C4 Internal Alkenes & 13,57 & 345 & 2-Butoxyethyl Acetate & 1,67 \\
\hline 8 & Cis-3-Methyl-2-Hexene & 13,38 & 346 & 2-Octanone & 1,66 \\
\hline 9 & 2,3-Dimethyl-2-Butene & 13,32 & 347 & C8 Ketones & 1,66 \\
\hline 10 & cis-2-Butene & 13,23 & 348 & 2,4-Dimethyl Pentane & 1,65 \\
\hline 11 & 2-Methyl-2-Pentene & 12,29 & 349 & 3,5-Dimethyl Heptane & 1,63 \\
\hline 12 & Methyl Acrylate & 12,23 & 350 & Branched C7 Alkanes & 1,63 \\
\hline 13 & C4 Alkenes & 11,93 & 351 & Di-Isopropyl Ketone & 1,63 \\
\hline 14 & Acrylic Acid & 11,66 & 352 & C12 Monosubstituted Benzenes & 1,63 \\
\hline 15 & Propene & 11,58 & 353 & 1-Ethyl-4-Methyl Cyclohexane & 1,62 \\
\hline 16 & 1,2,3-Trimethyl Benzene & 11,26 & 354 & Cyclohexanone & 1,61 \\
\hline 17 & 1,3,5-Trimethyl Benzene & 11,22 & 355 & C6 Cyclic Ketones & 1,61 \\
\hline 18 & Isoprene & 10,69 & 356 & s-Butyl Alcohol & 1,59 \\
\hline 19 & m-Xylene & 10,61 & 357 & C9 Bicycloalkanes & 1,57 \\
\hline 20 & 2,3-Dimethyl-2-Hexene & 10,41 & 358 & Branched C8 Alkanes & 1,57 \\
\hline 21 & 1-Butene & 10,29 & 359 & TLEV Exhaust -- M-85 & 1,57 \\
\hline 22 & C4 Terminal Alkenes & 10,29 & 360 & C9 Cycloalkanes & 1,55 \\
\hline 23 & cis-2-Pentene & 10,24 & 361 & 1-Tridecene & 1,55 \\
\hline 24 & 2-Pentenes & 10,23 & 362 & C13 Terminal Alkenes & 1,55 \\
\hline 25 & C5 Internal Alkenes & 10,23 & 363 & 2,3-Dimethyl Pentane & 1,54 \\
\hline 26 & trans-2-Pentene & 10,23 & 364 & n-Pentane & 1,54 \\
\hline 27 & Crotonaldehyde & 10,06 & 365 & Branched C6 Alkanes & 1,53 \\
\hline 28 & C9 Trisubstituted Benzenes & 9,90 & 366 & C10 Styrenes & 1,53 \\
\hline 29 & Dimethyl Amine & 9,38 & 367 & Isopropyl Cyclopropane & 1,52 \\
\hline 30 & Butyl Methacrylate & 9,08 & 368 & 2-(2-Ethoxyethoxy) ethyl acetate & 1,51 \\
\hline 31 & Ethene & 9,08 & 369 & C13 Monosubstituted Benzenes & 1,50 \\
\hline 32 & C5 Alkenes & 9,01 & 370 & 1,4-Diethyl-Cyclohexane & 1,49 \\
\hline 33 & Isobutyl Methacrylate & 8,99 & 371 & 2,4-Dimethyl Heptane & 1,49 \\
\hline 34 & Formaldehyde & 8,97 & 372 & 4-Methyl Heptane & 1,48 \\
\hline 35 & C10 Tetrasubstituted Benzenes & 8,86 & 373 & Methyl Ethyl Ketone & 1,48 \\
\hline 36 & C10 Trisubstituted Benzenes & 8,86 & 374 & Propyl Cyclohexane & 1,48 \\
\hline 37 & Ethyl Acrylate & 8,82 & 375 & Cyclohexane & 1,46 \\
\hline 38 & Methylvinyl ketone & 8,73 & 376 & C6 Cycloalkanes & 1,46 \\
\hline 39 & C6 Cyclic or di-olefins & 8,64 & 377 & n-Hexane & 1,45 \\
\hline 40 & Cis-2-Hexene & 8,44 & 378 & 3-Pentanone & 1,44 \\
\hline 41 & Trans-2-Hexene & 8,44 & 379 & 4-Ethyl Heptane & 1,44 \\
\hline 42 & 2-Hexenes & 8,44 & 380 & 2,2,4-Trimethyl Pentane & 1,44 \\
\hline 43 & C6 Internal Alkenes & 8,44 & 381 & s-Butyl Acetate & 1,43 \\
\hline 44 & Cis-3-Hexene & 8,22 & 382 & Cyclopentanone & 1,43 \\
\hline 45 & Trans-3-Hexene & 8,16 & 383 & C5 Cyclic Ketones & 1,43 \\
\hline 46 & C11 Pentasubstituted Benzenes & 8,03 & 384 & 1-Tetradecene & 1,41 \\
\hline 47 & C11 Tetrasubstituted Benzenes & 8,03 & 385 & C14 Terminal Alkenes & 1,41 \\
\hline 48 & C11 Trisubstituted Benzenes & 8,03 & 386 & C7 Cyclic Ketones & 1,41 \\
\hline 49 & Trans 4-Methyl-2-Hexene & 7,88 & 387 & 2-(2-Butoxyethoxy) ethyl acetate & 1,38 \\
\hline 50 & Propionaldehyde & 7,88 & 388 & 2-Methyl Hexane & 1,37 \\
\hline 51 & 1-Methyl Cyclohexene & 7,81 & 389 & 1-Pentadecene & 1,37 \\
\hline 52 & Ethyl Amine & 7,80 & 390 & C15 Terminal Alkenes & 1,37 \\
\hline 53 & 1-Pentene & 7,79 & 391 & 1,1,3-Trimethyl Cyclohexane & 1,36 \\
\hline
\end{tabular}




\begin{tabular}{|c|c|c|c|c|c|}
\hline & Composto & MIR & & Composto & MIR \\
\hline 54 & C5 Terminal Alkenes & 7,79 & 392 & 3,3-Diethyl Pentane & 1,35 \\
\hline 55 & Cyclopentadiene & 7,61 & 393 & Isobutane & 1,35 \\
\hline 56 & Acrolein & 7,61 & 394 & 3-Methyl Heptane & 1,34 \\
\hline 57 & o-Xylene & 7,49 & 395 & 1,3-Diethyl-Cyclohexane & 1,34 \\
\hline 58 & C7 Cyclic or di-olefins & 7,49 & 396 & 2,3-Dimethyl Hexane & 1,34 \\
\hline 59 & C8 Disubstituted Benzenes & 7,48 & 397 & 2,2-Dimethyl Butane & 1,33 \\
\hline 60 & Cyclopentene & 7,39 & 398 & n-Butane & 1,33 \\
\hline 61 & C11 Pentasubstituted Benzenes & 7,33 & 399 & 2,3,5-Trimethyl Hexane & 1,33 \\
\hline 62 & $\begin{array}{l}\text { C12 Hexaasubstituted } \\
\text { Benzenes }\end{array}$ & 7,33 & 400 & 2,2,5-Trimethyl Hexane & 1,33 \\
\hline 63 & C12 Tetrasubstituted Benzenes & 7,33 & 401 & 2,2,3-Trimethyl Butane & 1,32 \\
\hline 64 & C12 Trisubstituted Benzenes & 7,33 & 402 & 3,3-Dimethyl Pentane & 1,32 \\
\hline 65 & Trans-2-Heptene & 7,33 & 403 & 3-Methylpentyl Acetate & 1,31 \\
\hline 66 & 1,2,4-Trimethyl Benzene & 7,18 & 404 & 2-Nonanone & 1,30 \\
\hline 67 & Trimethyl Amine & 7,07 & 405 & C9 Ketones & 1,30 \\
\hline 68 & Trans 4,4-dimethyl-2-Pentene & 7,00 & 406 & Di-Isobutyl Ether & 1,30 \\
\hline 69 & 3-Methyl-1-Butene & 6,99 & 407 & C10 Bicycloalkanes & 1,29 \\
\hline 70 & Cis-3-Heptene & 6,96 & 408 & n-Heptane & 1,28 \\
\hline 71 & Trans-3-Heptene & 6,96 & 409 & $\begin{array}{l}\text { Mineral Spirits "A" (Type I-B, } \\
91 \% \text { Alkanes) }\end{array}$ & 1,27 \\
\hline 72 & 2-Heptenes & 6,96 & 410 & C10 Cycloalkanes & 1,27 \\
\hline 73 & C7 Internal Alkenes & 6,96 & 411 & 2,6-Dimethyl Octane & 1,27 \\
\hline 74 & Dimethyl Sulfoxide & 6,89 & 412 & 2,3,4,6-Tetramethyl Heptane & 1,26 \\
\hline 75 & C6 Alkenes & 6,87 & 413 & $\begin{array}{l}\text { 1-Methyl-3-Isopropyl } \\
\text { Cyclohexane }\end{array}$ & 1,25 \\
\hline 76 & Acetaldehyde & 6,84 & 414 & Branched C9 Alkanes & 1,25 \\
\hline 77 & 1,2-Dimethyl Cyclohexene & 6,77 & 415 & Ethyl Butyrate & 1,25 \\
\hline 78 & C13 Trisubstituted Benzenes & 6,75 & 416 & C8 Cyclic Ketones & 1,25 \\
\hline 79 & Butanal & 6,73 & 417 & Acetylene & 1,25 \\
\hline 80 & C4 aldehydes & 6,73 & 418 & 4-Propyl Heptane & 1,24 \\
\hline 81 & Hydroxy Methacrolein & 6,61 & 419 & $\begin{array}{l}\text { 2,3,6-Trimethyl 4-Isopropyl } \\
\text { Heptane }\end{array}$ & 1,24 \\
\hline 82 & C9 Disubstituted Benzenes & 6,61 & 420 & 3-Ethylpentyl Acetate & 1,24 \\
\hline 83 & 2-Methyl-1-Butene & 6,51 & 421 & $\begin{array}{l}\text { 8-Methyl-1-Nonanol (Isodecyl } \\
\text { Alcohol) }\end{array}$ & 1,23 \\
\hline 84 & Methyl Acetylene & 6,45 & 422 & 2,3,4-Trimethyl Pentane & 1,23 \\
\hline 85 & Isobutene & 6,35 & 423 & 2,2-Dimethyl Pentane & 1,22 \\
\hline 86 & 4-Methyl-1-Pentene & 6,26 & 424 & 3,5-Diethyl Heptane & 1,21 \\
\hline 87 & Methacrolein & 6,23 & 425 & 2-Methyl Heptane & 1,20 \\
\hline 88 & 3-Methyl-1-Pentene & 6,22 & 426 & 3,4-Diethyl Hexane & 1,19 \\
\hline 89 & Ethyl Acetylene & 6,20 & 427 & 2-Methoxyethyl Acetate & 1,19 \\
\hline 90 & 1-Hexene & 6,17 & 428 & n-Propyl Butyrate & 1,16 \\
\hline 91 & C6 Terminal Alkenes & 6,17 & 429 & Methyl Butyrate & 1,16 \\
\hline 92 & Trans-3-Octene & 6,13 & 430 & 3,4-Dimethylhexyl Acetate & 1,16 \\
\hline 93 & 3-Octenes & 6,13 & 431 & Propionic Acid & 1,16 \\
\hline 94 & Isomers of Propylbenzene & 6,12 & 432 & 2,3-Dimethyl Butane & 1,14 \\
\hline 95 & 3,3-Dimethyl-1-Butene & 6,06 & 433 & 2,2-Dimethyl Hexane & 1,13 \\
\hline 96 & C8 Cyclic or di-olefins & 6,02 & 434 & 2-(Cl-methyl)-3-Cl-Propene & 1,13 \\
\hline 97 & Trans 2,2-Dimethyl 3-Hexene & 5,98 & 435 & C9 Cyclic Ketones & 1,13 \\
\hline 98 & Ethanolamine & 5,97 & 436 & 2-Methyoxy-1-propyl Acetate & 1,13 \\
\hline 99 & Cis-4-Octene & 5,94 & 437 & Isopropyl Acetate & 1,12 \\
\hline 100 & C10 Disubstituted Benzenes & 5,92 & 438 & n-Butyl Butyrate & 1,12 \\
\hline 101 & Trans-4-Octene & 5,91 & 439 & $\begin{array}{l}\text { 1,3-Diethyl-5-Methyl } \\
\text { Cyclohexane }\end{array}$ & 1,11 \\
\hline 102 & C8 Internal Alkenes & 5,91 & 440 & 2,4,5,6,8-Pentamethyl Nonane & 1,11 \\
\hline 103 & 2-Methylpropanal & 5,87 & 441 & 2-Methylpentyl Acetate & 1,11 \\
\hline 104 & 2,4,4-trimethyl-2-Pentene & 5,84 & 442 & n-Octane & 1,11 \\
\hline
\end{tabular}




\begin{tabular}{|c|c|c|c|c|c|}
\hline & Composto & MIR & & Composto & MIR \\
\hline 105 & Pentanal (Valeraldehyde) & 5,76 & 443 & 2,6-Diethyl Octane & 1,10 \\
\hline 106 & C5 Aldehydes & 5,76 & 444 & 2,4-Dimethyl Octane & 1,10 \\
\hline 107 & C7 Alkenes & 5,76 & 445 & Branched C10 Alkanes & 1,09 \\
\hline 108 & 2,3-Dimethyl Naphthalene & 5,54 & 446 & 3,5-Dimethylhexyl Acetate & 1,09 \\
\hline 109 & C12 Disubstituted Naphthalenes & 5,54 & 447 & 4-Methyl Octane & 1,08 \\
\hline 110 & Dimethyl Naphthalenes & 5,54 & 448 & Butyl Cyclohexane & 1,08 \\
\hline 111 & $\begin{array}{l}\text { 3-Methylbutanal } \\
\text { (Isovaleraldehyde) }\end{array}$ & 5,52 & 449 & 3,7-Diethyl Nonane & 1,07 \\
\hline 112 & Isomers of Butylbenzene & 5,48 & 450 & 2,3,5,7-Tetramethyl Octane & 1,06 \\
\hline 113 & Cyclohexene & 5,45 & 451 & 1,3,5-Triethyl Cyclohexane & 1,06 \\
\hline 114 & Trans 2,5-Dimethyl 3-Hexene & 5,44 & 452 & 2-Decanone & 1,06 \\
\hline 115 & $\begin{array}{l}\text { 2,2-Dimethylpropanal } \\
\text { (pivaldehyde) }\end{array}$ & 5,40 & 453 & C10 Ketones & 1,06 \\
\hline 116 & C9 Cyclic or di-olefins & 5,39 & 454 & Cyclobutane & 1,05 \\
\hline 117 & C11 Disubstituted Benzenes & 5,35 & 455 & Diisopropyl Carbonate & 1,04 \\
\hline 118 & 3-Nonenes & 5,30 & 456 & 2-Methyl-2,4-Pentanediol & 1,04 \\
\hline 119 & C9 Internal Alkenes & 5,30 & 457 & Dimethoxy methane & 1,04 \\
\hline 120 & Trimethylene Oxide & 5,22 & 458 & 3-Ethylhexyl Acetate & 1,03 \\
\hline 121 & Trans-4-Nonene & 5,22 & 459 & Oxo-Hexyl Acetate & 1,02 \\
\hline 122 & 2-Methyl-1-Pentene & 5,18 & 460 & C10 Cyclic Ketones & 1,02 \\
\hline 123 & Isomers of Ethylbenzene & 5,16 & 461 & 3,5-Dimethylheptyl Acetate & 1,01 \\
\hline 124 & 2-Methyl-2-Butene-3-ol & 5,12 & 462 & 1,2-Epoxybutane & 1,01 \\
\hline 125 & C13 Disubstituted Naphthalenes & 5,08 & 463 & 3-Methylhexyl Acetate & 1,01 \\
\hline 126 & $\begin{array}{l}\text { C13 Trisubstituted } \\
\text { Naphthalenes }\end{array}$ & 5,08 & 464 & C11 Bicycloalkanes & 1,01 \\
\hline 127 & 2-Ethyl-1-Butene & 5,05 & 465 & C11 Cycloalkanes & 0,99 \\
\hline 128 & Hexanal & 4,98 & 466 & C11 Cycloalkanes & 0,99 \\
\hline 129 & C6 Aldehydes & 4,98 & 467 & $\begin{array}{l}\text { 1,3-Diethyl-5-Pentyl } \\
\text { Cyclohexane }\end{array}$ & 0,99 \\
\hline 130 & Isomers of Pentylbenzene & 4,96 & 468 & 4-Methyl Nonane & 0,99 \\
\hline 131 & Tetrahydrofuran & 4,95 & 469 & 2,4-Dimethylpentyl Acetate & 0,98 \\
\hline 132 & C12 Disubstituted Benzenes & 4,90 & 470 & Oxo-Heptyl Acetate & 0,97 \\
\hline 133 & Cis-5-Decene & 4,89 & 471 & 3-Methoxy-1-Butanol & 0,97 \\
\hline 134 & Glutaraldehyde & 4,79 & 472 & n-Nonane & 0,96 \\
\hline 135 & 23-Dimethyl-1-Butene & 4,77 & 473 & 4,5-Dimethylheptyl Acetate & 0,96 \\
\hline 136 & Dimethylaminoethanol & 4,76 & 474 & Oxo-Octyl Acetate & 0,96 \\
\hline 137 & C8 Alkenes & 4,68 & 475 & 2-Methyl Octane & 0,96 \\
\hline 138 & Alpha-Methyltetrahydrofuran & 4,62 & 476 & 1-Ethyl-2-Propyl Cyclohexane & 0,95 \\
\hline 139 & 2,3,3-trimethyl-1-Butene & 4,61 & 477 & n-Butyl Formate & 0,95 \\
\hline 140 & Methyl Naphthalenes & 4,61 & 478 & Amyl Acetate & 0,95 \\
\hline 141 & 1-Methyl Naphthalene & 4,61 & 479 & 2,6-Dimethyl Nonane & 0,95 \\
\hline 142 & 2-Methyl Naphthalene & 4,61 & 480 & $\begin{array}{l}\text { 1,3-Dipropyl-5- } \\
\text { EthylCyclohexane }\end{array}$ & 0,94 \\
\hline 143 & C10 Cyclic or di-olefins & 4,56 & 481 & 2,4,6,8-Tetramethyl Nonane & 0,94 \\
\hline 144 & 1-Heptene & 4,55 & 482 & Para Toluene Isocyanate & 0,93 \\
\hline 145 & C7 Terminal Alkenes & 4,55 & 483 & Dimethyl Ether & 0,93 \\
\hline 146 & Isomers of Hexylbenzene & 4,53 & 484 & 2,4-Dimethylhexyl Acetate & 0,93 \\
\hline 147 & C13 Disubstituted Benzenes & 4,50 & 485 & n-Propyl Propionate & 0,92 \\
\hline 148 & Trans-4-Decene & 4,49 & 486 & n-Propyl Formate & 0,92 \\
\hline 149 & C10 3-Alkenes & 4,49 & 487 & $\begin{array}{l}\text { 1-Hydroxy-2,2,4- } \\
\text { Trimethylpentyl-3-Isobutyrate }\end{array}$ & 0,92 \\
\hline 150 & C10 Internal Alkenes & 4,49 & 488 & Substituted C7 ester (C12) & 0,92 \\
\hline 151 & 4-Methyl Cyclohexene & 4,48 & 489 & Pentyl Cyclohexane & 0,92 \\
\hline 152 & 2-Ethyl Hexanoic Acid & 4,41 & 490 & 4-Methylpentyl Acetate & 0,91 \\
\hline 153 & 4-Methyl-2-Pentanone & 4,31 & 491 & 4-Methylhexyl Acetate & 0,91 \\
\hline 154 & a-Pinene & 4,29 & 492 & 1,3,5-Tripropyl Cyclohexane & 0,90 \\
\hline 155 & C11 Cyclic or di-olefins & 4,29 & 493 & Texanol isomers & 0,89 \\
\hline
\end{tabular}




\begin{tabular}{|c|c|c|c|c|c|}
\hline & Composto & MIR & & Composto & MIR \\
\hline 156 & p-Xylene & 4,25 & 494 & 2-Methylhexyl Acetate & 0,89 \\
\hline 157 & 3-Ethoxy-1-Propanol & 4,24 & 495 & n-Butyl Acetate & 0,89 \\
\hline 158 & Trans-5-Undecene & 4,23 & 496 & 3-Methyl Nonane & 0,89 \\
\hline 159 & C11 3-Alkenes & 4,23 & 497 & Isoamyl Isobutyrate & 0,89 \\
\hline 160 & C11 Internal Alkenes & 4,23 & 498 & Substituted C9 Ester (C12) & 0,89 \\
\hline 161 & Heptanal & 4,23 & 499 & 3,6-Dimethyl Decane & 0,88 \\
\hline 162 & C7 Aldehydes & 4,23 & 500 & Butyl Propionate & 0,88 \\
\hline 163 & $\begin{array}{l}\text { C12 Monosubstituted } \\
\text { Naphthalene }\end{array}$ & 4,20 & 501 & $\begin{array}{l}\text { 3-Hydroxy-2,2,4- } \\
\text { Trimethylpentyl-1-Isobutyrate }\end{array}$ & 0,88 \\
\hline 164 & TLEV Exhaust -- RFA & 4,09 & 502 & C12 Bicycloalkanes & 0,88 \\
\hline 165 & Diethanol Amine & 4,05 & 503 & 3,6-Dimethyloctyl Acetate & 0,88 \\
\hline 166 & TLEV Exhaust -- Phase 2 & 4,05 & 504 & 2,4-Dimethylheptyl Acetate & 0,88 \\
\hline 167 & C9 Alkenes & 4,03 & 505 & 3,6-Dimethylheptyl Acetate & 0,87 \\
\hline 168 & Diethyl Ether & 4,02 & 506 & n-Hexyl Acetate & 0,87 \\
\hline 169 & d-Limonene & 3,99 & 507 & C12 Cycloalkanes & 0,87 \\
\hline 170 & Toluene & 3,97 & 508 & Propyl Acetate & 0,87 \\
\hline 171 & 3,4-Diethyl-2-Hexene & 3,95 & 509 & Branched C11 alkanes & 0,87 \\
\hline 172 & Ethyl n-Butyl Ether & 3,86 & 510 & 2,3,5-Teimethylhexyl Acetate & 0,86 \\
\hline 173 & Ethyl Isopropyl Ether & 3,86 & 511 & 2,5-Dimethylheptyl Acetate & 0,86 \\
\hline 174 & $\begin{array}{l}\text { C13 Monosubstituted } \\
\text { Naphthalene }\end{array}$ & 3,86 & 512 & 4,5-Dimethylhexyl Acetate & 0,86 \\
\hline 175 & Tetrahydropyran & 3,81 & 513 & 2-Methyl Nonane & 0,85 \\
\hline 176 & C12 Cyclic or di-olefins & 3,80 & 514 & Oxo-Nonyl Acetate & 0,85 \\
\hline 177 & Terpene & 3,79 & 515 & 4,6-Dimethyloctyl Acetate & 0,85 \\
\hline 178 & 2-Ethoxyethanol & 3,78 & 516 & 2,3-Dimethylheptyl Acetate & 0,85 \\
\hline 179 & C12 2-Alkenes & 3,75 & 517 & 2,3-Dimethylbutyl Acetate & 0,84 \\
\hline 180 & C12 3-Alkenes & 3,75 & 518 & n-Decane & 0,83 \\
\hline 181 & C12 Internal Alkenes & 3,75 & 519 & 4,6-Dimethylheptyl Acetate & 0,83 \\
\hline 182 & Trans-5-Dodecene & 3,75 & 520 & Oxo-Decyl Acetate & 0,83 \\
\hline 183 & Base ROG Mixture & 3,71 & 521 & 3,5,7-Trimethyloctyl Acetate & 0,83 \\
\hline 184 & Sabinene & 3,67 & 522 & 3,6-Dimethyl Undecane & 0,82 \\
\hline 185 & Methyl n-Butyl Ether & 3,65 & 523 & Benzene & 0,82 \\
\hline 186 & Octanal & 3,65 & 524 & Trans-1,2-Dichloroethene & 0,81 \\
\hline 187 & C8 Aldehydes & 3,65 & 525 & 4-Methyl Decane & 0,81 \\
\hline 188 & Final LEV -- RFA & 3,64 & 526 & 1-Methyl-4-Pentyl Cyclohexane & 0,81 \\
\hline 189 & Ethyl 3-Ethoxy Propionate & 3,61 & 527 & 3-Ethyl-6-Methyloctyl Acetate & 0,80 \\
\hline 190 & Final LEV -- Phase 2 & 3,55 & 528 & Branched C12 Alkanes & 0,80 \\
\hline 191 & Methyl n-Butyl Ketone & 3,55 & 529 & 5-Methylhexyl Acetate & 0,79 \\
\hline 192 & C6 Ketones & 3,55 & 530 & $\begin{array}{l}\text { Methylene Diphenylene } \\
\text { Diisocyanate }\end{array}$ & 0,79 \\
\hline 193 & Diethylene Glycol & 3,55 & 531 & Ethyl Propionate & 0,79 \\
\hline 194 & 2-Propoxyethanol & 3,51 & 532 & C13 Bicycloalkanes & 0,79 \\
\hline 195 & 1-Octene & 3,45 & 533 & Mineral Spirits "D" (Type II-C) & 0,79 \\
\hline 196 & C8 Terminal Alkenes & 3,45 & 534 & Methyl t-Butyl Ketone & 0,78 \\
\hline 197 & C13 Cyclic or di-olefins & 3,42 & 535 & 2-Ethyl-Hexyl Acetate & 0,78 \\
\hline 198 & C10 Alkenes & 3,39 & 536 & C13 Cycloalkanes & 0,78 \\
\hline 199 & Trans-5-Tridecene & 3,38 & 537 & Mineral Spirits "C" (Type II-C) & 0,78 \\
\hline 200 & C13 3-Alkenes & 3,38 & 538 & $\begin{array}{l}\text { 2-Methyl 3,5-Diisopropyl } \\
\text { Heptane }\end{array}$ & 0,78 \\
\hline 201 & C13 Internal Alkenes & 3,38 & 539 & Mineral Spirits "B" (Type II-C) & 0,78 \\
\hline 202 & Ethylene Glycol & 3,36 & 540 & Methyl t-Butyl Ether & 0,78 \\
\hline 203 & Pentyl Alcohol & 3,35 & 541 & 1,3-Propyl-5-Butyl Cyclohexane & 0,77 \\
\hline 204 & n-Butyl Alcohol & 3,34 & 542 & $\begin{array}{l}\text { 5-Ethyl-3,6,8-Trimethylnonyl } \\
\text { Acetate }\end{array}$ & 0,77 \\
\hline 205 & 3-Methyl-2-Isopropyl-1-Butene & 3,28 & 543 & $\begin{array}{l}\text { 3-Ethyl-6,7-Dimethylnonyl } \\
\text { Acetate }\end{array}$ & 0,77 \\
\hline 206 & b-Pinene & 3,28 & 544 & 3-Methyl Decane & 0,76 \\
\hline
\end{tabular}




\begin{tabular}{|c|c|c|c|c|c|}
\hline & Composto & MIR & & Composto & MIR \\
\hline 207 & Vinyl Acetate & 3,28 & 545 & 2,6,8-Trimet 4-Isopropyl Nonane & 0,76 \\
\hline 208 & Glycerol & 3,27 & 546 & 3,5,7-Trimethylnonyl Acetate & 0,76 \\
\hline 209 & Naphthalene & 3,26 & 547 & 3-Methylheptyl Aceate & 0,76 \\
\hline 210 & 1-Ethoxy-2-Propanol & 3,25 & 548 & TLEV Exhaust -- CNG & 0,75 \\
\hline 211 & Di n-Propyl Ether & 3,24 & 549 & 3,7-Dimethyl Dodecane & 0,74 \\
\hline 212 & 3-Carene & 3,21 & 550 & Hexyl Cyclohexane & 0,74 \\
\hline 213 & 2-(2-Ethoxyethoxy) EtOH & 3,19 & 551 & $\begin{array}{l}2,3,5,6,8-P e n t a a m e t h y l n o n y l \\
\text { Acetate }\end{array}$ & 0,74 \\
\hline 214 & Di-n-butyl Ether & 3,17 & 552 & n-Undecane & 0,74 \\
\hline 215 & Indan & 3,17 & 553 & 2,3,5,7-Tetramethyloctyl Acetate & 0,74 \\
\hline 216 & C14 Cyclic or di-olefins & 3,11 & 554 & 5-Methylheptyl Aceate & 0,73 \\
\hline 217 & C11 Alkenes & 3,09 & 555 & Ethylene Glycol Diacetate & 0,73 \\
\hline 218 & Hydroxy Acetone & 3,08 & 556 & Branched C13 Alkanes & 0,73 \\
\hline 219 & Trans-5-Tetradecene & 3,08 & 557 & n-Heptyl Acetate & 0,73 \\
\hline 220 & C14 3-Alkenes & 3,08 & 558 & 4-Methylheptyl Acetate & 0,73 \\
\hline 221 & C14 Internal Alkenes & 3,08 & 559 & Oxo-Dodecyl Acetate & 0,72 \\
\hline 222 & 4-Octanol & 3,07 & 560 & 3,6,8-Trimethylnonyl Acetate & 0,72 \\
\hline 223 & 2-Pentanone & 3,07 & 561 & 5-Methyl Undecane & 0,72 \\
\hline 224 & C5 Ketones & 3,07 & 562 & 3-Isopropylheptyl Acetate & 0,72 \\
\hline 225 & $\begin{array}{l}\text { Dipropylene Glycol Methyl Ether } \\
\text { [(2-methoxymethylethoxy) } \\
\text { propanol] }\end{array}$ & 3,02 & 563 & Isopropyl Alcohol & 0,71 \\
\hline 226 & 2-Methoxy-1-Propanol & 3,01 & 564 & C14 Bicycloalkanes & 0,71 \\
\hline 227 & 2-(2-Propoxyethoxy) ethanol & 3,00 & 565 & Methanol & 0,71 \\
\hline 228 & 2-Methoxyethanol & 2,98 & 566 & Acetic Acid & 0,71 \\
\hline 229 & $\begin{array}{l}\text { Di-isobutyl ketone (2,6-dimethyl- } \\
\text { 4-heptanone) }\end{array}$ & 2,94 & 567 & Methyl Propionate & 0,71 \\
\hline 230 & Vinyl Chloride & 2,92 & 568 & C14 Cycloalkanes & 0,71 \\
\hline 231 & 2-Butoxyethanol & 2,90 & 569 & 3-Ethylheptyl Acetate & 0,70 \\
\hline 232 & 2-(2-Methoxyethoxy) Ethanol & 2,90 & 570 & 1-Methyl-2-Hexyl-Cyclohexane & 0,70 \\
\hline 233 & 1-Propoxy-2-Propanol & 2,86 & 571 & 3-Methyl Undecane & 0,70 \\
\hline 234 & C15 Cyclic or di-olefins & 2,85 & 572 & Neopentane & 0,70 \\
\hline 235 & Tetralin & 2,83 & 573 & Methyl Isobutyrate & 0,69 \\
\hline 236 & Trans-5-Pentadecene & 2,82 & 574 & $\begin{array}{l}\text { 2,7-Dimethyl 3,5-Diisopropyl } \\
\text { Heptane }\end{array}$ & 0,69 \\
\hline 237 & C15 3-Alkenes & 2,82 & 575 & Methyl Isopropyl Carbonate & 0,69 \\
\hline 238 & C15 Internal Alkenes & 2,82 & 576 & C15 Bicycloalkanes & 0,69 \\
\hline 239 & 3-Methyl-2-Hexanone & 2,81 & 577 & Cyclobutanone & 0,68 \\
\hline 240 & 2-Heptanone & 2,80 & 578 & Diacetone Alcohol & 0,68 \\
\hline 241 & C7 Ketones & 2,80 & 579 & 4-Methyloctyl Acetate & 0,68 \\
\hline 242 & Ethyl Benzene & 2,79 & 580 & C15 Cycloalkanes & 0,68 \\
\hline 243 & 1-Nonene & 2,77 & 581 & 3,8-Diethyl Decane & 0,68 \\
\hline 244 & C9 Terminal Alkenes & 2,77 & 582 & Oxo-Tridecyl Acetate & 0,67 \\
\hline 245 & Triethanolamine & 2,76 & 583 & 5-Methyloctyl Acetate & 0,67 \\
\hline 246 & Propylene Glycol & 2,75 & 584 & Isobutyl Acetate & 0,67 \\
\hline 247 & 1,2-Dihydroxy Hexane & 2,75 & 585 & Branched C14 Alkanes & 0,67 \\
\hline 248 & Methyl Lactate & 2,75 & 586 & Exxon Exxol(r) D95 Fluid & 0,67 \\
\hline 249 & 1-Hexanol & 2,74 & 587 & n-Dodecane & 0,66 \\
\hline 250 & n-Propyl Alcohol & 2,74 & 588 & Heptyl Cyclohexane & 0,66 \\
\hline 251 & C12 Alkenes & 2,74 & 589 & Exxon Isopar(r) M Fluid & 0,65 \\
\hline 252 & Ethyl Lactate & 2,72 & 590 & 3,7-Dimethyl Tridecane & 0,65 \\
\hline 253 & TLEV Exhaust -- E-85 & 2,70 & 591 & 5-Methyl Dodecane & 0,64 \\
\hline 254 & 2-(2-Butoxyethoxy)-EtOH & 2,70 & 592 & n-Octyl Acetate & 0,64 \\
\hline 255 & n-Butoxy-2-Propanol & 2,70 & 593 & 3-Methyl Dodecane & 0,64 \\
\hline 256 & Cyclopentane & 2,69 & 594 & Ethyl Acetate & 0,64 \\
\hline 257 & Glycolic Acid & 2,67 & 595 & 4,7-Dimethylnonyl Acetate & 0,64 \\
\hline
\end{tabular}




\begin{tabular}{|c|c|c|c|c|c|}
\hline & Composto & MIR & & Composto & MIR \\
\hline 258 & $\begin{array}{l}\text { 2-[2-(2-Ethoxyethoxy) ethoxy] } \\
\text { ethanol }\end{array}$ & 2,66 & 596 & $\begin{array}{l}\text { 2,4,6,8-Tetramethylnonyl } \\
\text { Acetate }\end{array}$ & 0,63 \\
\hline 259 & Di-n-Pentyl Ether & 2,64 & 597 & 2-Methyloctyl Acetate & 0,63 \\
\hline 260 & 1-Methoxy-2-Propanol & 2,61 & 598 & 3,9-Diethyl Undecane & 0,62 \\
\hline 261 & $\begin{array}{l}\text { 2-[2-(2-Methoxyethoxy) ethoxy] } \\
\text { ethanol }\end{array}$ & 2,61 & 599 & $\mathrm{n}$-Tridecane & 0,62 \\
\hline 262 & 3-Octanol & 2,56 & 600 & 6-Methyl Tridecane & 0,62 \\
\hline 263 & C11 Tetralin or Indane & 2,56 & 601 & Isobutyl Isobutyrate & 0,61 \\
\hline 264 & N-Methyl-2-Pyrrolidone & 2,56 & 602 & C16 Cycloalkanes & 0,61 \\
\hline 265 & 2-Butyl Tetrahydrofuran & 2,53 & 603 & n-Butyl Bromide & 0,60 \\
\hline 266 & Dipropylene Glycol & 2,48 & 604 & Branched C15 Alkanes & 0,60 \\
\hline 267 & 2-Hexanol & 2,47 & 605 & Trichloroethylene & 0,60 \\
\hline 268 & C13 Alkenes & 2,47 & 606 & Octyl Cyclohexane & 0,60 \\
\hline 269 & $\begin{array}{l}\text { 2-[2-(2-Propoxyethoxy) ethoxy] } \\
\text { ethanol }\end{array}$ & 2,46 & 607 & 1-Methyl-2-Octyl Cyclohexane & 0,60 \\
\hline 270 & 2-Hexyloxyethanol & 2,45 & 608 & $\mathrm{n}$-Tetradecane & 0,59 \\
\hline 271 & Methylcyclopentane & 2,42 & 609 & $\begin{array}{l}3,5,7,9-\text { Tetramethyldecyl } \\
\text { Acetate }\end{array}$ & 0,58 \\
\hline 272 & 2-Ethyl-Hexyl Acrylate & 2,42 & 610 & n-Nonyl Acetate & 0,58 \\
\hline 273 & Alkyl Phenols & 2,34 & 611 & 1-Methyl-4-Heptyl Cyclohexane & 0,58 \\
\hline 274 & m-Cresol & 2,34 & 612 & 4,8-Dimethyl Tetradecane & 0,58 \\
\hline 275 & p-Cresol & 2,34 & 613 & 6-Methyl Tetradecane & 0,57 \\
\hline 276 & o-Cresol & 2,34 & 614 & 3-Methyl Tridecane & 0,57 \\
\hline 277 & Isopropyl Benzene (cumene) & 2,32 & 615 & Propane & 0,56 \\
\hline 278 & 1-Decene & 2,29 & 616 & n-Pentadecane & 0,56 \\
\hline 279 & C10 Terminal Alkenes & 2,29 & 617 & 1-Methyl-4-Nonyl Cyclohexane & 0,55 \\
\hline 280 & Ethyl Cyclopentane & 2,27 & 618 & 4,7,9-Trimethyldecyl Acetate & 0,55 \\
\hline 281 & Cycloheptane & 2,26 & 619 & Nonyl Cyclohexane & 0,54 \\
\hline 282 & Cyclohexanol & 2,25 & 620 & Branched C16 Alkanes & 0,54 \\
\hline 283 & C14 Alkenes & 2,24 & 621 & 3-Methyl Tetradecane & 0,54 \\
\hline 284 & Isobutyl Alcohol & 2,24 & 622 & $\mathrm{n}-\mathrm{C} 16$ & 0,53 \\
\hline 285 & $\begin{array}{l}\text { 2-[2-(2-Butoxyethoxy) ethoxy] } \\
\text { ethanol }\end{array}$ & 2,24 & 623 & Ethyl Formate & 0,52 \\
\hline 286 & 1,2-Butandiol & 2,21 & 624 & 2,2-Dimethoxy Propane & 0,52 \\
\hline 287 & 1-Heptanol & 2,21 & 625 & 7-Methyl Pentadecane & 0,52 \\
\hline 288 & $\begin{array}{l}\text { Dipropylene Glycol Methyl Ether } \\
\text { (structure inferred) }\end{array}$ & 2,20 & 626 & Branched C17 Alkanes & 0,51 \\
\hline 289 & 2-Ethyl-1-Hexanol & 2,20 & 627 & Dimethyl Glutarate & 0,51 \\
\hline 290 & n-Propyl Benzene & 2,20 & 628 & 3-Methyl Pentadecane & 0,50 \\
\hline 291 & C9 Monosubstituted Benzenes & 2,20 & 629 & Decyl Cyclohexane & 0,50 \\
\hline 292 & 2-Octanol & 2,16 & 630 & $\mathrm{n}-\mathrm{C} 17$ & 0,50 \\
\hline 293 & 1,3-Dimethyl Cyclopentane & 2,15 & 631 & Branched C18 Alkanes & 0,48 \\
\hline 294 & 2,5,8,11-Tetraoxatridecan-13-ol & 2,15 & 632 & Dimethyl Sebacate & 0,48 \\
\hline 295 & Methyl t-Amyl Ether & 2,14 & 633 & $\mathrm{n}-\mathrm{C} 18$ & 0,47 \\
\hline 296 & Methoxy Acetone & 2,14 & 634 & t-Butyl Alcohol & 0,45 \\
\hline 297 & Ethyl t-Butyl Ether & 2,11 & 635 & 2,2,3,3-Tetramethyl Butane & 0,44 \\
\hline 298 & TLEV Exhaust -- LPG & 2,11 & 636 & $\mathrm{n}-\mathrm{C} 19$ & 0,44 \\
\hline 299 & 5-Methyl-2-Hexanone & 2,10 & 637 & Acetone & 0,43 \\
\hline 300 & C15 Alkenes & 2,10 & 638 & $\mathrm{n}-\mathrm{C} 20$ & 0,42 \\
\hline 301 & 3-Methylpentane & 2,07 & 639 & $\mathrm{n}-\mathrm{C} 21$ & 0,40 \\
\hline 302 & 2-(2-Hexyloxyethoxy) ethanol & 2,03 & 640 & Methyl Pivalate & 0,39 \\
\hline 303 & 1-Octanol & 2,01 & 641 & $\mathrm{n}-\mathrm{C} 22$ & 0,38 \\
\hline 304 & Methylcyclohexane & 1,99 & 642 & Monochlorobenzene & 0,36 \\
\hline 305 & C7 Cycloalkanes & 1,99 & 643 & n-Propyl Bromide & 0,35 \\
\hline 306 & s-Butyl Benzene & 1,97 & 644 & Propylene Oxide & 0,32 \\
\hline 307 & C10 Monosubstituted Benzenes & 1,97 & 645 & Ethane & 0,31 \\
\hline 308 & n-Butyl Benzene & 1,97 & 646 & Benzotrifluoride & 0,26 \\
\hline
\end{tabular}




\begin{tabular}{|c|l|c|c|l|c|}
\hline & Composto & MIR & & Composto & MIR \\
\hline 309 & Dimethyl Adipate & 1,96 & 647 & Propylene Carbonate & 0,25 \\
\hline 310 & Cyclopentanol & 1,96 & 648 & Ethyl Chloride & 0,25 \\
\hline 311 & 1-Undecene & 1,95 & 649 & Dimethyl Succinate & 0,23 \\
\hline 312 & C11 Terminal Alkenes & 1,95 & 650 & t-Butyl Acetate & 0,20 \\
\hline 313 & Styrene & 1,95 & 651 & p-Dichlorobenzene & 0,20 \\
\hline 314 & Propyl Cyclopentane & 1,91 & 652 & p-Trifluoromethyl-Cl-Benzene & 0,11 \\
\hline & Tripropylene Glycol Monomethyl & & & & \\
315 & Ether & 1,90 & 653 & Ethyl Bromide & 0,11 \\
\hline 316 & 2-Ethoxyethyl Acetate & 1,89 & 654 & Cyclopropane & 0,10 \\
\hline & 3,6,9,12-Tetraoxahexadecan-1- & & & & \\
317 & ol & 1,89 & 655 & 1,1-Dichloroethane & 0,10 \\
\hline 318 & 3-Methyl Hexane & 1,85 & 656 & 1,2 -Dichloroethane & 0,10 \\
\hline 319 & Phenol & 1,82 & 657 & Formic Acid & 0,08 \\
\hline 320 & 2-tert-Butoxy-1-Propanol & 1,81 & 658 & Methyl Acetate & 0,07 \\
\hline 321 & 2,4-Dimethyl Hexane & 1,81 & 659 & Nitrobenzene & 0,07 \\
\hline 322 & 2-Methyl Pentane & 1,80 & 660 & Dichloromethane & 0,07 \\
\hline 323 & 2-Methyl-3-Hexanone & 1,79 & 661 & Methyl Formate & 0,06 \\
\hline 324 & C11 Monosubstituted Benzenes & 1,78 & 662 & Dimethyl Carbonate & 0,06 \\
\hline 325 & Ethylcyclohexane & 1,75 & 663 & $1,1,2-$ Trichloroethane & 0,06 \\
\hline 326 & C8 Cycloalkanes & 1,75 & 664 & Carbon Monoxide & 0,06 \\
\hline 327 & 3 methoxy -3 methyl-Butanol & 1,74 & 665 & 1,2 -Dibromoethane & 0,05 \\
\hline 328 & 2-Pentanol & 1,74 & 666 & Ethylene Oxide & 0,04 \\
\hline 329 & 2,2,4-Trimethyl-1,3-Pentanediol & 1,74 & 667 & Perchloroethylene & 0,04 \\
\hline 330 & 1-phenoxy-2-propanol & 1,73 & 668 & Methyl Chloride & 0,03 \\
\hline 331 & 3-Pentanol & 1,73 & 669 & Chloroform & 0,03 \\
\hline 332 & Cyclooctane & 1,73 & 670 & Methyl Bromide & 0,02 \\
\hline 333 & C12 Terminal Alkenes & 1,72 & 671 & Methane & 0,01 \\
\hline 334 & 1-Dodecene & 1,72 & 672 & $1,1,1-$ Trichloroethane & 0,00 \\
\hline 335 & 1,3-Dimethyl Cyclohexane & 1,72 & 673 & Toluene Diisocyanate & $-0,13$ \\
\hline 336 & a-Methyl Styrene & 1,72 & 674 & Tolualdehyde & $-0,61$ \\
\hline 337 & C9 Styrenes & 1,72 & 675 & Benzaldehyde \\
\hline 338 & 1-tert-Butoxy-2-Propanol & 1,71 & & & \\
\hline & & & & & \\
\hline
\end{tabular}

